Universidade de São Paulo
Instituto de Física

\title{
Propriedades de termoluminescência, ressonância paramagnética eletrônica e absorção óptica da rodonita natural e sintética
}

\author{
José Roberto Braz Paião
}

Comissão examinadora:

Prof. Dr. Shigueo Watanabe (IF-USP)

Prof. Dr.Walter Maigon Pontuschka (IF-USP)

Prof. Dr. Said Rahnamaye Rabbani (IF-USP)

Prof. Dr. Oswaldo Baffa Filho (FFCLRP-USP)

Prof. Dr. Antônio Claret Soares Sabioni (UFOP)

Orientador: Prof. Dr. Shigueo Watanabe

Tese de doutorado apresentada ao Instituto de Física para a obtenção do título de Doutor em Ciências

São Paulo

2005 


\section{FICHA CATALOGRÁFICA}

Preparada pelo Serviço de Biblioteca e Informação do Instituto de Física da Universidade de São Paulo

Paião, José Roberto Braz

Propriedades de termoluminescência, ressonância paramagnética eletrônica e absorção óptica da rodonita natural e sintética.

Tese (Doutoramento) - Universidade de São Paulo Instituto de Física - Departamento de Física Nuclear

Orientador: Prof. Dr. Shigueo Watanabe

Área de Concentração: Física

$$
\text { Unitermos: }
$$

1. Estrutura dos sólidos - cristal iônico;

2. Ressonância paramagnética eletrônica;

3. Rodonita;

4. Óptica - absorção;

5. Propriedade dos sólidos - termoluminescência.

USP/IF/SBI-055/2005 
Aos meus pais, João e Josefa com todo amor e carinho.

Aos meus irmãos e, em especial à Maria Lúcia (em memória).

Para minha esposa, Amanda e minha filha Maria Eduarda. 


\section{Agradecimentos}

Em primeiro lugar à minha família, que esteve sempre junto a mim, em todos os momentos, alegres ou tristes.

Ao professor Dr. Shigueo Watanabe, pela orientação segura e a paciência demonstrada, mesmo nos momentos mais difíceis.

Aos companheiros do laboratório LACIFID, pela amizade e companheirismo demonstrados: Gilberto, Luiz, Chubaci, Lara, Edna, Roseli, Alberto, Cassiano, Tiago, Henry, Jéssica, Nilo, Walter, Wilmer, Juan Carlos, Susana e ao prof Masao.

Ao Manoel S. Sanchez pelas análises de Difração de raios-X, importantes para esse trabalho.

Ao Paulo E. Mori e ao Flávio do DGM do Instituto de Geociências da USP pelas medidas de difração de raios-X e fluorescência de raios-X.

À engenheira Elizabeth Somessari Ribeiro e ao engenheiro Carlos Gaia da Silveira do CTR-IPEN-SP pelas diversas vezes que me atenderam gentilmente para as irradiações das amostras.

Ao CNPq, pelo apoio financeiro durante a realização deste trabalho.

Em especial à Edna que além de dedicada, sempre me tratou com respeito.

Ao senhor Tágides Ferreira e a Sociedade Mineira de Mineração por terem fornecido a amostra de rodonita usada neste trabalho.

Ao engenheiro Maurício da UNIFRAX - Vinhedo - SP por nos ceder as placas necessárias para a manutenção dos fornos de alta temperatura.

Ao senhor Donato e ao Otávio da oficina mecânica, que ajudaram na confecção de peças, bem como na montagem de equipamentos do laboratório.

Ao pessoal da Secretaria do Departamento de Física Nuclear e da Comissão de Pós -Graduação, pela paciência no atendimento. 


\section{Resumo}

Neste trabalho investigamos as propriedades de TL, AO e RPE da rodonita natural, cuja fórmula química é $(\mathrm{Mn}, \mathrm{Ca}, \mathrm{Fe}, \mathrm{Mg}) \mathrm{SiO}_{3}$ e de amostras sintéticas de rodonita com variadas composições. O objetivo foi o de comparar as propriedades acima quando adicionados diferentes óxidos à estrutura do material. As amostras sintéticas foram obtidas através do método de fusão de componentes e resfriamento lento, o qual mostrou-se eficaz, prático e barato. Medidas de difração de raios $-x$ mostraram que a estrutura das amostras sintéticas concordavam com a da rodonita.

As curvas de emissão da amostra natural irradiada com doses variando entre $0,1 \mathrm{kGy}$ e $50 \mathrm{kGy}$ apresentaram picos TL em $140{ }^{\circ} \mathrm{C}, 250{ }^{\circ} \mathrm{C}, 280^{\circ} \mathrm{C}, 335^{\circ} \mathrm{C}$ e $460{ }^{\circ} \mathrm{C}$, os quais crescem sublinearmente. Por outro lado, as curvas de emissão da amostra recozida em $600^{\circ} \mathrm{C} / 1 \mathrm{~h}$ e depois irradiadas com doses variando de 0,1 a $50 \mathrm{kGy}$ apresentam picos TL em $140{ }^{\circ} \mathrm{C}, 180{ }^{\circ} \mathrm{C}, 260{ }^{\circ} \mathrm{C}, 300{ }^{\circ} \mathrm{C}, 340{ }^{\circ} \mathrm{C}$ e $460{ }^{\circ} \mathrm{C}$, destacando-se um novo pico em $180^{\circ} \mathrm{C}$. Esses picos crescem paralela e sublinearmente com a dose até cerca de $5 \mathrm{kGy}$, saturando-se, em seguida.

O espectro da luz TL da amostra natural apresentou uma banda larga estendendo-se de $500 \mathrm{~nm}$ até $625 \mathrm{~nm}$, para o pico de $260^{\circ} \mathrm{C}$ e uma banda levemente deslocada para o pico de $140^{\circ} \mathrm{C}$, estendendo-se entre $500 \mathrm{~nm}$ e $650 \mathrm{~nm}$. Isso indica que só há um centro de recombinação.

Curvas de emissão $T L$ das amostras sintéticas puras $\left(\mathrm{MnSiO}_{3}\right)$ mostraram que todos os picos encontrados na amostra natural estão presentes nesta amostra sintética, indicando que tais picos TL são devidos a defeitos intrínsecos e não dependem de outros compostos ou impurezas. Amostras sintéticas obtidas com a adição de $\mathrm{CaO}, \mathrm{Fe}_{2} \mathrm{O}_{3}, \mathrm{MgO}, \mathrm{TiO}_{2}$ e $\mathrm{Al}_{2} \mathrm{O}_{3}$ isoladamente ou em combinações também foram obtidas e suas propriedades TL e RPE foram estudadas. Em termos de $\mathrm{TL}$, a adição de $\mathrm{Al}_{2} \mathrm{O}_{3}$ causou grande aumento da sensibilidade, porém, ainda menor que a resposta TL da natural. A combinação de $\mathrm{CaO}$ e $\mathrm{Al}_{2} \mathrm{O}_{3}$ produziu os melhores resultados em termos de sensibilidade. Outros óxidos ou combinações pouco influenciaram a sensibilidade TL; no caso da adição de $\mathrm{Fe}_{2} \mathrm{O}_{3}$ houve uma diminuição da sensibilidade. 
A presença de $\mathrm{Al}_{2} \mathrm{O}_{3}$ mostrou-se muito importante na definição das propriedades TL, assim, propomos o seguinte mecanismo de emissão TL para a rodonita: inicialmente forma-se um centro segundo a reação:

$$
\mathrm{Al}^{3+}+\mathrm{M}+\left[\mathrm{SiO}_{4}^{4-}\right]^{0} \rightarrow\left[\mathrm{AlO}_{4} / \mathrm{M}^{+}\right]^{0}+\mathrm{Si}+e^{-}
$$

A irradiação remove $\mathrm{M}^{+}$deixando $\left[\mathrm{AlO}_{4} / \mathrm{h}\right]^{0}$ que é conhecido como centro de buraco de alumínio.

$$
\left[\mathrm{AlO}_{4} / \mathrm{M}^{+}\right]^{0} \stackrel{\mathrm{irr}}{\rightarrow}\left[\mathrm{AlO}_{4} / \mathrm{h}\right]^{0}+\mathrm{M}
$$

Durante o aquecimento para a leitura, $\mathrm{M}^{+}$que se tornara $\mathrm{M}^{0}$ por captura de um elétron da ionização (irradiação), agora libera um elétron que se recombina com o buraco do centro de alumínio, produzindo a luz TL e regenerando o centro $\left[\mathrm{AlO}_{4} / \mathrm{M}^{+}\right]$.

No espectro de absorção óptica da rodonita natural identificamos várias bandas, sendo as mais proeminentes em $344 \mathrm{~nm}, 357 \mathrm{~nm}, 367 \mathrm{~nm}, 410 \mathrm{~nm}, 415 \mathrm{~nm}$ e $542 \mathrm{~nm}$ e em 1040nm. Esta última atribuída ao $\mathrm{Fe}^{2+}$,e uma fraca na região de $1500 \mathrm{~nm}$.

Através de cálculos envolvendo teoria do campo cristalino, mostramos teoricamente que as bandas intensas em $410 \mathrm{~nm}$ e $542 \mathrm{~nm}$ podem ser melhor explicadas pela presença do $\mathrm{Mn}^{3+}$ em ambientes $\mathrm{O}_{\mathrm{h}}$ e $\mathrm{C}_{4 \mathrm{~V}}$, do que pela presença do $\mathrm{Mn}^{2+}$.

A espectroscopia XPS da amostra natural antes do tratamento térmico indicou a presença das espécies cristalinas $\mathrm{Mn}_{3} \mathrm{O}_{4}$ e $\mathrm{MnO}_{2}$. Após tratamento térmico em $600{ }^{\circ} \mathrm{C} / 1 \mathrm{~h}$, XPS indicou a presença das espécies cristalinas $\mathrm{MnO}$ e $\mathrm{MnO}_{2}$.

O espectro de EPR mostrou uma larga e intensa linha em $\mathrm{g}=1,988 \mathrm{com}$ largura de linha de pico a pico de aproximadamente 1,35 KG que é característico de alargamento dipolar, devido a uma forte interação spin-spin entre os $\mathrm{Mn}^{2+}$. Após tratamento térmico acima de $700^{\circ} \mathrm{C} / 1 \mathrm{~h}$ ocorre um grande aumento da quantidade de $\mathrm{Mn}^{4+}$, que não pode explicar esse alargamento (teoria de Van Vleck). Atribuímos este alargamento à presença de agrupamentos de $\mathrm{Fe}^{3+}$, que vêm da oxidação de $\mathrm{Fe}^{2+}$ por aquecimento acima de $700^{\circ} \mathrm{C} \mathrm{e}$ comprovado pela diminuição da banda em $1040 \mathrm{~nm}$ de $\mathrm{Fe}^{2+}$ à medida que se aquece a rodonita acima dessa temperatura. 


\section{Abstract}

The optical absorption, electron paramagnetic resonance and thermoluminescence properties of natural silicate mineral, rhodonite with chemical formula $(\mathrm{Mn}, \mathrm{Ca}, \mathrm{Fe}, \mathrm{Mg}) \mathrm{SiO}_{3}$ as well as synthetic samples pure or doped have been investigated. Synthetic samples were obtained heating appropriated mixture of oxides components of rhodonite to above melting temperature and then cooling slowly.

The x-ray diffract gram of these artificial rhodonites have shown rhodonite structure. A natural sample with additional radiation dose ranging 0.1 up to $50 \mathrm{kGy}$ presented a glow curve with $\mathrm{TL}$ peaks at $140^{\circ} \mathrm{C}, 250^{\circ} \mathrm{C}, 280^{\circ} \mathrm{C}, 335^{\circ} \mathrm{C}$ and $460^{\circ} \mathrm{C}$. These peaks glow sublinearly. A natural sample heat treated at $600^{\circ} \mathrm{C}$ for one hour then irradiated to 0.1 up to $50 \mathrm{kGy}$ presents almost the same TL peaks, except for $180^{\circ} \mathrm{C}$ new TL peak and splitting of $335^{\circ} \mathrm{C}$ into 300 and $340^{\circ} \mathrm{C}$ peaks. Their TL responses to radiation dose have same sublinear behavior. The spectrum of TL light at $260^{\circ} \mathrm{C}$ TL peak presented only one broad band extending from $500 \mathrm{~nm}$ to $625 \mathrm{~nm}$ and at $140^{\circ} \mathrm{C}$ TL peak, somewhat broader band from 500 to $650 \mathrm{~nm}$. This result shows that there is only one recombination center. The TL glow curves of synthetic pure $\left(\mathrm{MnSiO}_{3}\right)$ and doped samples show the same TL peak found in natural sample. These results indicate that the intrinsic defects have an important role. Addition of impurities such as $\mathrm{Ca}, \mathrm{Fe}, \mathrm{Mg}$ and $\mathrm{TL}$ did not change much the peaks height. However, the addition of aluminum has enhanced greatly the TL responses, and however, low temperature and high temperature peaks have grown prominently so that all the peaks became hidden.

The fact that $\mathrm{Al}$ impurity has striking effect on TL emission was interpreted as follows. In silica it has been demonstrated that the always present $\mathrm{Al}^{3+}$ substitutes for $\mathrm{Si}^{4+}$ in the $\mathrm{SiO}_{4}{ }^{4-}$ tetrahedron. Any neighboring alkaline metal ion $\mathrm{M}^{+}$form a center according the reaction

$$
\mathrm{Al}^{3+}+\mathrm{M}+\left[\mathrm{SiO}_{4}^{4-}\right]^{0} \rightarrow\left[\mathrm{AlO}_{4} / \mathrm{M}^{+}\right]^{0}+\mathrm{Si}+e^{-}
$$

Under irradiation, $\mathrm{M}^{+}$is removed leaving the defect $\left[\mathrm{AlO}_{4} / \mathrm{h}\right]^{0}$, known as aluminum hole center.

$$
\left[\mathrm{AlO}_{4} / \mathrm{M}^{+}\right]^{0} \stackrel{\mathrm{irr}}{\rightarrow}\left[\mathrm{AlO}_{4} / \mathrm{h}\right]^{0}+\mathrm{M}
$$


During heating for TL reading, the alkali atom liberated in the formation of aluminum center releases an electron to recombine with the hole of the aluminum center regenerating the original $\left[\mathrm{AlO}_{4} / \mathrm{M}^{+}\right]$center. In the optical absorption spectrum of natural sample of rhodonite there are several absorption bands, the prominent being $344 \mathrm{~nm}, 357 \mathrm{~nm}, 367 \mathrm{~nm}, 410 \mathrm{~nm}$, $415 \mathrm{~nm}, 542 \mathrm{~nm}$ in visible region and a broad band in $1040 \mathrm{~nm}$ in the infrared region. A very weak band at $1500 \mathrm{~nm}$ is also detected. The $1040 \mathrm{~nm}$ is known to be due to $\mathrm{Fe}^{2+}$.

The theory of crystal field calculation has shown that $410 \mathrm{~nm}$ and $542 \mathrm{~nm}$ bands can be explained assuming that $\mathrm{Mn}^{3+}$ in $\mathrm{O}_{\mathrm{h}}$ and $\mathrm{C}_{4 \mathrm{~V}}$ sites are responsible rather than $\mathrm{Mn}^{2+}$.

The XPS spectroscopy measurements of the natural sample indicated the presence of $\mathrm{Mn}_{3} \mathrm{O}_{4}$ and $\mathrm{MnO}_{2}$. An annealing at $600^{\circ} \mathrm{C}$ for one hour replaced $\mathrm{Mn}_{3} \mathrm{O}_{4}$ by $\mathrm{MnO}$ and $\mathrm{MnO}_{2}$.

The EPR spectrum consists of a very broad line, about 1350 Gauss, of $\mathrm{g} \cong 2.0$. This due to spin-spin interaction. Van Vleck theory was used to shown that Mn dipole-dipole interaction above $700^{\circ} \mathrm{C}$ increases the microwave absorption width. The increase of the $\mathrm{Fe}^{3+}$ concentration due to $\mathrm{Fe}^{2+} \rightarrow \mathrm{Fe}^{3+}$ conversion under strong heating, was shown by the observed decrease of $\mathrm{Fe}^{2+}$ absorption band above $700^{\circ} \mathrm{C}$. 


\section{Sumário}

\section{INTRODUÇÃO}

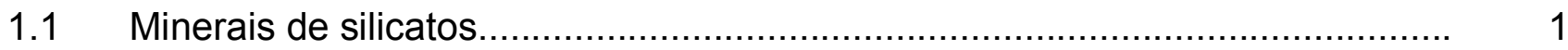

1.2 Estudos realizados por outros autores............................................................ 2

1.2.1 Amostras naturais......................................................................... 2

1.2.2 Amostras artificiais.....................................................................

1.3 Termoluminescência................................................................................ 8

1.3.1 Armadilhas e centros de recombinação.......................................... 10

1.3.2 Um modelo simples para termoluminescência.................................. 12

1.4 Centros de cor e absorção óptica.............................................................. 15

1.4.1 Absorção óptica..................................................................... 15

1.4.2 Um pouco sobre a teoria do campo cristalino................................... 18

1.4.3 Lei de Buger-Lambert................................................................ 19

1.5 Ressonância paramagnética eletrônica (RPE) .............................................. 21

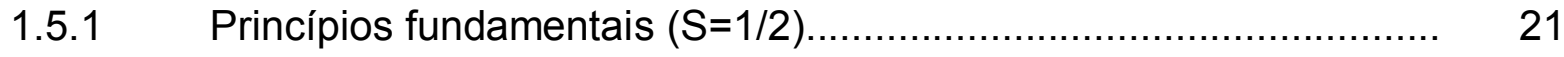

1.5.2 O espectrômetro de RPE......................................................... 23

1.5.3 Interação Spin-Spin..................................................................... 25

1.5.3.1 Campo local de um momento magnético na posição de seu

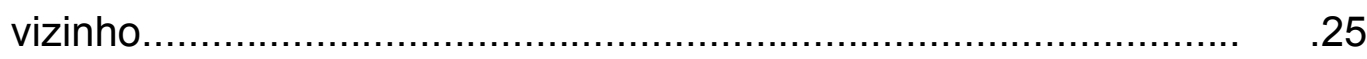

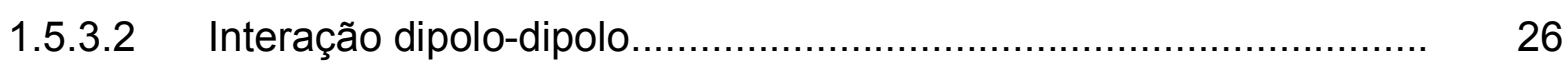

1.5.3.3 Tratamento de Van Vleck........................................................ 32

1.5.3.4 Um exemplo de alargamento das linhas de RPE em função da concentração de manganês......................................................... 36

1.6 Vitrificação - Cristalização.................................................................... 38

1.6.1 Cristalização...................................................................... 40

1.6.2 Teoria clássica da nucleação Homogênea..................................... 42

$1.7 \quad$ Espectroscopia de fotoelétrons excitados por raios - X (XPS) ....................... 47 
$2.1 \quad$ Considerações gerais................................................................... 49

2.2 Análise da composição química............................................................... 50

2.3 Difração de raios-X..................................................................................... 50

2.4 Amostras sintéticas de rodonita, pura ou dopada........................................... 50

2.5 Irradiação, tratamentos térmicos e medidas de AO, RPE e TL....................... 51

$2.6 \quad$ Medidas de XPS ........................................................................... 51

2.7 Mecanismo de indução TL............................................................................ 52

3 MATERIAIS E MÉTODOS EXPERIMENTAIS 53

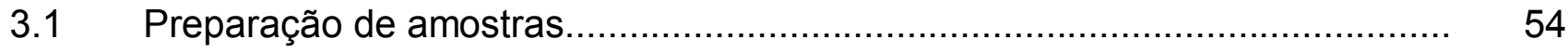

3.2 Amostras artificiais....................................................................... 54

3.3 Irradiação................................................................................... 56

3.4 Equipamentos de medida............................................................... 57

3.4.1 Termoluminescência............................................................... 57

3.4.1.1 Curvas de Emissão.................................................................... 57

3.4.1.2 Espectros de Emissão........................................................... 58

3.4.2 Absorção Óptica...................................................................... 60

3.4.3 Ressonância Paramagnética Eletrônica (RPE).............................. 62

4 RESULTADOS $\quad 64$

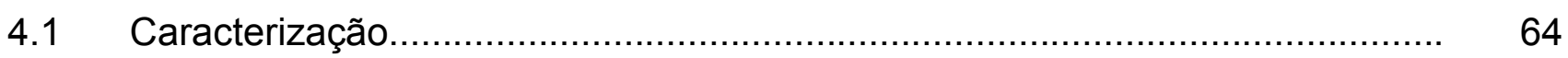

4.2 Medidas de Termoluminescência (TL) ...................................................... 67

4.2.1 Amostra natural.................................................................... 67

4.2.2 Amostras sintéticas........................................................... 74

4.2.2.1 Primeiras amostras sintéticas................................................... 74

4.2.2.2 Amostras sintéticas com diferentes composições........................... 78 
4.3 Absorção óptica.................................................................................. 94

4.3.1 Cálculo das bandas de AO através da teoria do campo cristalino.... 100

4.4 Espectroscopia de fotoelétrons excitados por raios - X (XPS) ....................... 101

4.5 Ressonância Paramagnética Eletrônica (RPE)................................................ 103

4.5.1 Cálculo do segundo momento (teoria de Van Vleck)...................... 106

5 DISCUSSÃO DOS RESULTADOS 109

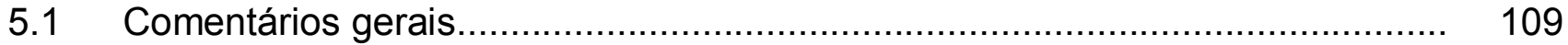

5.2 Termoluminescência............................................................................. 109

5.3 Absorção óptica............................................................................ 112

5.3.1 Aspectos gerais.............................................................. 112

5.3.2 Cálculo das bandas de AO por teoria do campo cristalino................ 116

5.4 Ressonância paramagnética eletrônica....................................................... 121

6 CONCLUSÕES 123

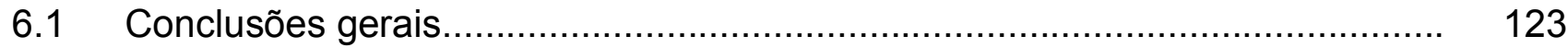

6.2 Trabalhos futuros....................................................................... 129

7 REFERÊNCIAS $\quad 130$ 
Capítulo 1

\section{Introdução}




\section{0 - INTRODUÇÃO}

\section{1- Minerais de silicatos}

Devido ao fato de haver grande abundância de silicatos na composição da crosta terrestre, igualmente, grande abundância de quartzo e minerais de silicatos são encontrados no solo brasileiro. Alguns desses minerais são importantes na indústria de cerâmicas, outros no mercado gemológico, além de serem fontes de extração de elementos especiais para as indústrias de alta tecnologia.

Muitos desses minerais foram objetos de estudos geológicos - mineralógicos, mas, excetuando aquelas de interesse geológico, poucos tem sido investigados quanto as suas propriedades físicas.

O presente trabalho é desenvolvido dentro desse contexto de examinar algumas propriedades físicas da rodonita, que é um dos minerais naturais brasileiros de silicatos.

Esses minerais são todos cristalinos. Sua rede cristalina tem como ânions, blocos tetraédricos $\mathrm{SiO}_{4}^{4-}$, que formam cadeias com um ou mais tipos de cátions.

Segundo Liebau (1985), como os íons metálicos $\mathbf{M}$ são maiores e têm valências menores do que os íons de silício, as ligações $\mathbf{M}$ - $\mathbf{O}$ são mais fracas do que as ligações $\mathbf{S i}-\mathbf{O}$. Isto quer dizer que o silício atrai os íons de oxigênio mais fortemente que os íons metálicos, formando o tetraedro $\left[\mathrm{SiO}_{4}\right]$ com uma distância $\left(\mathrm{Si}^{|4|}-\mathrm{O}\right)=0,162 \mathrm{~nm}$. Por outro lado, se $\mathbf{M}$ fosse um metalóide, a ligação $\mathbf{M}$ - $\mathbf{O}$ tornar-se-ia comparável à ligação $\mathbf{S i} \mathbf{- O}$. Os átomos pequenos de metalóide, que têm uma carga formal alta, podem competir com os de silício na atração de íons de oxigênio. Essa competição faz com que a distância $\left(S i^{|4|}-O\right)$ seja maior, da ordem de $0,177 \mathrm{~nm}$, favorecendo a formação do bloco octaédrico, figura 1.1. 

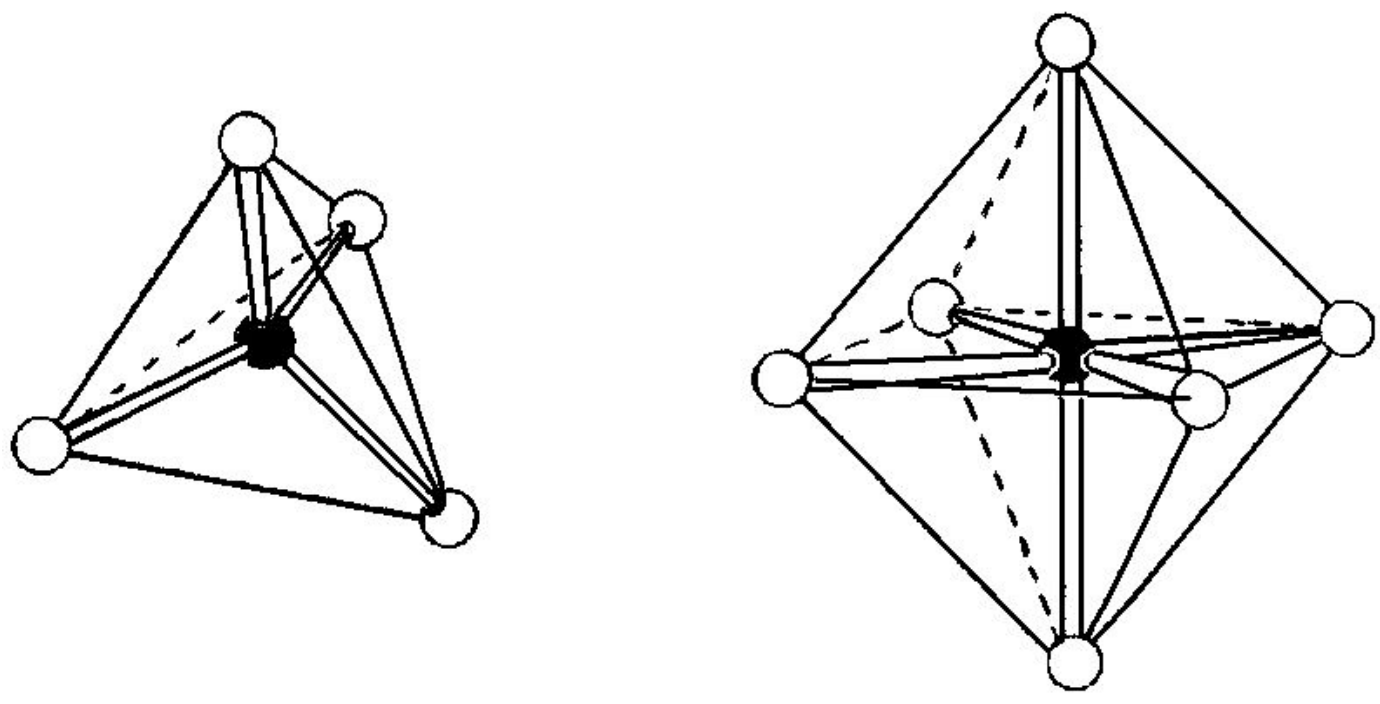

$\begin{array}{lll}1,62 \AA & \langle d(s i-o)\rangle & 1,77 \AA \\ 2,64 \AA & \langle d(O \ldots O)\rangle & 2,50 \AA\end{array}$

Figura 1.1: Tetraedro $\left[\mathrm{SiO}_{4}\right]$ e octaedro $\left[\mathrm{SiO}_{6}\right] \mathrm{com}$ dimensões médias indicadas [retirado de Liebau (1985)].

\section{2 - Estudos realizados por outros autores}

\subsection{1 - Amostras naturais}

A rodonita sintética, obtida a partir de uma mistura estequiométrica de $\mathrm{MnO}$ e $\mathrm{SiO}_{2}$, tem, é claro, por fórmula química $\mathrm{MnSiO}_{3}$. A rodonita natural, além de várias impurezas com concentrações da ordem de ppm, encerra, em geral, $\mathrm{Ca}, \mathrm{Mg}$ e $\mathrm{Fe}$ em porcentagem de peso nada pequeno, estes participam da rede substituindo o $\mathrm{Mn}$ em certas posições. Dessa forma o cristal de rodonita tem a seguinte fórmula ( $\mathrm{Mn}, \mathrm{Ca}, \mathrm{Fe}, \mathrm{Mg}) \mathrm{SiO}_{3}$. Liebau e seus colaboradores (1956 e 1959), Mamedov (1955), Peacor e Niizeki (1963) determinaram os parâmetros da célula unitária de ( $\mathrm{Mn}, \mathrm{Ca}, \mathrm{Fe}, \mathrm{Mg}) \mathrm{SiO}_{3}$. Nas amostras, por eles examinadas, havia $\mathrm{Mn}, \mathrm{Ca}, \mathrm{Mg}$ e Fe na proporção de 8,01; 1,62; 0,32 e 0,29 por célula 
unitária. Duas estruturas diferentes têm sido propostas, cujos parâmetros de célula unitária aparecem na tabela 1.1 .

Tabela 1.1- Parâmetros da célula unitária da rodonita.

\begin{tabular}{|c|c|c|c|c|}
\hline & \multirow[t]{2}{*}{ Mamedov } & \multirow[t]{2}{*}{ Leibau et al. } & \multicolumn{2}{|c|}{ Peacor e Niizeki } \\
\hline & & & célula Buerger & célula Hilmer \\
\hline$a$ & $7,77 \stackrel{\circ}{A}$ & $6,68 A$ & $(7,6816 \pm 0,0002) A$ & $(6,7073 \pm 0,0004) A$ \\
\hline $\mathrm{b}$ & $12,20 \mathrm{~A}$ & $7,66 \mathrm{~A}$ & $(11,8180 \pm 0,0004) A$ & $(7,6816 \pm 0,0002) A$ \\
\hline C & $6,70 \mathrm{~A}$ & $12,20 \mathrm{~A}$ & $(6,7073 \pm 0,0004) A$ & $(12,2337 \pm 0,0004) A$ \\
\hline $\mathrm{A}$ & $85^{0} 15^{\prime}$ & $111,1^{0}$ & $(92,355 \pm 0,006)^{0}$ & $(111.538 \pm 0,002)^{0}$ \\
\hline$\beta$ & $94^{0} 00^{\prime}$ & $86,0^{0}$ & $(93,948 \pm 0,005)^{0}$ & $(85,247 \pm 0,005)^{0}$ \\
\hline$\gamma$ & $111^{0} 29^{\prime}$ & $93,2^{0}$ & $(105,665 \pm 0,004)^{0}$ & $(93,948 \pm 0,005)^{0}$ \\
\hline
\end{tabular}

Aparentemente, as duas estruturas diferem por considerar os eixos b e c trocados.

Na figura 1.2 tem-se a projeção no plano perpendicular ao eixo c, onde se vêem os picos das densidades $\rho(x, y, z)$. As posições dos íons de oxigênio, silício e dos cátions de manganês $M_{1}, M_{2}, M_{3}, M_{4}$ e $M_{5}$, aparecem, na realidade com as cotas $Z=\frac{1}{2}$ até 1.0 poliedro de coordenação do $M_{1}, M_{2}, M_{3}$ e $M_{4}$ é aproximadamente octaédrico, mas, a de $M_{5}$ é irregular com coordenação 7 . 


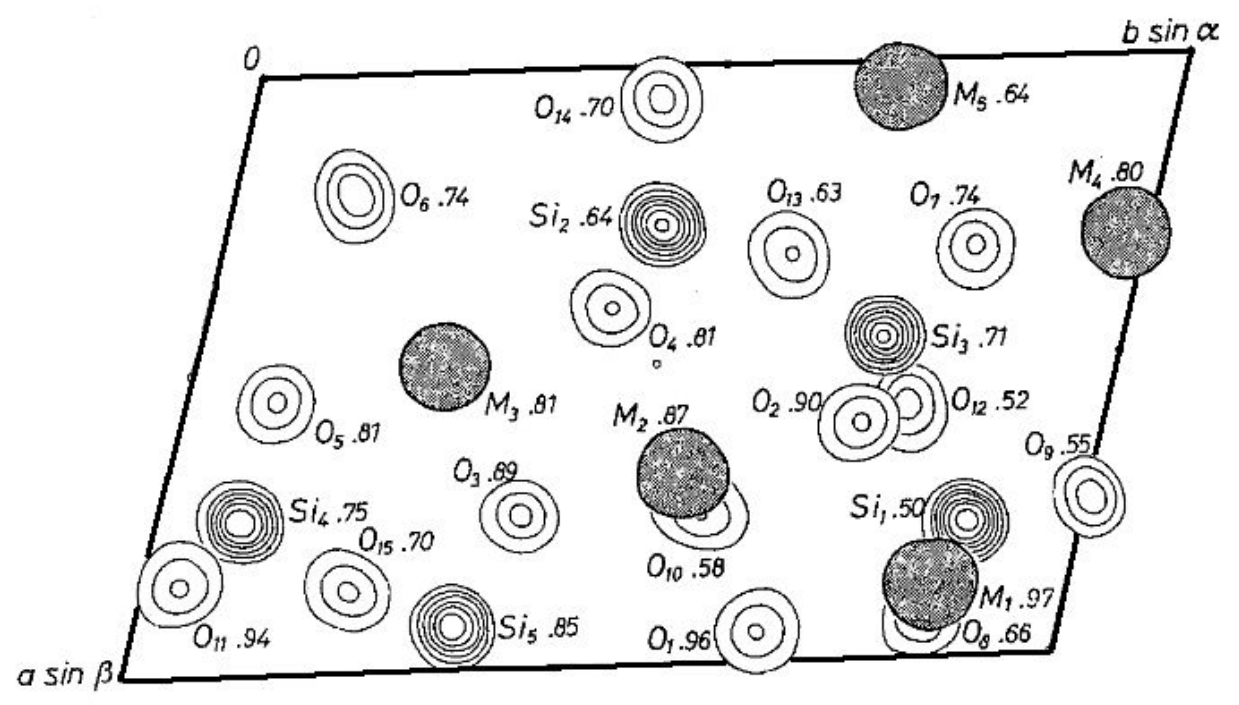

Figura 1.2: Picos de $\rho(x, y, z)$ projetados ao longo do eixo c [retirado de Peacor e Niizeki (1963)].

A interpretação desse resultado e de trabalhos de Peacor et al. (1978) temos a estrutura da rodonita mostrada na figura 1.3a e, na figura 1.3b pode ser vista a estrutura da rodonita num esquema de bolas e palitos.

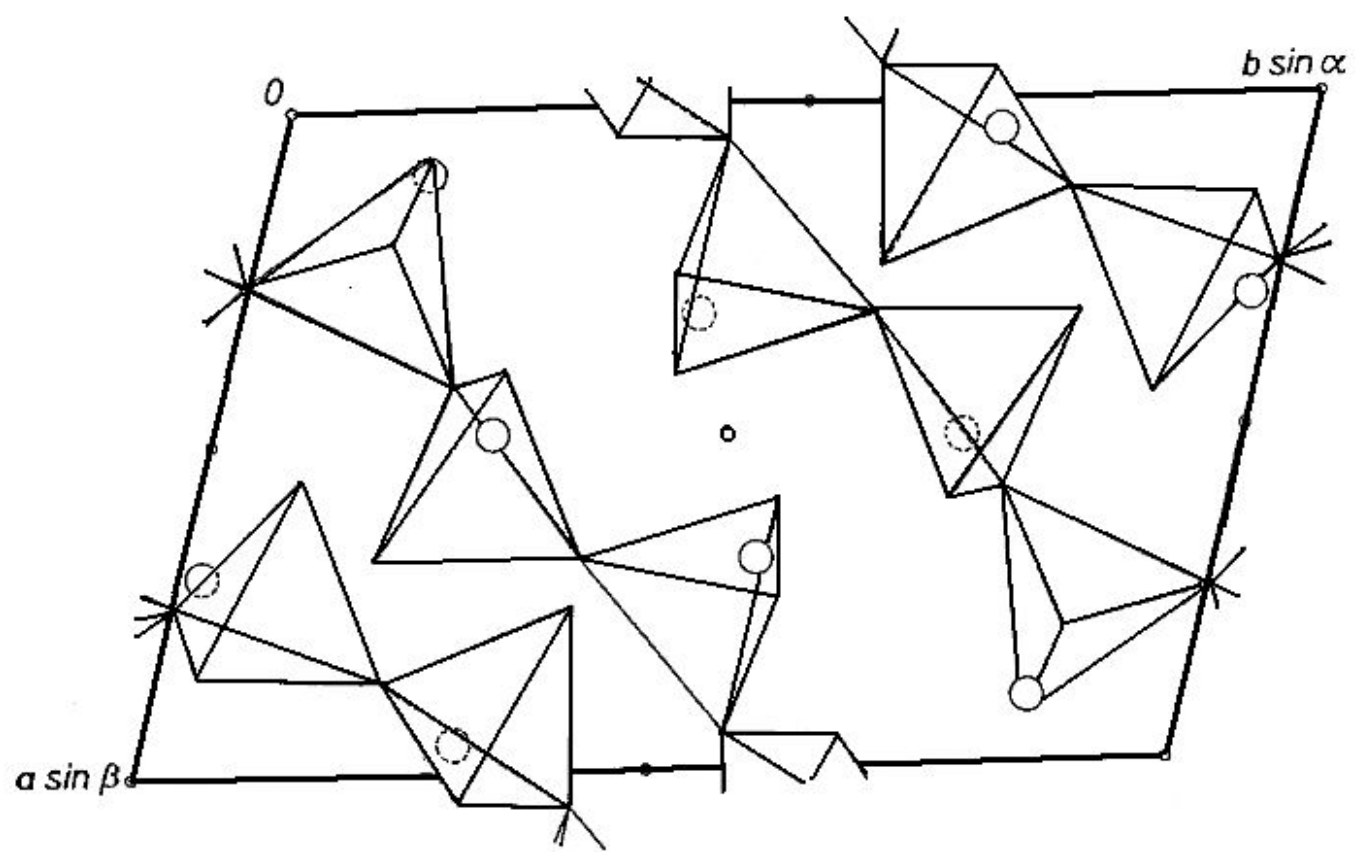

Figura 1.3a: Interpretação da estrutura da rodonita, projetada ao longo de c [retirado de Peacor e Niizeki (1963)]. 


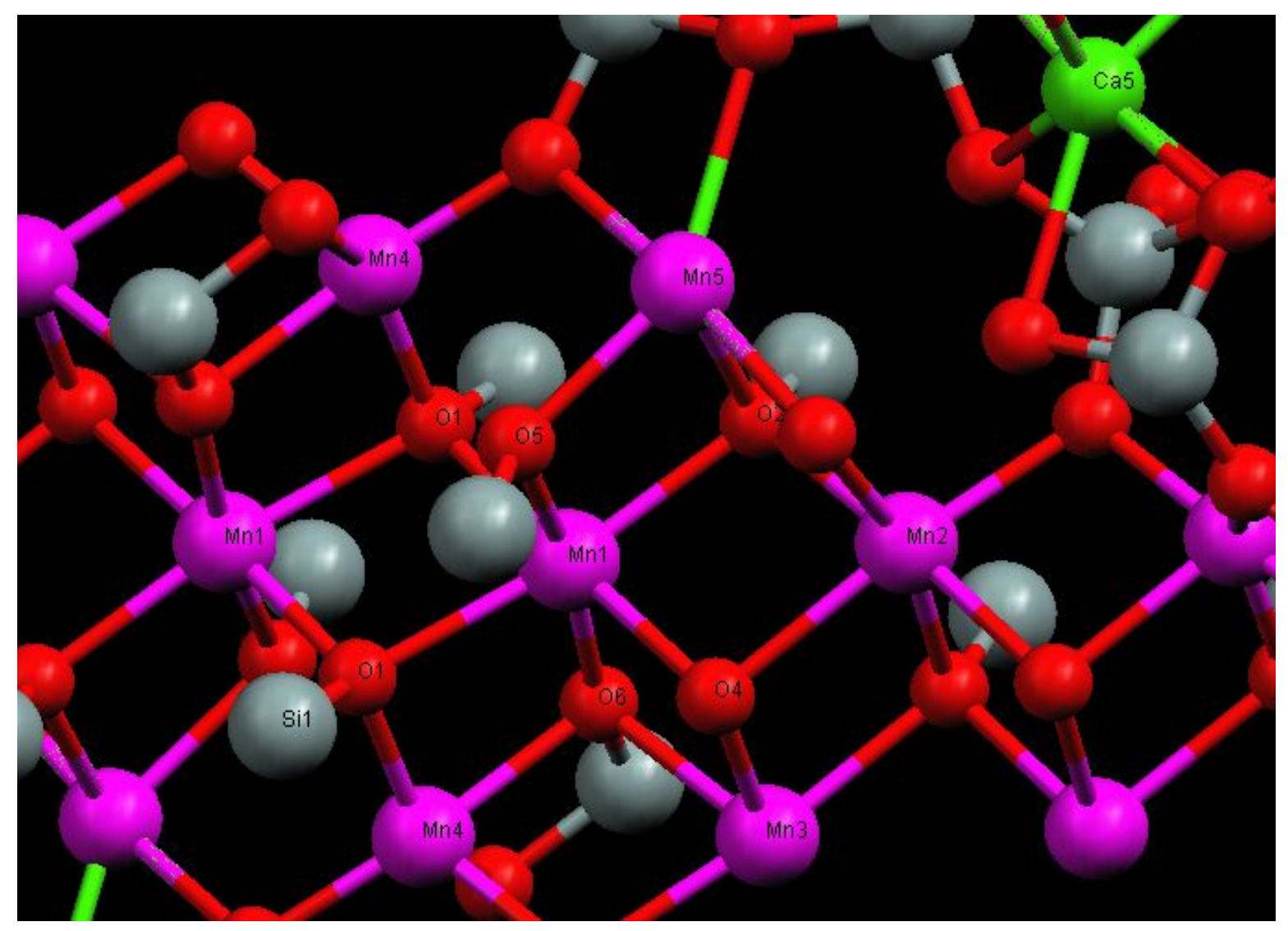

Figura 1.3b: Interpretação da estrutura da rodonita, num esquema de bolas e palitos [estrutura obtida através do programa Mercury 1.3 , usando dados de Peacor et al. (1978)].

Peacor e Niizeki (1963) fizeram estimativas das distâncias dos cátions $\mathbf{M}$ aos átomos de oxigênio. A partir desse resultado concluíram que $\mathbf{M n}$ ocupa as posições de $\mathbf{M}_{\mathbf{1}}$, $\mathbf{M}_{\mathbf{2}}$ e $\mathbf{M}_{3}$, enquanto que $\mathbf{M g}$ e $\mathbf{F e}$ ocupam a posição $\mathbf{M}_{\mathbf{4}} \mathrm{e}$, o $\mathbf{C a}$, a posição $\mathbf{M}_{\mathbf{5}}$. Ainda sobre o Fe, Dickson (1975), trabalhando com Mossbauer, concorda que a posição de preferência do Fe seja $\mathbf{M}_{\mathbf{4}}$, porém, pode ocupar as posições $\mathbf{M}_{\mathbf{1}}, \mathbf{M}_{\mathbf{2}}$ ou $\mathbf{M}_{\mathbf{3}}$.

Segundo Deer et al $(1962,1992)$, os seguintes minerais de silicatos são aparentados e, se caracterizam por conterem Mn como o principal componente catiônico:

\begin{tabular}{|c|c|}
\hline Piroxmangita & $(\mathrm{Mn}, \mathrm{Fe}) \mathrm{SiO}_{3}$ \\
\hline Rodonita & $(\mathrm{Mn}, \mathrm{Ca}, \mathrm{Fe}, \mathrm{Mg}) \mathrm{SiO}_{3}$ \\
\hline Bustamita & $(\mathrm{Mn}, \mathrm{Ca}, \mathrm{Fe}) \mathrm{SiO}_{3}$ \\
\hline Serandita & $(\mathrm{Ca}, \mathrm{Mn})_{2} \mathrm{NaH}\left(\mathrm{SiO}_{3}\right)_{2}$ \\
\hline
\end{tabular}


Ainda segundo esses autores, os íons de Mn estão localizados principalmente nos sítios octaédricos. Somente menos de $5 \%$ do total de Mn são encontrados nos sítios tetraédricos (Si). Manning (1968) mediu os espectros de absorção dos quatro minerais acima, comparando-os com o esquema de níveis de energia de íons $\mathbf{d}^{5}$ num campo cúbico. Sua principal conclusão é a de que os espectros de absorção de piroxmangita, rodonita e serandita mostram uma coloração rosada devido ao $\mathbf{M n}^{2+}$ no sítio octaédrico.

Por outro lado, a cor marrom da bustamita pode ser atribuída, ainda, ao Mn (II) na coordenação octaédrica, porém, superposto à absorção forte de fundo. Lakshman e Reddy (1973) calcularam as bandas de $\mathrm{AO}$ para o $\mathbf{M n}^{2+}$ na rodonita, usando um modelo de acoplamento spin-órbita. A tabela 1.2 mostra as bandas observadas e calculadas por esses autores.

Tabela 1.2- Posições das bandas de AO observadas e calculadas por Lakshman e Reddy (1973) para um cristal de rodonita.

\begin{tabular}{|c|c|}
\hline \multicolumn{2}{|c|}{ Posição das bandas (nm) } \\
\hline Observadas (90 K) & Calculadas \\
\hline 542 & 531 \\
432 & 450 \\
424 & ---- \\
414 & 415 \\
411 & 415 \\
407 & ---- \\
376 & 384 \\
374 & ---- \\
371 & 361 \\
369 & ---- \\
368 & ---- \\
361 & ---- \\
355 & ---- \\
346 & 340 \\
344 & ---- \\
\hline
\end{tabular}




\section{INTRODUÇÃO}

Observando a tabela 1.2 verificamos que Lakshman e Reddy (1973) não encontraram através de seus cálculos todas as bandas observadas e, mesmo algumas das que encontraram não tinham boa concordância com os dados observados, de onde se conclui que o modelo usado não era o mais adequado para explicar as bandas de AO. Esses autores inferiram que essa discrepância seria devido a algum tipo de distorção no campo cristalino ao redor do $\mathrm{Mn}^{2+}$.

Gibbons et al.(1974), trabalhando com pressão mecânica e tratamento térmico, concluíram que a banda de $542 \mathrm{~nm}$ na rodonita está associada ao $\mathbf{M n}^{3+}$. Sang - Bo et al. (1985) em uma análise usando um esquema de campo forte simplificado de $\mathbf{M n}^{2+}$ em rodonita, mostraram que os íons de $\mathbf{M n}^{2+}$ podem ocupam os sítios $\mathrm{O}_{\mathrm{h}}$ e $\mathrm{C}_{4 \mathrm{v}}$ e, a partir disso calcularam o espectro de $A O$ da rodonita, porém a banda em $410 \mathrm{~nm}$ também não foi explicada de forma satisfatória.

\subsection{2 - Amostras sintéticas}

Há métodos tradicionais para o crescimento de cristais, como os de Bridgman, Czochralski entre outros, para haletos, sulfatos, carbonatos, etc., o método hidrotérmico para a sílica e silicatos e ainda o sol-gel. Por outro lado um método bem simples, barato e que produz grandes quantidades de material é o de fusão de componentes e posterior lento e controlado resfriamento. Por esse método Haren e Woensdregt (2001) obtiveram amostras sintéticas de esperssatita $\left(\mathrm{Mn}_{3} \mathrm{Al}_{2} \mathrm{Si}_{3} \mathrm{O}_{12}\right)$ em atmosfera ambiente. Eles mostraram que os planos de crescimento na amostra sintética coincidem com os da amostra natural. $O$ detalhamento das etapas de produção da amostra sintética de esperssatita foram feitas por Nicolov e Woensdregt (2003). É conhecido que certos cristais naturais podem variar em cor devido à presença de impurezas. Dessa forma, Souza et al. (2004) estudaram como as impurezas Fe e Mn influenciam os espectros TL e RPE de amostras sintéticas de espodumênio. Para isso fundiram uma mistura de $\mathrm{SiO}_{2}, \mathrm{Al}_{2} \mathrm{O}_{3}$ e $\mathrm{Li}_{2} \mathrm{CO}_{3}$ em $1480{ }^{\circ} \mathrm{C}$ por $2 \mathrm{~h}$ e então a resfriaram lentamente. Ito (1972) estudou o sistema $\mathrm{MnSiO}_{3}-\mathrm{MgSiO}_{3}$ quanto à concentração dos componentes. Verificou que dependendo da razão $\mathrm{Mn} / \mathrm{Mg}$ é possível obter rodonita pura, piroximangita pura, uma mistura das duas ou mesmo outras fases. A estrutura da rodonita foi obtida na mistura $\left(\mathrm{Mg}_{0,32} \mathrm{Mn}_{0,68}\right) \mathrm{SiO}_{3}$ fundida a uma temperatura de $1400{ }^{\circ} \mathrm{C}$ 
por 3 horas e, então esfriada a uma taxa de $20{ }^{\circ} \mathrm{C}$ por hora. $\mathrm{O}$ estudo da estrutura da amostra produzida por Ito (1972) e comparação com as estudadas por outros autores, em amostras naturais, foi feita por Murakami e Takeuchi (1979). Nenhum trabalho sobre TL ou RPE sobre a rodonita natural ou sintética foi encontrado.

\section{3 - Termoluminescência (TL)}

Termoluminescência ( $T L$ ) é a luz que uma amostra sólida (usualmente um isolante ou um semicondutor) emite quando é aquecida após ser irradiada, a uma baixa temperatura, que pode ser tão baixa quanto a temperatura do hélio líquido e tão alta quanto a temperatura ambiente, por algum tipo de radiação, tal como: raios- $X$, raios $\gamma$, luz uv, etc (Kirsh (1992). Uma característica particular da termoluminescência é que, uma vez aquecido para excitar a emissão de luz, o material não pode novamente emitir termoluminescência simplesmente pelo resfriamento e reaquecimento. Para uma nova emissão o material deve ser reexposto à radiação e em seguida aquecido.

Os princípios fundamentais que governam a produção de termoluminescência são essencialmente os mesmos daqueles que governam todos os processos luminescentes, dessa forma, termoluminescência é meramente um membro de uma família grande de fenômenos luminescentes, McKEEVER (1985). A emissão de luz acontece em um tempo característico $\tau_{c}$ após a absorção da radiação e este parâmetro permite sub-classificar os processos de luminescência. Assim, podemos distinguir entre fluorescência $\left(\tau_{c}<10^{-8} \mathrm{~s}\right) \mathrm{e}$ fosforescência $\left(\tau>10^{-8} \mathrm{~s}\right)$.

Em geral, emissão luminescente é explicada pela transferência de energia da radiação para os elétrons do sólido, assim excitando os elétrons de um estado fundamental $E_{0}$ para um estado excitado $E_{1}$ (transição (i) na figura 1.4a). A emissão de um fóton luminescente acontece quando um elétron excitado retorna ao seu estado fundamental (transição (ii)). Portanto, para fluorescência, o atraso entre as transições (i) e (ii) é menor do

que $10^{-8} \mathrm{~s}$ e este processo é independente da temperatura. Por sua vez, o diagrama de níveis de energia de um material fosforescente é modificado pela presença de um nível metaestável $m$ na banda de energia proibida (figura 1.4b). Um elétron excitado de $E_{0}$ para 
$E_{1}$ pode agora ser aprisionado em $m$, onde permanecerá até receber a energia $E$ para retornar ao estado $E_{1}$, e assim podendo retornar ao estado $E_{0}$ com a subseqüente emissão de luz. O atraso observado na fosforescência corresponde ao tempo gasto pelo elétron na armadilha $m$. De argumentos termodinâmicos, pode ser mostrado que o tempo médio gasto na armadilha a uma temperatura $T$ é dado pela equação de Arrhenius:

$$
\tau=s^{-1} \exp \left(\frac{E}{k T}\right)
$$

Sendo $s$ uma constante chamada fator de freqüência ou freqüência de escape, $E$ é a diferença de energia entre os estados $m$ e $E_{1}$ (chamada de profundidade da armadilha), $k$ é a constante de Boltzmann. Assim o processo fosforescente depende exponencialmente da temperatura.

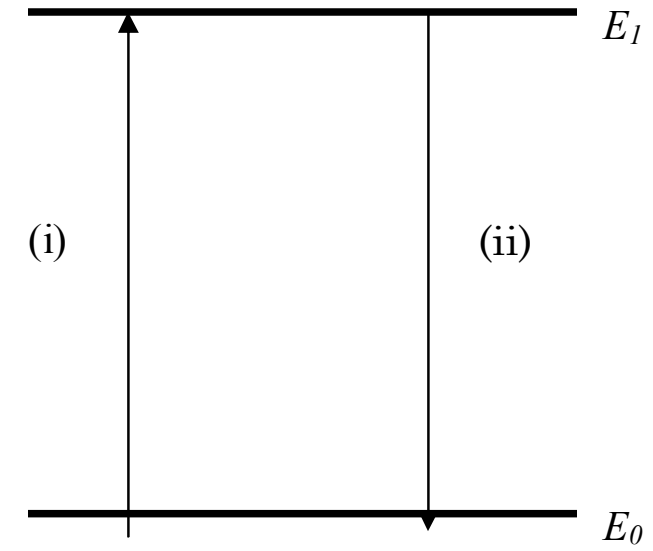

(a)

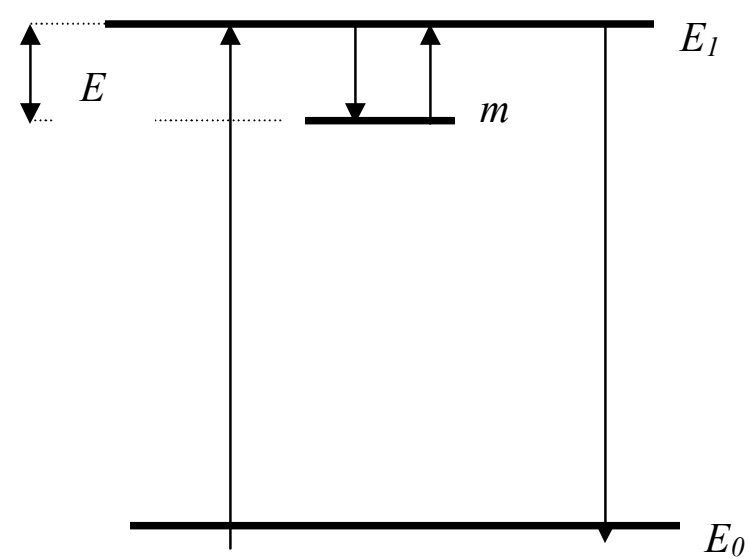

(b)

Figura 1.4:Transições entre os níveis de energia envolvidos na produção de fluorescência (a) e fosforescência (b). E $E_{0}$ : nível fundamental, $E_{1}$ : nível excitado, m: nível correspondente a um estado metaestável, $E$ : diferença de energia entre o estado metaestável e o estado excitado [retirado de McKEEVER (1985)].

Para uma certa temperatura $T$, podemos considerar que a diferença de energia $E$ do estado metaestável seja muito maior do que $k T$, então a luminescência não ocorrerá. Esta só será observada se o material for aquecido. Neste caso, a fosforescência recebe o nome de termoluminescência ou luminescência termicamente estimulada. 


\subsection{1 - Armadilhas e centros de recombinação}

Um fator essencial de todos os processos luminescentes é a alteração populacional dos vários estados de energia localizados. Estas alterações acontecem devido às transições eletrônicas de um estado de energia para outros. A figura 1.5 mostra vários tipos possíveis de transições para elétrons e buracos.

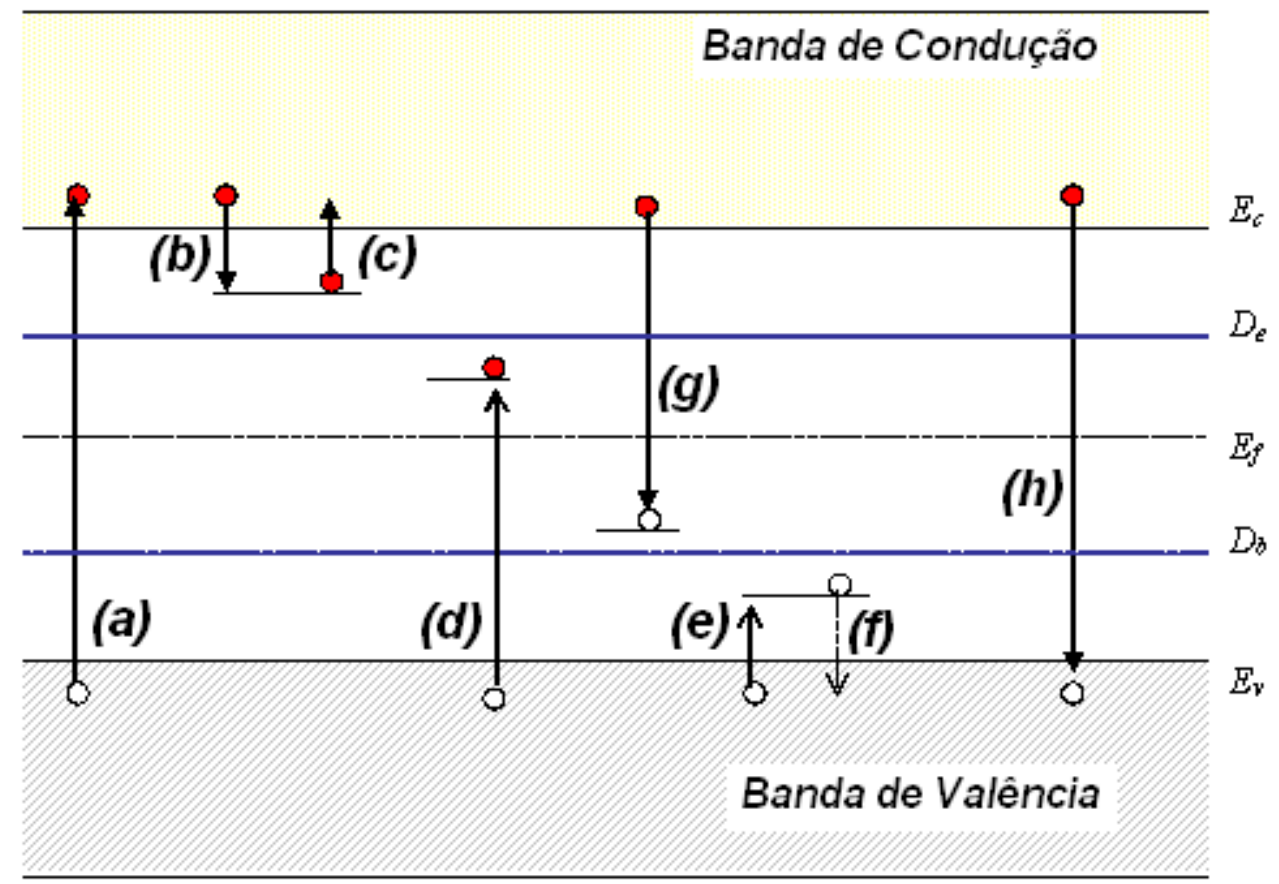

Figura 1.5: Transições em semicondutores e isolantes: (a) ionização, (b) e (e) aprisionamento de elétron e buraco, respectivamente, (c) e (f) liberação de elétron e buraco, respectivamente, $(d)$ e $(g)$ recombinação indireta e $(h)$ recombinação direta. Os elétrons são representados pelos círculos cheios e os buracos por círculos vazios, $D_{e}$ e $D_{b}$ são os níveis demarcadores para elétrons e buracos, respectivamente. Os níveis entre $E_{c}$ e $D_{e}$ são armadilhas eletrônicas e entre $D_{e}$ e $E_{f}$ são centros de recombinação. Analogamente, os níveis das armadilhas de buraco estão entre $E_{v}$ e $D_{b}$ e os centros de recombinação estão entre $D_{b}$ e $E_{f}$. 


\section{INTRODUÇÃO}

A transição (a) é a excitação de um elétron de valência de um átomo da rede cristalina para a banda de condução, em tal estado, ele pode mover-se livremente pelo cristal. Então, a transição (a) corresponde ao processo de ionização e é um resultado da absorção de energia de uma fonte externa, por exemplo radiação (raios $\mathbf{X}$, raios $\gamma$, etc.). Para todo elétron livre na banda de condução um buraco livre é deixado na banda de valência. Assim a ionização cria pares de elétrons e buracos livres que se deslocam pelo cristal até que sejam aprisionados (transições (b) e (e)). Esses elétrons e buracos podem ser liberados de suas armadilhas por excitação térmica ou óptica (transições (c) e (f)), tornando-se livres novamente, até serem capturados por cargas opostas em centros de recombinação (transições (d) ou (g)). Uma segunda possibilidade para os elétrons e buracos livres é a recombinação direta (transição $(h)$ ), embora esse processo seja menos provável. Se os mecanismos de recombinação são acompanhados de emissão de luz (transições radiativas), então temos como resultado luminescência.

Portanto, alguns níveis de energia localizados atuarão como armadilhas e outros como centros de recombinação. Os fatores reguladores destes papéis são as probabilidades de recombinação e excitação térmica (ou óptica). Portanto, um determinado nível representa uma armadilha eletrônica, se a probabilidade de liberação do elétron aprisionado for maior do que a sua probabilidade de recombinação com um buraco livre oriundo da banda de valência. Inversamente, um nível localizado será um centro de recombinação, se a probabilidade de recombinação do elétron aprisionado com um buraco for maior do que a probabilidade de liberação deste elétron. O critério apresentado é similarmente empregado para os níveis de buraco. Esta distinção entre uma armadilha e um centro de recombinação leva a uma possibilidade que, a uma dada temperatura, existirá um nível localizado para o qual as probabilidades de transição são iguais. Tal nível, de "profundidade" $D$, representaria uma demarcação entre armadilhas e centros de recombinação, tal que um centro com profundidade de energia $E$ seria uma armadilha se $E$ $<D$ ou seria um centro de recombinação se $E>D$. Como a profundidade dos níveis localizados refere-se à diferença energética entre o nível localizado e a banda delocalizada associada (banda de condução para elétrons e banda de valência para buracos), temos um nível de demarcação para elétrons $D_{e}$, e um correspondente para os buracos, $D_{b}$. Estes níveis são representados na figura 1.5 . 


\subsection{2 - Um modelo simplificado para termoluminescência}

TL surge quando parte da energia absorvida por uma amostra durante a irradiação é armazenada, e posteriormente retorna com luz quando a amostra é aquecida. O modelo básico assume que a irradiação produz elétrons livres e buracos e que alguns deles são armadilhados em níveis de energia local dentro de bandas proibidas. Esses estados armadilhados são usualmente associados com defeitos tais como: vacâncias, intersticiais, ou impurezas. Durante o aquecimento, elétrons armadilhados (ou buracos) podem ser termicamente promovidos para a banda de condução (valência) e então recombina-se com cargas armadilhadas de sinal oposto. O modelo simples para TL consiste de um único nível de elétrons e um único nível de buraco na banda proibida, como pode ser visto na figura 1.6.

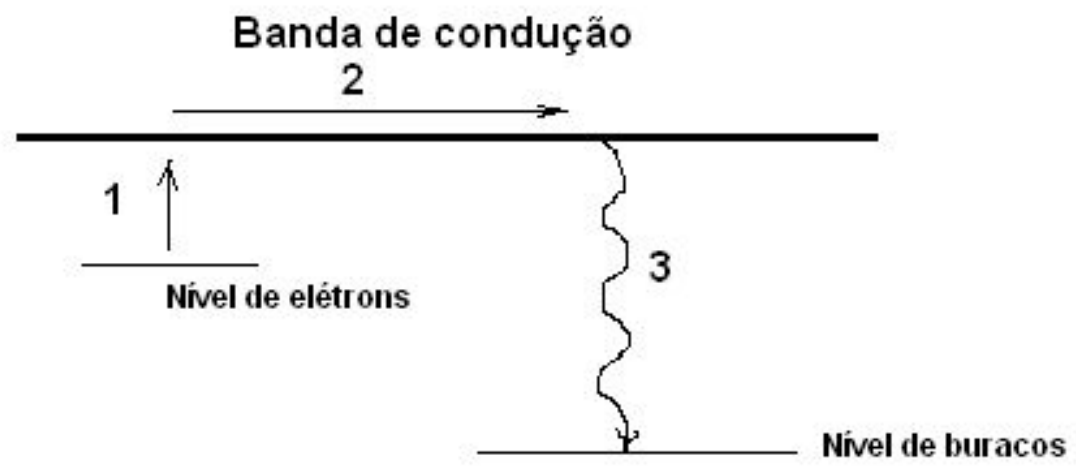

\section{Banda de valência}

Figura 1.6: Um modelo simples para TL [retirado de Kirsh (1992)].

Se o nível de elétrons é relativamente raso, o centro de buraco é relativamente estável durante o aquecimento, enquanto elétrons são termicamente liberados e movem-se para a banda de condução. Eventualmente eles recombinam com os centros de buraco para produzir TL. A probabilidade por segundo de liberação de uma carga armadilhada aumenta com o aumento da temperatura. Em muitos casos está probabilidade é dada por:

$$
p=\tau^{-1}=s \cdot \exp \left(\frac{-E}{k T}\right)
$$


Onde $E$, a energia de ativação, é a separação vertical entre a armadilha e a banda de condução (valência), s é o fator de freqüência, $k$ a constante de Boltzmann e $T$ a temperatura absoluta. Quando a temperatura é aumentada, a taxa de recombinação aumenta, pois mais cargas armadilhadas são liberadas por segundo. Após atingir um máximo, diminui conforme as armadilhas (ou centros de recombinação) são reduzidas. A curva TL é, portanto, um único pico, como mostrado na figura 1.7. Em um experimento deste tipo a temperatura é aumentada como uma função linear do tempo, $T=T_{0}+\beta . t$, sendo $\beta$ definida como a taxa de aquecimento dada por:

$$
\beta=\frac{d T}{d t}
$$

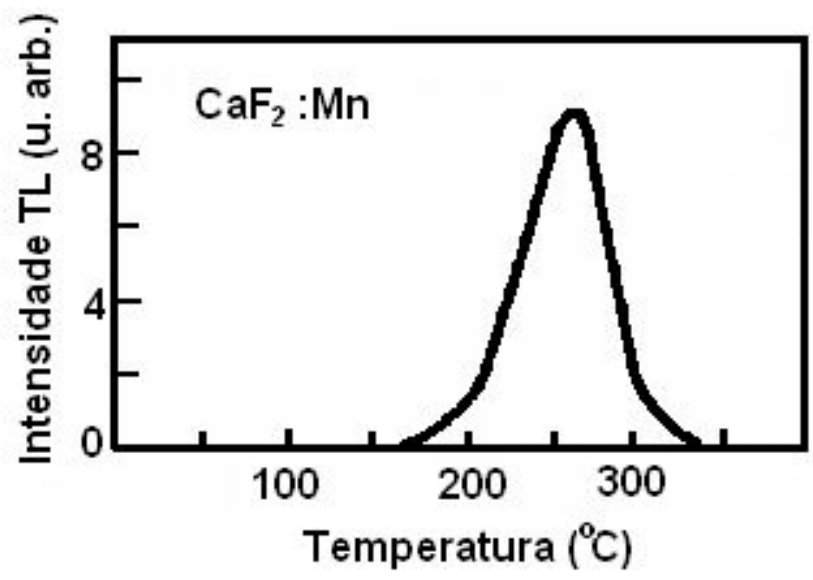

Figura 1.7: Curva de emissão $T L$ de $\mathrm{CaF}_{2}: \mathrm{Mn}$ após irradiação $\gamma$ e taxa de aquecimento $25^{\circ} \mathrm{C} / \mathrm{min}$ [Retirado de Sunta(1984)].

Devemos destacar algumas propriedades das curvas de emissão. Em primeiro lugar, a temperatura $\left(T_{m}\right)$ na qual a intensidade da emissão é máxima relaciona-se com a profundidade da armadilha $E$. Portanto, uma curva de emissão com vários picos TL significa que o espécime possui diferentes armadilhas, cada uma com seu valor próprio de profundidade $E$. Em segundo lugar, a área (ou a altura) do pico TL é proporcional ao número de armadilhas preenchidas durante a irradiação, isto é, ela é proporcional à dose de radiação dada ao espécime. Para obtermos informação a respeito dos centros de emissão é 
necessário um outro tipo de medida, chamada decomposição espectral da emissão TL ou espectro da emissão TL. Usualmente, é feita uma varredura em uma faixa de comprimentos de onda em uma dada temperatura da curva de emissão (ou sobre uma faixa estreita de temperaturas). O espectro da emissão $\mathrm{TL}$ para o pico em torno de $250^{\circ} \mathrm{C}$ de $\mathrm{CaF}_{2}: \mathrm{Mn}$ é mostrado na figura 1.8 e corresponde a emissão característica do dopante $\mathrm{Mn}^{2+}$.

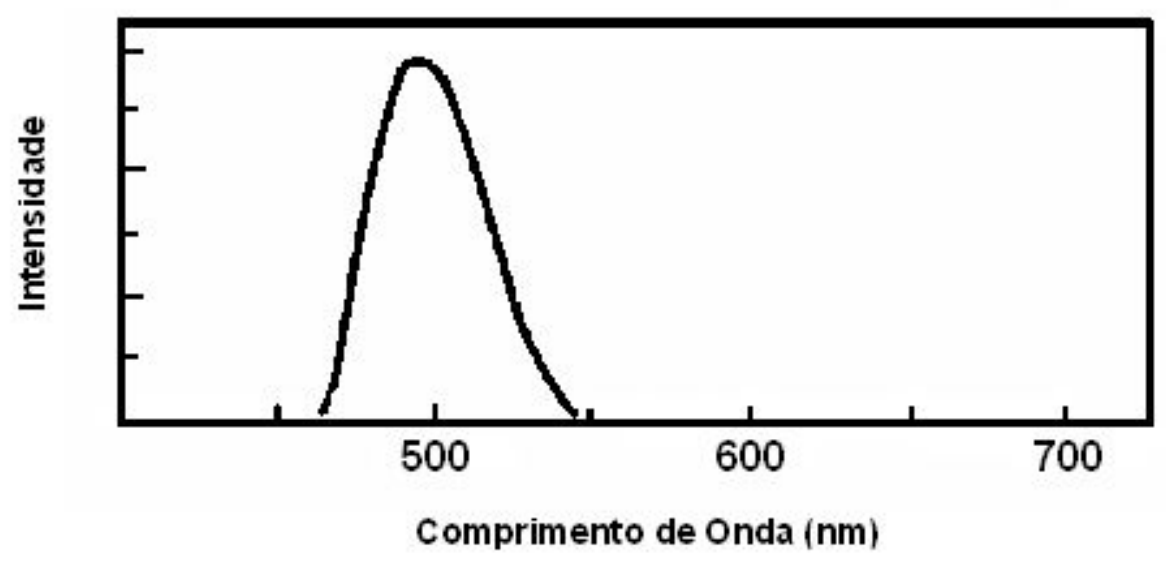

Figura 1.8: Espectro de emissão do pico $T L$ de $\mathrm{CaF}_{2}: \mathrm{Mn}$ em torno de $250^{\circ} \mathrm{C}$. A banda observada corresponde a transição eletrônica ${ }^{4} G-{ }^{6} S$ do dopante $M n^{2+}$ [Retirado de Sunta(1984)]. 


\section{4 - Centros de cor e absorção óptica}

As imperfeições da rede e impurezas podem capturar portadores de carga e tornarem-se centros de cor, isto é, podem causar alterações na aparência do cristal. Muitas vezes, cristais recém crescidos são transparentes à luz visível, mas quando irradiados com raios $\mathbf{X}$ ou raios $\gamma$, adquirem cor. Isto acontece devido à ocupação dos níveis de energia (das armadilhas) dentro da banda proibida pelos portadores de carga. Esses portadores de carga podem agora absorver a luz visível (com determinado comprimento de onda), tornando o cristal colorido. Os níveis de energia e centros de cor estão intimamente relacionados com a técnica experimental Absorção Óptica.

\subsection{1- Absorção óptica}

A absorção de energia de um feixe de luz que incide sobre um cristal ocorre quando o comprimento de onda da luz corresponde à diferença dos níveis de energia de um íon (ou átomo) deste cristal. Com isso, temos o aparecimento de uma banda de absorção no espectro óptico do cristal. A figura 1.9 mostra uma representação simplificada do arranjo experimental necessário para obtenção de um espectro de absorção óptica (AO).

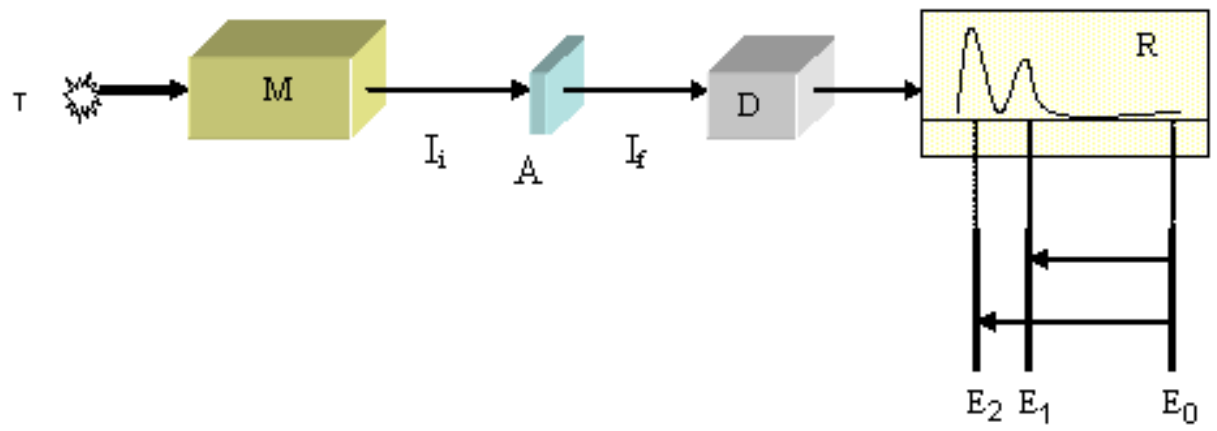

Figura 1.9: Arranjo experimental simplificado para obtenção de um espectro óptico. As letras acima representam: $L$, fonte de luz; $M$, monocromador; $A$, amostra; $D$, detector; $R$, registro do espectro, $l_{i}$ e $I_{f}$, intensidades incidente e transmitida do feixe de luz. Também são mostrados os níveis de energia e transições (hipotéticos) correspondentes ao espectro de absorção [adaptado de Marfunin (1979b)]. 
Em geral, as energias dos níveis dos íons no cristal podem ser determinadas pela posição das bandas de absorção no espectro óptico, estas energias são freqüentemente expressas em elétron volt $(\mathrm{eV})\left(1 \mathrm{eV}=1,6022 \times 10^{-19} \mathrm{~J}\right)$, mas para uma definição mais exata da posição das bandas de absorção é mais conveniente utilizar o comprimento de onda $\lambda$ da luz que a originou (geralmente expresso em $1 \mathrm{~nm}=10^{-9} \mathrm{~m}$ ) ou o número de onda $\bar{v}$ da mesma (geralmente expresso $\mathrm{em} \mathrm{cm}^{-1}$ ). Temos as seguintes relações entre as unidades das grandezas utilizadas em espectroscopia óptica:

$$
E(\mathrm{eV})=\frac{1240}{\lambda(\mathrm{nm})} \quad \text { e } \quad \bar{v}\left(1000 \mathrm{~cm}^{-1}\right)=\frac{10^{4}}{\lambda(\mathrm{nm})}
$$

Enquanto a posição das bandas de absorção é relacionada com a diferença de energia entre os níveis dos íons do cristal, suas intensidades são relacionadas com a probabilidade de ocorrência de transição entre esses níveis.

Por simplicidade, consideremos as transições ópticas de átomos isolados. Se um feixe de luz isotrópica (não polarizada) de $N$ fótons por unidade de volume, cada um deles com energia $\hbar \omega$, incide em um átomo, a probabilidade por unidade de tempo $P_{m k}$ que o átomo fará uma transição do estado $m$ para o estado $k$ é dada por (1.5):

$$
P_{m k}=\frac{4 \pi^{2}\left|E_{k}-E_{m}\right|}{3 \hbar} N\left|\left\langle\psi_{k}|\hat{d}| \psi_{m}\right\rangle\right|^{2} \delta\left(\left|E_{k}-E_{m}\right|-\hbar \omega\right)
$$

sendo, $\left\langle\psi_{k}|\hat{d}| \psi_{m}\right\rangle=\sum_{s} \int \psi_{k}^{*} e \hat{r}_{s} \psi_{m} d \tau$ o elemento de matriz de dipolo elétrico, onde a soma é dada sobre todos os elétrons (carga elétrica e), $\psi_{k}$ e $\psi_{m}$ são soluções da equação de Schrödinger independente do tempo, com autovalores $E_{k}$ e $E_{m}$ respectivamente. A integral é calculada sobre todas as coordenadas eletrônicas.

A equação (1-4) é válida nas seguintes circunstâncias:

a) A densidade de fótons $N$ é pequena, somente processos lineares em $N$ são considerados.

b) Anteriormente à transição, a probabilidade do átomo estar no estado $m$ era 1 .

c) Somente transições de dipolo elétrico são consideradas, portanto sendo válidas as respectivas regras de seleção.

d) Todos os estados envolvidos são discretos. 
A intensidade da banda de absorção que surge devido a esta transição pode ser relacionada a várias quantidades, uma delas é a quantidade adimensional intensidade do oscilador $f$. Esta é definida como o quociente entre a probabilidade da transição que origina a banda de absorção e a probabilidade de transição de um oscilador harmônico tridimensional isótropo no qual o número quântico vibracional $n_{x}$ ou $n_{y}$ ou $n_{z}$ troque de 0 para 1. (O oscilador harmônico se define de modo que sua massa e sua carga sejam iguais à massa e à carga do elétron e a freqüência de vibração seja igual à freqüência da transição em questão). Portanto, a intensidade do oscilador para a transição descrita pela probabilidade $P_{m k}$ acima é dada por:

$$
f_{m k}=\frac{2 m}{3 \hbar^{2} e^{2}}\left|E_{k}-E_{m}\right|\left|\left\langle\psi_{k}|\hat{d}| \psi_{m}\right\rangle\right|^{2}
$$

Uma outra quantidade importante é o coeficiente de absorção $\alpha$, definido em termos da intensidade da radiação $/$ incidente e do decréscimo desta intensidade em função da espessura $x$ :

$$
\alpha=-\frac{1}{I} \frac{d I}{d x}
$$

assim, $\alpha$ pode ser escrito em função da energia $E=\hbar w$ do feixe incidente, por:

$$
\alpha(E)=\frac{P_{m k} \cdot n_{a}}{N . c}=\frac{4 \pi^{2} n_{a}\left|E_{k}-E_{m}\right|}{3 \hbar c}\left|\left\langle\psi_{k}|\hat{d}| \psi_{m}\right\rangle\right|^{2} \delta\left(\left|E_{k}-E_{m}\right|-E\right)
$$

sendo $n_{a}$ o número de átomos por unidade de volume e N.c o fluxo de fótons incidentes.

Nas expressões acima estamos supondo um feixe de luz incidente estritamente monocromático, fato este que não ocorre nas condições experimentais. Então, a probabilidade $P_{m k}$ possui valores maiores do que zero para energias próximas da energia de transição $E$. Portanto é apropriado definir o coeficiente de absorção integrado , sendo:

$$
I=\int_{0}^{\infty} \alpha(E) d E=h c \int_{0}^{\infty} \alpha(\bar{v}) d \bar{v}
$$

este representa a área sob a banda de absorção quando $\alpha$ é obtido em função de $E$ ou $\bar{v}$ (espectro).

Um simples relacionamento é encontrado entre a intensidade do oscilador $f_{m k}$ (1.10) e o coeficiente de absorção integrado: 


$$
f_{m k}=\frac{m c}{2 \pi^{2} e^{2} \hbar} \int_{0}^{\infty} \frac{\alpha(E)}{n_{a}} d E=\frac{m c^{2}}{\pi e^{2}} \int_{0}^{\infty} \frac{\alpha(\bar{v})}{n_{a}} d \bar{v}
$$

Todos os resultados obtidos até o momento estão baseados na condição do átomo ou íon estar isolado, mas se este estiver em um cristal, devemos destacar a influência gerada pelo campo cristalino, que é o potencial elétrico determinado pelas posições, cargas e natureza eletrônica dos íons da rede cristalina em equilíbrio. E em segundo lugar a simetria deste campo: as posições destes íons determinam a simetria das funções de onda envolvidas nas transições. Estes efeitos afetam a localização dos níveis de energia dos íons, bem como podem causar a separação destes. Um outro efeito importante é a influência das vibrações da rede cristalina sobre os íons absorvedores, estas vibrações assistem a absorção de fótons com comprimentos de onda ligeiramente diferentes daqueles correspondentes a uma transição, portanto causam o alargamento das bandas de absorção.

\subsubsection{Um pouco sobre a teoria do campo cristalino}

Existem várias teorias que explicam o comportamento dos íons em cristais, entre elas, destacamos a teoria do campo cristalino, através da qual podemos entender a cor de minerais contendo metais de transição (Nassau - 1978). ĺons em cristais têm propriedades individuais que dependem do tipo, número e arranjo dos íons vizinhos.

Em modelos de estrutura cristalina usamos poliedros de coordenação (exemplo: octaedro, tetraedro,...), onde podemos distinguir, para o poliedro, um íon central, diretamente ligado com íons negativos localizados nos vértices do poliedro, que chamamos de íons ligantes ou simplesmente ligantes. Esses ligantes são tratados como cargas pontuais, tendo o papel de criar um potencial eletrostático que é denominado campo cristalino.

Este potencial produz uma separação dos níveis de energia do íon central. Somente os níveis de energia de íons com subníveis incompletos sofrem separação, com elétrons d e f, dessa forma, a teoria do campo cristalino é a teoria do comportamento dos íons de metais de transição em cristais ou moléculas. O tipo de íon ligante e a distância entre este e o íon central determina a intensidade do campo cristalino. Simetrias 
correspondentes a octaedros ou tetraedros regulares não ocorrem em muitas estruturas. A maioria dos poliedros são distorcidos e têm baixa simetria, Marfunin (1979b), como é o caso da rodonita, Peacor e Niizeki (1963).

Distorções do poliedro de coordenação em estruturas cristalinas de cristais com metais de transição são esperadas por razões teóricas conhecidas como efeito Jahn-Teller. Jahn -Teller (1937) provaram que se o estado fundamental ou menor nível de energia de uma molécula é degenerado, ele irá distorcer espontaneamente para uma menor simetria a fim de remover a degenerescência e tornar o nível de energia mais estável. Por exemplo, se um dos orbitais $3 d$ está completamente vazio ou completamente cheio enquanto outro de igual energia está com meia ocupação, o ambiente em torno do íon do metal de transição irá distorcer espontaneamente para uma geometria diferente na qual uma configuração eletrônica mais estável é obtida.

\subsubsection{Lei de Buger-Lambert}

A definição do coeficiente de absorção $\alpha$ (equação 1-6) decorre da chamada Lei de Buger-Lambert. Segundo esta lei, o decréscimo da intensidade do feixe de luz incidente ao atravessar uma amostra de espessura $\mathrm{x}$ é diretamente proporcional à intensidade do feixe incidente. Então,

$$
\frac{d I}{d x}=-\alpha \cdot I \quad \Rightarrow \quad I=I_{0} e^{-\alpha x}
$$

sendo $I_{0}$ a intensidade inicial do feixe de luz incidente. A equação acima pode ser escrita como:

$$
\ln \frac{I_{0}}{I}=\alpha x \quad \text { ou } \quad \log \frac{I_{0}}{I}=\alpha \cdot \log e \cdot x
$$


Experimentalmente trabalhamos com as seguintes grandezas:

$$
\text { Transmitância: } T=\frac{I}{I_{0}}
$$

$$
\text { Densidade Óptica ou Absorbância: } D O=A=\log \frac{I_{0}}{I}=\log \frac{1}{T}
$$

Então, a equação 1-11 torna-se:

$$
A=0,434 . \alpha \cdot x=\alpha^{\prime} \cdot x
$$

A equação 1-13 é importante, pois ela é utilizada para normalizar espectros de absorção de amostras de um mesmo cristal que possuem espessuras diferentes. 


\section{5 - Ressonância paramagnética eletrônica (RPE)}

\subsection{1 - Princípios fundamentais $(S=1 / 2)$}

Qualquer carga girando comporta-se como um imã, com seus pólos na direção do eixo de rotação. Um elétron girando em torno de si mesmo tem um momento angular rotacional $\vec{S}$, chamado spin e, conseqüentemente um momento magnético $\vec{\mu}_{e}$ que é proporcional e colinear com $\vec{S}$. Dessa forma, $\vec{\mu}_{e}=\gamma \vec{S}$, onde $\gamma$ recebe o nome de razão giromagnética. Sobre o eixo de quantificação, o vetor spin, $\vec{S}$, pode tomar os valores $\pm \frac{1}{2}$ em unidades múltiplas de $\hbar$. Se um sistema que contém elétrons desemparelhados, ou seja, com spin $\neq 0$, é colocado em um campo magnético externo $\overrightarrow{\mathrm{H}}$, a energia do sistema será dada por:

$$
E=-\vec{\mu}_{e} \overrightarrow{\mathrm{H}}=-g_{e} \beta \vec{S} \cdot \overrightarrow{\mathrm{H}}= \pm \frac{1}{2} g_{e} \beta \mathrm{H}
$$

onde $g_{e}$ é a constante chamada fator $g$ e $\beta$ é o magneton de Bohr para o elétron.

Todo spin eletrônico é então orientado na mesma direção (paralela) ou direção oposta (antiparalela) em relação a $\overrightarrow{\mathrm{H}}$. Na ausência de um campo magnético, os elétrons ficam orientados aleatoriamente. Sobre um campo magnético aplicado, $\vec{H}$ existem duas populações de spins e uma diferença de energia, $\Delta E$, igual a:

$$
\Delta E=g_{e} \beta \mathrm{H}
$$

No equilíbrio, a razão entre as populações de dois estados é dado pelo fator de Boltzmann.

$$
\frac{n^{+}}{n^{-}}=\exp \left(\frac{\Delta E}{k T}\right) \cong 1-\frac{\Delta E}{k T}
$$


onde k é a constante de Boltzmann e $n^{+}$e $n^{-}$são populações de elétrons com $+\frac{1}{2}$ e $-\frac{1}{2}$ respectivamente.

Quando um sistema de spins eletrônicos está sujeito a um campo magnético $\overrightarrow{\mathrm{H}}$ e a uma microonda de freqüência $v$ perpendicular ao campo magnético, a componente $\mathrm{m}_{z}$ do spin do elétron muda da direção antiparalela para a direção paralela. Isso ocorre quando o fator de energia $h v$ é tal que a condição $\Delta E=g_{e} \beta \mathrm{H}=h v$ é atingida. Essa é a condição de ressonância (para $S=1 / 2$ ) e resulta de uma absorção de energia como mostrado na figura 1.10 .

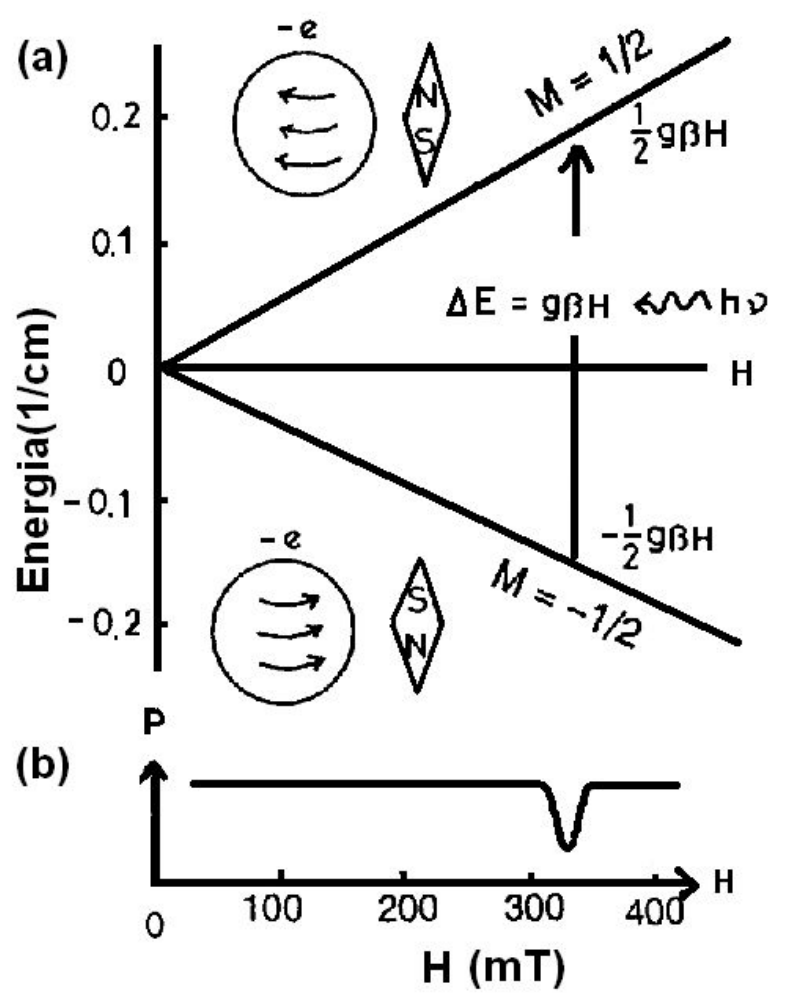

Figura 1.10: (a) Níveis de energia de um spin eletrônico em função do campo magnético $\overrightarrow{\mathrm{H}}$. (b) Para $\mathrm{H}=\frac{h v}{g \beta}$ ocorre uma absorção da potência, isto é, uma ressonância [ retirado de Ikeya (1993)]. 
Devemos lembrar que a espectroscopia RPE somente é aplicável em sistemas com no mínimo um elétron desemparelhado, ou seja, compostos paramagnéticos.

O retorno do elétron ao estado de spin inicial está associado ao equilíbrio de Boltzmann. Este libera sua energia, $h v$, que é dissipada através da estrutura. Isto é chamado de relaxação spin-rede e caracterizada pelo tempo $T_{1}$. O retorno ao estado inicial também ocorre para a fase do spin por troca de energia dos spins, sem perda de energia para a rede e, é chamada de relaxação spin-spin, caracterizada pelo constante de tempo $T_{2}$.

Os seguintes parâmetros caracterizam os elétrons desemparelhados:

Momento angular do spin: $S$ em unidade $\frac{h}{2 \pi}=\hbar$ onde $\mathrm{h}$ é a constante de Planck.

Número quântico do spin: $\vec{S}: \vec{m}_{s}: m_{s}= \pm \frac{1}{2}$

Magnéton de Bohr: $\beta$

Momento magnético: $\vec{\mu}_{e}: \mu_{e}=-g \beta S$

Fator de separação espectroscópica: $\vec{g}: g=2,0023$ para um elétron livre.

\subsection{2 - O espectrômetro de RPE}

A figura 1.11 mostra um diagrama de blocos de um espectrômetro RPE. As microondas são produzidas por um Klystron ou diodo-Gunn e seguem por um guia de ondas a uma cavidade ressonante dentro de um campo magnético produzido por um eletroímã.

A amostra é colocada dentro da cavidade onde um campo magnético, cuja intensidade varia à medida que a corrente elétrica no eletroímã varia.

Um detector de diodo registra, através de um amplificador "lock-in", a absorção das microondas. 


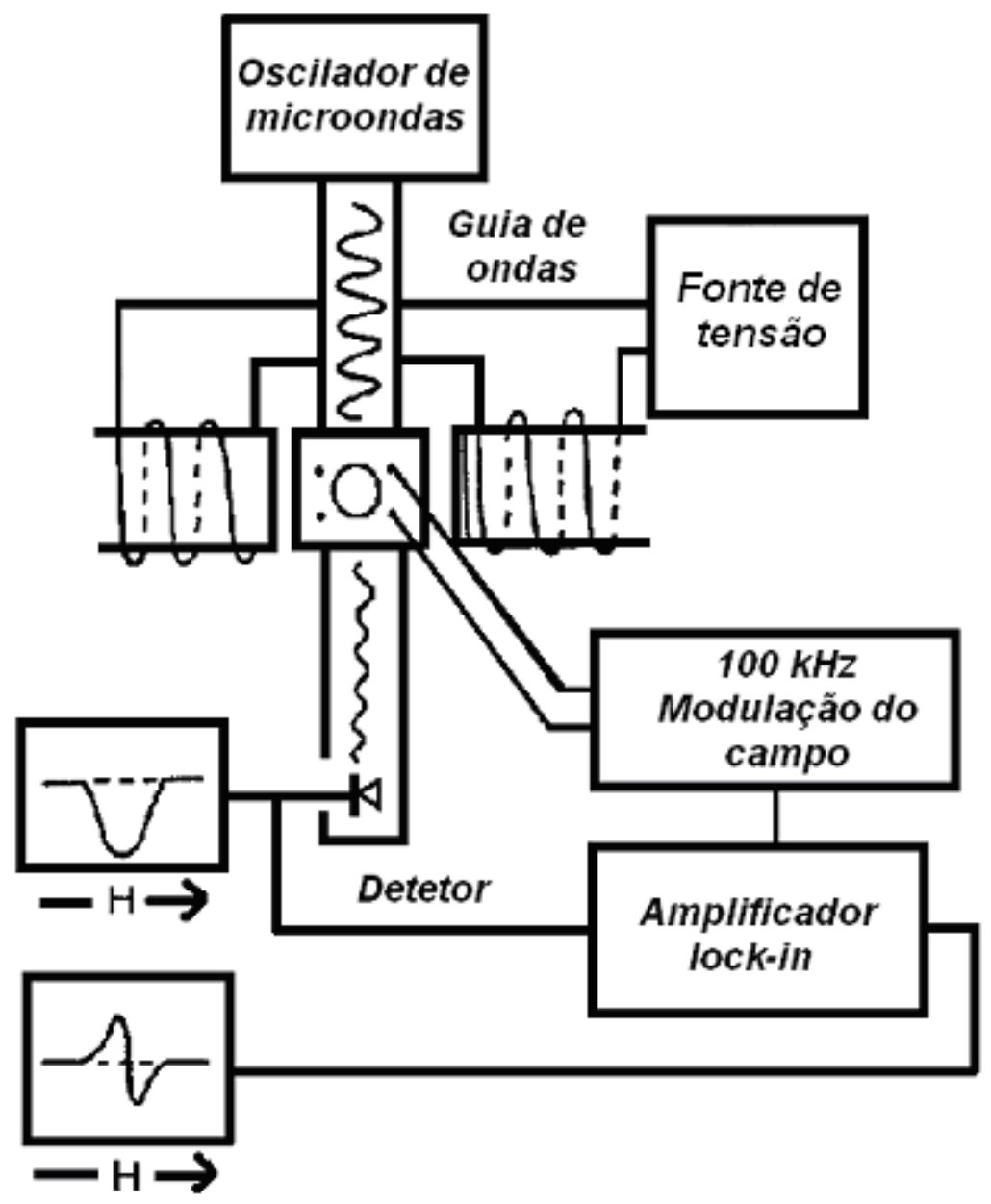

Figura 1.11: Esquema de um espectrômetro RPE [retirado de Ikeya(1993)]

O fator g é um parâmetro importante; um valor $\mathrm{g}$ de uma linha obtém-se da condição de ressonância:

$$
g=\left(\frac{h}{\beta}\right)\left(\frac{v}{\mathrm{H}}\right)=71,455\left(\frac{v}{\mathrm{H}}\right)
$$

A tabela 1.2 mostra as bandas de microondas usadas ( em comprimento de onda) e o campo magnético $\overrightarrow{\mathrm{H}}$ de ressonância para o sinal de $g=2,0$. 
Tabela 1.2: bandas de microondas, seus comprimentos de onda, freqüências e $\overrightarrow{\mathrm{H}}$ de ressonância para $g=2,0$.

\begin{tabular}{|l|l|l|l|}
\hline Banda & $\lambda(\mathbf{c m})$ & $v(\mathbf{G H z})$ & $\mathrm{H}(\mathrm{mT})$ \\
\hline L & 20,0 & 1,5 & 53,5 \\
\hline S & 9,4 & 3,2 & 114 \\
\hline X & 3,2 & 9,5 & 339 \\
\hline K & 1,2 & 25 & 892 \\
\hline Q & 0,86 & 35 & 1250 \\
\hline
\end{tabular}

Essa introdução sobre RPE foi adaptada de Abragam e Bleaney (1970), Stucki e Banwart (1979), e lkeya (1993).

\subsection{3 - Interação Spin-Spin}

\subsubsection{1 - Campo local de um momento magnético na posição de seu vizinho}

Há situações em que, os momentos magnéticos $\vec{\mu}_{e}$, dos elétrons não-pareados no cristal, estão separados entre si por uma distância média $r_{m}$, tal que, o campo magnético produzido por um, na posição de seu vizinho, torna-se não desprezível em relação ao campo magnético $\mathrm{H}$ típico de laboratório, contribuindo para a condição de ressonância.

Por exemplo, se um momento magnético $\vec{\mu}_{e}$ dista, em média, $r_{m}=n \AA$, $n>2$, do seu vizinho o campo local neste seria da ordem de:

$$
H_{l o c} \cong \frac{8 \cdot 10^{3}}{n^{3}} \text { Gauss }
$$


Como esse campo pode adicionar ou opor-se ao campo estático $H$, resulta num alargamento da condição de ressonância, com uma absorção significativa tendo lugar num intervalo do valor de $H_{l o c}$.

\subsubsection{2 - Interação dipolo-dipolo}

Se dois momentos magnéticos $\vec{\mu}_{1}$ e $\vec{\mu}_{2}$, estão separados de um raio vetor $\vec{r}$, classicamente a energia $E$ de interação é dada por:

$$
E=\frac{\vec{\mu}_{1} \cdot \vec{\mu}_{2}}{r^{3}}-\frac{3\left(\vec{\mu}_{1} \cdot \vec{r}\right)\left(\vec{\mu}_{2} \cdot \vec{r}\right)}{r^{5}}
$$

Para elétrons 1 e 2 ,

$$
\vec{\mu}_{1}=g_{1} \beta \vec{S}_{1} \text { e } \vec{\mu}_{2}=g_{2} \beta \vec{S}_{2}
$$

Se houver N spins, a contribuição dessa interação para a Hamiltoniana será dada por:

$$
\mathrm{H}=\frac{1}{2} \sum_{j=1}^{N} \sum_{k=1}^{N}\left[\frac{\vec{\mu}_{j} \cdot \vec{\mu}_{k}}{r_{j k}^{3}}-\frac{3\left(\vec{\mu}_{j} \cdot \vec{r}_{j k}\right)\left(\vec{\mu}_{k} \cdot \vec{r}_{j k}\right)}{r_{j k}^{5}}\right]
$$

Omitindo os índices de $\vec{r}$, de (1-19) pode-se ver que, a Hamiltoniana dipolar $H_{d}$ contém termos da forma:

$$
\beta^{2} g_{1} g_{2} S_{1 x} S_{2 x} \frac{1}{r^{3}} \quad \text { e } \quad \beta^{2} g_{1} g_{2} S_{1 x} S_{2 y} \frac{x y}{r^{5}}
$$

Usando os operadores $I_{1}^{ \pm}=\left(I_{1 x} \pm I_{1 y}\right)$ e as coordenadas esféricas $(r, \theta, \varphi)$ ao invés de $(x, y, z)$ a Hamiltoniana pode ser decomposta em: 


$$
H_{d}=\frac{g_{1} g_{2}}{r^{3}} \beta^{2}(A+B+C+D+E+F)
$$

Onde,

$$
\begin{aligned}
& A=S_{1 z} S_{2 z}\left(1-3 \cos ^{2} \theta\right) \\
& B=-\frac{1}{4}\left(S_{1}^{+} S_{2}^{-}+S_{1}^{-} S_{2}^{+}\right)\left(1-3 \cos ^{2} \theta\right) \\
& C=-\frac{3}{2}\left(S_{1}^{+} S_{2 z}+S_{1 z} S_{2}^{+}\right) \operatorname{sen} \theta \cos \theta e^{-i \varphi} \\
& D=-\frac{3}{2}\left(S_{1}^{-} S_{2 z}+S_{1 z} S_{2}^{-}\right) \operatorname{sen} \theta \cos \theta e^{i \varphi} \\
& E=-\frac{3}{4} S_{1}^{+} S_{2}^{+} \operatorname{sen}^{2} \theta e^{-2 i \varphi} \\
& F=-\frac{3}{4} S_{1}^{-} S_{2}^{-} \operatorname{sen}^{2} \theta e^{2 i \varphi}
\end{aligned}
$$

Como foi visto, $\frac{\hbar^{2} g^{2} \beta^{2}}{r^{3}} \cong \frac{8}{h^{3}} 10^{3}$ Gauss, comparado com a Hamiltoniana Zeeman de alguns milhares de Gauss. Por isso, para $n \cong 10$, a interação dipolar pode ser tomada como uma perturbação.

Para se ter uma idéia dos termos $A, B, C, \ldots$, consideram-se dois momentos iguais de spin $\frac{1}{2}$. A energia e as funções de onda de Zeeman podem ser escritas em termos dos números quânticos $m_{1}$ e $m_{2}$ e $S_{1 z}$ e $S_{2 z}$ :

$$
E_{z}=-g \beta \hbar H_{0} m_{1}-g \beta \hbar H_{0} m_{2}
$$


A figura 1.12 mostra os níveis de energia de Zeeman no caso de dois spins idênticos.

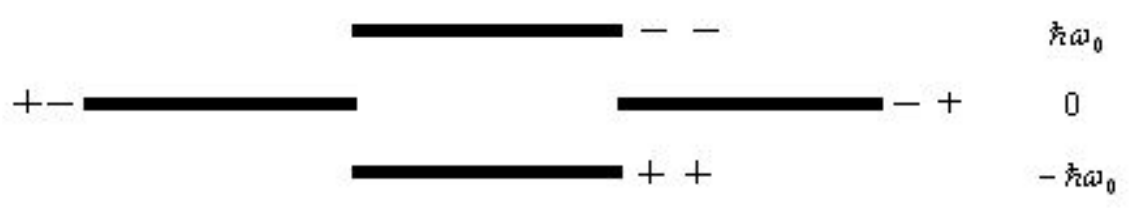

Figura 1.12: Níveis de energia de Zeeman de dois spins idênticos [retirado de Slichter (1990)].

$\mathrm{Na}$ figura $1.13,+-$ indica nível de energia do estado $|+-\rangle$ com $m_{1}=+\frac{1}{2} \mathrm{e}$ $m_{2}=-\frac{1}{2}$. Vê-se, então, que os dois estados $|+-\rangle$ e $|-+\rangle$ são degenerados, ambos com $E_{z}=0, \omega_{0}=g H_{0}$.

A pergunta é, quais estados são conectados pelo termo de interação dipolar?

O termo A é proporcional a $S_{1 z} S_{2 z}$, isto é, é diagonal, por isso, só pode levar de $\left|m_{1} m_{2}\right\rangle$ a $\left|m_{1} m_{2}\right\rangle$. B por outro lado, contém termos do tipo $S_{1}^{+} S_{2}^{-}+S_{1}^{-} S_{2}^{+}$, portanto, conecta $\left|m_{1} m_{2}\right\rangle$ aos estados $\left(m_{1}+1, m_{2}-1\right)$ ou $\left(m_{1}-1, m_{2}+1\right)$. Isto quer dizer que B inverte um spin para cima e outro para baixo, isto é, ele conecta os estados $|+-\rangle \mathrm{e}|-+\rangle$. 


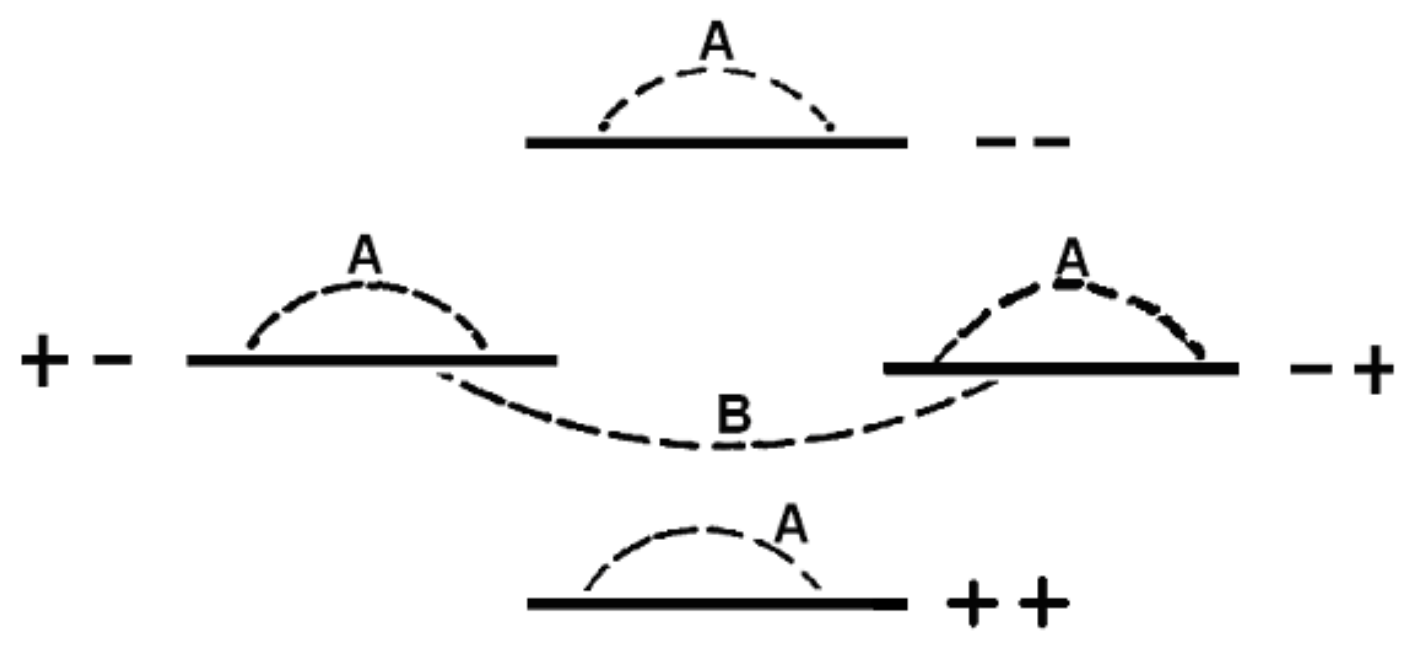

A figura 1.13: mostra os estados conectados por A e B idênticos [retirado de Slichter (1990)].

Observa-se que B não tem elementos de matriz diagonais, mas tem elementos não-diagonais entre os dois estados degenerados. O fato de que os elementos nãodiagonais ligam os estados degenerados $|+-\rangle$ e $|-+\rangle$ indica que, eles não são estados próprios de ordem zero.

B desempenha, por isso, um papel importante na determinação de funções de ondas próprias de ordem zero, quando $B$ passa a ter elementos diagonais.

Como os termos C e D invertem, cada vez, somente um spin, a conexão dos estados acontece como está ilustrado na figura 1.14(a). E e F inverte os dois spins, indicados na figura 1.14(b). 
(a)

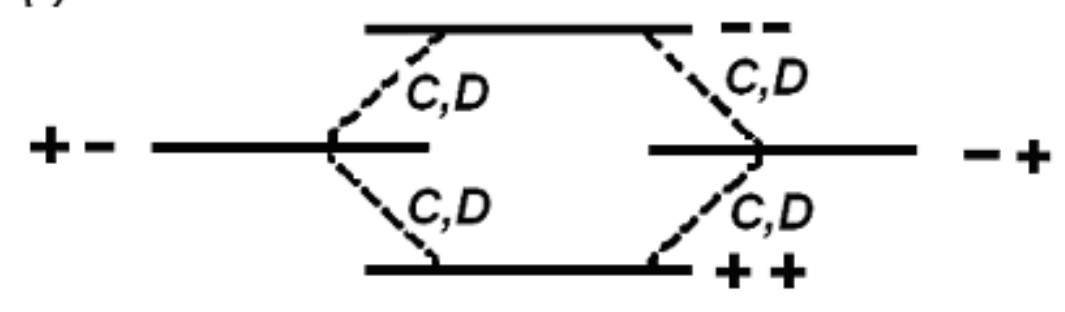

(b)

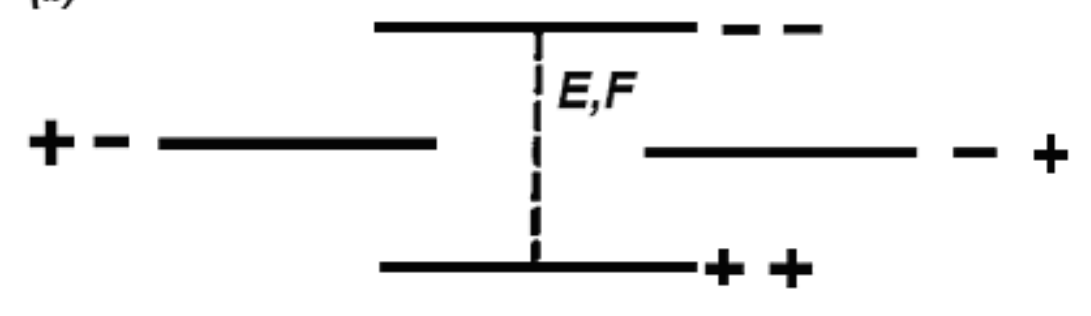

Figura 1.14: Estados conectados por $C$ e $D$ (a). E e $F$ conectam os estados $|++\rangle$ e $|--\rangle$ [retirado de Slichter (1990)].

Essa análise mostra que, os termos C e D, E e F são não-diagonais e, produzem uma pequena mistura de estados de ordem zero aos estados exatos. O cálculo da teoria de perturbação de segunda ordem pode dar a ordem de grandeza da mistura acima.

Sendo $u_{n}^{0}$ e $E_{n}$ as funções de onda e a energia de ordem zero, a perturbação de segunda ordem é:

$$
u_{n}=u_{n}^{0}+\sum_{n^{\prime}} \frac{\left(n^{\prime}\left|H_{p e r t}\right| n\right)}{E_{n}-E_{n^{\prime}}} u_{n^{\prime}}^{0}
$$

Se $u_{n}^{0}$ é o estado $|++\rangle$, segundo (1-26) ele terá uma pequena mistura dos estados $|+-\rangle,|-+\rangle$ e $|--\rangle$. A quantidade dessa mistura depende de $\left(n^{\prime}\left|H_{\text {pert }}\right| n\right)$ e de $E_{n}-E_{n}^{\prime}$. O primeiro termo será $\frac{g^{2} \hbar^{2}}{r^{3}}$ multiplicado pelo elemento da matriz do spin e, como 
este é de ordem de 1, e como $H_{l o c} \cong \frac{g^{2} \hbar^{2}}{r^{3}}$, tem-se $\left(n^{\prime}\left|H_{p e r t}\right| n\right) \cong g \hbar H_{l o c}$. Por outro lado, $E_{n}-E_{n}=\hbar \omega_{0}=g \hbar H_{0}$ então:

$$
\left|\frac{\left(n^{\prime}\left|H_{p e r t}\right| n\right)}{E_{n}-E_{n^{\prime}}}\right| \cong \frac{H_{l o c}}{H_{0}}
$$

que é pequeno como já foi visto. É claro que essa mistura produz um desvio da energia de segunda ordem. Um segundo efeito importante, é que essa mistura permite ao campo oscilante induzir transições que, de outra maneira, seriam proibidas.

Assim, a transição de $|++\rangle$ para $|--\rangle$, que seria proibida, pode agora acontecer devido a pequena mistura dos estados $|+-\rangle$ e $|-+\rangle$, verifique a figura 1.15.

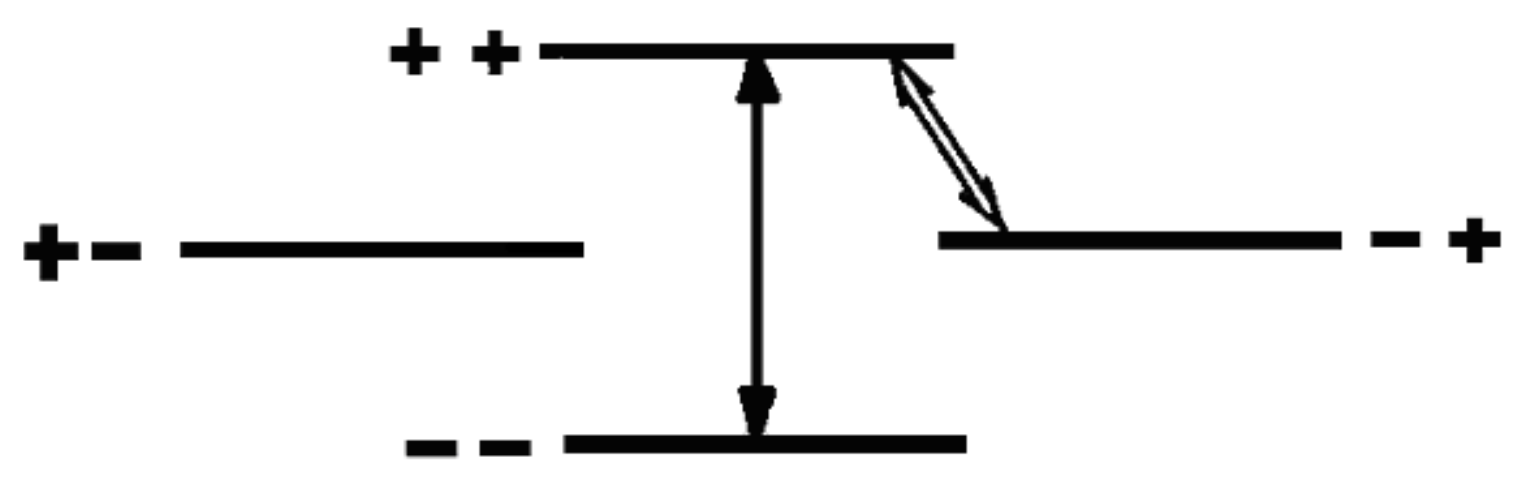

Figura 1.15: A flecha dupla indica transição forte. A transição fraca acontece devido à interação dipolar [retirado de Slichter (1990)].

Não será aqui mostrado que, os efeitos dos termos C,D,E e F são os de produzir absorção em torno de $\omega=0$ e $2 \omega_{0}$. Mas essas bandas são muito fracas da ordem de $\left(\frac{H_{l o c}}{H_{0}}\right)^{2}$ e podem ser desprezadas.

O termo dipolar restante $A+B=H_{d}{ }^{0}$ somado ao termo de Zeeman $H_{z}$ dá a Hamiltoniana total.

É possível mostrar que $\mathrm{H}_{z}$ e $\mathrm{H}_{\mathrm{d}}^{0}$ comutam e supondo as soluções 


$$
\begin{gathered}
H_{d}^{0} u_{\alpha}=E_{\alpha} u_{\alpha} \\
H_{z} u_{M}=\left(-g \hbar H_{0} M\right) u_{M}
\end{gathered}
$$

Teríamos as soluções da Hamiltoniana total. Por outro lado, em $H_{d}^{0}, S_{1 z} S_{2 z}$ e $\vec{S}_{1} \vec{S}_{2}$ não comutam, na prática não sabemos obter $u_{\alpha}$ e $E_{\alpha}$.

Felizmente, Van Vleck (1948) havia introduzido uma técnica inteligente chamada método de momentos que permite encontrar a solução do problema de interação dipolar ou spin-spin.

\subsubsection{3 - Tratamento de Van Vleck.}

A seguir, será exposta a idéia de Van Vleck (1948). Sendo $S_{x}=\sum_{j} S_{j x}$, o elemento de matriz $\left(S_{x}\right) n n^{\prime}$ faz a conexão dos estados n e n'. A freqüência correspondente é, então,

$$
v_{n n^{\prime}}=\frac{H_{n}-H_{n^{\prime}}}{h}
$$

A média quadrática da freqüência de absorção, que é a freqüência calculada, atribuindo peso a cada componente da estrutura fina, associada à amplitude ao quadrado, é dada por:

$$
\left\langle v^{2}\right\rangle_{m}=\frac{\sum_{n n^{\prime}}\left\{v_{n n^{\prime}}^{2}\left|\left(S_{n n^{\prime}}\right)\right|^{2}\right\}}{\sum_{n n^{\prime}}\left|(S)_{n n^{\prime}}\right|^{2}}
$$

Nessa expressão, as somas no numerador e no denominador são nada mais do que a soma dos elementos diagonais de $\left(H S_{n}-S_{x} H\right)^{2}$ e de $\left(S_{x}\right)^{2}$, respectivamente, isto é; 


$$
\left\langle v^{2}\right\rangle_{m}=-\frac{\operatorname{Tr}\left(H S_{x}-S_{x} H\right)^{2}}{h^{2} \operatorname{Tr}\left(S_{x}\right)^{2}}
$$

Na realidade, (1-31) é o método usual para o cálculo da média quadrática de freqüências. A sua vantagem está no fato de que, a invariância do traço torna desnecessário o conhecimento dos valores característicos individuais $\mathrm{H}_{\mathrm{n}}$. A soma diagonal pode, então, ser calculada em um sistema arbitrário de quantização, em particular e conveniente é naquele em que cada spin está quantizado espacial e individualmente.

Os termos $(A+B) \frac{g^{2} \beta^{2}}{r^{3}}$ de (1-23), para $g=g_{1}=g_{2}$, somados à energia de Zeeman no campo constante $\mathrm{H}$, podem ser reescritos:

$$
H=g \beta \mathrm{H} \sum_{j} S_{j z}+\sum_{k>j} A_{j k} \vec{S}_{j} \cdot \vec{S}_{k}+\sum_{k>j} B_{j k} S_{j z} \cdot S_{k z}
$$

Com:

$$
\begin{aligned}
& A_{j k}=-2 z^{2} J_{j k}+\frac{g^{2} \beta^{2}}{r_{j k}^{3}}\left[\frac{3}{2} \gamma_{j k}^{2}-\frac{1}{2}\right] \\
& B_{j k}=-\frac{3 g^{2} \beta^{2}}{r_{j k}^{3}}\left[\frac{3}{2} \gamma_{j k}^{2}-\frac{1}{2}\right]
\end{aligned}
$$

$J_{j k}=$ integral de Exchange

$\alpha_{i k}, \beta_{j k}, \gamma_{j k}=$ cossenos diretores de $\vec{r}_{j k}$ em relação aos eixos $(\mathrm{x}, \mathrm{y}, \mathrm{z})$.

Note que, o coeficiente $A_{j k}$ contém tanto o termo de exchange como a contribuição dipolar, e é o coeficiente de $\vec{S}_{j} \cdot \vec{S}_{k}$. O coeficiente $\mathrm{B}_{\mathrm{jk}}$ é, por outro lado, puramente dipolar.

O termo $\vec{S}_{j} \cdot \vec{S}_{k}$ é um produto escalar que comuta com $S_{x}=\sum_{j} S_{j x}$. Portanto, o segundo termo de (1-32) não influi no $\left\langle v^{2}\right\rangle_{m}$, o que significa que o termo de exchange não contribui. As seguintes relações serão usadas no cálculo dos traços da equação (1-31): 


$$
\begin{aligned}
& S_{j x} S_{k y}-S_{k y} S_{j x}=S_{j k} S_{j z} i \\
& \operatorname{Tr}\left(S_{j z}\right)^{2}=\frac{1}{3} S(S+1)(2 S+1)^{N} \\
& \operatorname{Tr} S_{j z}=0
\end{aligned}
$$

Onde $S$ é o número quântico de spin de um átomo individual. Segue-se, então:

$$
\begin{gathered}
\operatorname{Tr}\left(S_{x}\right)^{2}=\frac{1}{3} N S(S+1)(2 S+1)^{N} \\
H S_{x}-S_{x} H=g \beta H i \sum_{j} S_{j y}+i \sum_{k>j} B_{j k}\left(S_{j y} S_{k z}+S_{k y} S_{j z}\right) \\
-\operatorname{Tr} \frac{\left(H S_{x}-S_{x} H\right)^{2}}{(2 S+1)^{N}}=\frac{1}{3} N g^{2} \beta^{2} H^{2} S(S+1)+\left(\frac{2}{9}\right) S^{2}(S+1)^{2} \sum_{k>j} B_{j k}
\end{gathered}
$$

$\mathrm{N}$ é o número total de átomos no cristal.

Assim segue-se de (1.31), (1.35) e (1.36), o desvio médio quadrático da freqüência em relação ao valor de Larmor $=\frac{g \beta H}{\hbar}$ :

$$
\left\langle\Delta v^{2}\right\rangle_{m}=\left\langle\left(v-\frac{g \beta H}{h}\right)^{2}\right\rangle_{m}=\left\langle v^{2}\right\rangle-\frac{g^{2} \beta^{2} H^{2}}{\hbar^{2}}=\frac{1}{3} S(S+1) h^{-2} \sum_{K} B_{j k}^{2}
$$

Supõe-se que todos os átomos estão localizados de modo similar, de modo que o último membro da equação (1.37) é independente de j.

No caso de um cristal com uma simetria cúbica, usando o valor de $B_{j k}$ de (1.33), tem-se:

$$
\left\langle\Delta v^{2}\right\rangle_{m}=\frac{3}{8} g^{4} \beta^{4} h^{-2}\left[a+b\left(\lambda_{1}^{4}+\lambda_{2}^{4}+\lambda_{3}^{4}\right)\right] S(S+1)
$$

onde $\lambda_{1}, \lambda_{2}$ e $\lambda_{3}$ são os cossenos diretores do campo magnético aplicado $\mathrm{H}$, relativo ao eixo cúbico principal $(\mathrm{x}, \mathrm{y}, \mathrm{z})$. As constantes a e b não dependem de $\lambda_{1}, \lambda_{2}$ e $\lambda_{3}$ e são dadas por:

$$
\begin{aligned}
& a=\sum_{k} r_{j k}^{-6}\left[7-9\left(\mu_{j k}^{4}+v_{j k}^{4}+\zeta_{j k}^{4}\right)\right] \\
& b=\sum_{k} r_{j k}^{-6}\left[-9+15\left(\mu_{j k}^{4}+v_{j k}^{4}+\zeta_{j k}^{4}\right)\right]
\end{aligned}
$$


$\mu_{j k}, v_{j k}$ e $\zeta_{j k}$ são os cossenos diretores de $\vec{r}_{j k}$ em relação aos eixos $(\mathrm{x}, \mathrm{y}, \mathrm{z})$.

No caso de simetria cúbica, a soma sobre k pode ser efetuada e tem-se:

$$
\left\langle\Delta v^{2}\right\rangle_{m}=36,8 g^{4} \beta^{4} h^{-2} d^{-6}\left[\frac{1}{3} S(S+1)\right]\left[\lambda_{1}^{4}+\lambda_{2}^{4}+\lambda_{3}^{4}-0,187\right]
$$

d sendo a constante de spin-rede, isto é, a distância entre os átomos magnéticos vizinhos localizados numa grade cúbica simples.

Se a medida for feita com o pó, ao invés de um monocristal, os cossenos diretores a quarta potência podem ser substituídos pelas suas médias sobre a esfera, com o que se tem:

$$
\left\langle\Delta v^{2}\right\rangle_{m}=\frac{3}{5} g^{4} \beta^{4} h^{-2} S(S+1) \sum_{k} r_{j k}^{-6}
$$

A hipótese usual é a de que as freqüências têm uma distribuição Gaussiana:

$$
f(v)=\left[\frac{1}{2 \pi\left\langle v^{2}\right\rangle_{m}}\right]^{\frac{1}{2}} \exp \frac{\left[-\left(v-\frac{g \beta H}{h}\right)^{2}\right]}{2\left\langle\Delta v^{2}\right\rangle_{m}}
$$

Então a largura da banda a meia-altura é:

$$
\Delta v_{\frac{1}{2}}=2(\log \sqrt{2})^{\frac{1}{2}} \sqrt{2}\left[\left\langle\Delta v^{2}\right\rangle_{m}\right]^{\frac{1}{2}}=2,35\left[\left\langle\Delta v^{2}\right\rangle_{m}\right]^{\frac{1}{2}}
$$

Nesse caso, a separação em freqüência $\Delta v_{m . s l}$ dos dois pontos de máximo da derivada $\left(\frac{d f}{d v}\right)_{\max .}$ da curva de absorção é dada por: 


$$
\Delta v_{m \cdot a l}=2\left[\left\langle\Delta v^{2}\right\rangle_{m}\right]^{\frac{1}{2}}
$$

Se lembrarmos que $\Delta E=g_{e} \beta \mathrm{H}=h v$, podemos escrever 1.41 em uma forma alternativa, Andrew et al. (1953) dada por:

$$
\left\langle\Delta \mathrm{H}^{2}\right\rangle_{m}=\frac{3}{5} g^{2} \beta^{2} S(S+1) \sum_{j>k} r_{j k}^{-6}
$$

\subsubsection{Um exemplo de alargamento das linhas de RPE em função da concentração de manganês}

$\mathrm{O}$ espectro de RPE de $\mathrm{Mn}^{2+}$ em soluções consiste normalmente das seis linhas da interação hiperfina devido ao acoplamento do spin do elétron $S=5 / 2 \mathrm{com}$ o spin nuclear $\mathrm{I}=5 / 2$. A largura das linhas é a soma de duas contribuições, $\Delta H=\Delta H_{I}+\Delta H_{D}$ onde $\Delta H_{I}$ é a largura que aparece devido a processos intramoleculares e $\Delta H_{D}$ é a largura devido à interação spin-spin entre primeiros vizinhos do $\mathrm{Mn}^{2+}$ (Hinckley e Morgan, 1966). O termo $\Delta H_{D}$ é dependente da concentração pois as interações spin-spin são proporcionais a $\mathbf{r}^{-6}$,

onde $r$ é a distância média $\left(\mathrm{Mn}^{2+}-\mathrm{Mn}^{2+}\right)$. Em soluções diluídas $(<0,01 \mathrm{M}, \mathrm{r}>55 \AA)$ as linhas são estreitas e determinadas exclusivamente por $\Delta H_{I}$. Quando a concentração é aumentada, as seis linhas da interação hiperfina também se alargam até concentrações de 2,3 M ou maior $(r<9 \AA$ ) então ocorre um colapso da estrutura hiperfina e o espectro aparece como uma única linha larga, figura 1.16. 
INTRODUÇÃO

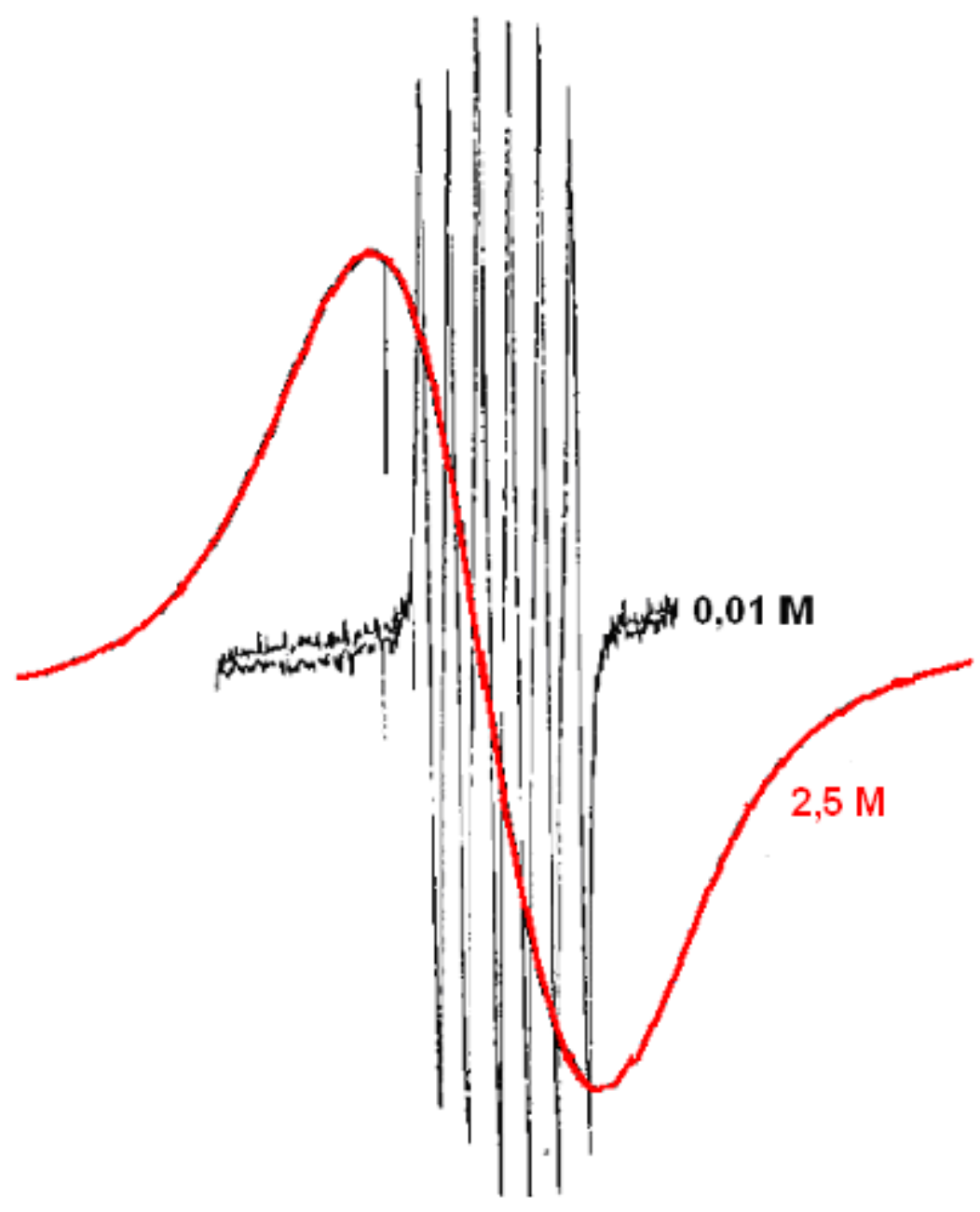

Figura 1.16: Comparação entre espectros RPE de perclorato de manganês em concentrações de 2,5 e 0,01M [retirado de Hinckley e Morgan (1966)]. 


\section{6 - Vitrificação - Cristalização}

Considerando a obtenção do vidro através do "congelamento" de um líquido superesfriado, o qual deve ser suficientemente rápido para não ocorrer cristalização, podemos fazer um estudo do comportamento de algumas variáveis termodinâmicas como, volume específico, índice refração, coeficiente de dilatação ou outra quantidade em função da temperatura.

$\mathrm{Na}$ figura 1.17 temos o diagrama do volume específico como função da temperatura V-T. Começamos considerando um volume de material no estado líquido. Neste diagrama seu estado é dado pelo ponto "a".

Com o esfriamento o volume diminui ao longo de "ab", onde o ponto "b" corresponde a $T_{f}$, temperatura de fusão do correspondente cristal. Se neste ponto existir um número suficientemente grande de núcleos presentes na massa total e, ainda existir uma taxa suficientemente alta de crescimento do cristal, ocorrerá cristalização. Se as condições acima forem respeitadas, a contração do volume é acompanhada da cristalização e então o cristal formado se esfria, contraindo-se ao longo da linha-cristal até o ponto "d".

Se a cristalização não ocorrer abaixo de $\mathrm{T}_{\mathrm{f}}$ (principalmente devido a uma alta taxa de resfriamento), a massa líquida torna-se, então, um líquido super-esfriado ao longo de "be". O volume, todavia, contrai-se continuamente, isto é, a estrutura se auto arranja em um volume menor.

Com o contínuo esfriamento as moléculas tornam-se menos e menos móveis, isto é, a viscosidade do sistema rapidamente aumenta. 


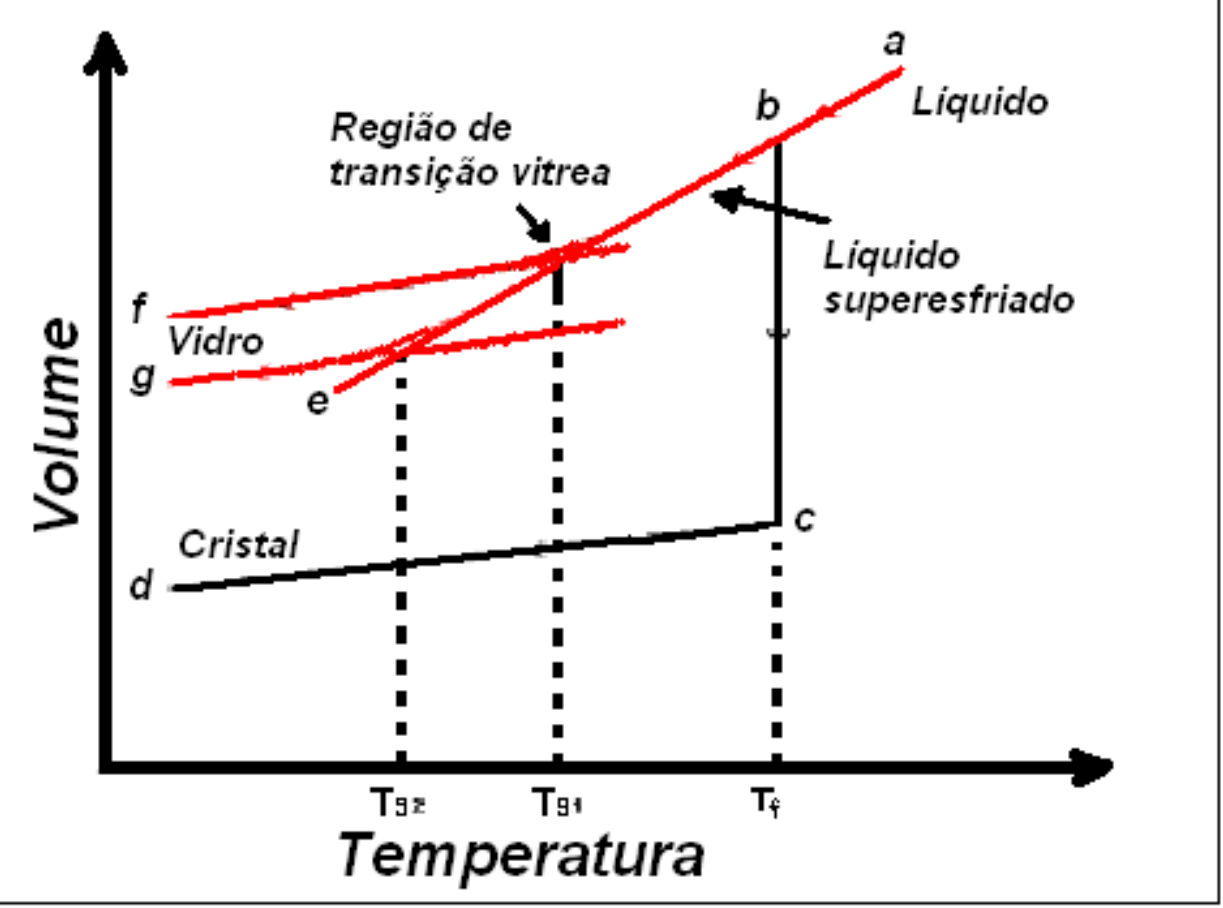

Figura 1.17. Diagrama de volume - temperatura para transformação de um líquido superesfriado em vidro e definição de transição vítrea [retirado de Varshneya (1994)].

Para temperaturas suficientemente baixas as moléculas não conseguem se arranjar rápido o suficiente para alcançar o volume característico daquela temperatura.

A linha de estado começa então levemente a desviar-se de "be"e rapidamente torna-se quase reta ( muitas vezes paralela a "cd") terminando em "f", quando esfriamento for rápido e em "g", quando o esfriamento for um pouco mais lento.

Este é o chamado estado vítreo, no qual a viscosidade do vidro atinge aproximadamente $10^{15}$ Pa.s. A região levemente curvada recebe o nome de região de transição vítrea e a interseção da linha extrapolada do vidro e o líquido superesfriado costuma ser chamada de temperatura de transição vítrea, $T_{g}$.

Esta temperatura depende como ficou claro pelo diagrama, da taxa de esfriamento e poderíamos dizer que esta seria a temperatura na qual a estrutura do líquido superesfriado é instantaneamente congelada para o vidro. 


\subsection{1 - Cristalização}

Vimos que o rápido resfriamento de um líquido abaixo da temperatura de fusão $\mathrm{T}_{\mathrm{f}}$ leva à formação de um vidro, porém, se a taxa de esfriamento for suficientemente pequena ocorrerá cristalização do material. A seguir, tratamos resumidamente, o mecanismo de cristalização.

A cristalização de uma fase homogênea, líquida ou vítrea, não se processa através do volume todo de uma só vez. Com o resfriamento do líquido na vizinhança do ponto $T_{f}$ formam-se centros discretos distribuídos por toda a massa, que se expandem no decorrer do tempo. Em outras palavras, à medida que o calor é "retirado", a força de coesão entre poucas moléculas supera a energia cinética e então se formam aglomerados ordenados.

Tais aglomerados recebem o nome de embriões, podendo até desaparecer, o que é um processo típico de flutuações estruturais a uma dada temperatura na vizinhança de $T_{f}$. A retirada gradual do calor favorece a formação, bem como o crescimento desses embriões. Quando eles atingem uma dimensão crítica diz-se que eles constituem núcleos. Quando a nucleação se dá de um modo aleatório tem-se uma, nucleação homogênea. Isso só ocorre se a substância em cristalização for quimicamente homogênea e sem imperfeições estruturais. Na prática, mesmo que o volume todo da fase seja quimicamente homogêneo, a superfície e as paredes do vasilhame constituem uma imperfeição e a energia necessária para a formação de núcleos é abaixada nessas localidades. Se houver impurezas, estas constituirão outros pontos onde a nucleação ocorre com preferência. Temse então, uma nucleação heterogênea, que é o processo que se dá no mundo real. A descrição cinética da cristalização será feita levando-se em consideração, no entanto, o caso ideal de nucleação homogênea.

O número de núcleos, I, produzidos em uma unidade de volume por unidade de tempo recebe o nome de taxa de nucleação e, a velocidade u com a qual essas partículas crescem é chamada taxa de crescimento. A figura 1.18, mostra esquematicamente a dependência de I e u em função da temperatura. 


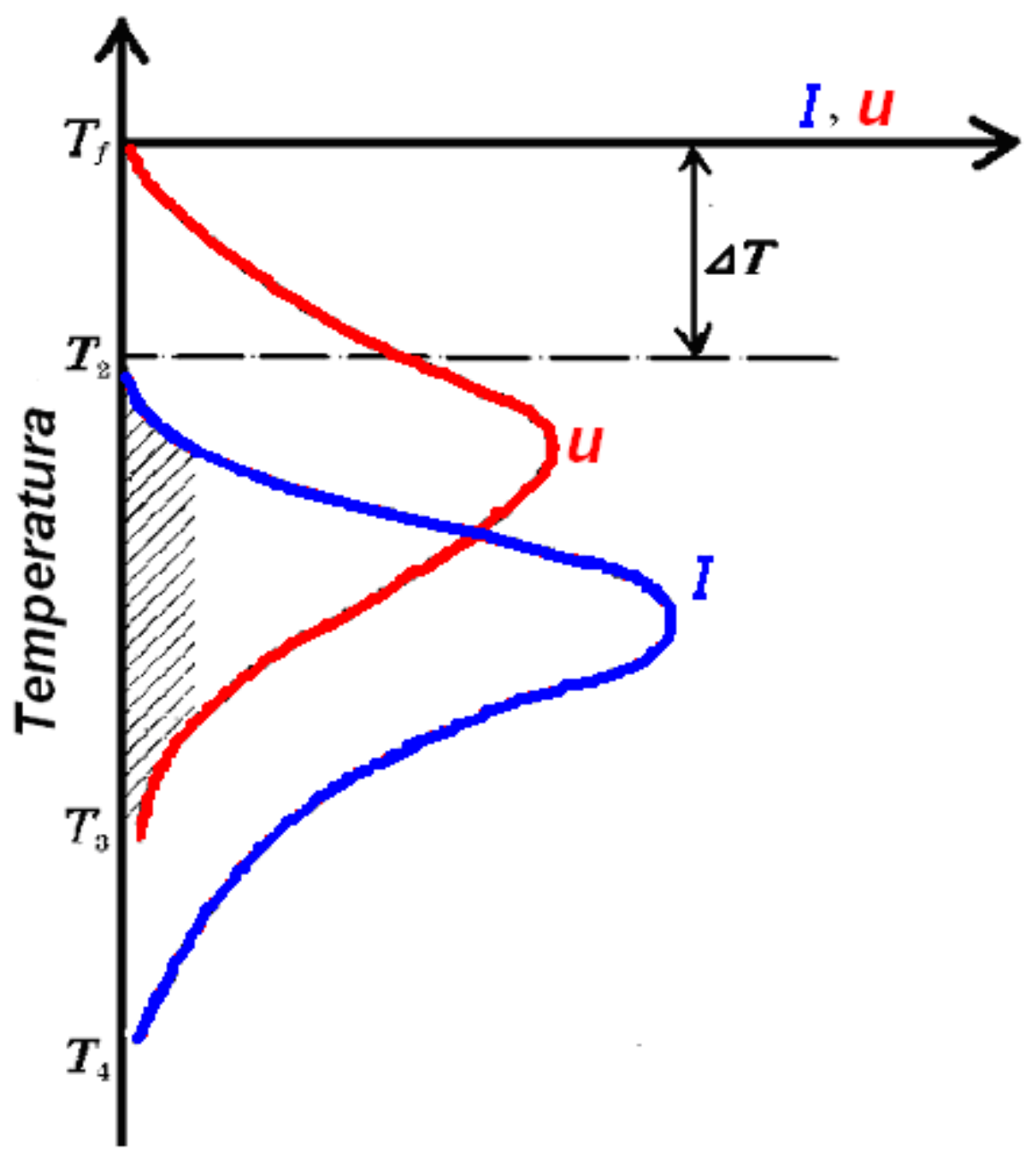

Figura1.18: A taxa de nucleação le a taxa de crescimento u em função de $\boldsymbol{T}$ [retirado de Zarzycki (1982)].

Se o líquido for resfriado rapidamente, ocorrerá a formação de vidro, mas se o resfriamento for lento poderá ocorrer cristalização. Acima da temperatura de fusão, $T_{f}, 0$ líquido está em uma fase estável. Quando o líquido é superesfriado abaixo de $T_{f}, o$ crescimento do cristal é teoricamente possível entre $T_{f}$ e $T_{3}$. Todavia, a formação inicial de núcleos necessário antes do crescimento, é possível, ocorrendo entre $T_{2}$ e $T_{4}$.

A região crítica está entre $T_{2}$ e $T_{3}$ e a possibilidade de cristalização dependerá da maneira pela qual as curvas se superpõem e também dos valores absolutos das taxas na região da superposição. Se, no intervalo $T_{2}-T_{3}$, I ou u, ou ambos, forem pequenos, não ocorrerá 
cristalização perceptível, dessa forma, o sistema passará para o estado vítreo. Se as taxas I e u forem altas ocorrerá cristalização total. Se, no intervalo $T_{2}-T_{3}$, I é baixa e, u é alta, um pequeno número de cristais estará distribuído em uma fase vítrea. Por outro lado, se I é alta e, u é baixa, ocorrerá cristalização parcial do material com pequenos grãos.

\subsection{2 - Teoria clássica da nucleação homogênea.}

Para termos uma idéia da termodinâmica envolvida no processo, a apresentação da teoria da nucleação homogênea, desenvolvida por Volmer e Weber (1925) e Becker e Döring (1935) é suficiente.

Para temperaturas acima da de fusão, a mobilidade atômica é apreciável, qualquer aglomerado que se forma, rapidamente se desfaz. Na proximidade da temperatura de fusão, com a fase no estado metaestável, essas aglomerações têm tempo de vida maior e, como já foi mencionado, tornam-se fontes potenciais de uma fase estável. Tais aglomerações diferem em tamanho, forma, estrutura e composição. Volmer e Weber (1925) e Becker e Döring (1935), partem da hipótese que os embriões diferem entre si em tamanho e forma, mas as outras propriedades são iguais às da fase de cristal. A forma de um núcleo deve tornar mínima a energia de formação a qual está intimamente conectada com a natureza da interface.

Assumindo em primeira aproximação que a energia da interface é independente da orientação cristalográfica e que a energia devido a deformação elástica é desprezível, o embrião é função das condições de estabilidade termodinâmica.

A figura 1.19 mostra qualitativamente como a energia livre molar $\mathbf{G}$ de Gibbs varia com $T$ na fase líquida cristalina. As curvas para o liquido $L$ e o cristal $c$ interceptam-se em $\mathbf{T}_{\mathbf{f}}$, onde as duas fases estão em equilíbrio, assim neste ponto $\Delta G=0$. O grau de superesfriamento na temperatura $\mathbf{T}>\mathbf{T}_{\mathbf{f}}$ é dado por $\Delta T=T_{f}-T$.

A passagem de um estado superesfriado para o estado cristalino se dá pela liberação de energia $\Delta g_{2}$ por unidade de volume. Para um embrião esférico de raio $r$, a quantidade de energia liberada é igual a $\left(\frac{4 \pi}{3}\right) r^{3} \Delta g_{2}$. 


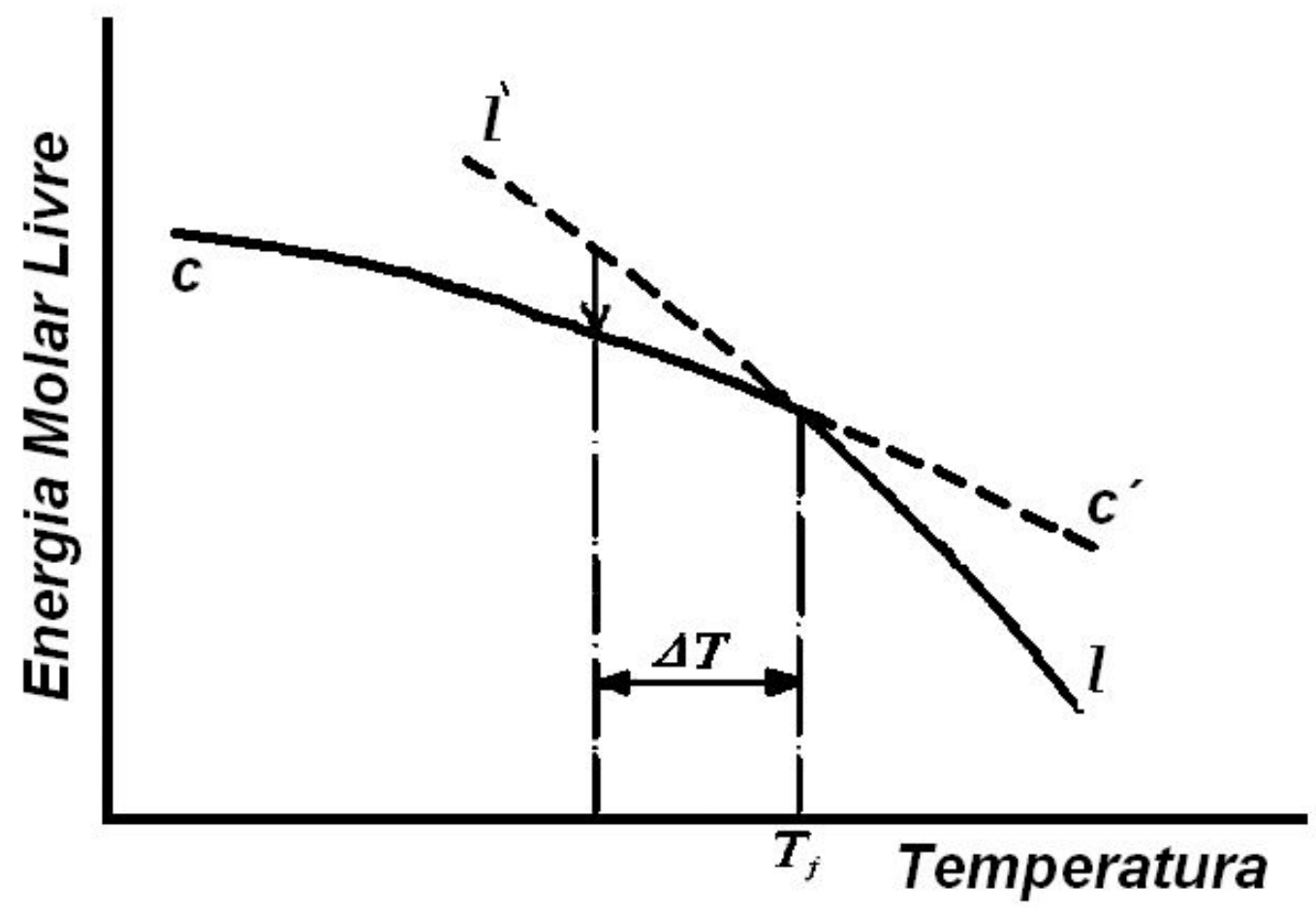

Figura 1.19: Energia livre, molar $\mathbf{G}$ do cristal $\boldsymbol{c}$ e do liquido $\mathbf{I}$ em torno do ponto de fusão $\boldsymbol{T}_{\boldsymbol{f}} \mathbf{I}$ é o liquido superesfriado e c o cristal superaquecido [retirado de Zarzycki (1982)].

Um embrião tem uma superfície que o separa do meio que the deu origem. A formação dessa superfície requer uma energia, que pode ser escrita como $\Delta g_{s}$ por unidade de área. Um embrião de raio $r$ exige uma energia $4 \pi r^{2} \Delta g_{s}$ para formação da superfície.

Então a energia total $\Delta g_{r}$ necessária para a formação de um embrião de raio $r$ é dada por:

$$
\Delta g_{r}=\frac{4}{3} \pi r^{3} \Delta g_{v}+4 \pi r^{2} \Delta g_{s}
$$


A figura 1.20 fornece uma idéia da variação $\Delta g_{r}$ em função do raio $\mathrm{r}$, para um dado grau de superesfriamento $\Delta T$. Enquanto $\Delta g_{s}$ é positivo, $\Delta g_{v}$ é negativo. Vê-se, então, que $\Delta g_{r}$ é crescente para r pequeno e decrescente para $r$ grande. Isso significa dizer que um valor $r_{c}$ para o qual $\Delta g_{r}$ é maximo, dado a partir de:

$$
\frac{\partial}{\partial r} \Delta g_{r}=0, \text { o qual dá } r_{c}=\frac{-2 \Delta g_{s}}{\Delta g_{v}}
$$

A energia $\mathrm{E}_{\mathrm{c}}$ de $\Delta g_{r}$ para $\mathrm{r}=\mathrm{r}_{\mathrm{c}}$ é dada por:

$$
E_{c}=\frac{16 \pi}{3} \frac{\Delta g_{s}^{3}}{\Delta g_{v}^{2}}
$$

Um embrião contém $\frac{4}{3} \pi r_{c}^{3} \frac{N}{V_{m}}$ moléculas, onde $\mathrm{V}_{\mathrm{m}}$ é o volume molar do cristal e $\mathrm{N}$ o número de moléculas contidas num núcleo crítico de raio $r_{c}$ pode ser escrita:

$$
\frac{4}{3} \pi r_{c}^{3} \frac{N}{V_{m}}=\frac{32 \pi}{3}\left(\frac{\Delta g_{s}}{\Delta g_{2}}\right)^{3} \frac{N}{V_{m}}
$$




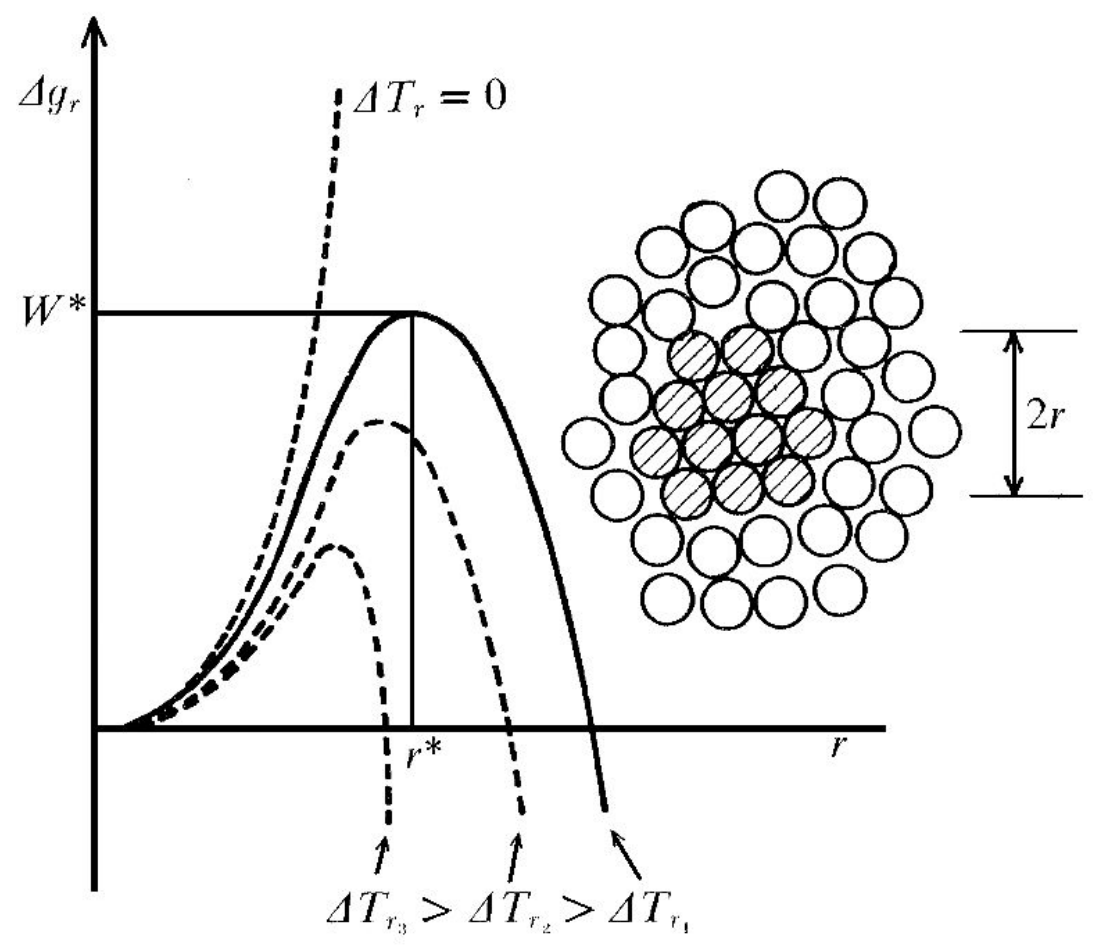

Figura 1.20: variação da energia $\Delta g_{r}$, para a formação de um núcleo em função do seu raio $r$. As linhas tracejadas correspondem a diferentes valores de graus de superesfriamento [retirado de Zarzycki (1982)].

A partir de $\mathrm{E}_{\mathrm{c}}$ e da energia livre de ativação $\Delta G^{\prime}$ para nucleação, é possível escrever uma expressão termodinâmica para a taxa I de nucleação.

$$
I=K \exp \left(\frac{-E_{c} N}{R T}\right) \exp \left(\frac{-\Delta G^{\prime}}{R T}\right)
$$

Onde k é uma constante. Segundo Turnbull e Fisher:

$$
k=\left[\left(\frac{4 r_{c}^{2} \Delta g_{s}}{9 K T}\right)^{2} n^{*}\right] n v
$$

Onde $\mathbf{n}^{*}$ é o número de átomos sobre a superfície de um núcleo crítico, $\mathbf{n}$ é o número de átomos ou moléculas por centímetro cúbico da fase precipitada, e $v$ representa a freqüência de vibração fundamental. 
Para a taxa de crescimento u dos núcleos, Turnbull e Cohen (1958) deduziram a expressão:

$$
u=f \frac{R T}{3 \pi a_{0}^{2} n N}\left[1-\exp \left(\frac{\Delta G_{2}}{R T}\right)\right]
$$

$\Delta G_{2}$ : A barreira de energia livre para vencer no processo cristal - líquido.

$\mathrm{n}$ : viscosidade.

$a_{0}$ : Distância entre dois poços de potencial que representa a interface cristal - líquido, figura 1.21.

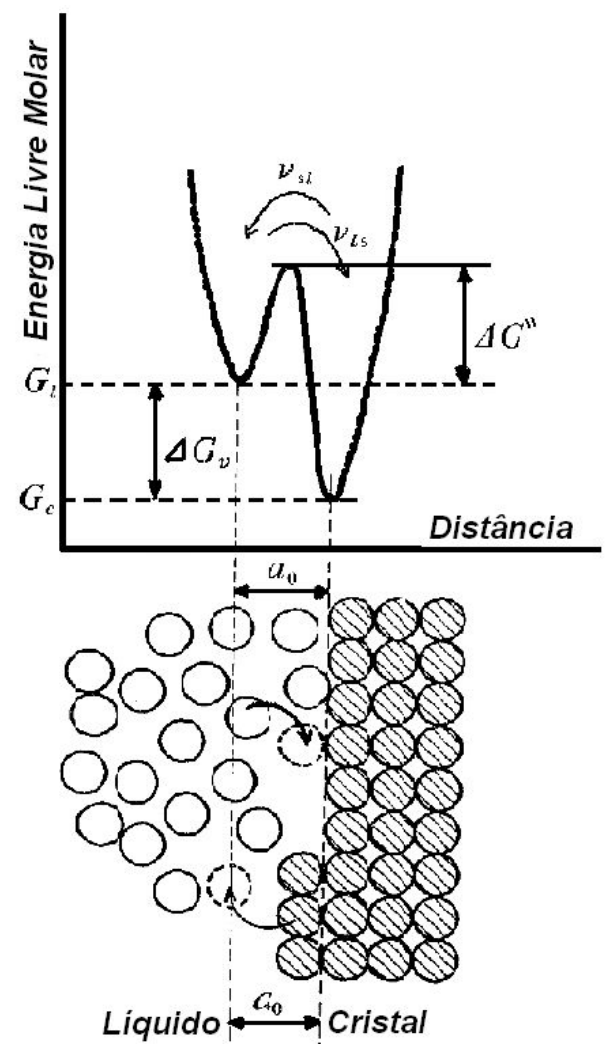

Figura 1.21: Mecanismo de crescimento controlado pela interface [retirado de Zarzycki (1982)].

Do que foi exposto, partindo de um vidro e mantendo-o em temperatura na vizinhança da temperatura de vitrificação $T_{g}<T_{f}$ (por tempo longo) suficiente para os átomos 
formarem núcleos, é possível obter um policristal. Outra maneira, como comentado, é a partir do líquido, para que ocorra a cristalização e por conseqüência a obtenção do policristal.

\section{7-Espectroscopia de fotoelétrons excitados por raios-X (XPS)}

Em espectroscopia de elétrons por raios-x, elétrons em sólidos são excitados por raios - X. Tal energia de excitação deve ser grande o suficiente para fazer com que elétrons deixem o sólido e, através de sua energia cinética sejam subseqüentemente detectados em um espectrômetro de elétrons.

A figura 1.22, mostra um diagrama de níveis de energia do processo de fotoemissão.

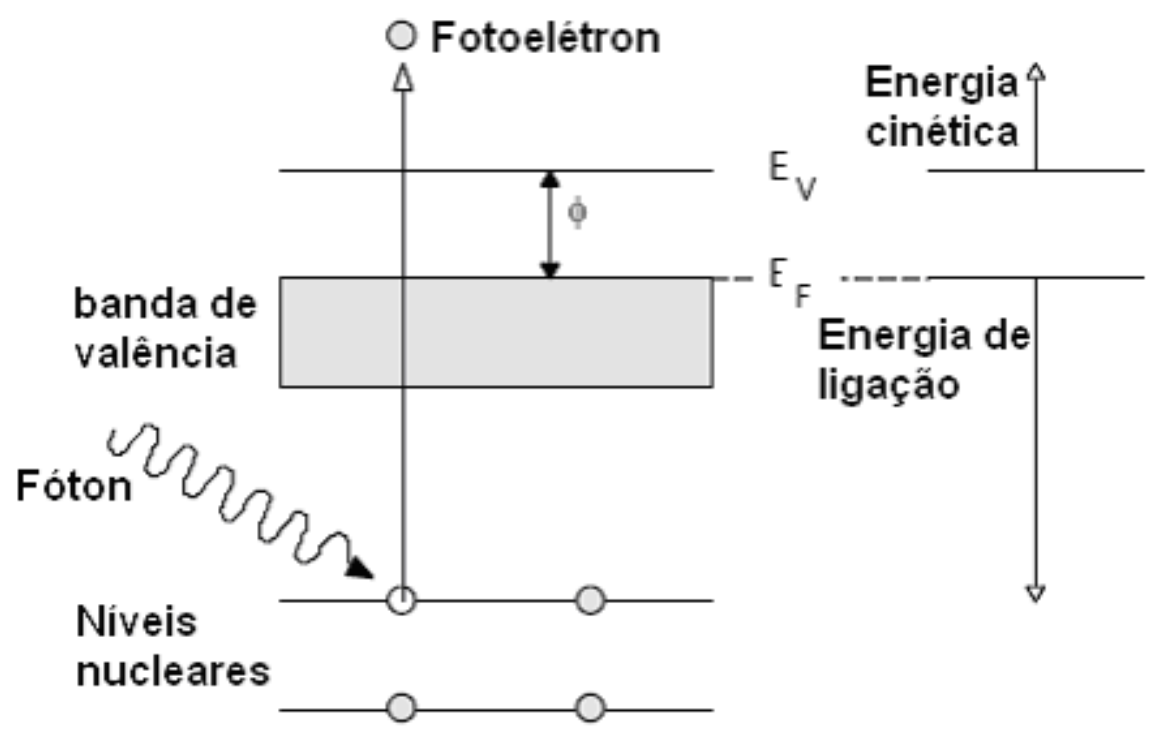

Figura 1.22: Processo de emissão de fotoelétrons.

Como os níveis de energia são quantizados, os fotoelétrons possuem uma distribuição de energia cinética que consiste de picos discretos, associados às camadas eletrônicas do átomo fotoionizado. Como os termos referentes à função trabalho, $\phi$, podem ser compensados eletronicamente, a energia cinética do fotoelétron é dada por: 


$$
E_{K}=h v-E_{B}
$$

onde $E_{B}$ é a energia de ligação deste elétron em relação ao nível de vácuo e $h v$ é a energia do fóton incidente. Como os níveis de energia são quantizados, os fotoelétrons possuem uma distribuição de energia cinética que consiste de picos discretos, associados às camadas eletrônicas do átomo fotoionizado. A identificação dos elementos presentes na superfície é feita diretamente pela determinação das energias de ligação dos picos dos fotoelétrons de caroço (binding energy). A intensidade (área integrada do pico fotoelétrico) é proporcional ao número de átomos no volume detectado, permitindo, portanto, obter-se informações sobre a composição da superfície.

Em XPS tem-se que levar em conta a separação spin-órbita em dubletos, um elétron desemparelhado em um orbital degenerado ( $p, d$, $f$, etc.), o momento angular de spin, S, e o momento angular orbital, L, podem combinar-se de várias maneiras, e produzir novos estados que são caracterizados pelo momento angular total do elétron, J, dado por:

$$
J=|L \pm S|
$$

onde, $L=0,1,2, \ldots ; S=1 / 2 ; J=1 / 2,3 / 2,5 / 2, \ldots$ As energias dos novos estados são assim diferentes porque os momentos magnéticos devidos ao spin do elétron e ao movimento orbital podem opor-se ou reforçar-se mutuamente.

A posição exata de um pico fotoelétrico indica o estado químico do átomo emissor. A tabela 1.3 relaciona a energia de ligação com o correspondente(s) óxido(s) de manganês.

Tabela 1.3 Alguns óxidos de manganês e a correspondente energia de ligação [Wagner et al. (2005)].

\begin{tabular}{|l|l|l|}
\hline Energia de ligação $(\mathrm{eV})$ & Óxidos & Valência \\
\hline 640,8 & $\mathrm{MnO}$ & $\mathrm{Mn}^{2+}$ \\
\hline 641,2 & $\mathrm{Mn}_{3} \mathrm{O}_{4}, \mathrm{Mn}_{2} \mathrm{O}_{3}$ & $\mathrm{Mn}^{2+}, \mathrm{Mn}^{3+}$ \\
\hline 642,4 & $\mathrm{MnO}_{2}$ & $\mathrm{Mn}^{4+}$ \\
\hline 642,6 & $\mathrm{MnO}_{2}$ & $\mathrm{Mn}^{4+}$ \\
\hline 642,7 & $\mathrm{MnO}_{2}$ & $\mathrm{Mn}^{4+}$ \\
\hline
\end{tabular}


Capítulo 2

Objetivos 


\section{0 - Objetivos do trabalho}

\section{1 - Considerações gerais}

Como discutido na introdução, a rodonita já foi estudada por alguns pesquisadores, no que se refere à absorção óptica e produção de amostras sintéticas. Pouco ou nada tem sido feito quanto a termoluminescência e ressonância paramagnética eletrônica. Esta última, não tem sido aplicada provavelmente pelo fato de a rodonita possuir em sua estrutura grande quantidade de manganês que dificulta a obtenção de resultados, pois a interação dipolar causa um alargamento nas linhas, encobrindo outros efeitos. Quanto a amostras sintéticas de rodonita, encontramos poucos trabalhos que se preocupavam com a produção e caracterização da amostra, exceto um que utilizava espodumênio sintético (Souza et al -2004) para estudar as propriedades de TL, AO e RPE.

Pretendeu-se aqui estudar a rodonita natural originária de Conselheiro Lafaiete (MG), através das técnicas, TL, AO e RPE e outras que se fizessem necessárias.

Queríamos também obter, pelo método de fusão e lento resfriamento, amostras sintéticas, puras ou dopadas de forma controlada com $\mathrm{Ca}, \mathrm{Mg}, \mathrm{Al}, \mathrm{Ti}$ e $\mathrm{Fe}$, ou mesmo combinações destes, através dos quais seriam feitas medidas de TL e RPE e, então comparadas com as medidas feitas com a amostra natural.

Pretendeu-se também, correlacionar as propriedades de AO e de RPE com TL, tentando identificar os responsáveis pelas emissões termoluninescentes e centros de cor, propondo modelos microscópicos de indução termoluminescente.

Para o estudo dessas propriedades, algumas análises e medidas seriam feitas, tanto na amostra natural quanto na artificial. 


\section{2 - Análise da composição química}

Amostras naturais, em geral e, em particular a rodonita apresentam vários elementos estranhos ao cristal base, em concentrações que variam de amostra para amostra. Muitas dessas impurezas (há indícios de que a maioria não afeta as propriedades de interesse nesse trabalho) têm papel importante na definição das propriedades, assim deveria-se conhecer suas concentrações, por unidade de volume, presentes na amostra em estudo.

Além disso, como seriam produzidas amostras sintéticas para comparação, tornou-se imprescindível tal informação. A técnica usada foi a fluorescência de raios- $X$, que forneceu a porcentagem em massa de moléculas componentes.

\section{3 - Difração de raios-X}

A amostra natural de que dispúnhamos seria analisada pela técnica de difração de raios- $X$, para nos certificarmos de que se tratava da rodonita. Parte importante do trabalho deveria ser a produção de amostras sintéticas e, como tínhamos como objetivo fazer comparações com amostra natural, devíamos ter certeza de que a estrutura era a mesma da rodonita.

\section{4 - Amostras sintéticas de rodonita, pura ou dopada}

Inicialmente, desejávamos produzir amostras puras de rodonita, para verificarmos propriedades de TL e RPE devido aos defeitos estruturais. Para isso, prepararíamos uma mistura estequiométrica de sílica $\left(\mathrm{SiO}_{2}\right)$ e óxido de manganês $(\mathrm{MnO})$ que seria fundida em temperaturas próximas de $1500{ }^{\circ} \mathrm{C}$ e, então esfriada lentamente para evitar a vitrificação. Em outras misturas, como essa, seriam adicionadas quantidades controladas de impurezas. 


\section{5 - Irradiação, tratamentos térmicos e medidas de AO RPE e TL}

As propriedades de interesse neste trabalho ( $A O, R P E$ e $T L)$ são fortemente afetadas por irradiação gama e tratamentos térmicos. Dessa forma, as amostras deveriam ser submetidas à irradiação gama, para diferentes doses, tratadas termicamente ou não. Assim queríamos obter:

i-) Curvas de emissão da Rodonita natural;

ii-) Curvas de emissão da Rodonita natural submetida a doses de radiação adicionais;

iii-) Curvas de emissão da Rodonita recozida em $600{ }^{\circ} \mathrm{C}$ por 30 a 60 minutos e, depois irradiada com diferentes doses;

iv-) Curvas de (TL $x$ dose), analisando supralinearidade e sublinearidade dos diversos picos;

v-) Espectros RPE da Rodonita de (i), (ii), (iii);

vi-) Leituras TL e RPE de Rodonita com tratamento térmico em $600{ }^{0} \mathrm{C}$ e então irradiadas - as leituras TL serão feitas em temperaturas que variam de $70{ }^{\circ} \mathrm{C}$ a $500{ }^{\circ} \mathrm{C}$;

vii-) Medidas de Absorção Óptica das amostras de (i), (ii), (iii);

viii-) Espectros de emissão TL.

\section{6 - Medidas de XPS}

Existem trabalhos indicando que a cor rosa da rodonita natural é devido ao $\mathrm{Mn}^{2+}$. A técnica de XPS é valiosa na determinação da valência dos elementos, quando estes estão presentes em grandes quantidades na amostra estudada, como é o caso do manganês na rodonita (aproximadamente $37 \%$ em massa na amostra desse trabalho).

Dessa forma, queríamos fazer tratamento térmico na rodonita para verificar a correlação entre a valência do manganês e a cor da rodonita, já que esta ficava escura após aquecimento. 


\section{7 - Mecanismo de indução TL}

À medida do possível, seria proposto um mecanismo pelo qual um dado pico de emissão TL é produzido. 


\section{Capítulo 3}

\section{Materiais e métodos experimentais}




\section{0 - Materiais e métodos experimentais}

No desenvolvimento deste trabalho foi utilizada uma amostra natural de rodonita proveniente de Conselheiro Lafaiete-MG, figura 3.1 e várias amostras sintéticas obtidas pelo método de fusão de componentes em forno de alta temperatura seguido de lento resfriamento. A construção do forno e produção de amostras artificiais ocorreram no laboratório LACIFID. A preparação dessas amostras, bem como os métodos experimentais utilizados nas medidas são descritos a seguir.

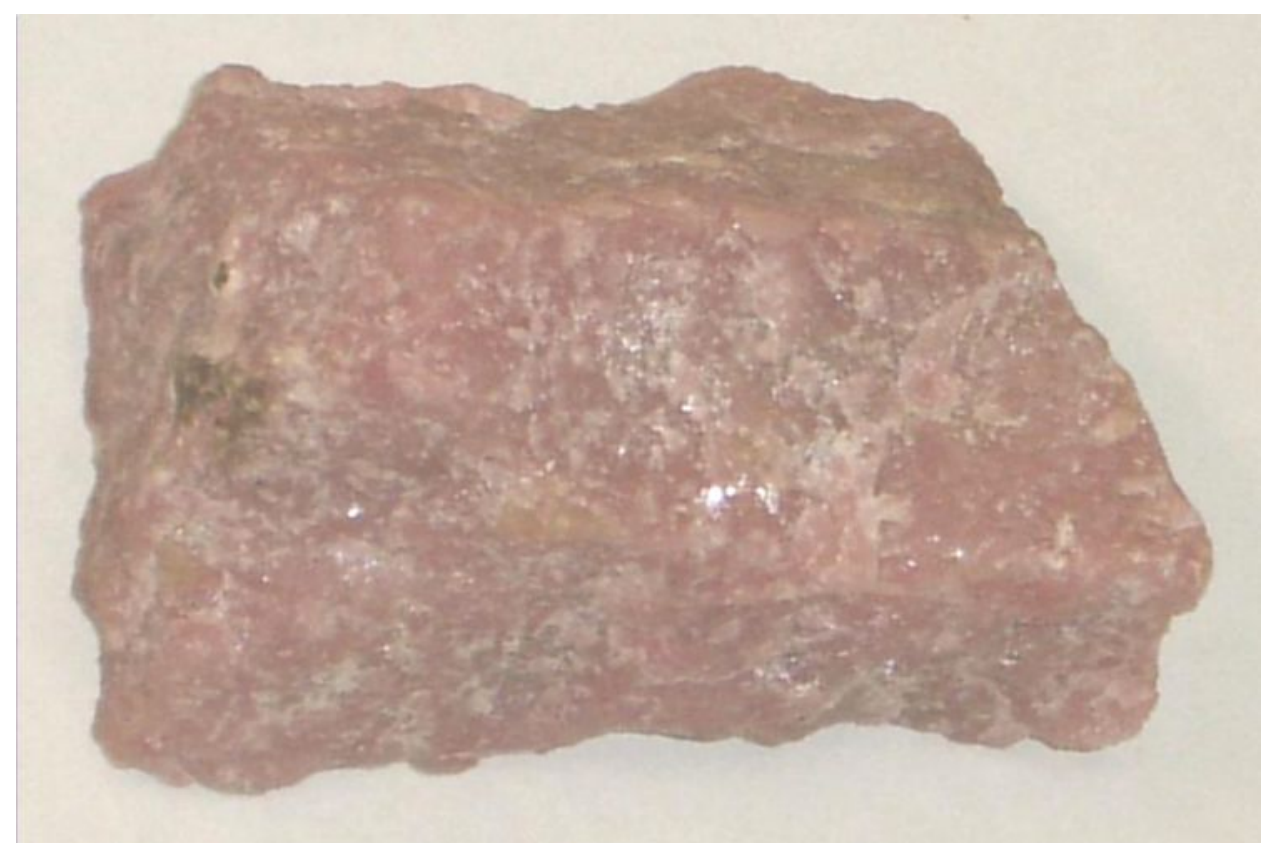

Figura 3.1: Amostra de rodonita natural utilizada neste trabalho. 


\section{1 - Preparação de amostras}

Para as medidas de termoluminescência $(T L)$, ressonância paramagnética eletrônica (RPE) e difração de Raios - X, as amostras foram pulverizadas em um almofariz com o auxílio de um pistilo, ambos de porcelana. Através de peneiras, foram selecionados grãos com diâmetros entre $0,180 \mathrm{~mm}$ e $0,075 \mathrm{~mm}$ para as medidas de TL e RPE. Para medidas de difração de raios- $X$, usamos grãos com diâmetros inferiores a 0,075 mm.

No caso da Absorção Óptica (AO), lâminas de espessura $1 \mathrm{~mm}$ e 0,5 mm foram cortadas utilizando-se uma serra do tipo isomet com lâmina recoberta de diamante. Fazendo uso de alumina em pó de diferentes granulações, foi possível obter um polimento satisfatório das lâminas.

\section{2 - Amostras sintéticas}

Misturas apropriadas de diferentes óxidos foram selecionadas e agrupadas em cadinho de platina e levadas ao forno, onde a temperatura foi gradualmente elevada, até uma temperatura de $1450-1500{ }^{\circ} \mathrm{C}$ onde permaneceram durante $2 \mathrm{~h}$ sob constante movimentação para obter melhor homogeneização da mistura.

Em seguida, a temperatura foi reduzida até $900{ }^{\circ} \mathrm{C}$, em um intervalo de tempo de $24 \mathrm{~h}$. A partir de então, esfriou-se lentamente até atingir a temperatura ambiente em 12h. $\mathrm{O}$ ciclo térmico para as amostras pode ser visto na figura 3.2 . 


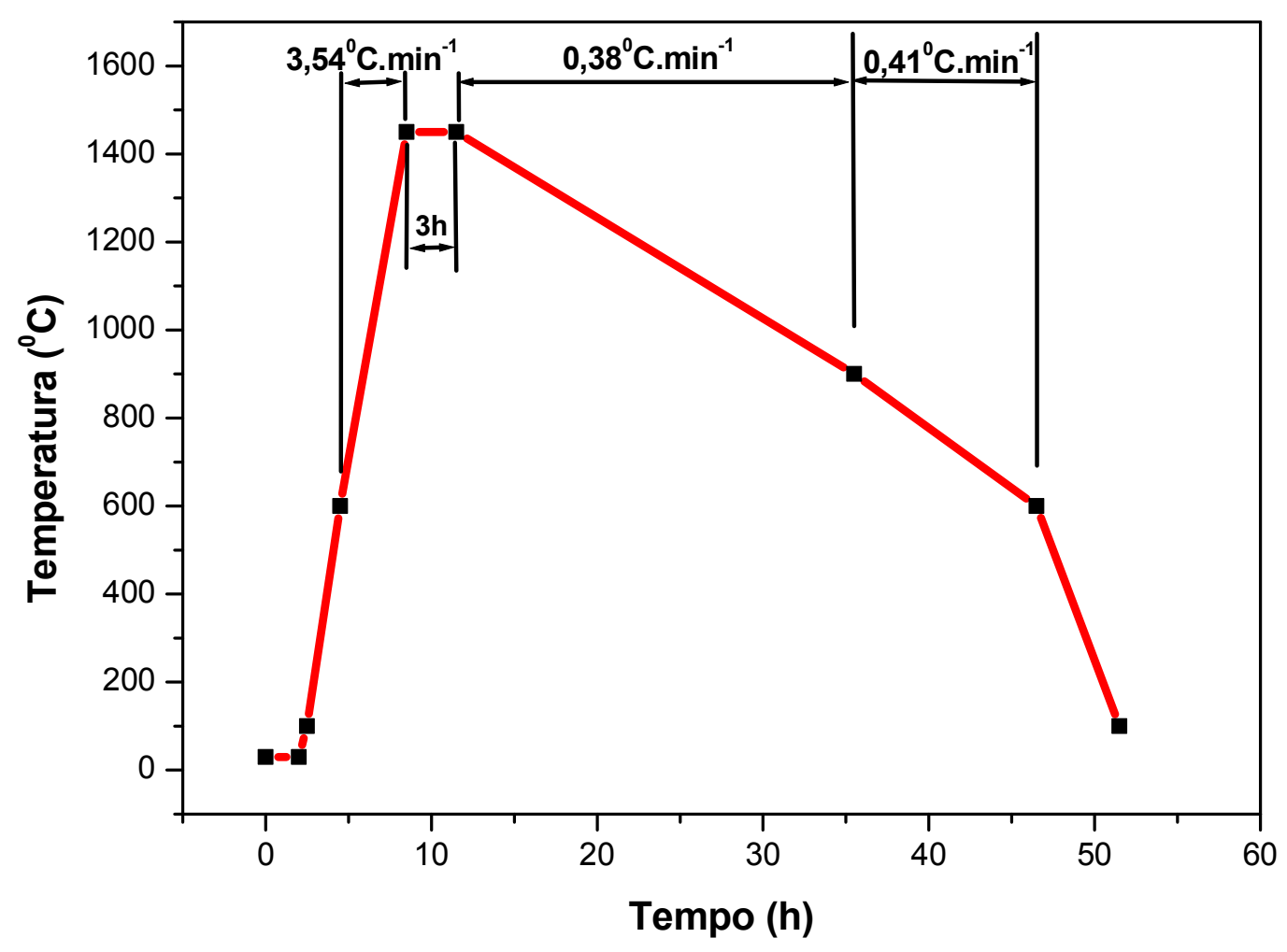

Figura 3.2: Ciclo térmico usado para a obtenção de amostras sintéticas.

O forno usado para a fusão dos materiais foi construído no laboratório LACIFID. O sistema de aquecimento utiliza 6 resistores de Carbeto de Silício SiC em forma cilíndrica, cujo aquecimento é controlado por um sistema do tipo Júnior da Ecil e um termopar do tipo b.

Fornos de menor porte, também construídos no Lacifid foram usados para tratamento térmico das amostras. Esses utilizam como elemento de aquecimento resistores do tipo Kanthal e atingem temperaturas da ordem de $1100{ }^{\circ} \mathrm{C}$. O sistema controlador de temperatura é o mesmo do utilizado no forno de SiC, porém, o termopar é do tipo chromelalumel. Esses fornos foram utilizados para estudar a influência do tratamento térmico sobre o espectro de AO, TL e RPE. 


\section{3 - Irradiação}

As amostras, em pó ou lâminas foram irradiadas no DRT-IPEN-SP. Eram acondicionadas em pequenos envelopes de papel vegetal e então embrulhados em papel alumínio, selados para proteger as amostras de luz. Após esse procedimento, foram expostas à irradiação por raios gama de uma fonte de ${ }^{60} \mathrm{Co}$ à temperatura ambiente. Para doses altas foi usada uma fonte Gamma cell com taxa de $8 \mathrm{kGy} / \mathrm{min}$ e para doses baixas, usamos uma fonte panorâmica com taxa de $41 \mathrm{~Gy} / \mathrm{h}$. Todas as irradiações foram efetuadas à temperatura ambiente. A figura 3.3 mostra esses irradiadores.

a)

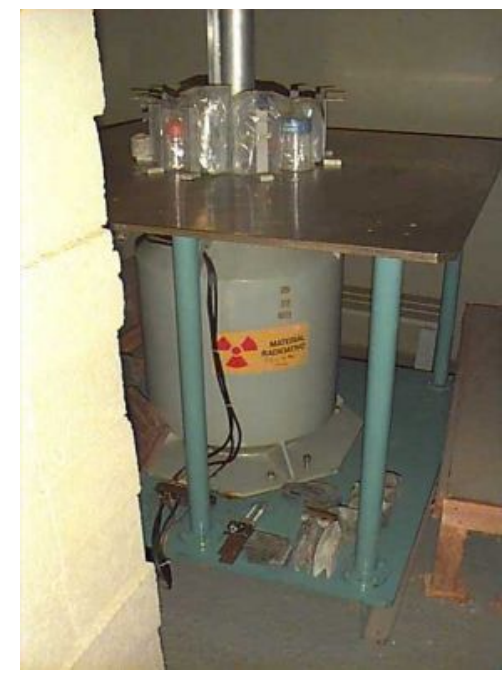

b)

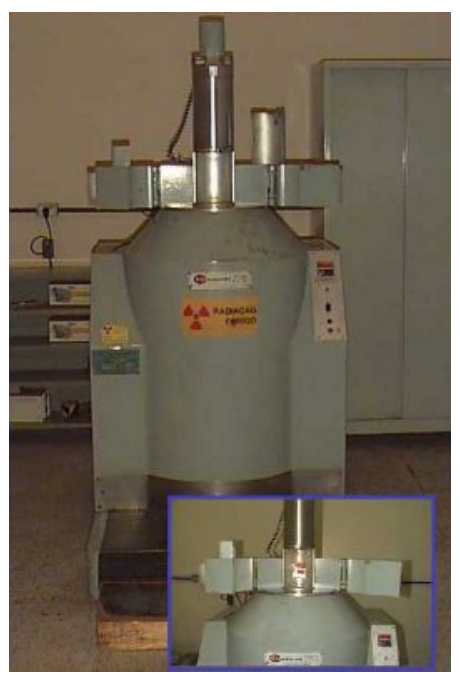

Figura 3.3: Irradiadores Gama tipo Panorâmico (a) e Gammacell (b).

As temperaturas das amostras durante as irradiações não sofriam grandes elevações, pois a taxa de dose era 0,399 kGy/h (Abril/2003) para o irradiador Gama tipo Panorâmico e uma taxa de dose da ordem de 4,43 kGy/h (Abril/2003) para o irradiador Gama tipo Gammacell. Estas amostras ficaram localizadas a uma distância de $100 \mathrm{~mm}$ da fonte de irradiação. 


\section{4 - Equipamentos de medida}

\subsection{1 - Termoluminescência}

\subsubsection{1 - Curvas de emissão}

As curvas de emissão TL foram obtidas utilizando-se um leitor tipo Daybreak1100 Automated TL System, fabricado por Systems Inc. Daybreak Nuclear and Medical, figura 3.4. Neste tipo de leitora, a luz não atravessa o monocromador, ou seja, toda a faixa do espectro de sensibilidade da fotomultiplicadora gera o sinal registrado. As curvas são armazenadas por um computador no qual roda um software TLAPPLIC.

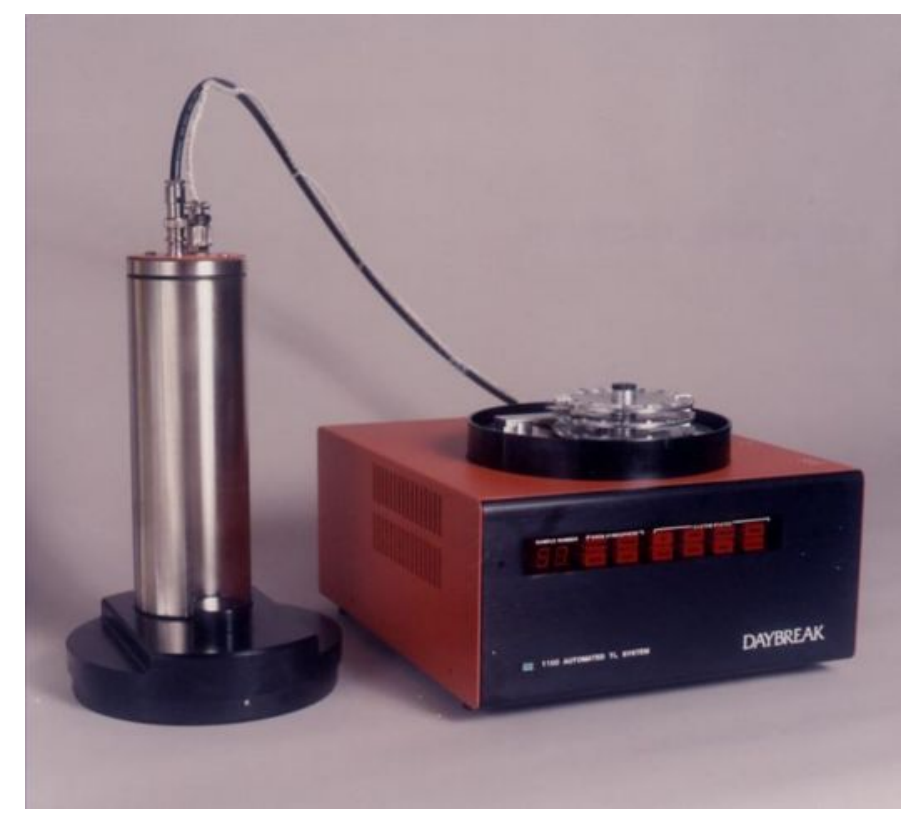

Figura 3.4: Equipamento usado para obtenção das curvas de emissão TL. (Retirado de http://www.daybreaknuclear.com/1100_series_spec.html) 


\subsubsection{2 - Espectros de emissão}

O espectro de emissão TL foi obtido utilizando-se um aparelho montado no LACIFID. Uma foto panorâmica pode ser vista na figura 3.5. Debaixo de um tubo cilíndrico negro, há uma gaveta com uma placa de platina com $0,1 \mathrm{~mm}$ de espessura, pela qual passa uma corrente elétrica quando se inicia o processo de leitura. Esta placa (panela) é um resistor e a passagem de corrente elétrica, monitorada por um controlador de temperatura, aquece a placa. A amostra é colocada sobre a placa e, devido ao aquecimento emite luz TL, parte desta é coletada numa válvula fotomultiplicadora (PMT).

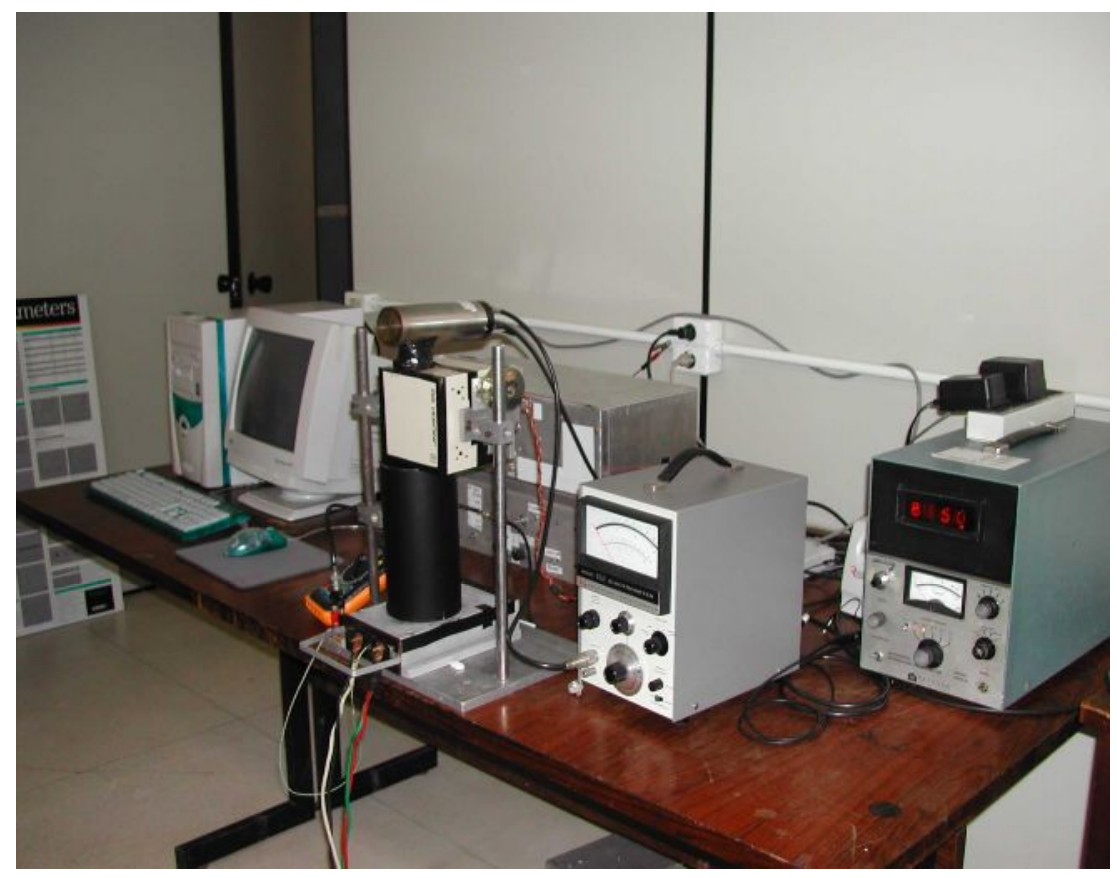

Figura 3.5: Foto panorâmica do leitor utilizado. Para o espectro de emissão, um monocromador separa os comprimentos de onda desejados. Para as curvas de emissão TL a luz passa diretamente para a fotomultiplicadora. 


\section{MATERIAIS E MÉTODOS EXPERIMENTAIS}

Para o controle da temperatura da panela, um termopar tipo chromel-alumel (K) conectado à panela envia a corrente ao controlador que, possibilita um aquecimento linear.

O aparelho leitor TL pode ser adaptado para a medida do espectro da luz TL emitida. Neste arranjo experimental, uma lente de vidro permite a passagem de comprimentos de onda maiores que $300 \mathrm{~nm}$ e concentra a luz em um feixe direcionado à fenda de um monocromador (UNICRON 100 - FUNBEC). O feixe de luz que sai do monocromador deixa emergir comprimentos de onda com: $\lambda=\left(\lambda_{0}+\Delta \lambda / 2\right) \mathrm{nm}$, onde $\lambda_{0}$ é o comprimento de onda indicado no mostrador e $\Delta \lambda$ é a largura da banda que é dependente das dimensões da fenda utilizada e de $\lambda_{0}$.

Nas medidas efetuadas para este trabalho, utilizamos uma fenda de $1,1 \mathrm{~mm}$ de largura por $10 \mathrm{~mm}$ de altura, varrendo uma faixa espectral de 200 a $800 \mathrm{~nm}$. Levando-se em consideração essas características, com $\lambda_{0}=800 \mathrm{~nm}$ tem-se $\Delta \lambda=10 \mathrm{~nm}$ e com $\lambda_{0}=200$ $\mathrm{nm}, \Delta \lambda=9 \mathrm{~nm}$. Então, seria bem razoável admitir simplesmente que a luz emergente do monocromador possui comprimento de onda dado por $\lambda=\left(\lambda_{0} \pm 5,0\right) \mathrm{nm}$, o que pode ser considerado um bom valor.

Um motor de passo controla o bastão de varredura para varrer o espectro de emissão numa faixa de 190 a $800 \mathrm{~nm}$ a uma taxa de $20 \mathrm{~nm} / \mathrm{s}$ e taxa de aquecimento de 0,9 ${ }^{\circ} \mathrm{C} / \mathrm{s}$. Tomando-se o máximo na emissão TL do pico dentro de um intervalo de $20 \mathrm{~s}$, faz-se com que a intensidade da luz incidente no monocromador fique praticamente constante. Para detecção dos diferentes comprimentos de onda de saída do monocromador, foi utilizada uma válvula fotomultiplicadora HAMAMATSU 551S. Nas leituras da luz TL emitidas por amostras, é importante que as massas do material, usadas em cada leitura, sejam constantes.

A figura 3.6 mostra a curva de sensibilidade relativa do monocromador e a sensibilidade absoluta da fotomultiplicadora utilizada. A corrente gerada pela fotomultiplicadora é enviada ao eletrômetro Keithley Instruments - modelo 610C que converte a corrente em tensão e é registrada através de um registrador ECB RB202. 


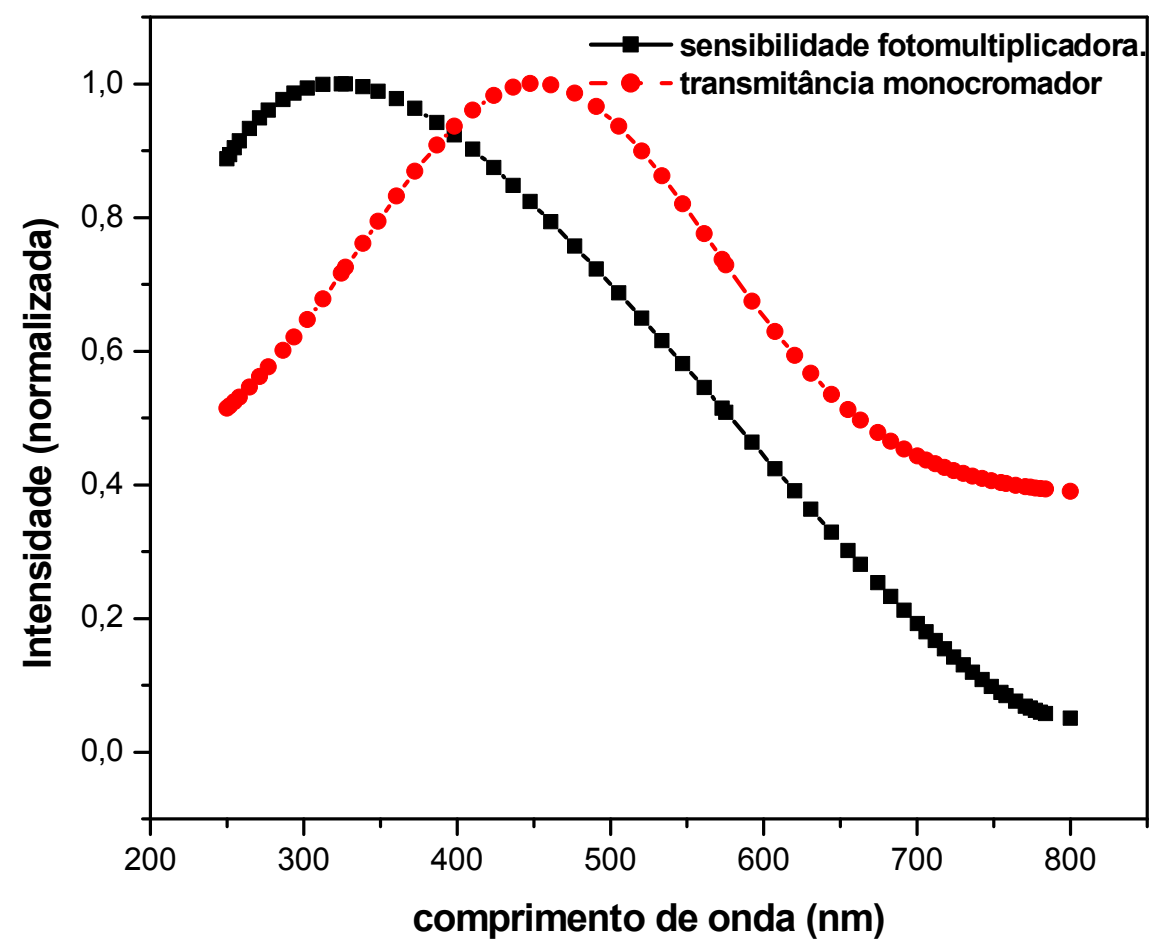

Figura 3.6: Curva de sensibilidade relativa do monocromador UNICROM 100 e a sensibilidade absoluta da fotomultiplicadora Hamamatsu 551S.

\subsection{2 - Absorção óptica}

Para obtenção dos espectros de Absorção Óptica (AO), foi utilizado um espectrofotômetro de feixe duplo (Cary - Varian 500) pertencente ao LACIFID, figura 3.7, que possui uma capacidade de registrar comprimentos de onda desde 190 até $3300 \mathrm{~nm}$. Lâminas de rodonita natural foram cortadas de uma mesma amostra, todas na mesma direção e então polidas. 


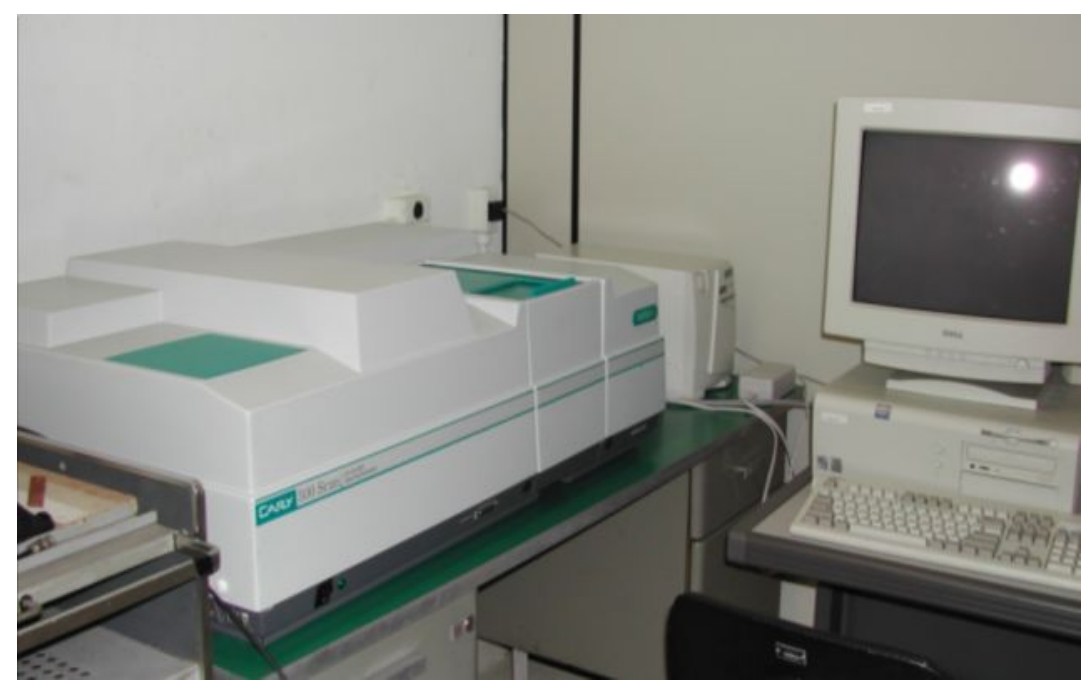

Figura 3.7: Espectrofotômetro Cary-Varian 500 do LACIFID.

Neste equipamento, o feixe de luz proveniente da fonte do espectrofotômetro divide-se em dois, um deles atravessando a amostra e o outro, o meio de referência. Um computador registra os espectros através de um detector. Esses espectros de absorção podem ser relativos, onde o meio de referência pode ser um outro cristal ou espectros absolutos, tendo o ar como meio de referência.

As medidas foram tomadas à temperatura ambiente e devido à atmosfera ambiente, presente no aparelho, ocorre a absorção de comprimentos de onda menores do que $200 \mathrm{~nm}$, limitando as medidas à faixa entre 200 e $3300 \mathrm{~nm}$. 


\subsection{3 - Ressonância paramagnética eletrônica (RPE)}

Um espectrômetro de RPE é basicamente formado de uma fonte de microondas de freqüência estável e de um eletroímã que gera um campo magnético que pode ser lentamente variado ao longo de uma faixa selecionada para se determinar o espectro. Os elementos básicos de um espectrômetro convencional são mostrados na figura 3.8.

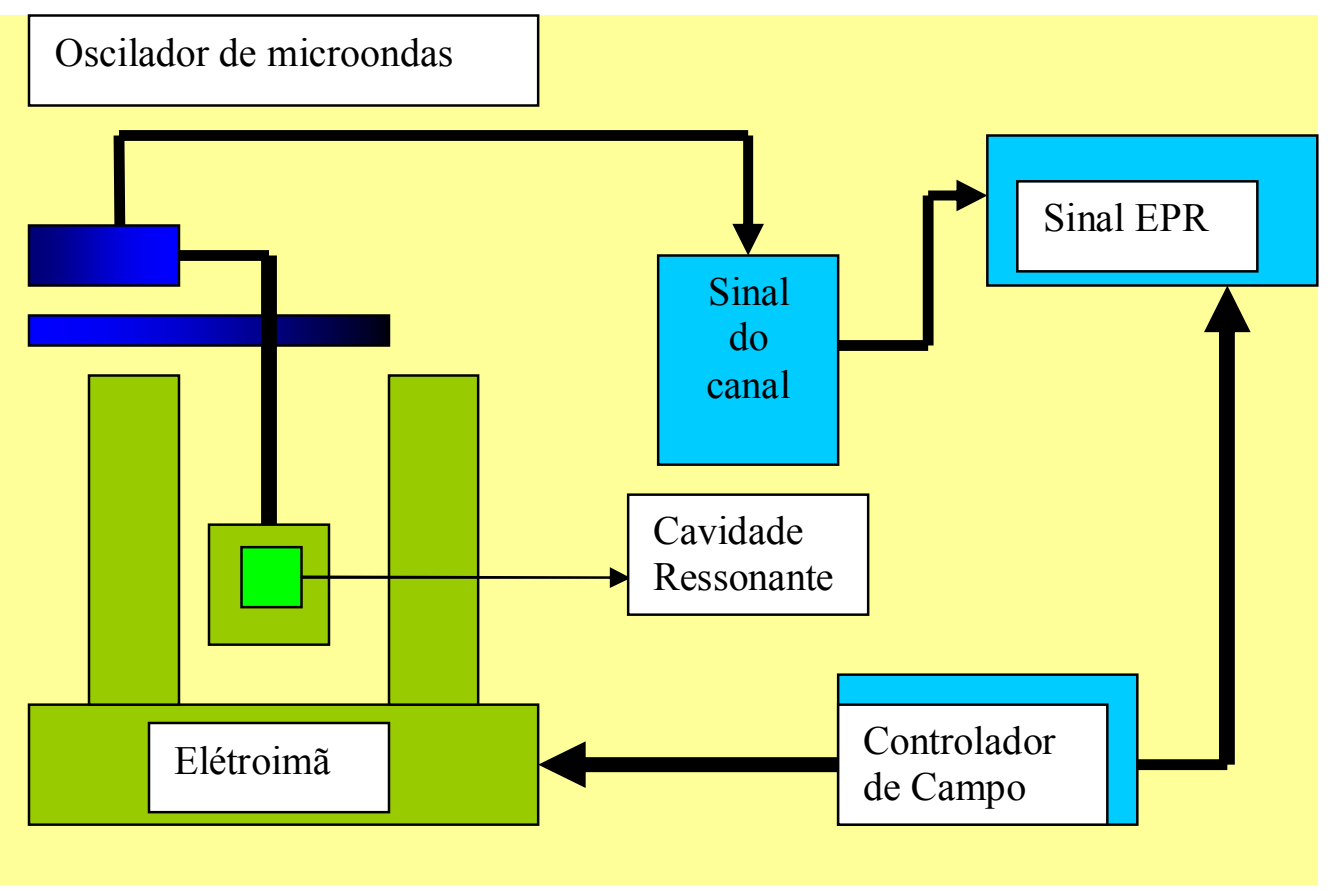

Figura 3.8: Diagrama de bloco de um aparelho de RPE Bruker.

A radiação de microondas é gerada por um "gun" e enviada à amostra, passando através de um guia de ondas de secção retangular. A quantidade de potência que chega à amostra é controlada por um atenuador. A amostra é então colocada em uma cavidade ressonante, cuja dimensão casa com o comprimento de onda da radiação incidente. A freqüência exata na qual a cavidade entra em ressonância depende das propriedades elétricas da amostra e da temperatura da cavidade. Então, o equipamento permite também que a freqüência de microondas possa ser levemente variada para acompanhar a freqüência ressonante da cavidade. 
A radiação passa do guia de ondas à cavidade através de um pequeno orifício, chamado íris, cujo tamanho também pode ser variado. Através de um ajuste apropriado da íris e da freqüência da radiação, uma condição de ressonância apropriada pode ser obtida.

Todas as medidas de Ressonância Paramagnética Eletrônica (RPE) foram realizadas no espectrômetro BRUKER EMX RPE, de banda $X$ pertencente ao grupo de multi-usuários do Instituto de Física da USP.

Essas medidas foram feitas com uma modulação de amplitude de $1 \mathrm{G}$ e modulação de freqüência igual a $100 \mathrm{kHz}$. Para essas medidas eram colocadas $100 \mathrm{mg}$ de cada amostra em pó em tubos de quartzo (diâmetro interno entre 4 e $5 \mathrm{~mm}$, comprimento de $270 \mathrm{~mm}$ ) que, então, eram inseridos na cavidade ressonante do aparelho. 
Capítulo 4

\section{Resultados}




\section{0 - Resultados}

\section{1 - Caracterização}

O primeiro passo para a caracterização da rodonita natural foi a obtenção da composição dos elementos que a constituem, bem como das impurezas. A técnica utilizada foi a Fluorescência de raios $-\mathrm{X}$ e os resultados podem ser observados no gráfico da figura 4.1.

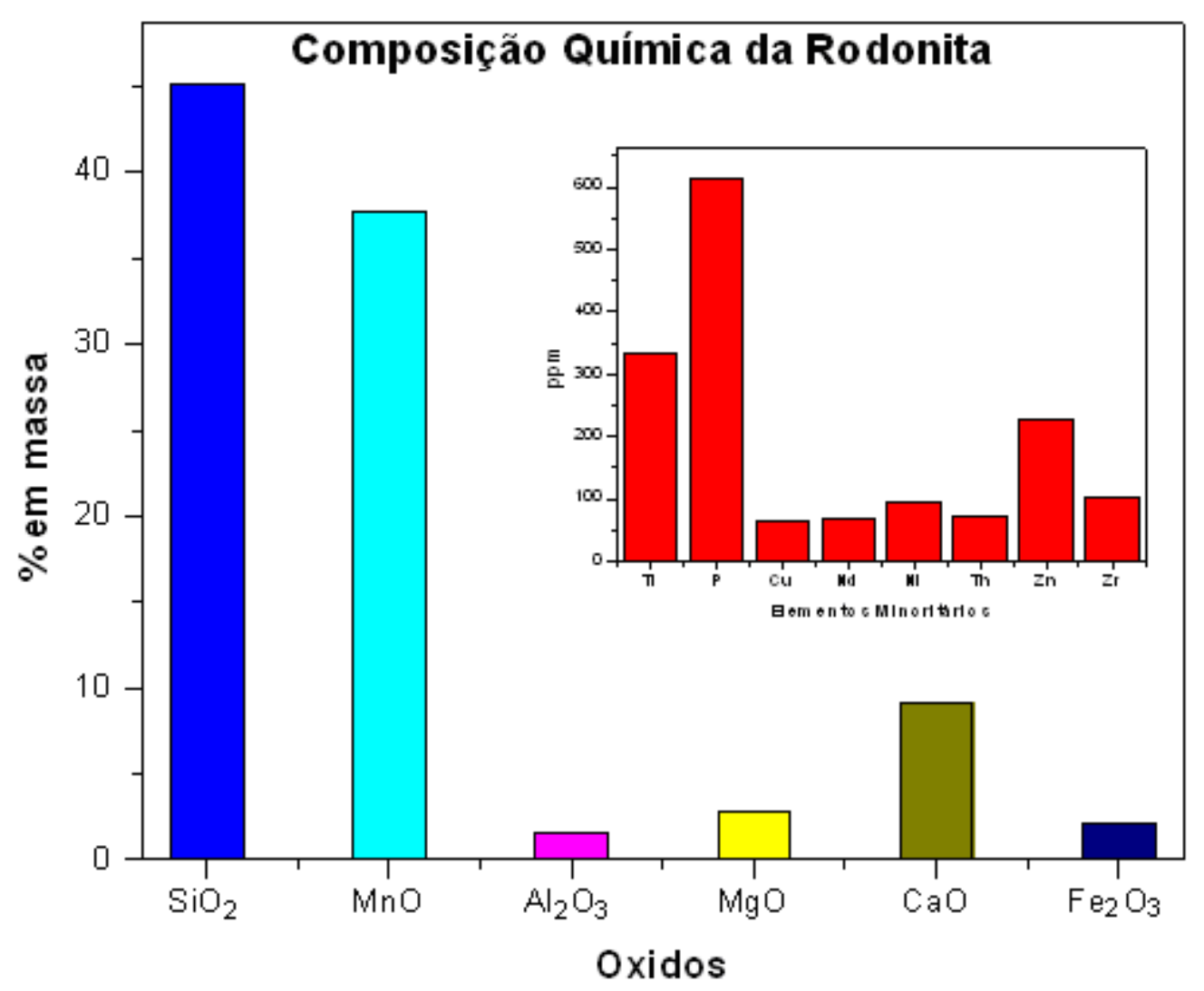

Figura 4.1: Análise da composição química da amostra de rodonita [medidas realizadas no Instituto de Geociências da Universidade de São Paulo]. 
A composição química de um cristal puro de rodonita é $\mathrm{MnSiO}_{3}$, dessa forma a grande quantidade de $\mathrm{SiO}_{2}$ e $\mathrm{MnO}$ já eram esperadas. Porém, podemos observar que algumas impurezas comparecem com quantidades significativas, tais como: $\mathrm{CaO}(9,14 \%)$, $\mathrm{Fe}_{2} \mathrm{O}_{3}(2,18 \%), \mathrm{MgO}(2,78 \%)$ e $\mathrm{Al}_{2} \mathrm{O}_{3}(1,64 \%)$, algumas das quais desempenham papel importante como centro TL.

Por isso, tanto a rodonita quanto a bustamita naturais são consideradas minerais de silicatos de $\mathrm{Mn}$, Ca e Fe. Adotaremos, dessa forma, ( $\mathrm{Mn}, \mathrm{Ca}, \mathrm{Fe}, \mathrm{Mg}) \mathrm{SiO}_{3}$ como sendo a fórmula química da rodonita utilizada neste trabalho. Outra técnica de grande importância foi a difração de raios-X que foi usada para verificar se a amostra do cristal que tínhamos em mãos era de fato a rodonita. A concordância entre o difratograma da amostra e o padrão de rodonita mostrou que de fato tratava-se do material em questão, figura 4.2.

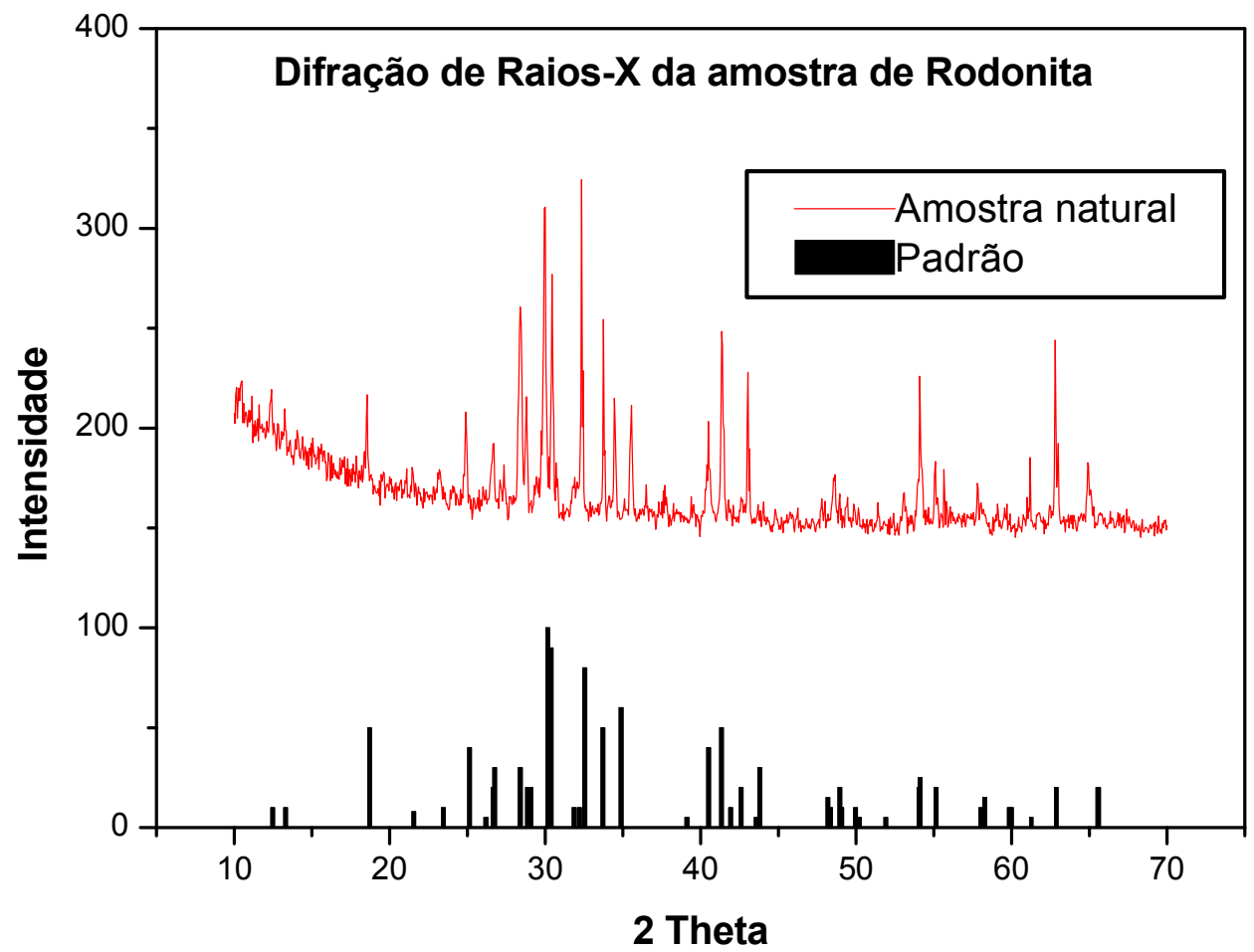

Figura 4.2: Difração de Raio-X da amostra utilizada no trabalho. 
Neste trabalho estudamos a influência do tratamento térmico sobre as propriedades TL, AO e de RPE do cristal de rodonita, dessa forma precisávamos saber até que temperatura a estrutura mantinha-se inalterada. Foram obtidos difratogramas da amostra natural tratada em diferentes temperaturas, por $1 \mathrm{~h}$, em $400^{\circ} \mathrm{C}, 500^{\circ} \mathrm{C}, 600^{\circ} \mathrm{C} \mathrm{e}$ $800^{\circ} \mathrm{C}$, como pode ser verificado na figura 4.3. Podemos ver que não ocorreram mudanças significativas na estrutura do material até a temperatura de $600^{\circ} \mathrm{C}$. Todavia, para um tratamento em $800^{\circ} \mathrm{C}$ ocorreu uma diminuição sensível na intensidade dos picos e a relação sinal ruído tornou-se praticamente igual a 1, dificultando qualquer interpretação do resultado.

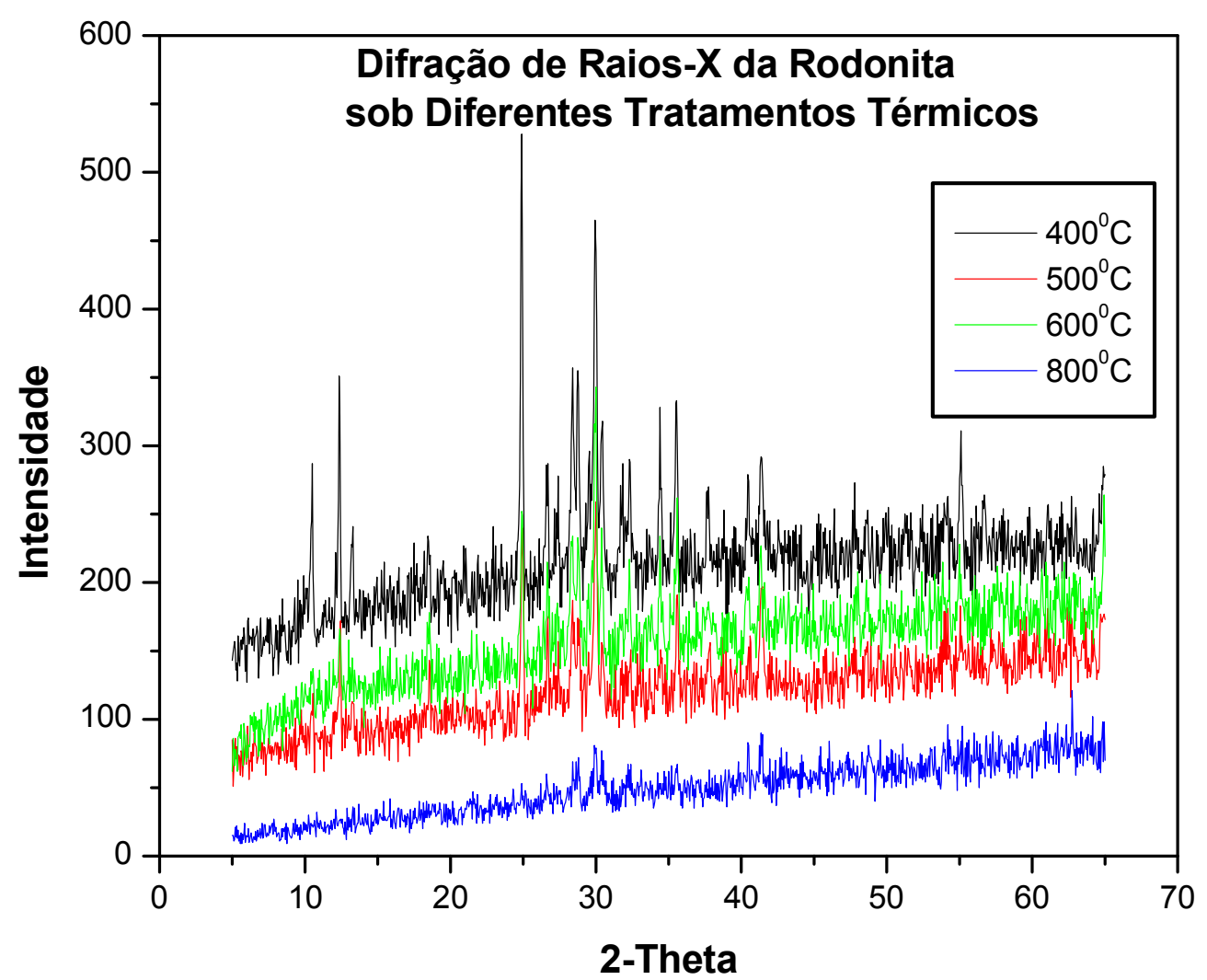

Figura 4.3: Difração de raios- $X$ para diferentes temperaturas de tratamento térmico.

Grande ênfase foi dada à produção de amostras sintéticas de rodonita pura ou com quantidades controladas de dopantes. Dessa forma, outros difratogramas foram feitos nessas amostras para verificação de sua estrutura e serão mostradas oportunamente. 


\section{2 - Medidas de Termoluminescência (TL)}

As medidas de $T L$ foram realizadas com amostras naturais e sintéticas do cristal de rodonita pura ou dopada com quantidades controladas de impurezas.

\subsection{1 - Amostra natural}

A figura 4.4 mostra as curvas de emissão TL de uma amostra de Rodonita natural sem qualquer dose, ou seja, apenas com radiação natural. Quatro picos são visíveis, um em $250^{\circ} \mathrm{C}$, outro em $335^{\circ} \mathrm{C}$, mais um em $380^{\circ} \mathrm{C}$ e um último em $460^{\circ} \mathrm{C}$, pouco visível.

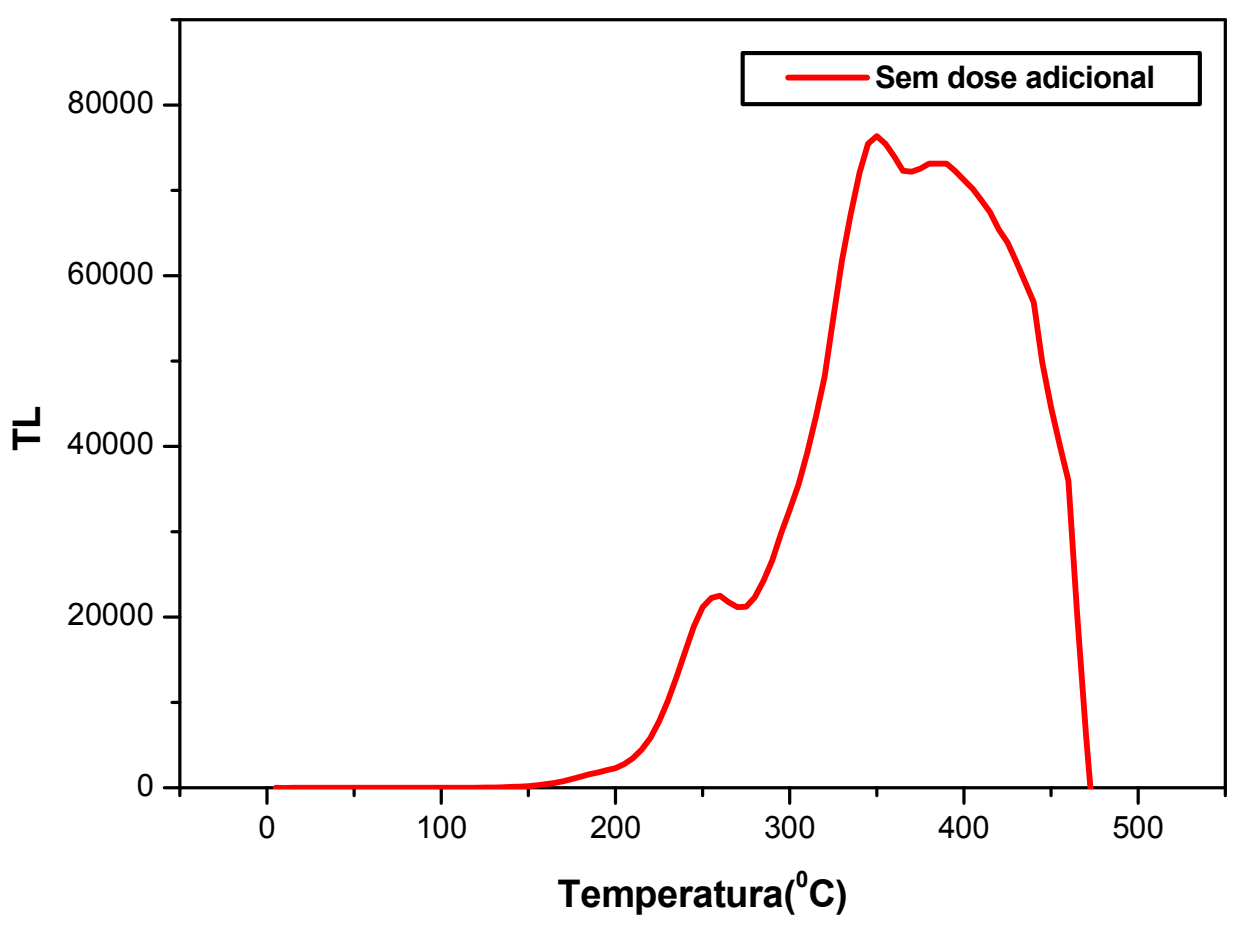

Figura 4.4: TL da Rodonita natural sem dose adicional. 
O efeito da irradiação sobre a amostra natural pode ser visto na figura 4.5 , onde mostramos as curvas de emissão TL para diferentes doses e taxa de aquecimento $4^{\circ} \mathrm{C} / \mathrm{s}$.

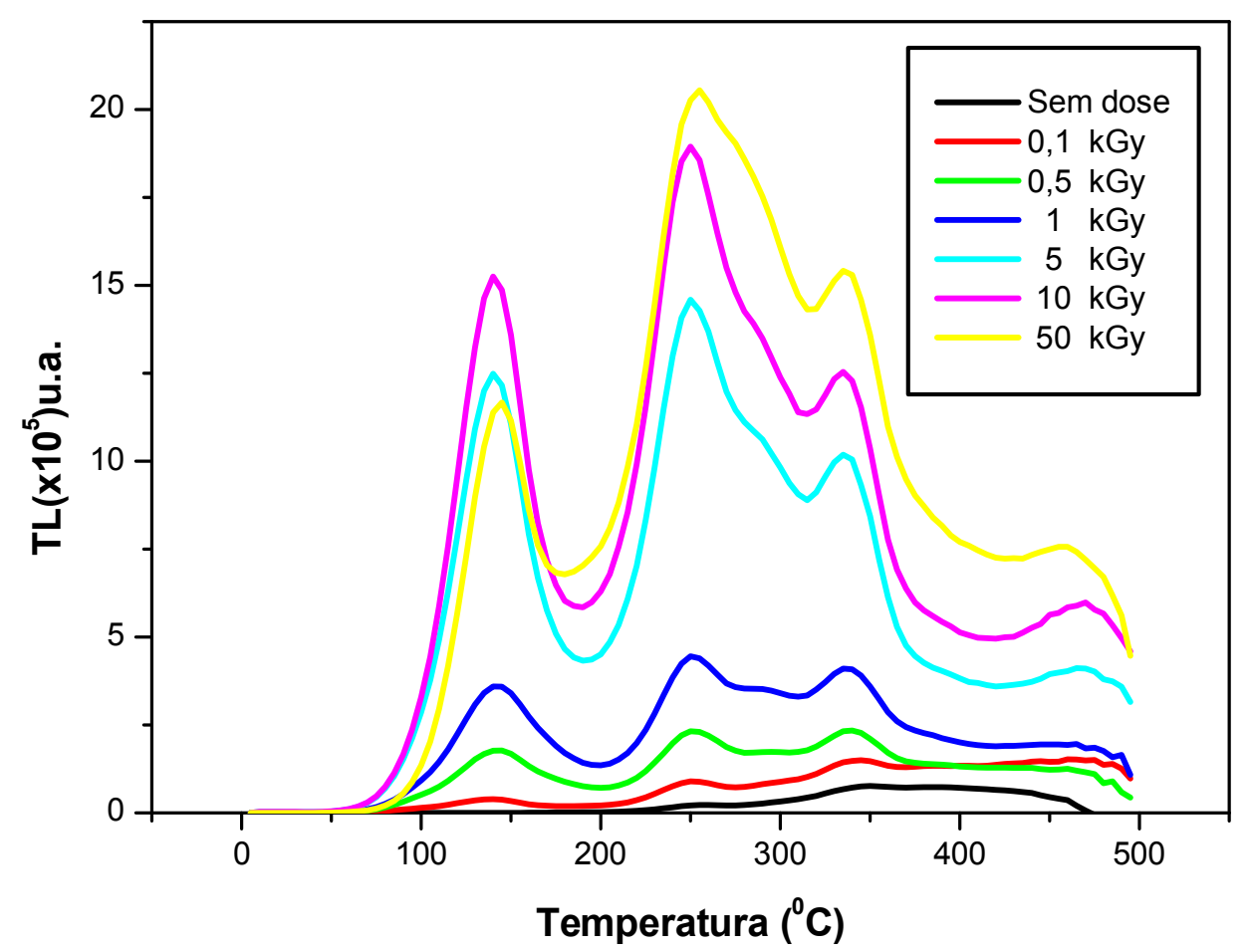

Figura 4.5: Curva de emissão TL da amostra natural mais doses adicionais entre 0,1 kGy e $50 \mathrm{kGy}$. Taxa de aquecimento de $4{ }^{\circ} \mathrm{C} / \mathrm{s}$.

Vários picos TL são identificados, $140^{\circ} \mathrm{C}, 250^{\circ} \mathrm{C}, 280^{\circ} \mathrm{C}$ e $335^{\circ} \mathrm{C}$ e um em $460^{\circ} \mathrm{C}$. Para doses entre 0,1 e $0,5 \mathrm{kGy}$ o pico de $335^{\circ} \mathrm{C}$ cresce mais rapidamente que os outros, porém entre $0,5 \mathrm{kGy}$ e $10 \mathrm{kGy}$ os outros dois picos crescem levemente mais rápido porém todos são sublineares para doses acima de 0,5 kGy, figura 4.6. 


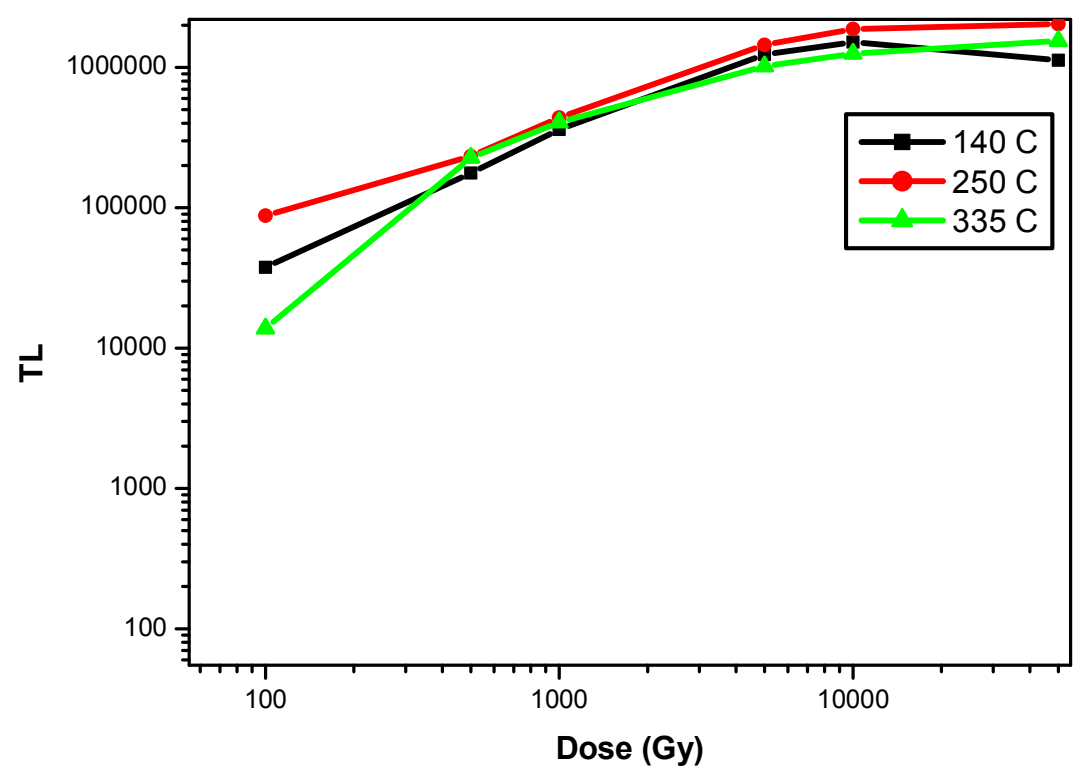

Figura 4.6: Crescimento do pico em função da dose em uma amostra rodonita natural.

O espectro de emissão TL da Rodonita natural com dose adicional de 10 kGy é mostrado na figura 4.7. O espectro foi obtido na faixa de temperaturas entre a temperatura ambiente e $450^{\circ} \mathrm{C}$ e entre 400 e $700 \mathrm{~nm}$, onde foram estudados dois picos, figura 4.7.

Podemos ver, para o pico $260^{\circ} \mathrm{C}$ uma banda de emissão bem larga estendendose por uma faixa de aproximadamente $100 \mathrm{~nm}$, centrada em $560 \mathrm{~nm}$ e para o pico de $140^{\circ} \mathrm{C}$ podemos identificar uma banda larga estendendo-se por uma faixa de $150 \mathrm{~nm}$ e centrada em $585 \mathrm{~nm}$. 


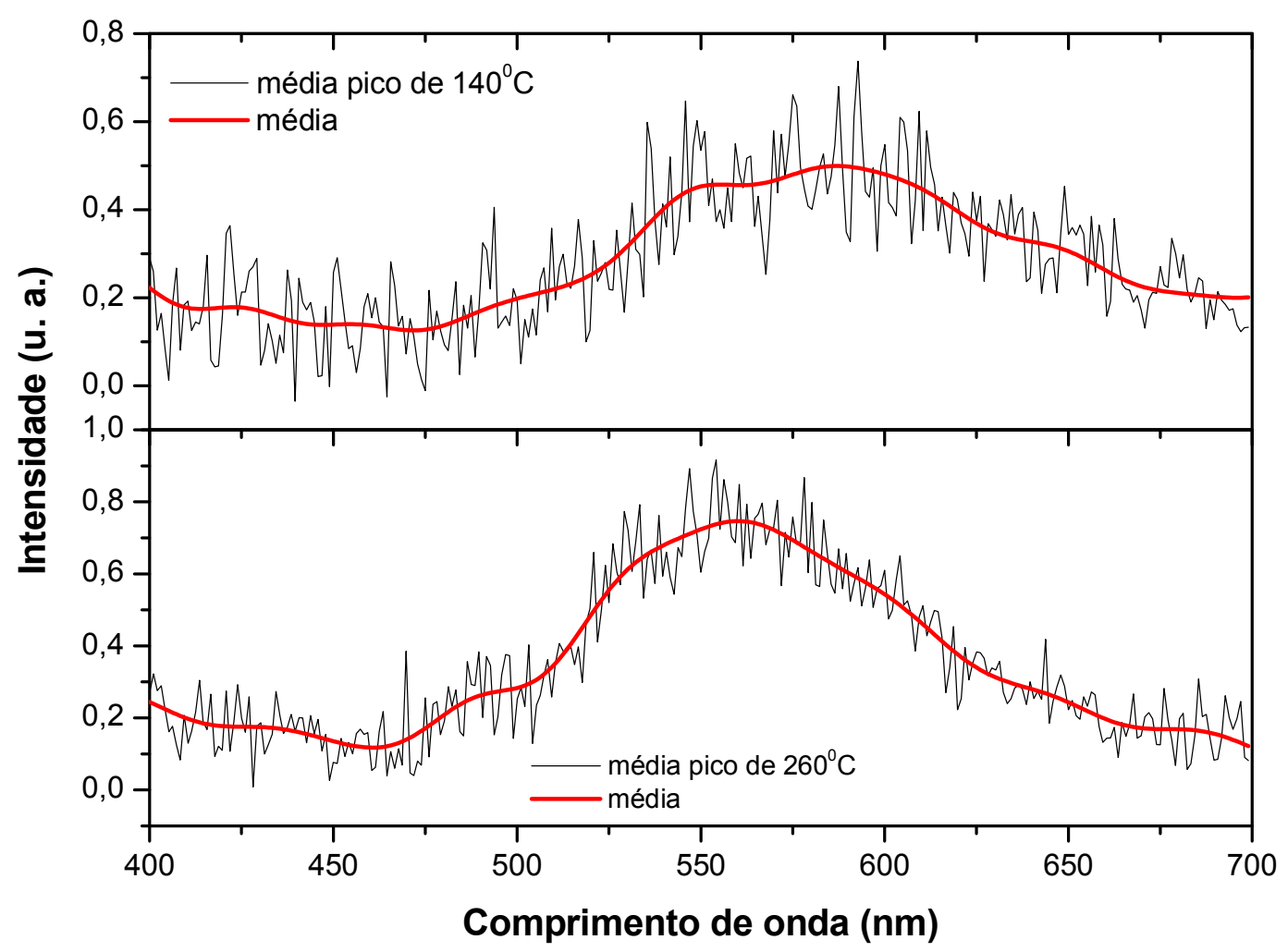

Figura 4.7: Espectro de emissão da Rodonita.

O estudo de TL das amostras foram realizados após tratamento térmico cujo objetivo é de limpar a TL residual. Vários tratamentos foram testados, figura 4.8, onde vemos que, para temperaturas até $700^{\circ} \mathrm{C}$ ocorre um aumento da sensibilidade, porém não ocorre mudança da forma, a figura 4.9 mostra que a sensibilidade TL é maior para um tratamento térmico em $700^{\circ} \mathrm{C}$. Escolhemos o tratamento em $600^{\circ} \mathrm{C}$ por 1 hora para eliminação de TL residual. 


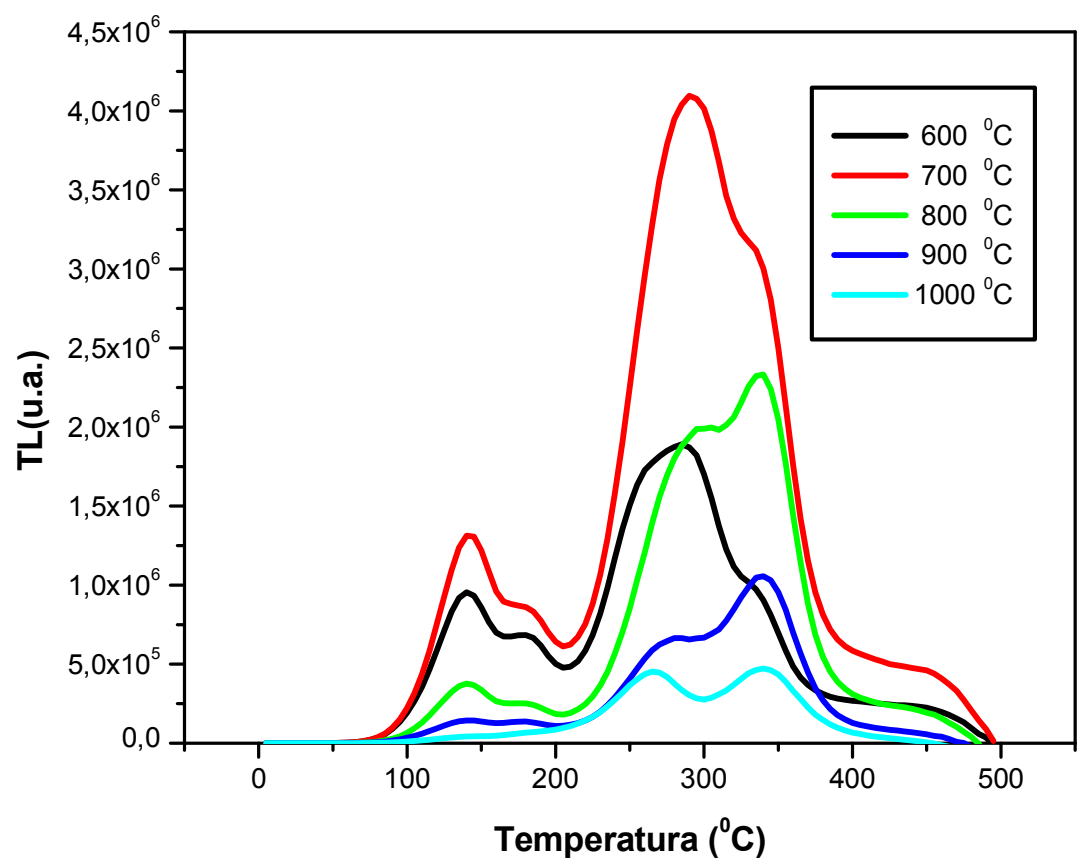

Figura 4.8: Curvas de emissão TL para amostras recozidas em diferentes temperaturas por $1 \mathrm{~h}$ e posterior dose gama adicional de $10 \mathrm{kGy}$. Taxa de aquecimento $4^{\circ} \mathrm{C} / \mathrm{s}$.

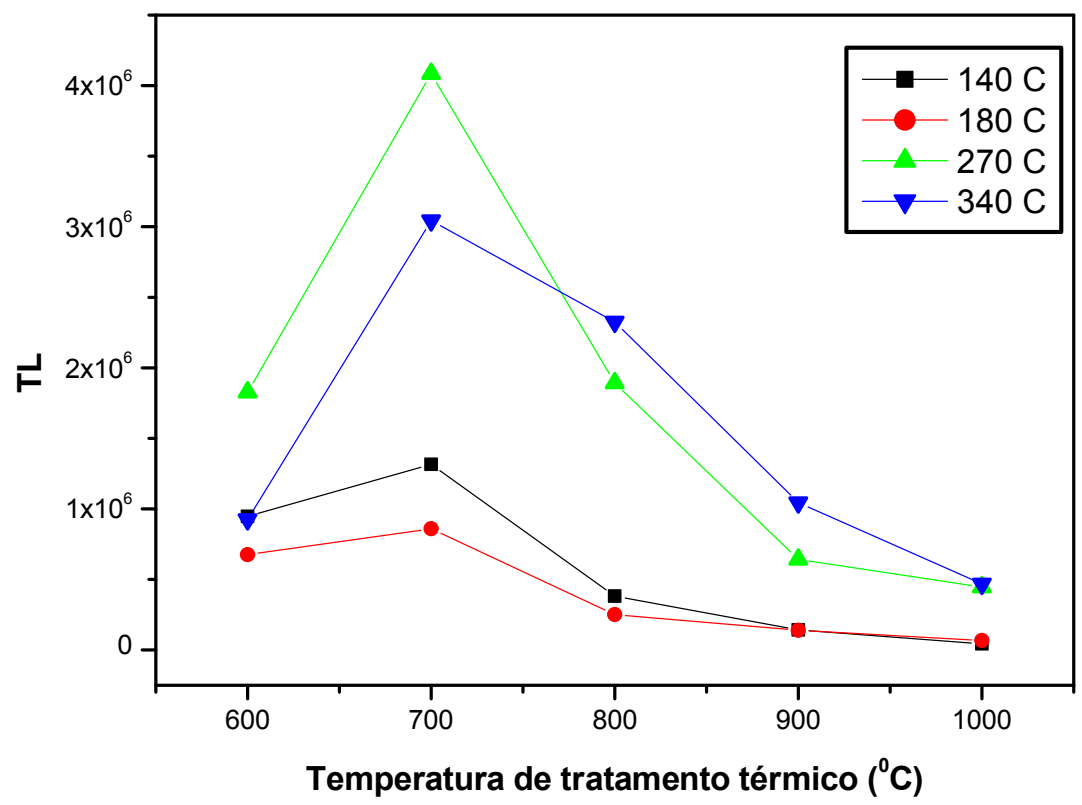

Figura 4.9: Sensibilidade TL em função do tratamento térmico. 
Após tratamento térmico em $600^{\circ} \mathrm{C} / 1 \mathrm{~h}$ as amostras de rodonita foram irradiadas com doses de radiação gama de 0,1 kGy até $50 \mathrm{kGy}$. A figura 4.10 mostra as curvas de emissão $\mathrm{TL}$, onde podemos notar diversos picos, $140^{\circ} \mathrm{C}, 180^{\circ} \mathrm{C}$ (este não aparecia no espectro de emissão $\mathrm{TL}$ do material natural sem tratamento térmico) em $260^{\circ} \mathrm{C}$ e em $340^{\circ} \mathrm{C}$. Por outro lado, o pico em 460 já não é bem visível.

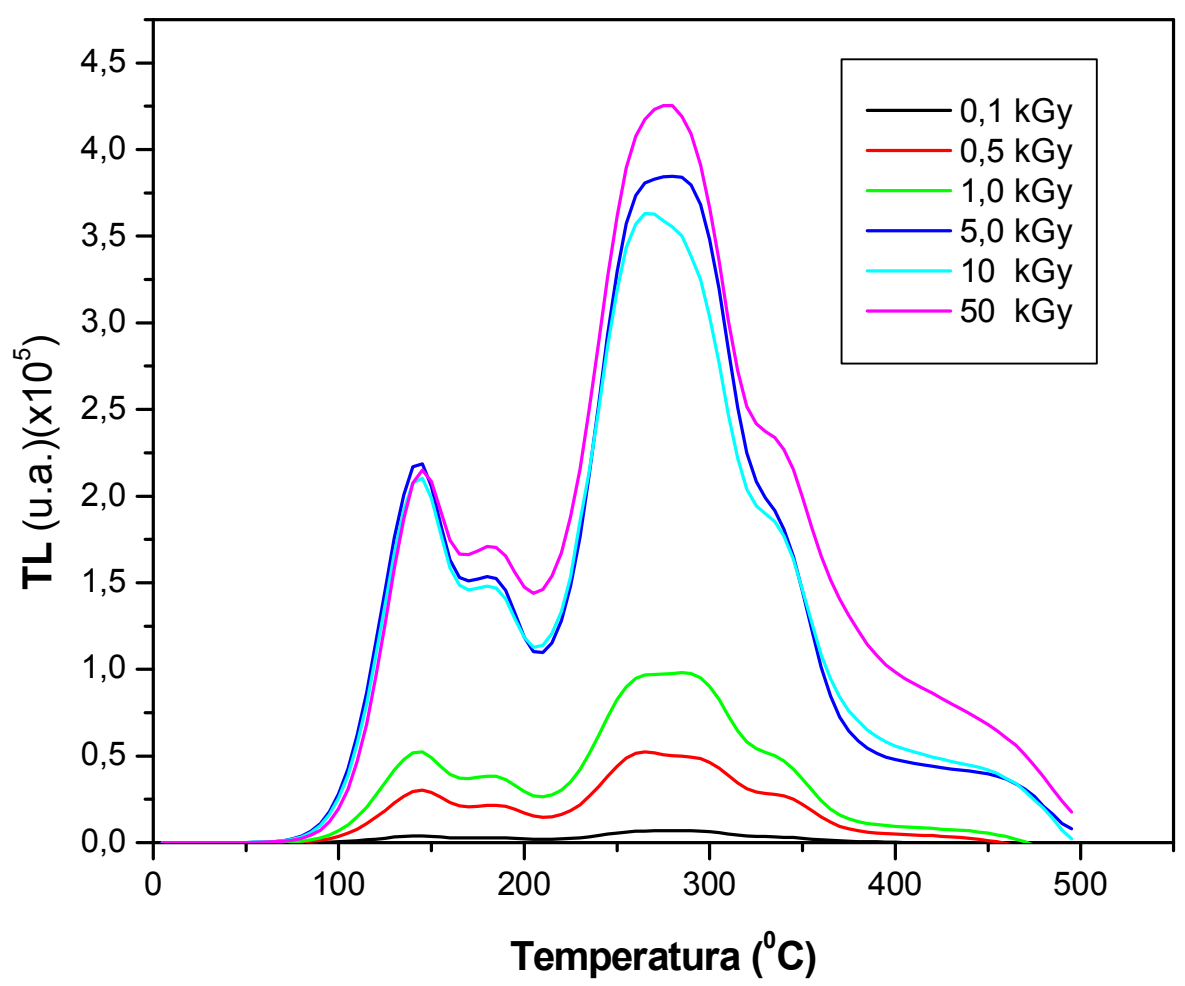

Figura 4.10: Curvas de emissão TL para amostra natural tratada em $600^{\circ} \mathrm{C}$ por $1 \mathrm{~h}$ com dose gama adicional. Taxa de aquecimento $4^{\circ} \mathrm{C} / \mathrm{s}$. 
Podemos perceber pela figura 4.11 que o crescimento dos picos em função da dose, neste caso ocorrem de forma parecida, sendo sublineares para doses acima de 0.5 kGy, ocorrendo saturação acima de 5 kGy.

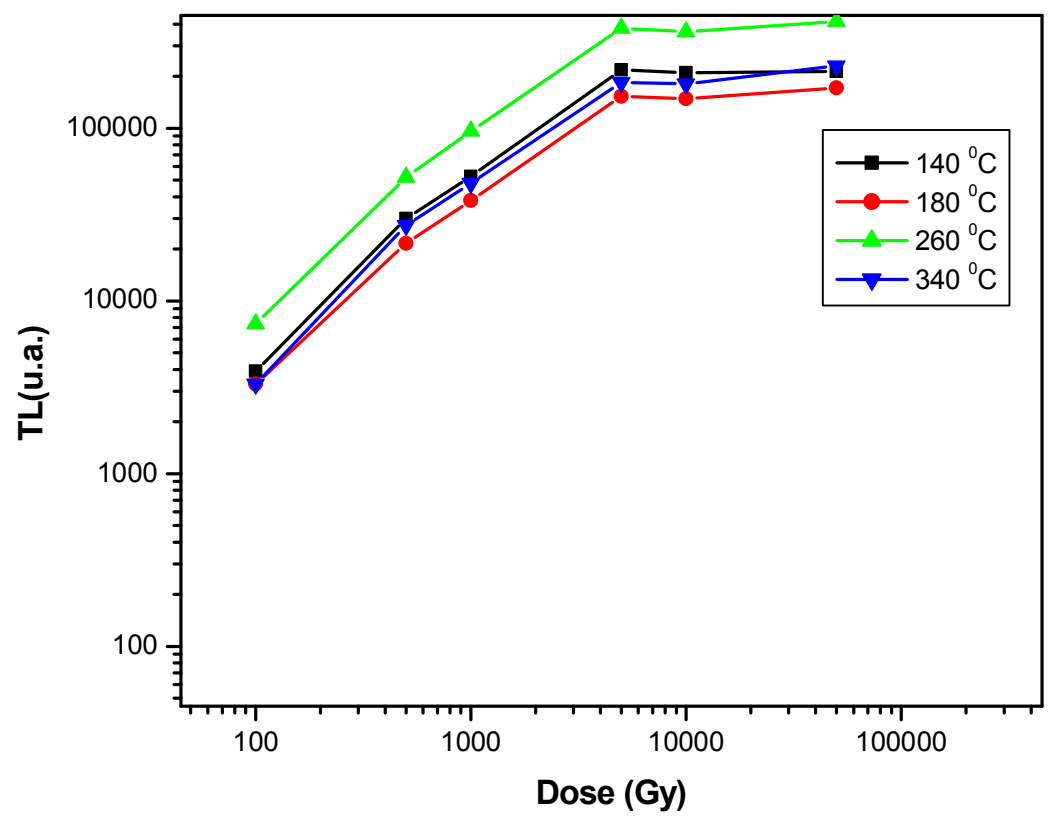

Figura 4.11: Comportamento dos picos $T L$ da rodonita natural tratada em $600^{\circ} \mathrm{C}$ por $1 \mathrm{~h}$ com a dose de radiação gama.

O decaimento isócrono dos picos TL é mostrado na figura 4.12, nela verificamos que nenhum pico estava escondido e, além disso, podemos ver que houve um aumento do pico de $340^{\circ} \mathrm{C}$ devido ao pré-aquecimento para temperatura de $272^{\circ} \mathrm{C}$. 


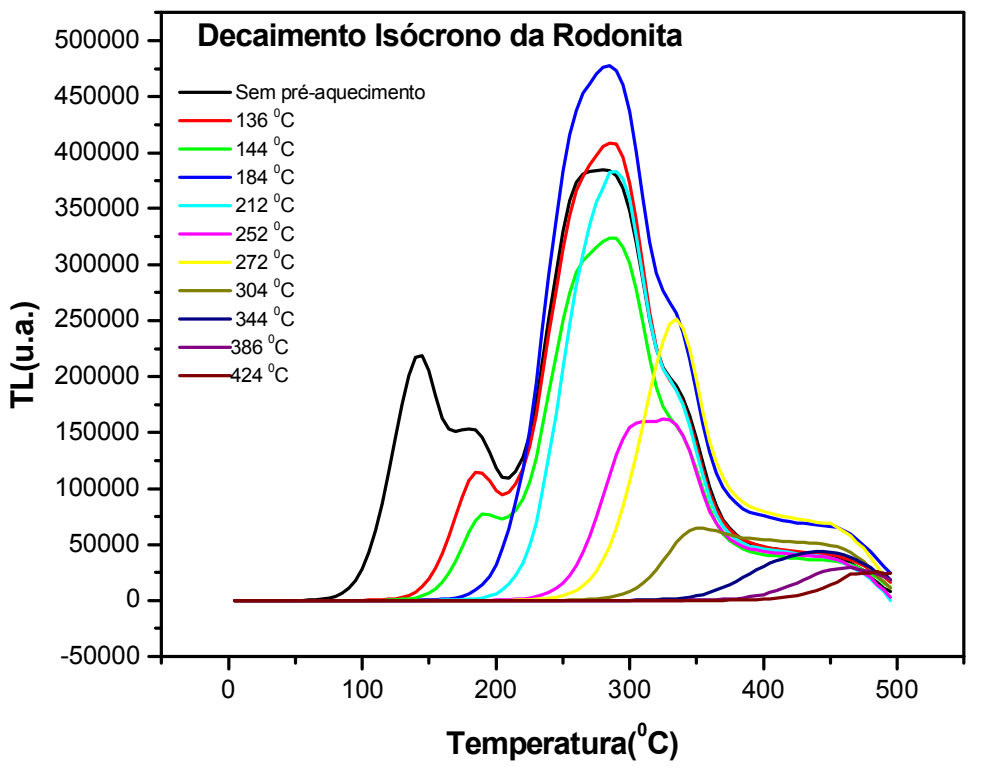

Figura 4.12: Decaimento isócrono (2 $\mathrm{min}$ ) dos picos $T L$ na rodonita natural tratada em $600^{\circ} \mathrm{C} / 1 \mathrm{~h}$ e irradiada com $5 \mathrm{kGy}$. Taxa de aquecimento $4^{\circ} \mathrm{C} / \mathrm{s}$.

\subsection{2 - Amostras sintéticas}

Foram produzidas pelo método de fusão de componentes e posterior resfriamento controlado, amostras sintéticas de rodonita contendo diferentes composições, a maioria em atmosfera ambiente e uma amostra em atmosfera controlada de argônio. $O$ método tem suas limitações, é claro, mas pode fornecer informações valiosas sobre a importância de cada impureza sobre as propriedades de TL e RPE do cristal de rodonita.

\subsubsection{1 - Primeiras amostras sintéticas}

Na primeira amostra sintetizada em nossos fornos, usamos como base, a própria amostra de rodonita natural, cuja composição aproximada é mostrada no gráfico da figura 4.1. A amostra natural foi pulverizada e colocada em um cadinho de platina, onde, por processos já descritos foi obtido a amostra sintética. A difração de raios-X mostrou que a estrutura concordava mais com a estrutura do cristal de bustamite, que tem composição similar à da rodonita utilizada neste trabalho. Mesmo assim, foram feitas medidas de 
emissão TL para essa amostra, para isso a amostra 1, recebeu doses entre 0,1 e $100 \mathrm{kGy}$. As curvas de emissão são mostradas na figura 4.13 .

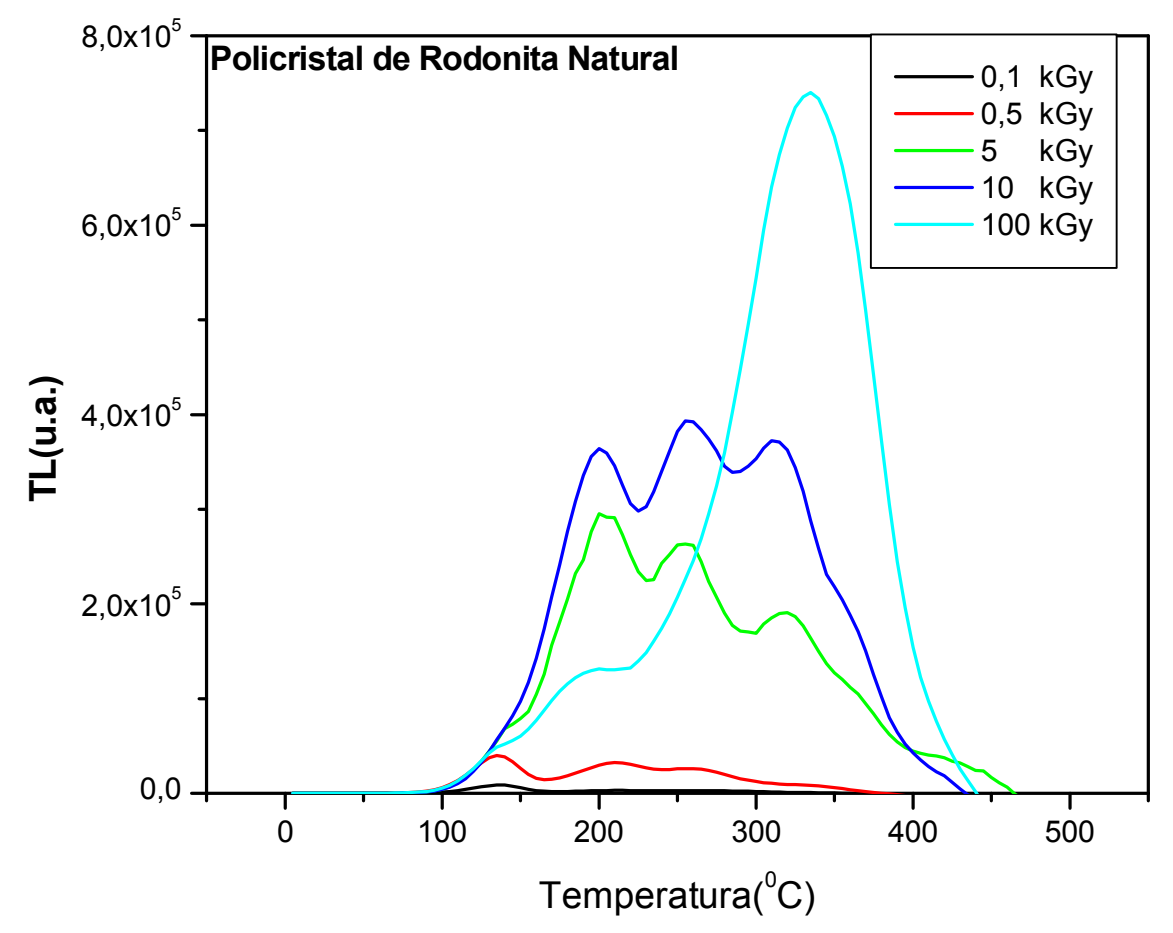

Figura 4.13: Curvas de emissão TL para amostra sintética de rodonita natural com dose gama adicional. Taxa de aquecimento $4^{\circ} \mathrm{C} / \mathrm{s}$.

O crescimento da intensidade TL em função da dose apresenta certa semelhança com a amostra natural, isso pode ser verificado na figura 4.14. 


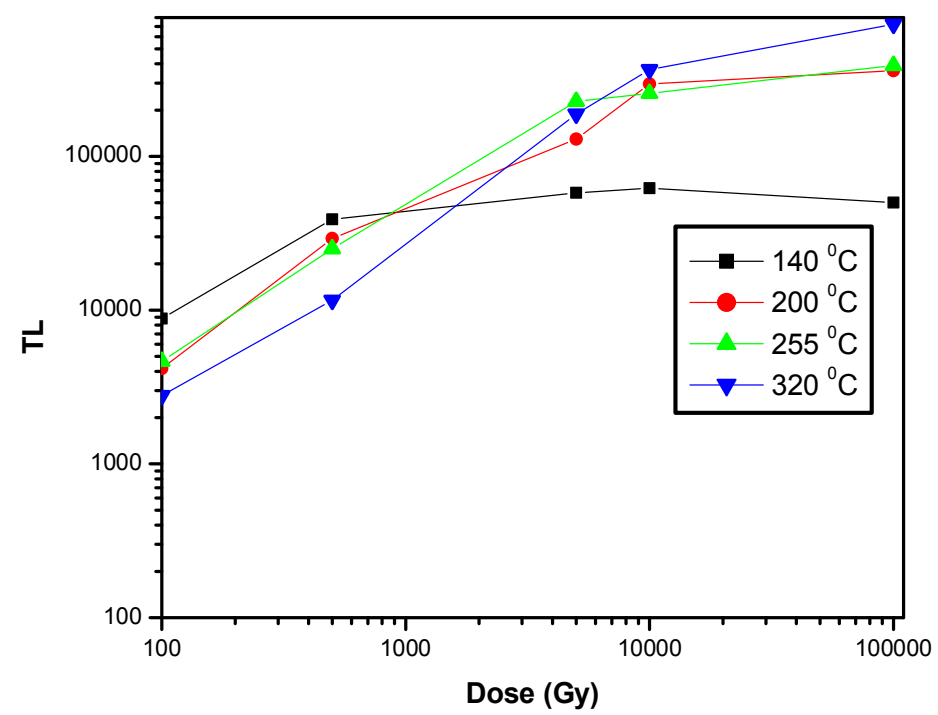

Figura 4.14: Comportamento dos picos TL da amostra sintética de rodonita natural com dose gama adicional. Taxa de aquecimento $4^{0} \mathrm{C} / \mathrm{s}$.

A comparação feita na figura 4.15 mostra uma certa similaridade entre as curvas de crescimento TL para a amostra sintética de rodonita natural e a amostra natural, tanto em termos da posição dos picos (aproximadamente), como da intensidade TL, apesar da diferença de estrutura cristalina. A diferença fica por conta das proporções entre os picos.

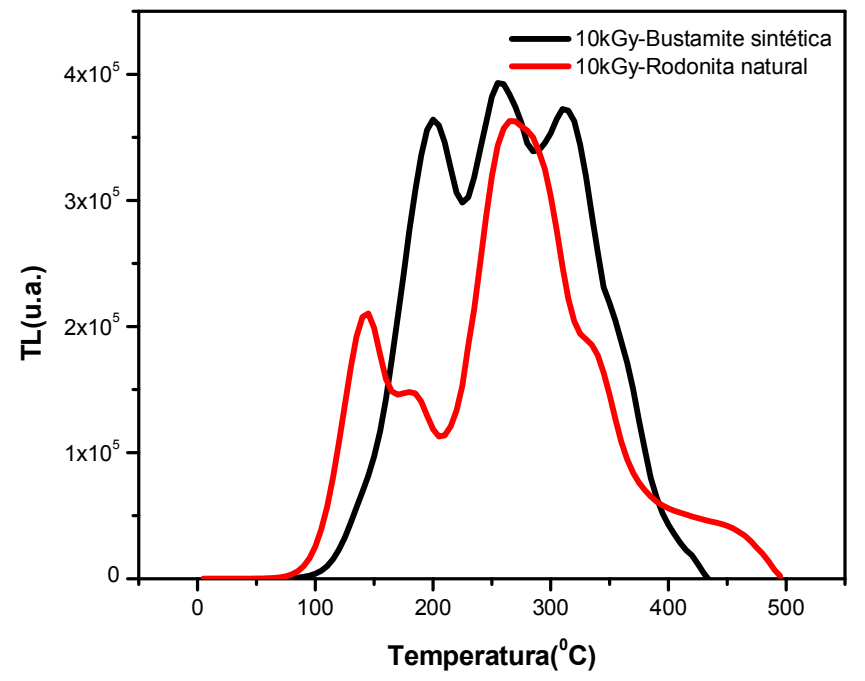

Figura 4.15: Comparação entre os espectros TL para a amostra natural de rodonita e a amostra sintética da rodonita natural. 
Como a estrutura obtida não foi a da rodonita, preparamos uma amostra com a mesma composição da rodonita natural, adicionando controladamente os óxidos necessários ( $\mathrm{MnO}, \mathrm{SiO}_{2}, \mathrm{CaO}, \mathrm{Fe}_{2} \mathrm{O}_{3}, \mathrm{Al}_{2} \mathrm{O}_{3}, \mathrm{MgO}, \mathrm{TiO}_{2}$ e $\mathrm{P}_{2} \mathrm{O}_{5}$ ). A curva de emissão TL pode ser visualizada na figura 4.16. Na figura 4.17 mostramos a curva de emissão $T L$ dessa amostra após tratamento térmico de $208^{\circ} \mathrm{C}$ por $2 \mathrm{~min}$. Podemos ver a presença clara dos picos de $280{ }^{\circ} \mathrm{C}$ e $340{ }^{\circ} \mathrm{C}$.

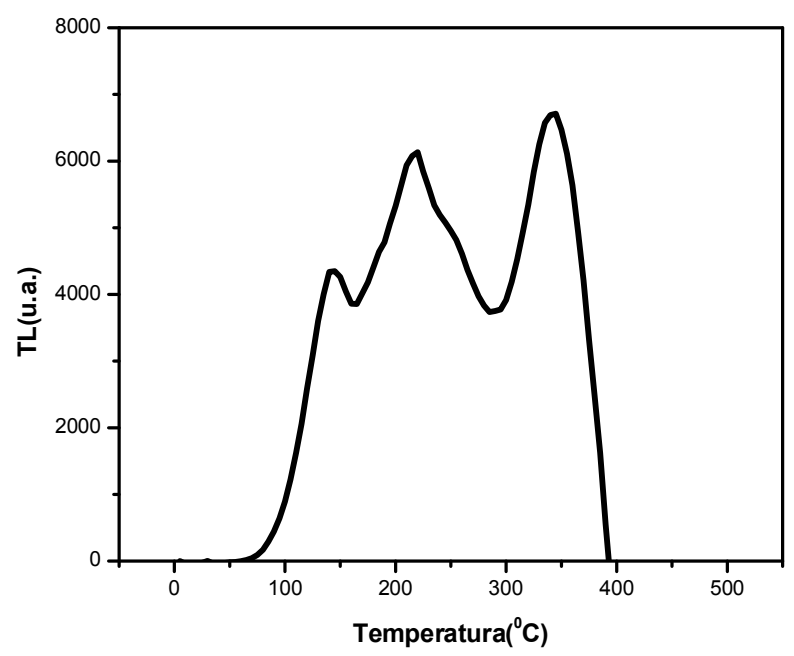

Figura 4.16: Curvas de emissão TL para amostra sintética com todos componentes com dose gama adicional de $10 \mathrm{kGy}$. Taxa de aquecimento $4^{\circ} \mathrm{C} / \mathrm{s}$.

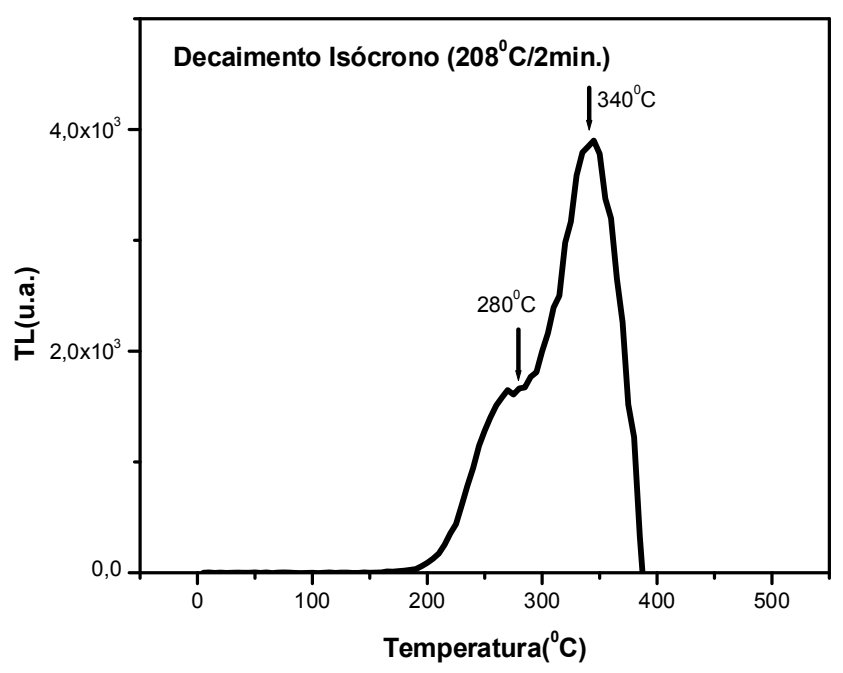

Figura 4.17 : Decaimento isócrono $\left(208^{\circ} \mathrm{C} / 2 \mathrm{~min}\right)$ dos picos $T L$ na rodonita sintética com dose adicional de $10 \mathrm{kGy}$. Taxa de aquecimento $4^{\circ} \mathrm{C} / \mathrm{s}$. 
A difração de raios - $X$ desta amostra, bem como de outras serão mostrados mais adiante. Outras amostras sintéticas foram produzidas, a primeira delas foi pura, contendo apenas $\mathrm{MnO}$ e $\mathrm{SiO}_{2}$ em proporções adequadas, em seguida produzimos outras amostras com quantidades controladas de impurezas.

\subsubsection{2 - Amostras sintéticas com diferentes composições}

Estas amostras sintéticas foram obtidas com uma composição de $\mathrm{MnSiO}_{3}$, ou seja, puras. A primeira em atmosfera ambiente e a segunda em atmosfera controlada com argônio. A verificação de que a estrutura da amostra obtida era mesmo a da rodonita foi feita através de difração de raios- $X$. A figura 4.18 mostra o difratograma da amostra obtida em atmosfera ambiente e a figura 4.19 o difratograma da amostra obtida em atmosfera controlada (com argônio) e as repectivas comparações com o padrão. Alguns picos de difração não aparecem, mas a grande maioria e os mais proeminentes estão em concordância. Na figura 4.20 mostramos uma comparação entre os difratogramas das amostras sintéticas pura (obtidas em atmosfera ambiente e em atmosfera de argônio), a amostra com todos os componentes, bem como a amostra natural.

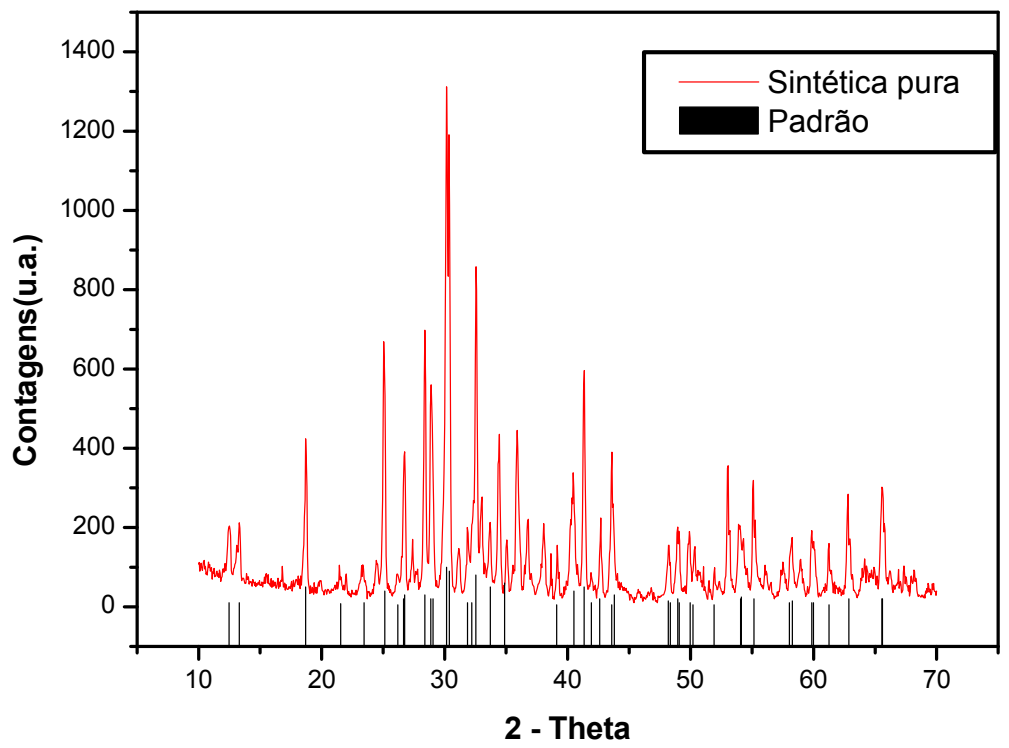

Figura 4.18: Difratograma de raios $-X$ da amostra artificial pura (MnSiO3 em atmosfera ambiente). 


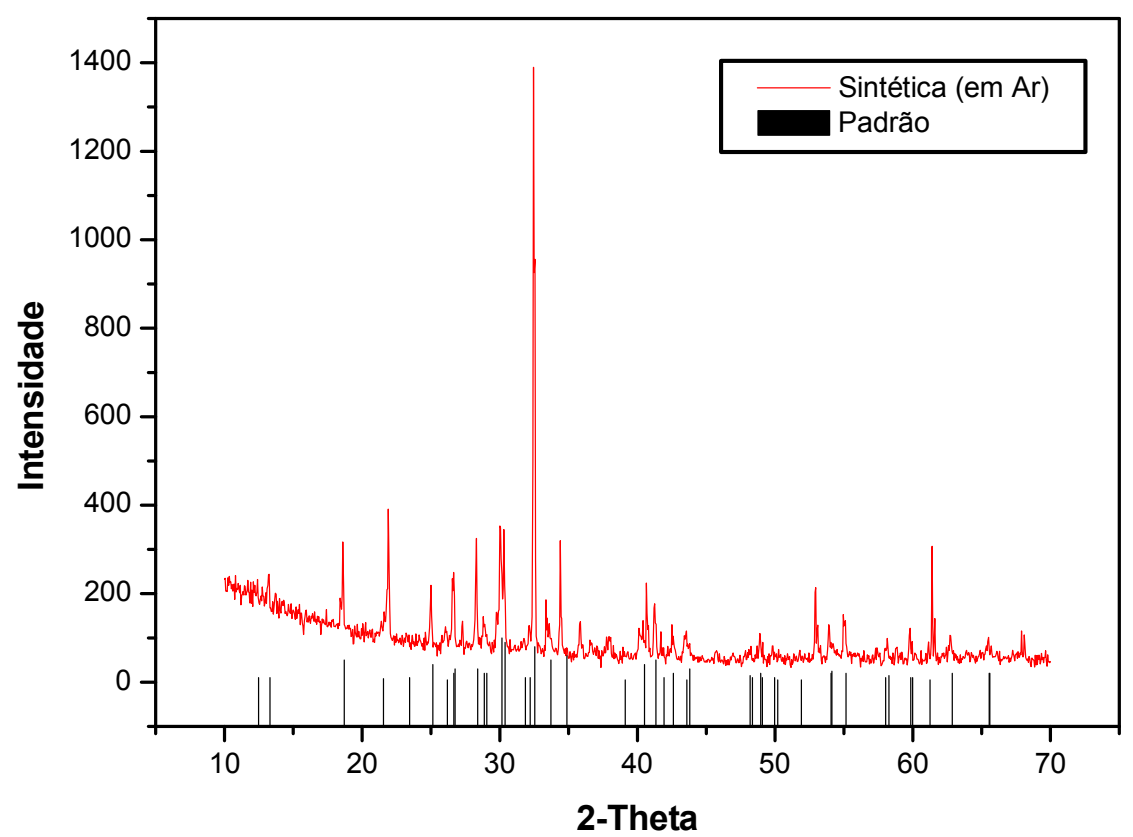

Figura 4.19: Difratograma de raios - $X$ da amostra sintética pura $\left(\mathrm{MnSiO}_{3}\right.$ em $\mathrm{Ar}$ ).

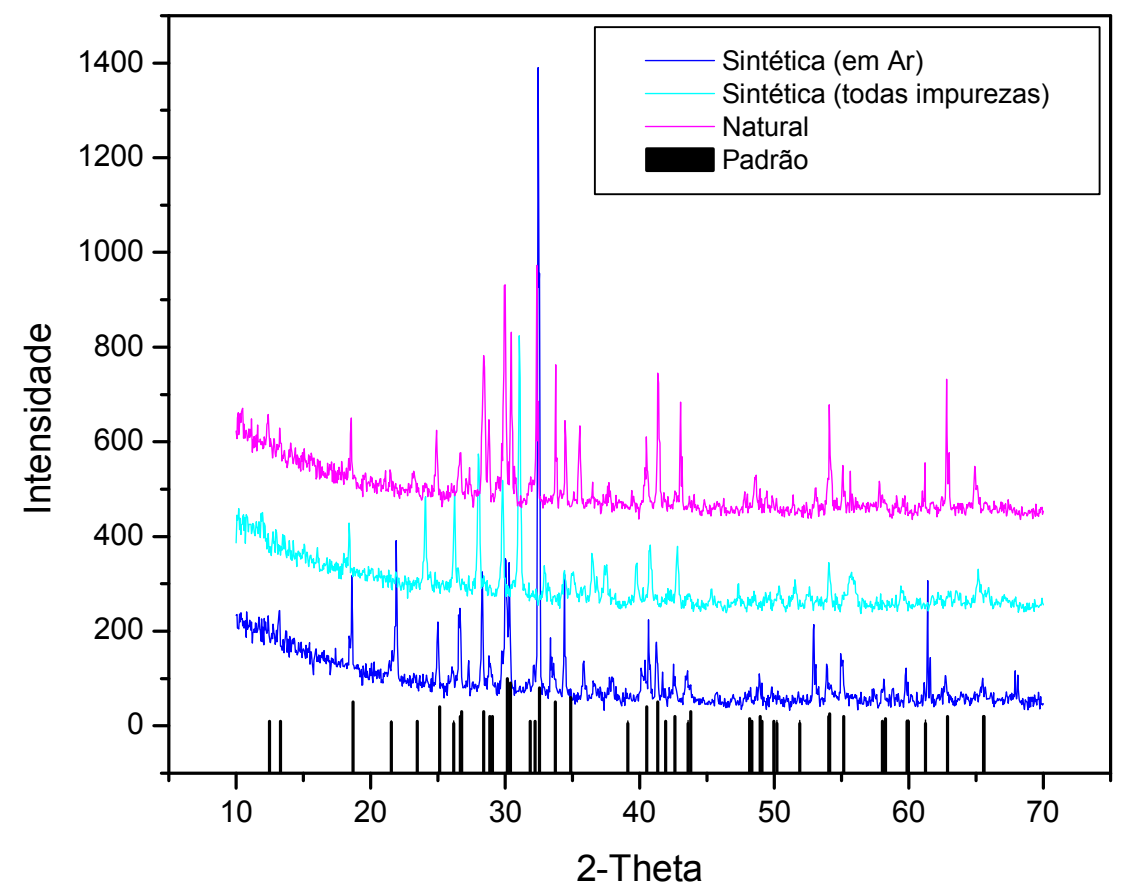

Figura 4.20: comparação entre os difratogramas de várias amostras sintéticas e a amostra natural. 
Medidas de TL foram feitas para essas amostras, a figura 4.21 mostra as curvas de emissão da amostra sintética pura $\left(\mathrm{MnSiO}_{3}\right.$ em atmosfera ambiente) sob irradiação gama. Dois picos, um em $140{ }^{\circ} \mathrm{C}$ e outro $340{ }^{\circ} \mathrm{C}$ são os mais evidentes, porém existem outros que podem estar deslocados, indicando que são devidos à estrutura e não têm origem nas impurezas, já que esta amostra foi obtida da forma mais pura possível. A intensidade TL na amostra pura (e irradiada com $10 \mathrm{kGy}$ - gama) para o pico de $340{ }^{\circ} \mathrm{C}$ é quase 280 vezes menor quando comparado ao mesmo pico da rodonita natural irradiada com mesma dose.

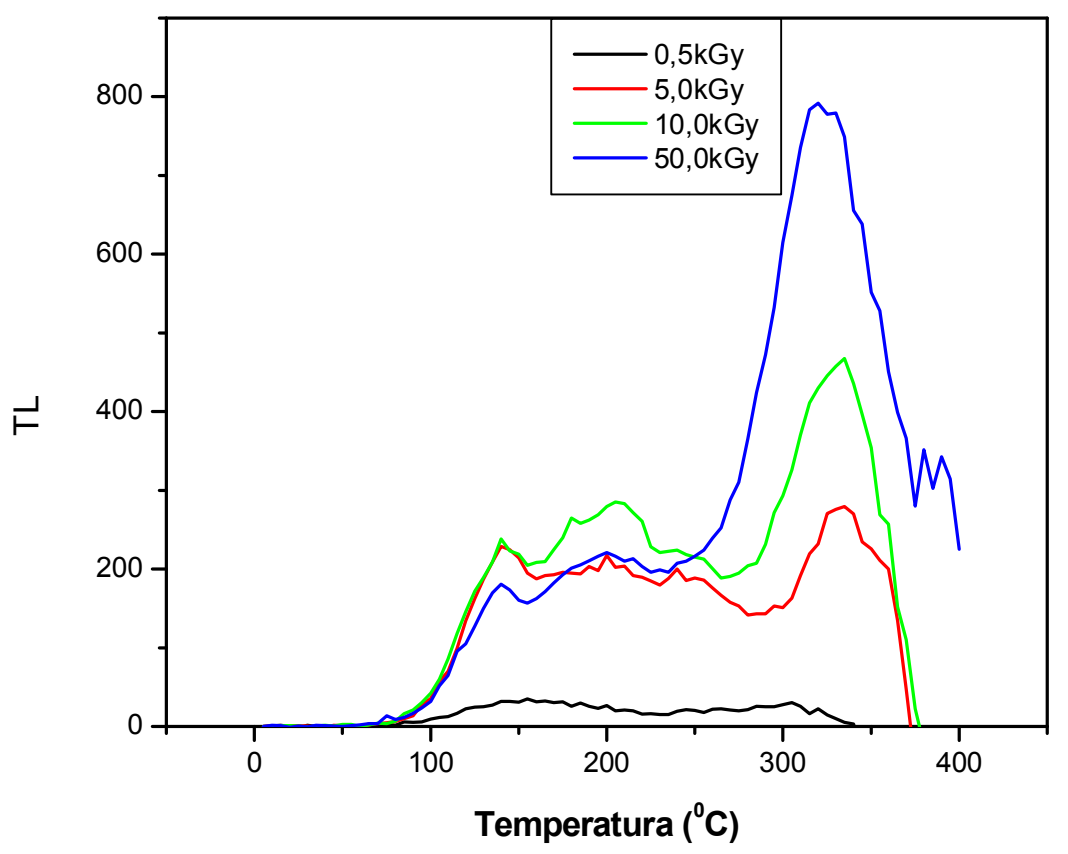

Figura 4.21: Curva de emissão TL de uma amostra de rodonita sintética $\left(\mathrm{MnSiO}_{3}\right)$ com dose gama adicional. Taxa de aquecimento $4^{0} \mathrm{C} / \mathrm{s}$.

A amostra sintética pura obtida em atmosfera de argônio foi irradiada com 10 kGy-gama e a curva de emissão obtida, a figura 4.22 mostra a medida. Aparentemente os mesmos picos que observamos na amostra sintética em atmosfera ambiente são observados na amostra em ambiente de argônio, com a diferença que a curva está melhor definida e, a intensidade TL é da ordem de $10^{4}$ vezes maior que na amostra sintética obtida em atmosfera ambiente, quando comparamos picos TL correspondentes, para uma mesma 
dose (pico de $340^{\circ} \mathrm{C}$ ). Quando comparado com a amostra natural, figura 4.5, para esse mesmo pico e dose de radiação, verificamos que tem uma intensidade TL menor e, igual a $2 / 3$ da natural.

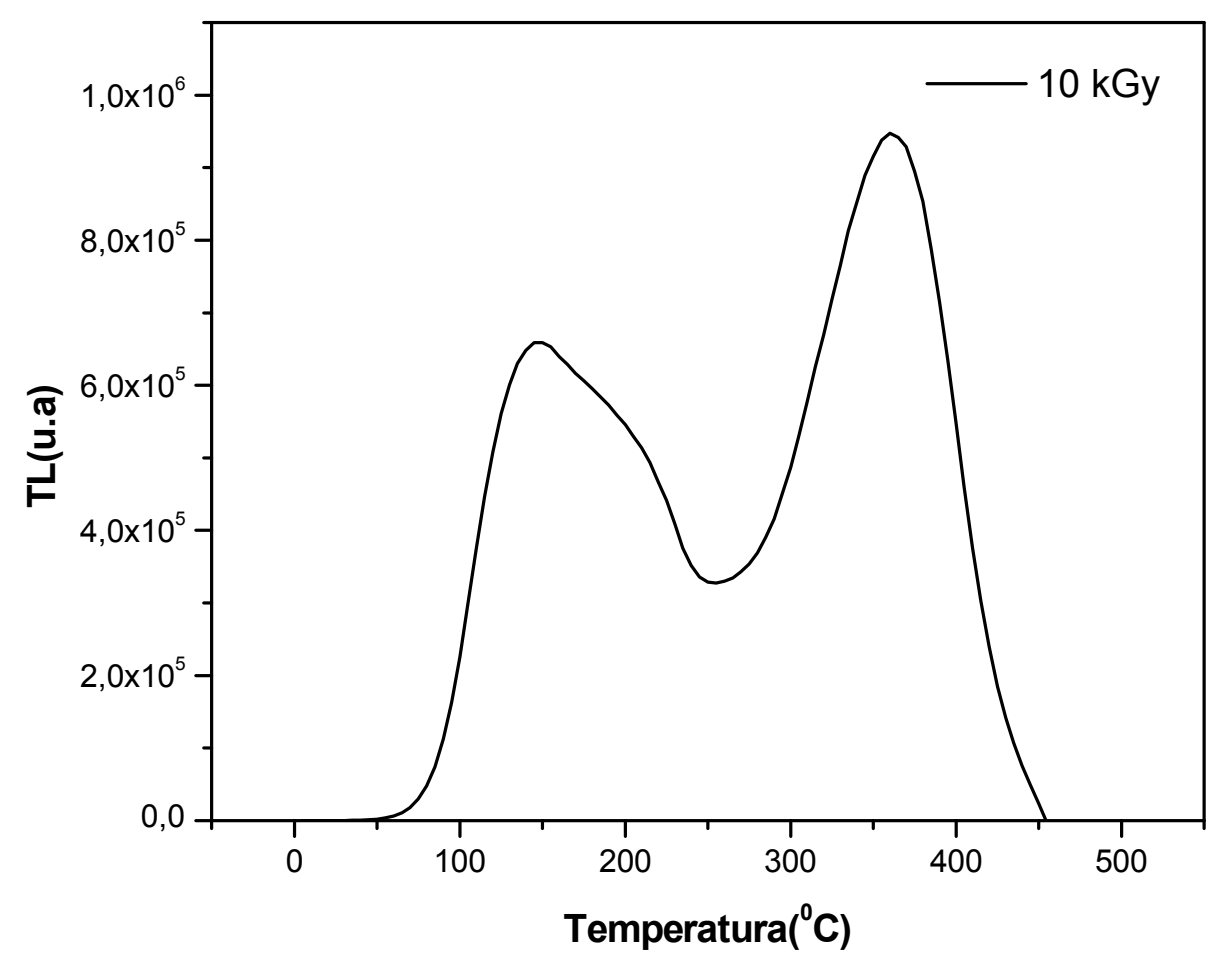

Figura 4.22: Curva de emissão $T L$ de uma amostra de rodonita sintética $\left(\mathrm{MnSiO}_{3}\right.$ em $\left.\mathrm{Ar}\right)$ com dose gama adicional de $10 \mathrm{kGy}$. Taxa de aquecimento $4^{\circ} \mathrm{C} / \mathrm{s}$.

Foram produzidas várias outras amostras sintéticas, com diferentes composições, entre elas, contendo separadamente, $\mathrm{Mg}$, $\mathrm{Fe}$, $\mathrm{Ti}$ e $\mathrm{Al}$, bem como combinações. A seguir mostramos os resultados de TL para diversas composições, bem como as curvas de crescimento dos picos em função da dose. A seguir, descrevemos as medidas TL para cada amostra sintética produzida. 


\section{$\mathrm{MnSiO}_{3}+\mathrm{Fe}_{2} \mathrm{O}_{3}$}

O primeiro dopante utilizado foi o ferro, porém quase não alterou a intensidade $\mathrm{TL}$, a não ser para o pico de $340^{\circ} \mathrm{C}$, figura 4.23 .

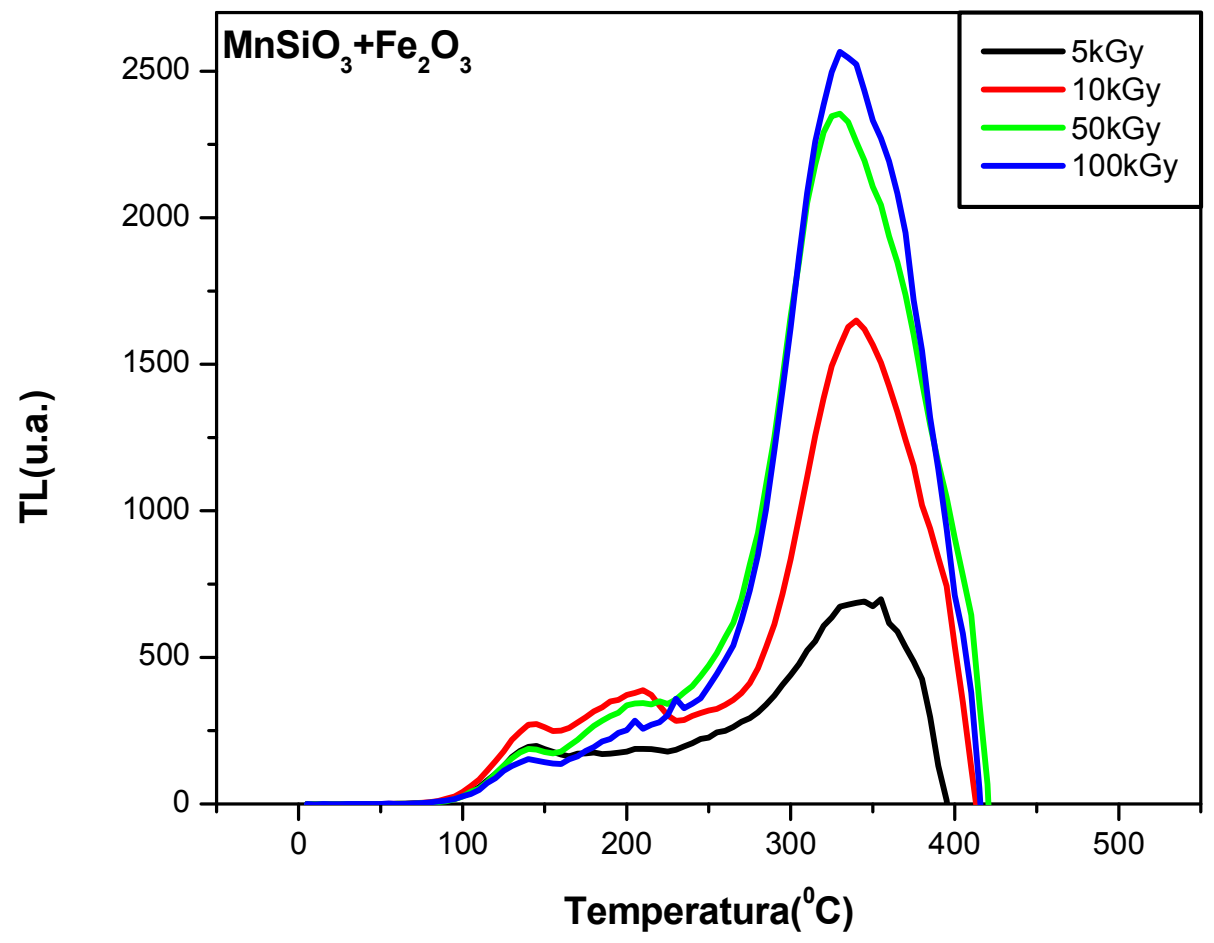

Figura 4.23: Curva de emissão TL de uma amostra de rodonita artificial dopada com $\mathrm{Fe}_{2} \mathrm{O}_{3}$ $\left(\mathrm{MnSiO}_{3}+\mathrm{Fe}_{2} \mathrm{O}_{3}\right)$ com dose gama adicional. Taxa de aquecimento $4^{\circ} \mathrm{C} / \mathrm{s}$.

$\mathrm{MnSiO}_{3}+\mathrm{CaO}$

A análise química da composição do cristal de rodonita indicou um presença de aproximadamente $9 \%$ de $\mathrm{CaO}$, dessa forma foi a segunda impureza acrescentada individualmente. Com relação ao material puro observamos um sensível aumento da intensidade TL. Os mesmos picos identificados no material puro também apareceram nessa amostra, figura 4.24. A curva de crescimento dos picos em função da dose é mostrada na figura 4.25 . 


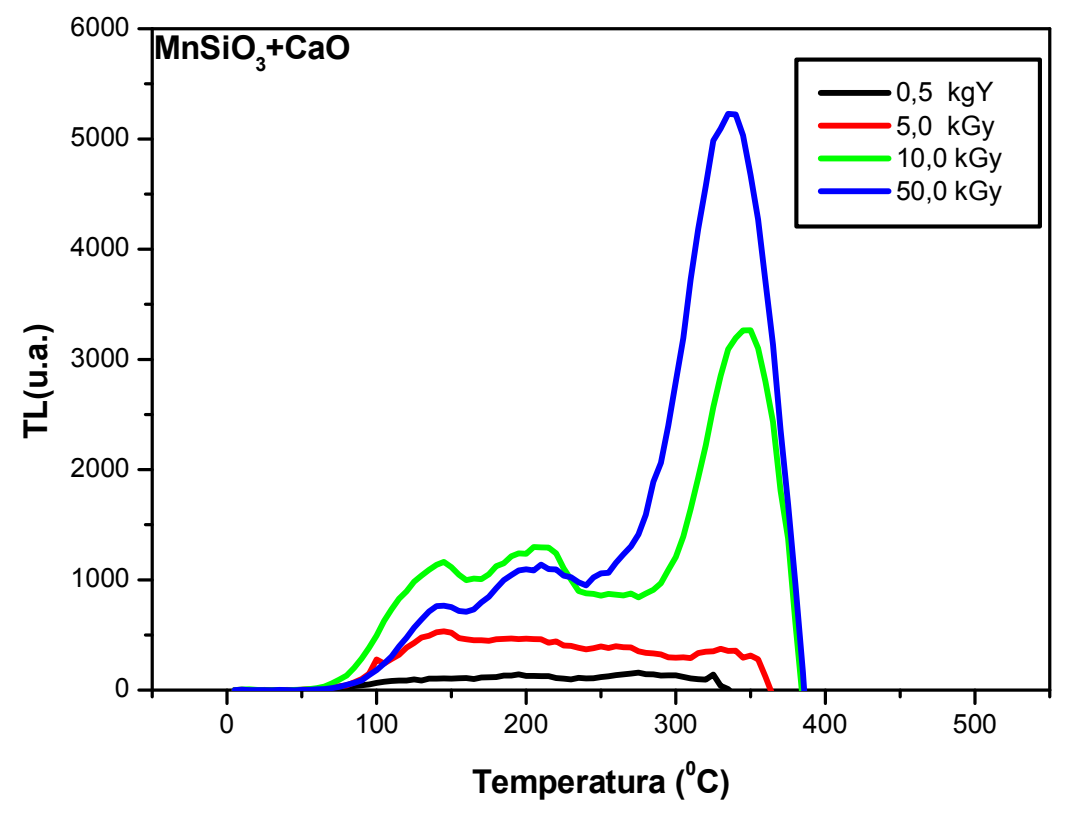

Figura 4.24: Curvas de emissão TL da amostra artificial de rodonita dopada com cálcio ( $\mathrm{MnSiO}_{3}+\mathrm{CaO}$ ) com dose gama adicional. Taxa de aquecimento $4^{\circ} \mathrm{C} / \mathrm{s}$.

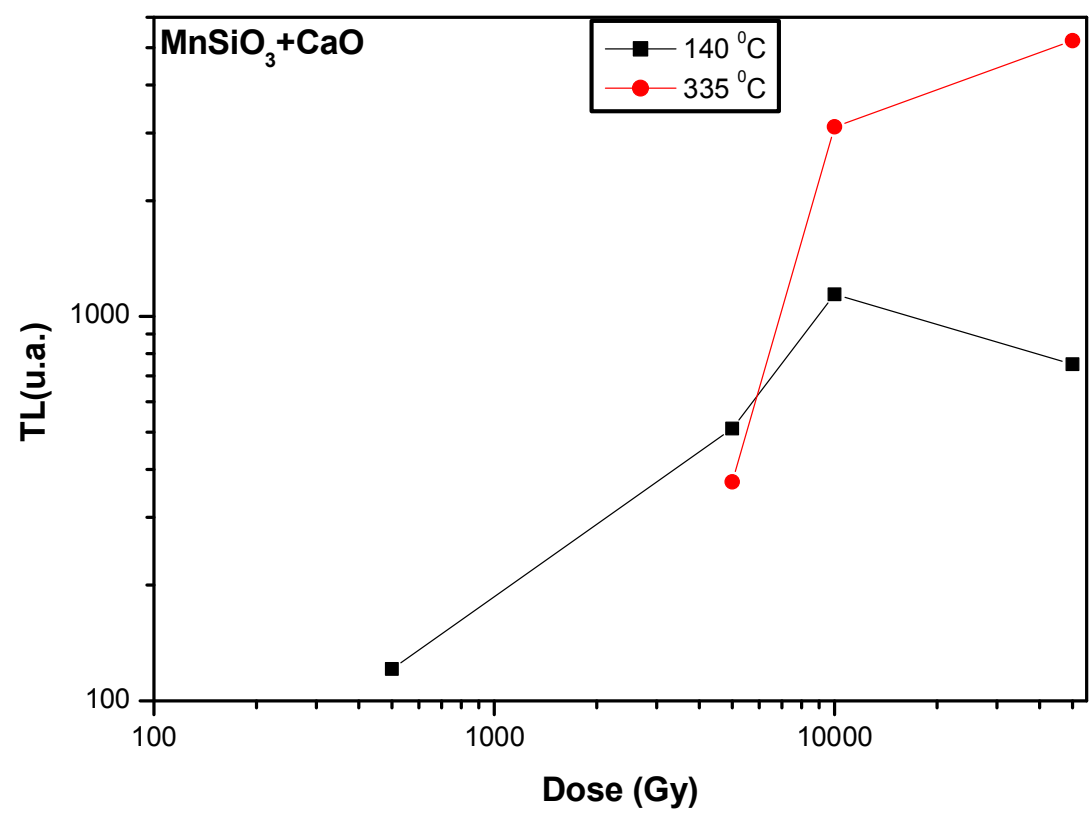

Figura 4.25: Comportamento dos picos TL da amostra artificial de rodonita dopada com cálcio $\left(\mathrm{MnSiO}_{3}+\mathrm{CaO}\right)$ com dose gama adicional. Taxa de aquecimento $4^{0} \mathrm{C} / \mathrm{s}$. 


\section{$\mathrm{MnSiO}_{3}+\mathrm{TiO}_{2}$}

A quantidade de $\mathrm{TiO}_{2}$ é da ordem de ppm, de acordo com a análise química da composição, porém o efeito sobre a sensibilidade TL é bem visível, figura 4.26, onde o efeito é levemente maior que a inclusão do $\mathrm{CaO}$. Dois picos, um em $140^{\circ} \mathrm{C}$ e outro em $340^{\circ} \mathrm{C}$ estão claramente definidos, tal como na amostra pura e na amostra dopada com $\mathrm{CaO}$. $\mathrm{Na}$ figura 4.27 , tem-se a curva de crescimento dos picos em função da dose.

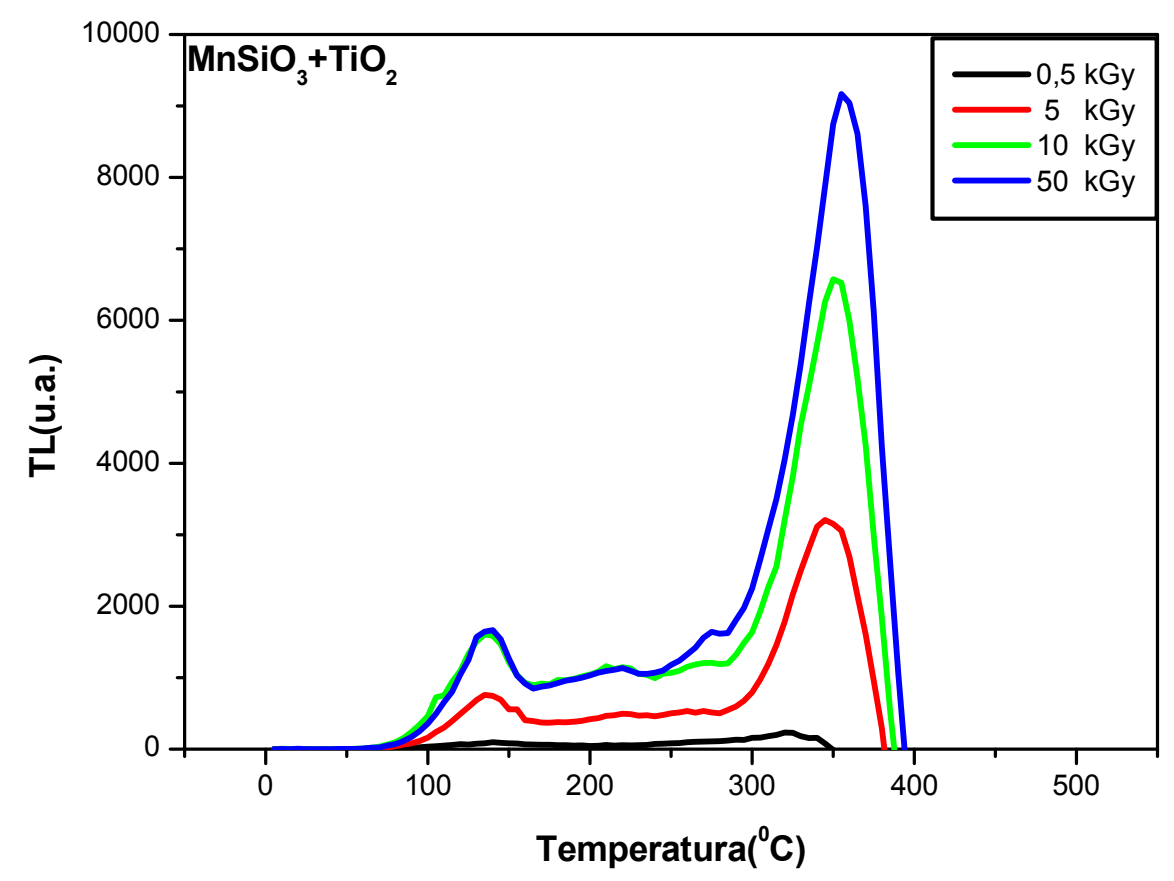

Figura 4.26: Curvas de emissão TL da amostra artificial de rodonita dopada com titânio $\left(\mathrm{MnSiO}_{3}+\mathrm{TiO}_{2}\right)$ 


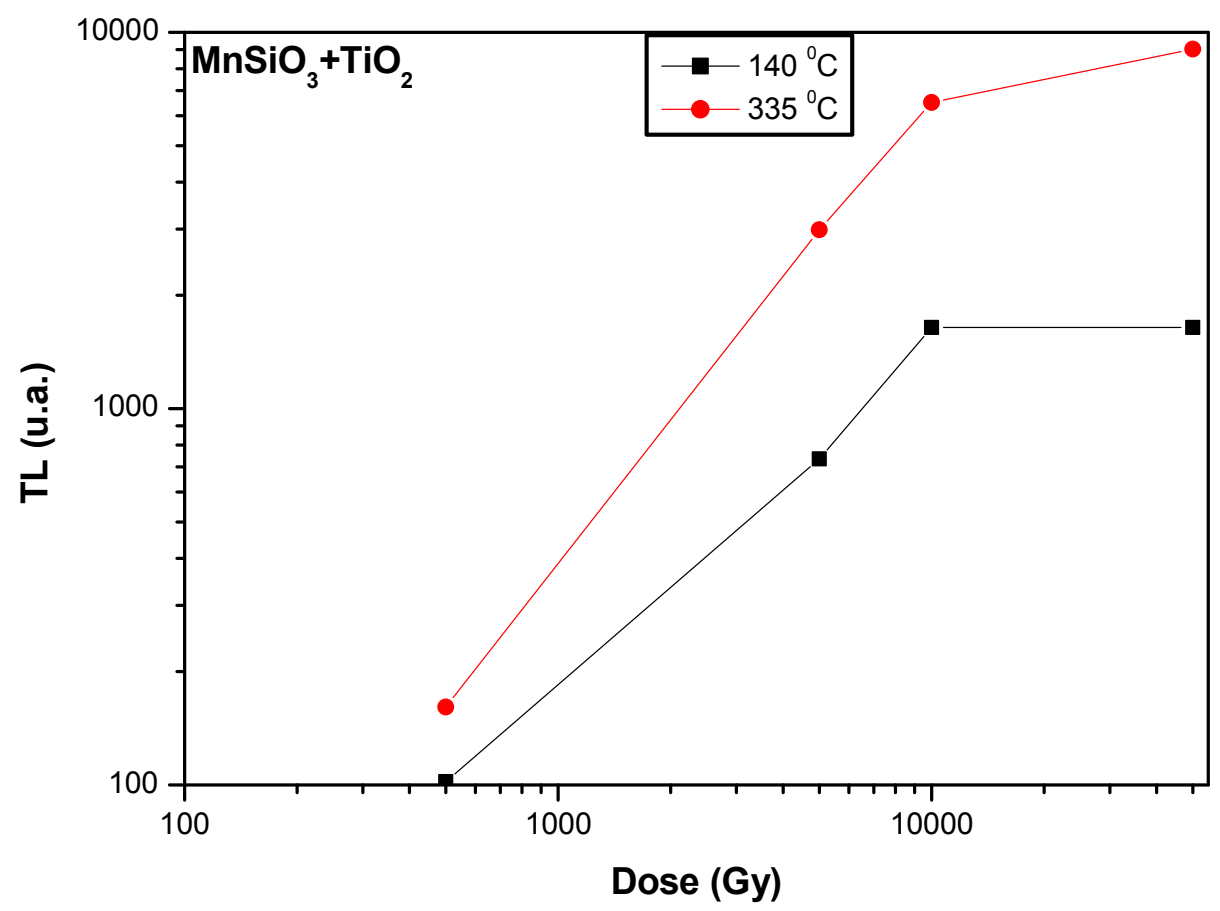

Figura 4.27: Comportamento dos picos TL da amostra artificial de rodonita dopada com titânio $\left(\mathrm{MnSiO}_{3}+\mathrm{TiO}_{2}\right)$ com dose gama adicional. Taxa de aquecimento $4^{0} \mathrm{C} / \mathrm{s}$.

\section{$\mathrm{MnSiO}_{3}+\mathrm{MgO}$}

O inclusão de $\mathrm{MgO}$ se dá basicamente pela grande quantidade encontrada na composição da amostra natural (2,78\% em massa). Aqui os resultados são também muito próximos aos encontrados no caso dos dopantes, $\mathrm{CaO}$ e $\mathrm{TiO}_{2}$, em termos de intensidade TL e posição de picos, figura 4.28. Na figura 4.29 tem-se a curva de crescimento dos picos em função da dose. 


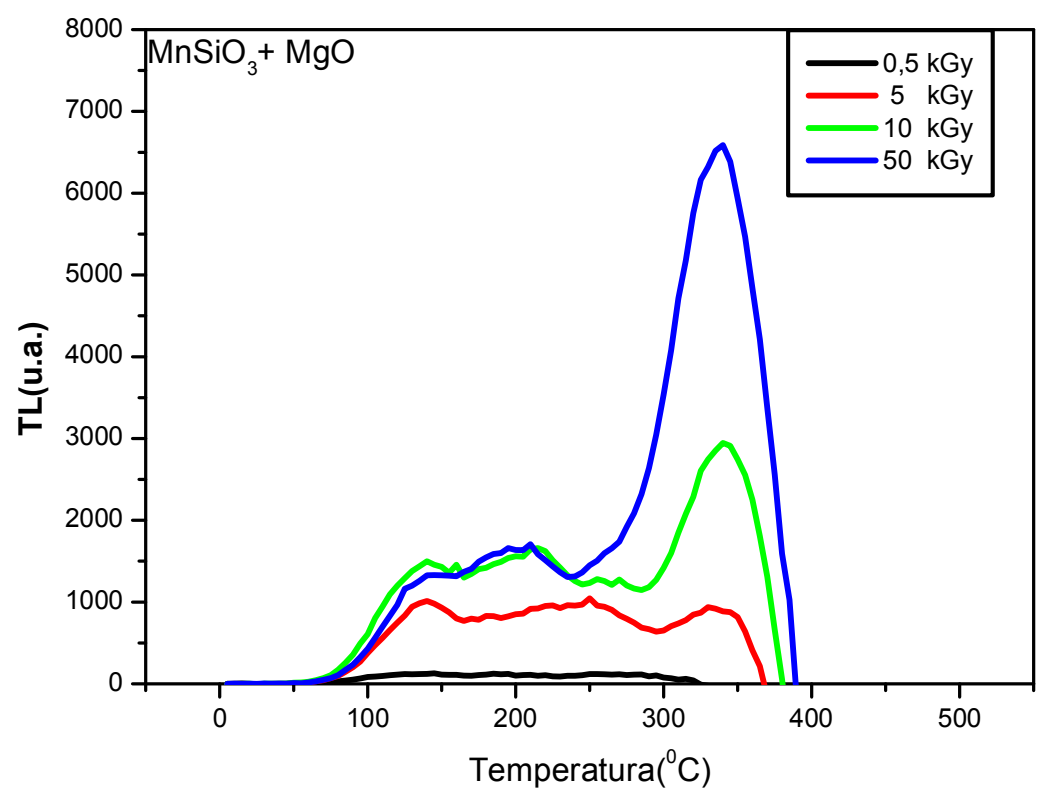

Figura 4.28: Curvas de emissão TL para a amostra artificial dopada com MgO ( $\mathrm{MnSiO}_{3}+\mathrm{MgO}$ ) com dose gama adicional. Taxa de aquecimento $4^{0} \mathrm{C} / \mathrm{s}$.

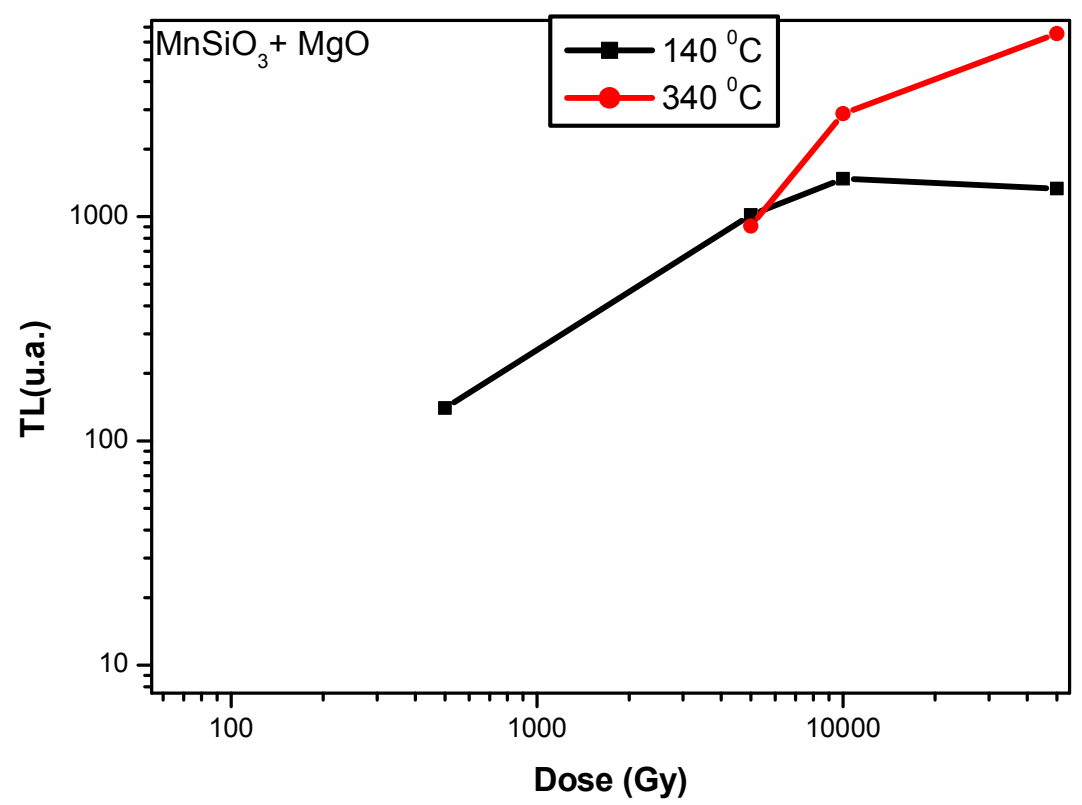

Figura 4.29: Comportamento dos picos TL da amostra artificial de rodonita dopada com magnésio $\left(\mathrm{MnSiO}_{3}+\mathrm{MgO}\right)$ com dose gama adicional. Taxa de aquecimento $4^{0} \mathrm{C} / \mathrm{s}$. 


\section{$\mathrm{MnSiO}_{3}+\mathrm{Al}_{2} \mathrm{O}_{3}$}

A amostra natural contém aproximadamente $1,64 \%$ de $\mathrm{Al}_{2} \mathrm{O}_{3} \mathrm{e}$, apesar de não ser a impureza encontrada em maior quantidade, aumenta sensivelmente a sensibilidade TL, principalmente do pico de $140{ }^{\circ} \mathrm{C}$, mostrando que este pico de ordem estrutural tem sua sensibilidade TL alterada pela presença do alumínio, figura 4.30. Comparando com a amostra natural é possível ver que a intensidade TL para o pico de $140^{\circ} \mathrm{C}$ e dose de $10 \mathrm{kGy}$ é menor por um fator de 8 . Na figura 4.31 tem-se a curva de crescimento dos picos em função da dose.

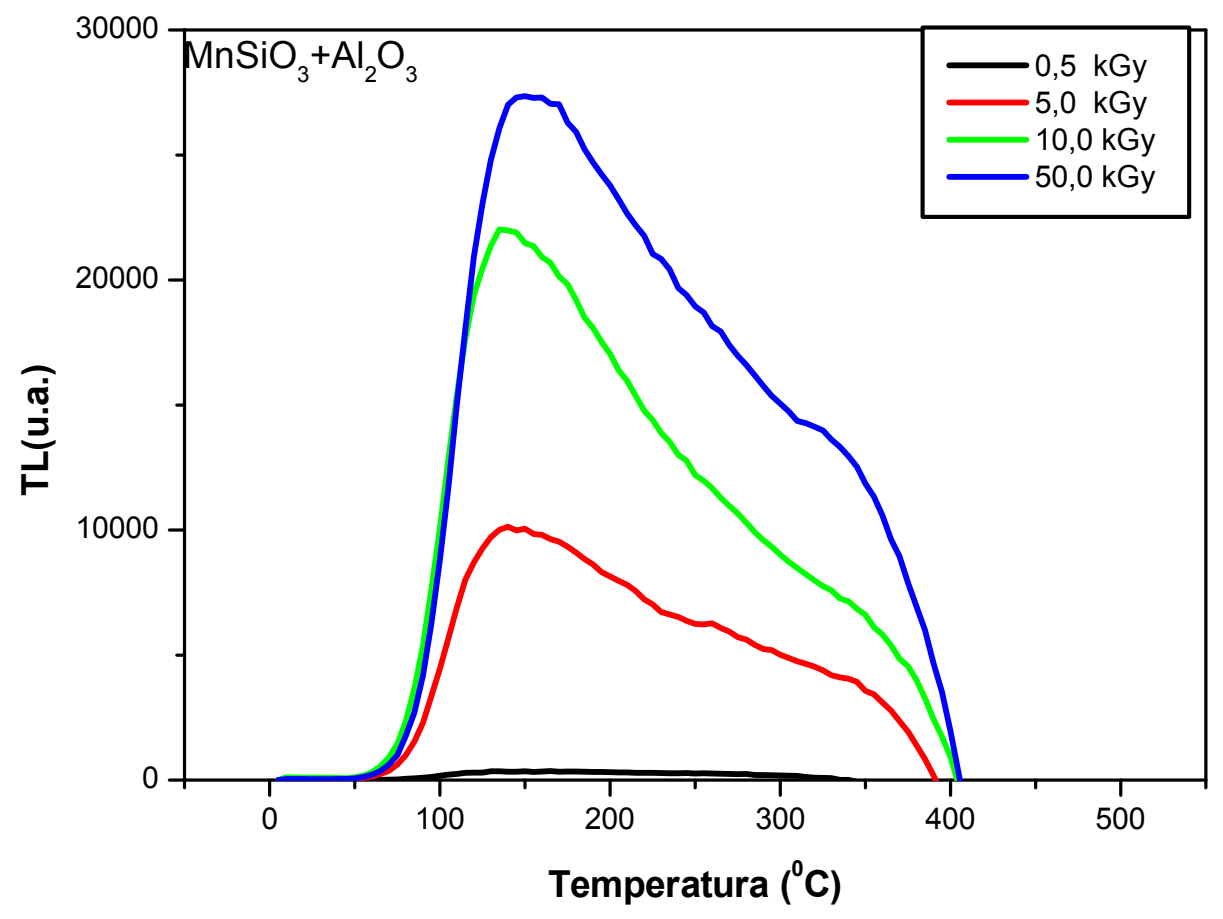

Figura 4.30: Curvas de emissão TL da amostra artificial de rodonita dopada com alumínio $\left(\mathrm{MnSiO}_{3}+\mathrm{Al}_{2} \mathrm{O}_{3}\right.$ ) com dose gama adicional. Taxa de aquecimento $4^{\circ} \mathrm{C} / \mathrm{s}$. 


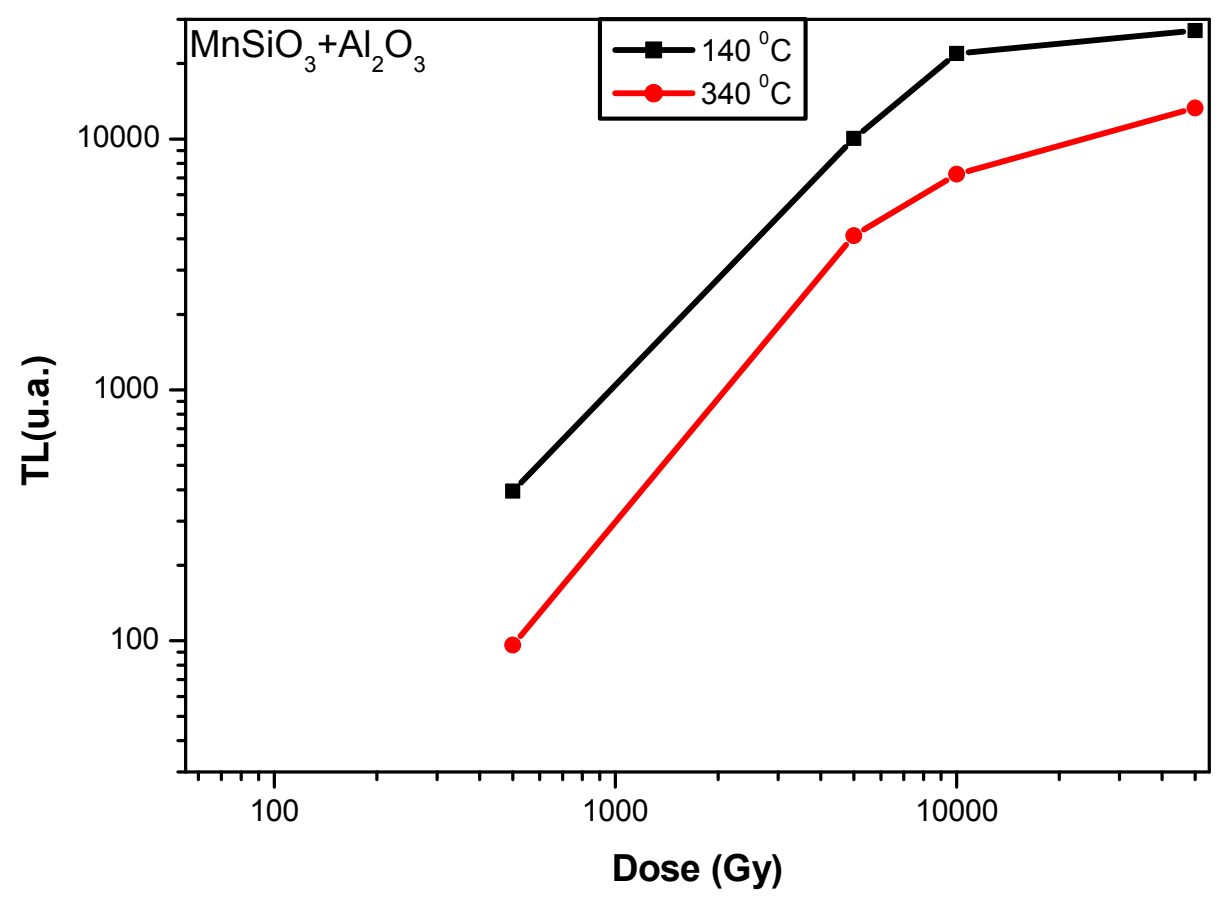

Figura 4.31: Comportamento dos picos TL da amostra artificial de rodonita dopada com alumínio $\left(\mathrm{MnSiO}_{3}+\mathrm{Al}_{2} \mathrm{O}_{3}\right.$ ) com dose gama adicional. Taxa de aquecimento $4^{\circ} \mathrm{C} / \mathrm{s}$.

\section{$\mathrm{MnSiO}_{3}+\mathrm{Al}_{2} \mathrm{O}_{3}+\mathrm{MgO}$}

Os melhores resultados em termos de sensibilidade $T L$ foram obtidos adicionando $\mathrm{Al}_{2} \mathrm{O}_{3}$, sendo assim, resolvemos manter como base $\mathrm{MnSiO}_{3}+\mathrm{Al}_{2} \mathrm{O}_{3}$ e adicionar outras impurezas. A primeira a ser testada foi o $\mathrm{MgO}$, a curva de emissão TL pode ser vista na figura 4.32. Na figura 4.33 tem-se a curva de crescimento dos picos em função da dose. 


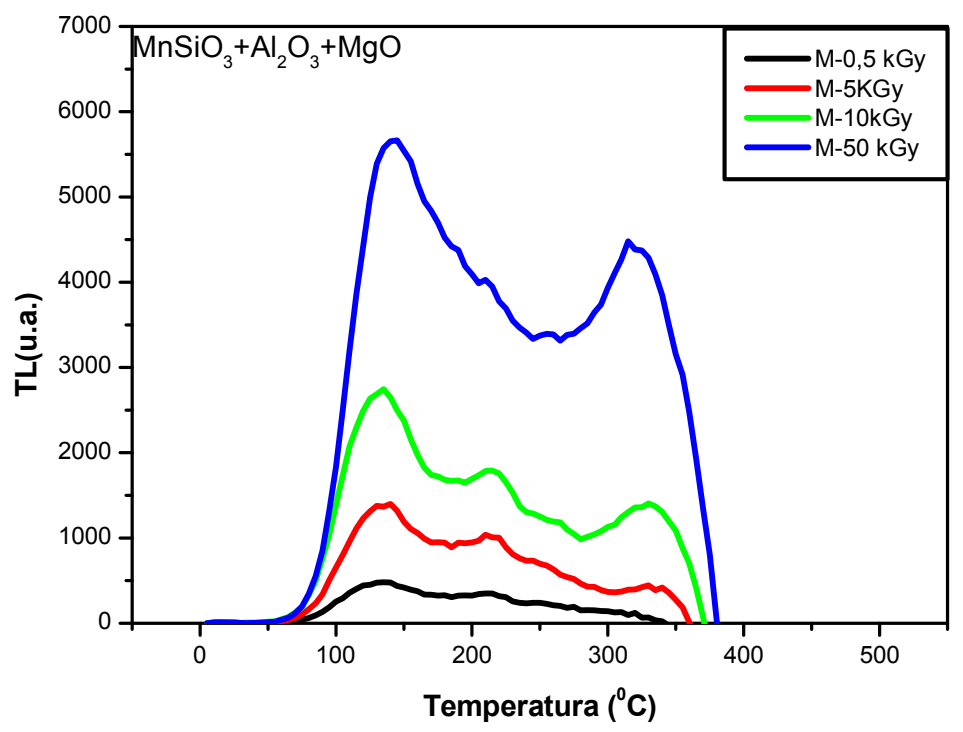

Figura 4.32: Curvas de emissão TL da amostra artificial de rodonita dopada com alumínio e magnésio $\left(\mathrm{MnSiO}_{3}+\mathrm{Al}_{2} \mathrm{O}_{3}+\mathrm{MgO}\right.$ ) com dose gama adicional. Taxa de aquecimento $4^{0} \mathrm{C} / \mathrm{s}$.

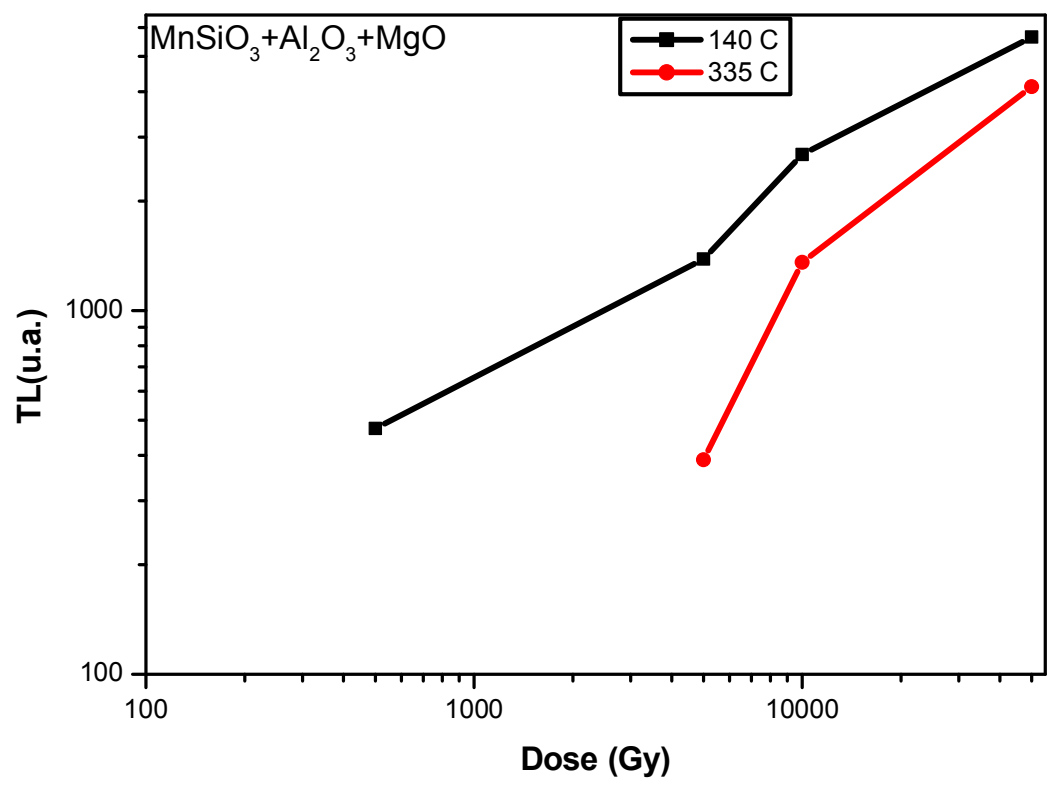

Figura 4.33: Comportamento dos picos TL da amostra artificial de rodonita dopada com alumínio e magnésio $\left(\mathrm{MnSiO}_{3}+\mathrm{Al}_{2} \mathrm{O}_{3}+\mathrm{MgO}\right)$ com dose gama adicional. Taxa de aquecimento $4^{\circ} \mathrm{C} / \mathrm{s}$. 


\section{$\mathrm{MnSiO}_{3}+\mathrm{Al}_{2} \mathrm{O}_{3}+\mathrm{Fe}_{2} \mathrm{O}_{3}$}

No caso da amostra $\mathrm{MnSiO}_{3}+\mathrm{Fe}_{2} \mathrm{O}_{3}$, figura 4.23 o pico de $140{ }^{\circ} \mathrm{C}$ praticamente não aparece, porém com adição de $\mathrm{Al}_{2} \mathrm{O}_{3}$ ocorre um aumento considerável da sensibilidade TL para este pico, figura 4.34. Na figura 4.35 tem-se a curva de crescimento dos picos em função da dose.

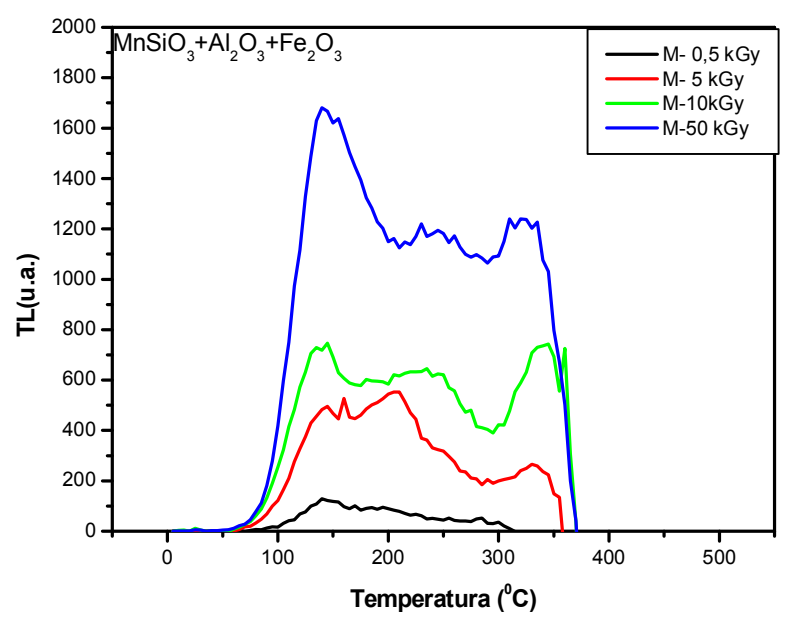

Figura 4.34: Curvas de emissão TL da amostra artificial de rodonita dopada com alumínio e ferro $\left(\mathrm{MnSiO}_{3}+\mathrm{Al}_{2} \mathrm{O}_{3}+\mathrm{Fe}_{2} \mathrm{O}_{3}\right)$ com dose gama adicional. Taxa de aquecimento $4^{\circ} \mathrm{C} / \mathrm{s}$.

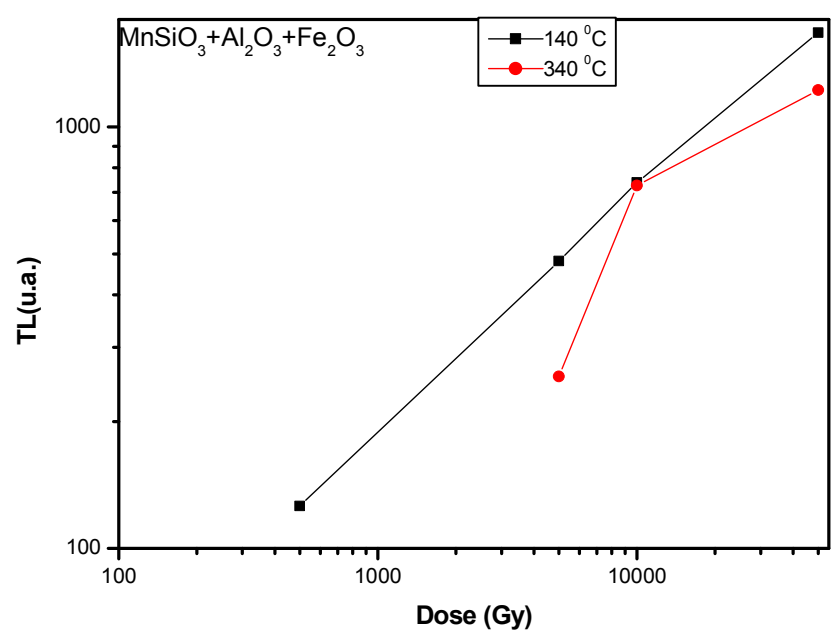

Figura 4.35: Comportamento dos picos TL da amostra artificial de rodonita dopada com alumínio e ferro $\left(\mathrm{MnSiO}_{3}+\mathrm{Al}_{2} \mathrm{O}_{3}+\mathrm{Fe}_{2} \mathrm{O}_{3}\right)$ com dose gama adicional. Taxa de aquecimento $4^{0} \mathrm{C} / \mathrm{s}$. 


\section{$\mathrm{MnSiO}_{3}+\mathrm{Al}_{2} \mathrm{O}_{3}+\mathrm{CaO}$}

Os melhores resultados, em termos de TL foram obtidos com a composição $\mathrm{MnSiO}_{3}+\mathrm{Al}_{2} \mathrm{O}_{3}+\mathrm{CaO}$. O pico de $140{ }^{\circ} \mathrm{C}$ tem um aumento de sensibilidade TL elevada, figura 4.36. Na figura 4.37, tem-se a curva de crescimento dos picos em função da dose. A intensidade TL aumenta por um fator de 1400 (pico $140^{\circ} \mathrm{C}$ ) quando comparado com o caso puro e, 50 quando comparado com a amostra dopada somente com $\mathrm{Al}_{2} \mathrm{O}_{3}$, figura 4.38.

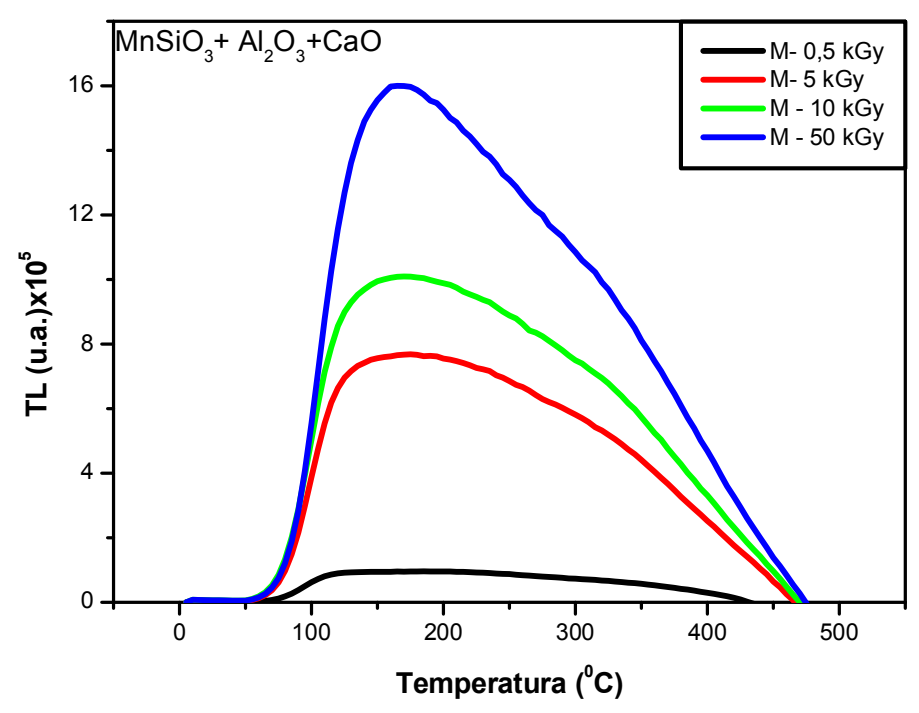

Figura 4.36: Curvas de emissão TL da amostra artificial de rodonita dopada com alumínio e cálcio $\left(\mathrm{MnSiO}_{3}+\mathrm{Al}_{2} \mathrm{O}_{3}+\mathrm{CaO}\right)$ com dose gama adicional. Taxa de aquecimento $4^{\circ} \mathrm{C} / \mathrm{s}$. 


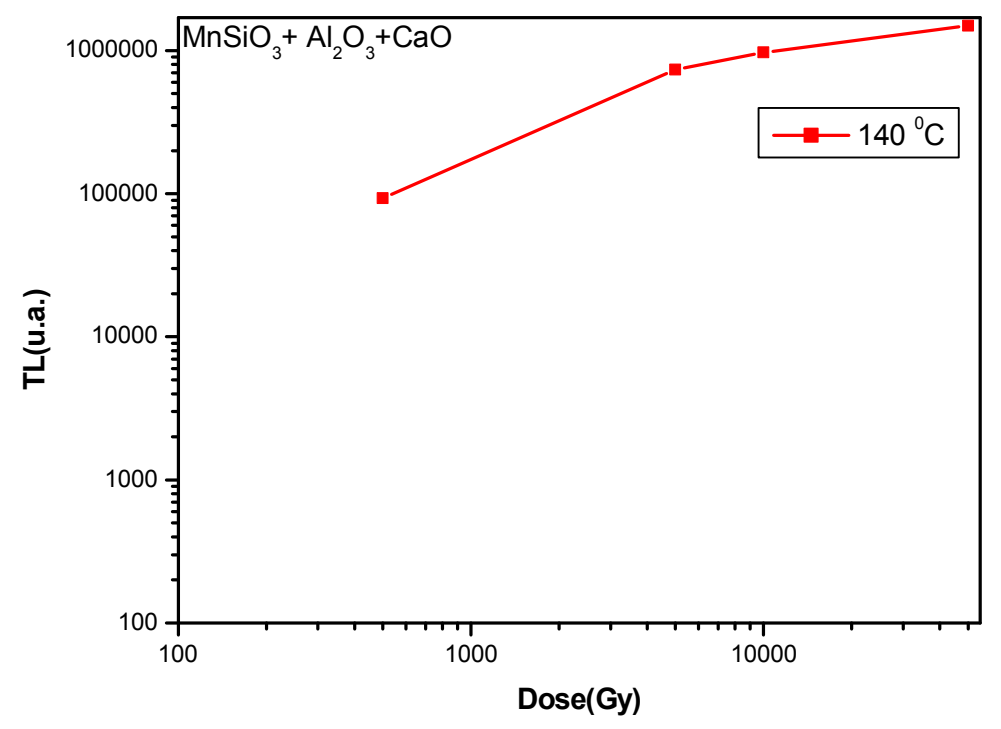

Figura 4.37: Comportamento dos picos $T L$ da amostra artificial de rodonita dopada com alumínio e cálcio $\left(\mathrm{MnSiO}_{3}+\mathrm{Al}_{2} \mathrm{O}_{3}+\mathrm{CaO}\right)$ com dose gama adicional. Taxa de aquecimento $4^{0} \mathrm{C} / \mathrm{s}$.

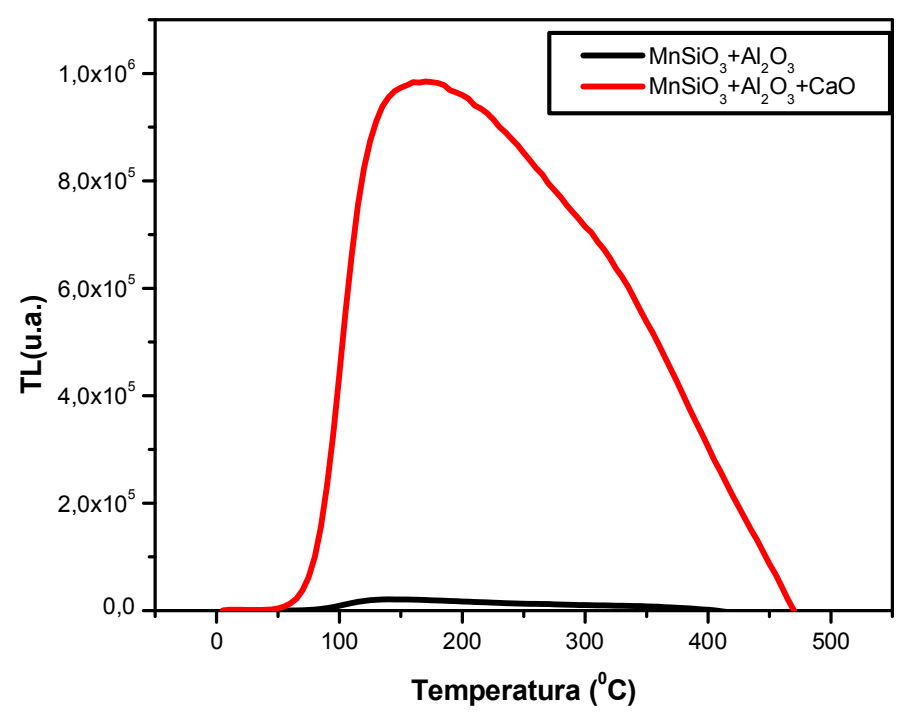

Figura 4.38: Comparativo entre intensidades TL de amostras artificiais. 
Para termos uma idéia do efeito produzido pela presença das impurezas, a figura 4.39 mostra a TL para alguns destes policristais irradiados com $10 \mathrm{kGy}$.

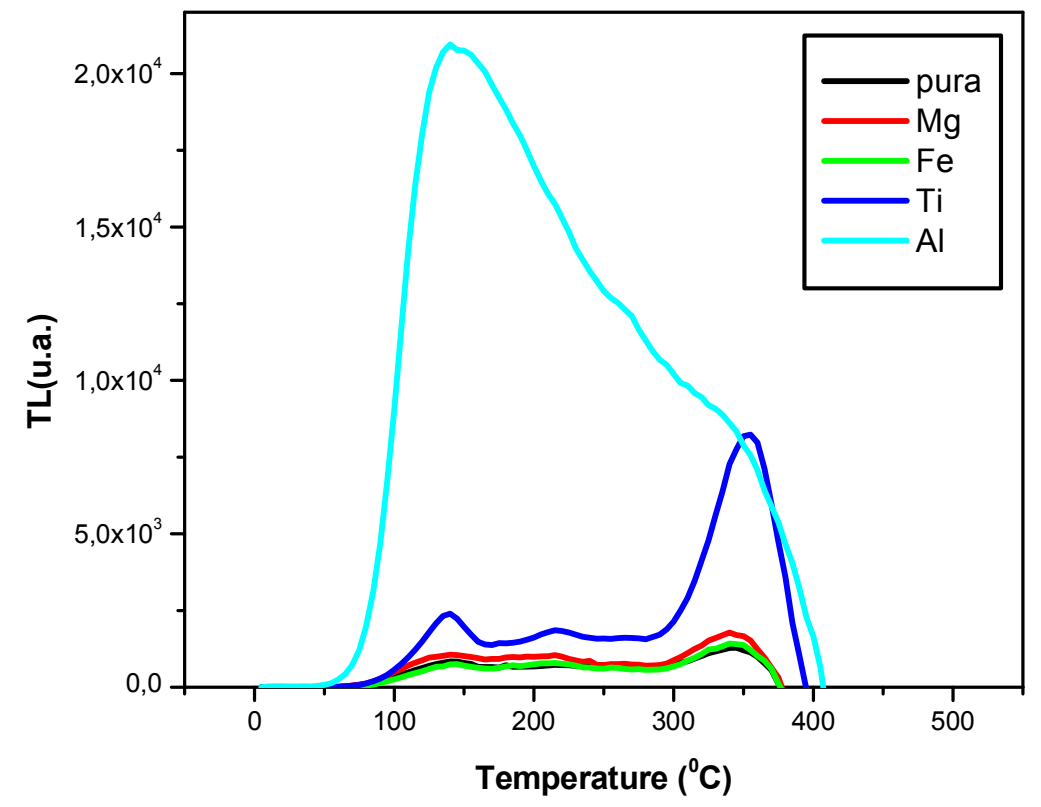

Figura 4.39: Comparativo entre intensidades TL de diversas amostras artificiais dopadas com diferentes impurezas. 


\section{3 - Absorção óptica}

Através do espectro de absorção óptica de lâminas finas de rodonita natural cor de rosa, identificamos várias bandas, sendo uma larga estendendo-se de $820 \mathrm{~nm}$ a $1300 \mathrm{~nm}$ no infravermelho e centrada em $1040 \mathrm{~nm}$, que segundo Manning (1969) é atribuida ao $\mathrm{Fe}^{2+}$, e outra banda larga estendendo-se de $500 \mathrm{~nm}$ a $600 \mathrm{~nm}$ e centrada em cerca de $540 \mathrm{~nm}$, atribuída ao $\mathrm{Mn}^{3+}$, Gibbons et al. (1974). Várias bandas estreitas foram também detectadas em $344,357,367,410,415 \mathrm{~nm}$, figuras 4.40 e 4.41 .

Lâminas foram irradiadas com doses entre 0,5 kGy e 300 kGy, porém nenhuma alteração no espectro foi verificada. Para lâminas submetidas ao aquecimento entre a temperatura ambiente e $5000 \mathrm{C}$, verificou-se que o fundo de absorção começa a crescer muito a partir de cerca de $400{ }^{\circ} \mathrm{C}$ e as bandas de absorção acima mencionadas começam a ser encobertas. Somente vestígios dessas bandas ainda são observáveis em $500{ }^{\circ} \mathrm{C}$, com o cristal tornando-se escuro, figura 4.42. Na figura 4.43 mostramos os detalhes das bandas, entre $200 \mathrm{~nm}$ e $600 \mathrm{~nm}$. Na figura 4.44 , mostramos os efeitos do tratamento térmico ( 1 hora) sobre as bandas, para temperaturas entre 600 e $1000^{\circ} \mathrm{C}$.

As bandas de absorção associadas ao $\mathrm{Mn}^{2+}$ e ao $\mathrm{Mn}^{3+}$ (entre 300 e $600 \mathrm{~nm}$ ) diminuem após aquecimento acima de $400{ }^{\circ} \mathrm{C}$, todavia, a banda associada ao $\mathrm{Fe}^{2+}$ diminui mesmo com aquecimentos abaixo de $200^{\circ} \mathrm{C}$. Na figura 4.45 , podemos ver que até $300^{\circ} \mathrm{C}$ as bandas de $540 \mathrm{~nm}$ têm mesma intensidade e a partir de $400{ }^{\circ} \mathrm{C}$ o fundo aumenta e a banda de $540 \mathrm{~nm}$ diminui. 


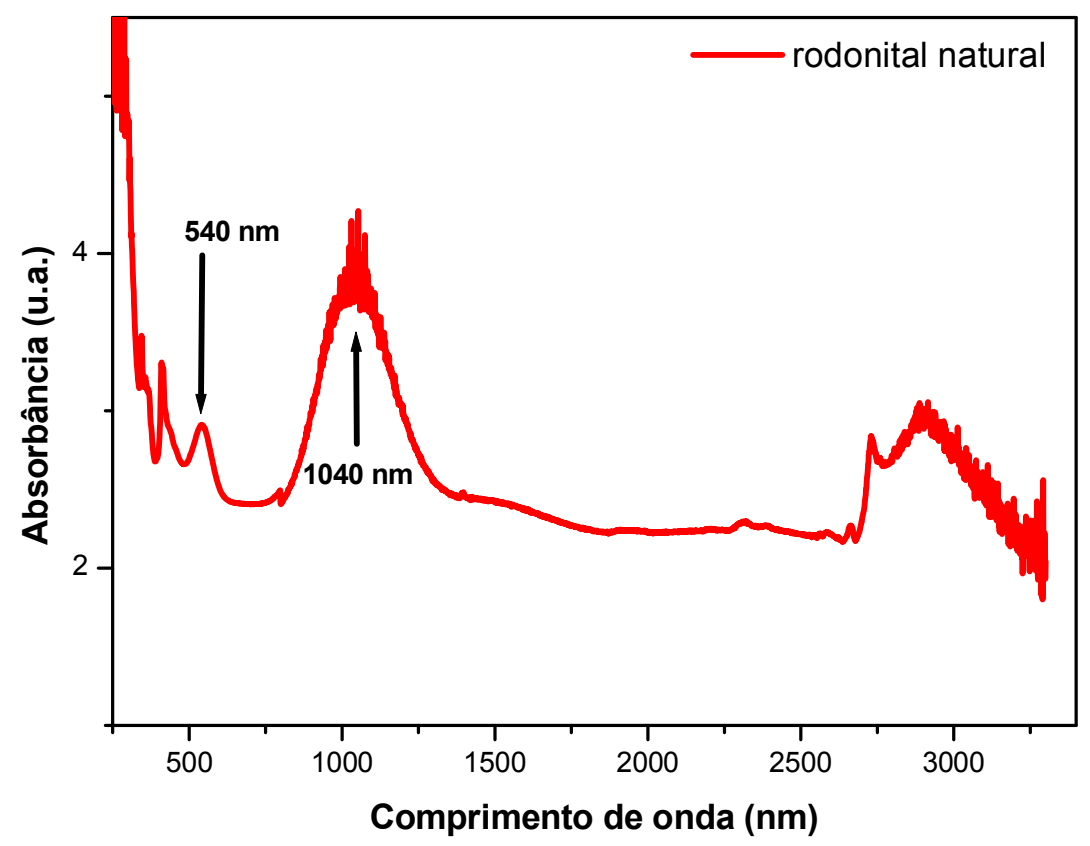

Figura 4.40: Espectro de absorção óptica da rodonita natural( lâmina com $1 \mathrm{~mm}$ de espessura).

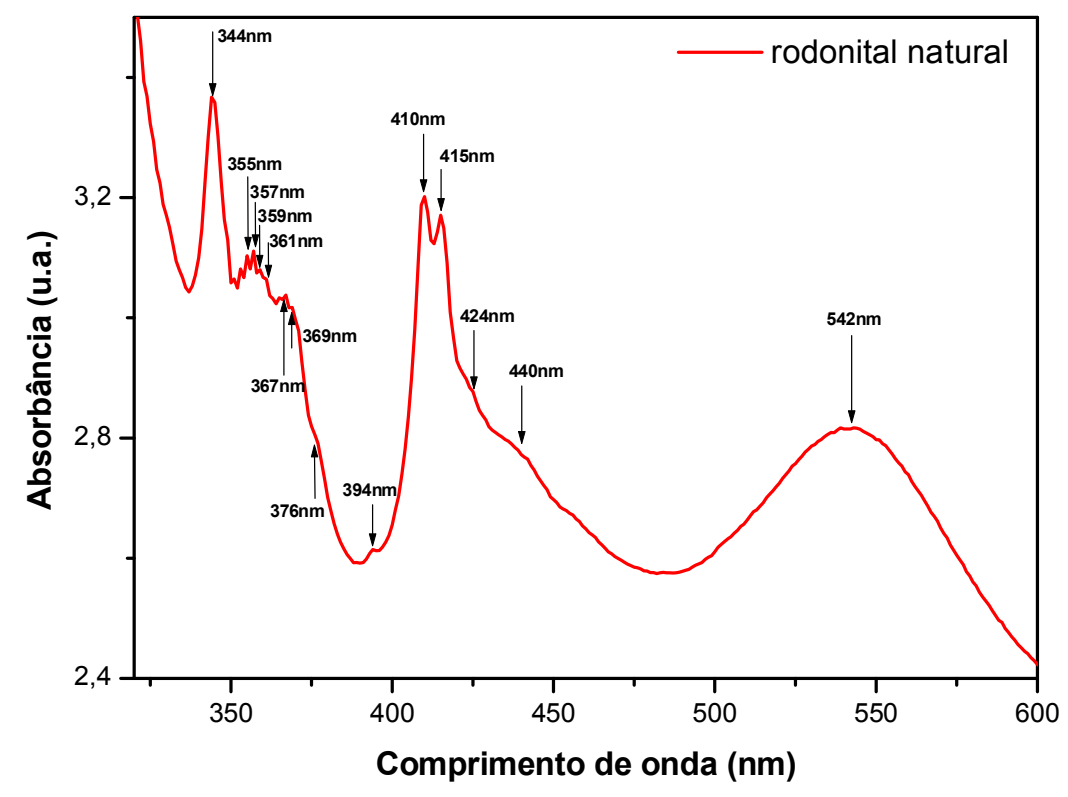

Figura 4.41: Espectro de absorção óptica da rodonita natural, entre 300nm e 600nm (lâmina com $1 \mathrm{~mm}$ de espessura). 


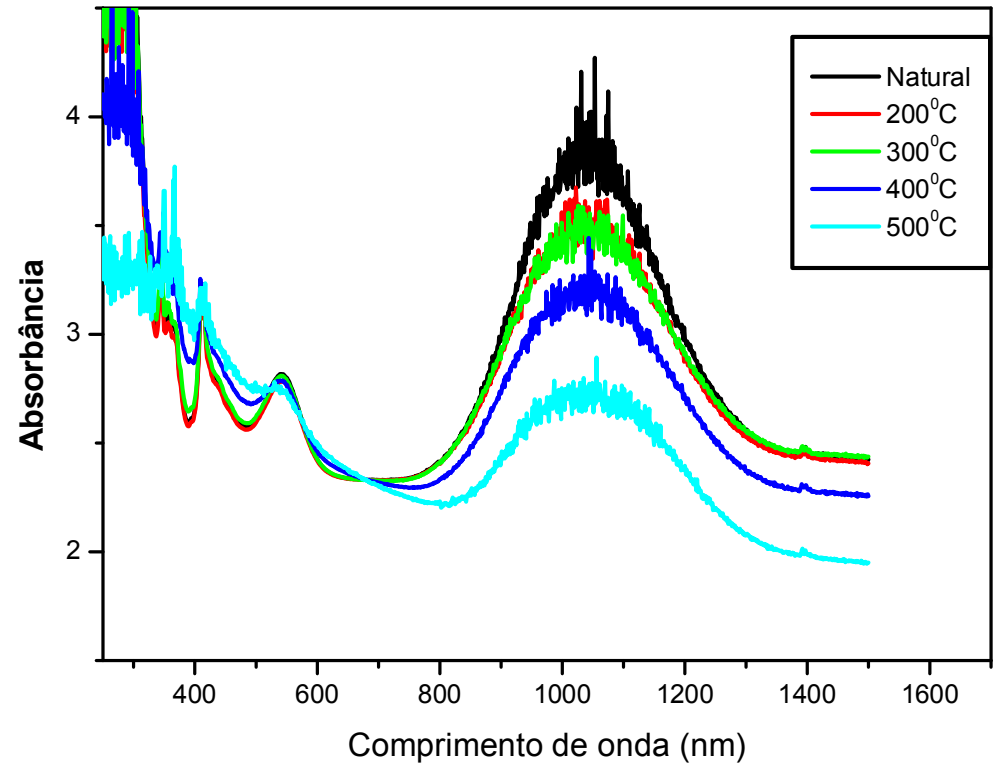

Figura 4.42: Espectro de absorção óptica de lâminas de rodonita após diferentes tratamentos térmicos entre a temperatura ambiente e $500^{\circ} \mathrm{C}$ (lâmina com $1 \mathrm{~mm}$ de espessura).

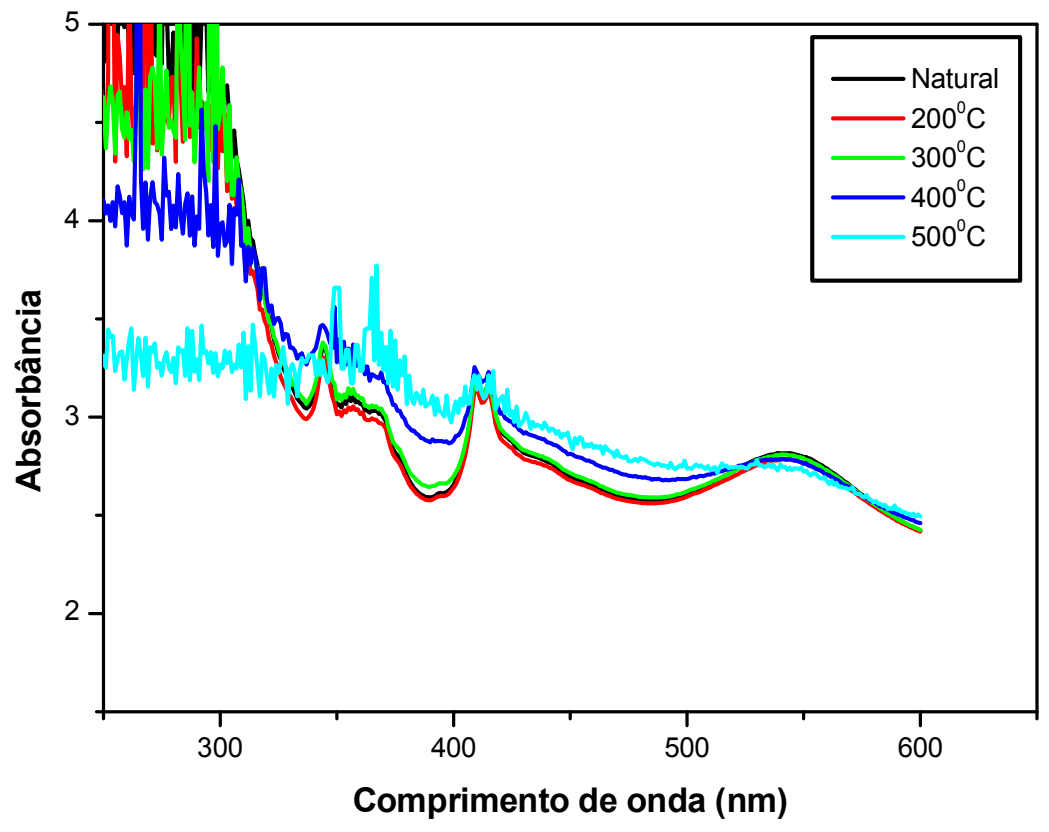

Figura 4.43: Espectro de absorção óptica de lâminas de rodonita após diferentes tratamentos térmicos, para a região entre $200 \mathrm{~nm}$ e $600 \mathrm{~nm}$ (lâmina com $1 \mathrm{~mm}$ de espessura). 


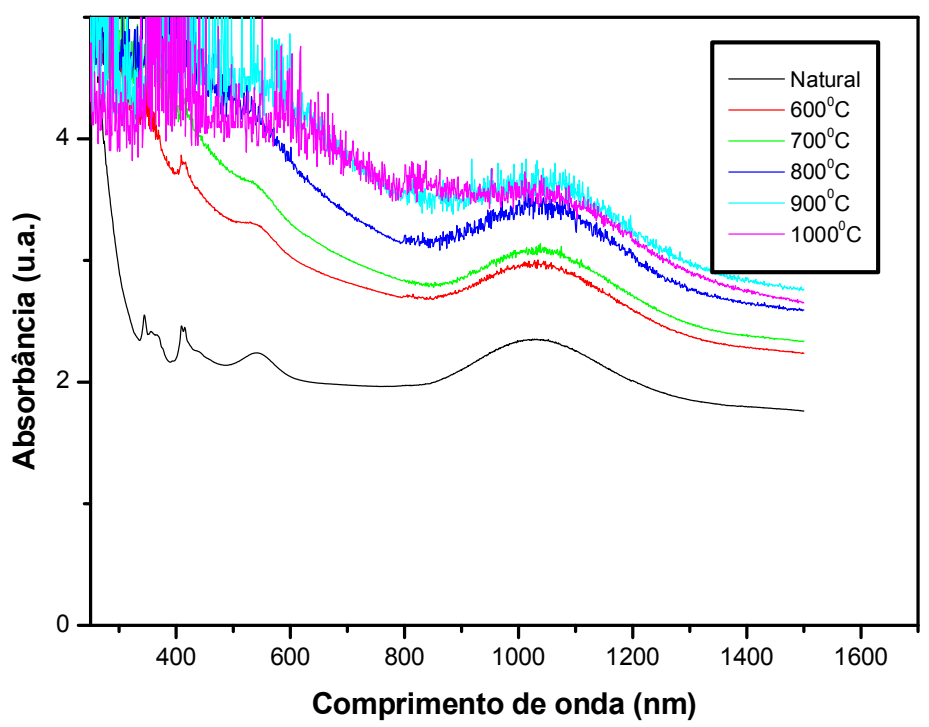

Figura 4.44: Espectro de absorção óptica de lâminas de rodonita após diferentes tratamentos térmicos, entre a temperatura ambiente e $1000^{\circ} \mathrm{C}$ (lâmina com espessura de $0,5 \mathrm{~mm})$.

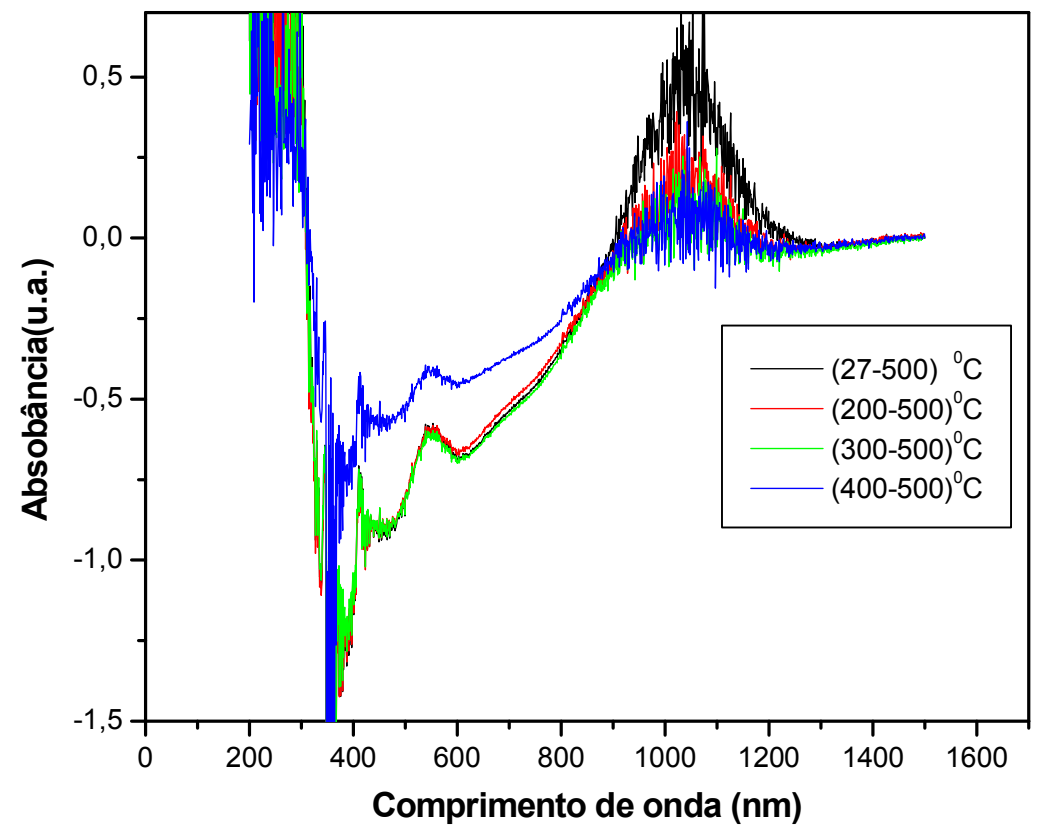

Figura 4.45: Espectros em diferentes temperaturas subtraído do espectro em $500^{\circ} \mathrm{C}$. 
Com o aquecimento, foi visto que as bandas de uma maneira geral diminuem de intensidade, dessa forma, estudamos o efeito da radiação após tratamento térmico. Uma lâmina foi tratada em $500{ }^{\circ} \mathrm{C}$ por 1 hora e então recebeu diferentes doses de radiação gama.

$\mathrm{Na}$ figura 4.46, verificamos que, após tratamento térmico, mesmo para doses altas as bandas não crescem novamente, Na figura 4.47, tem se a média, pois na figura 4.46 aparecem muitos ruídos.

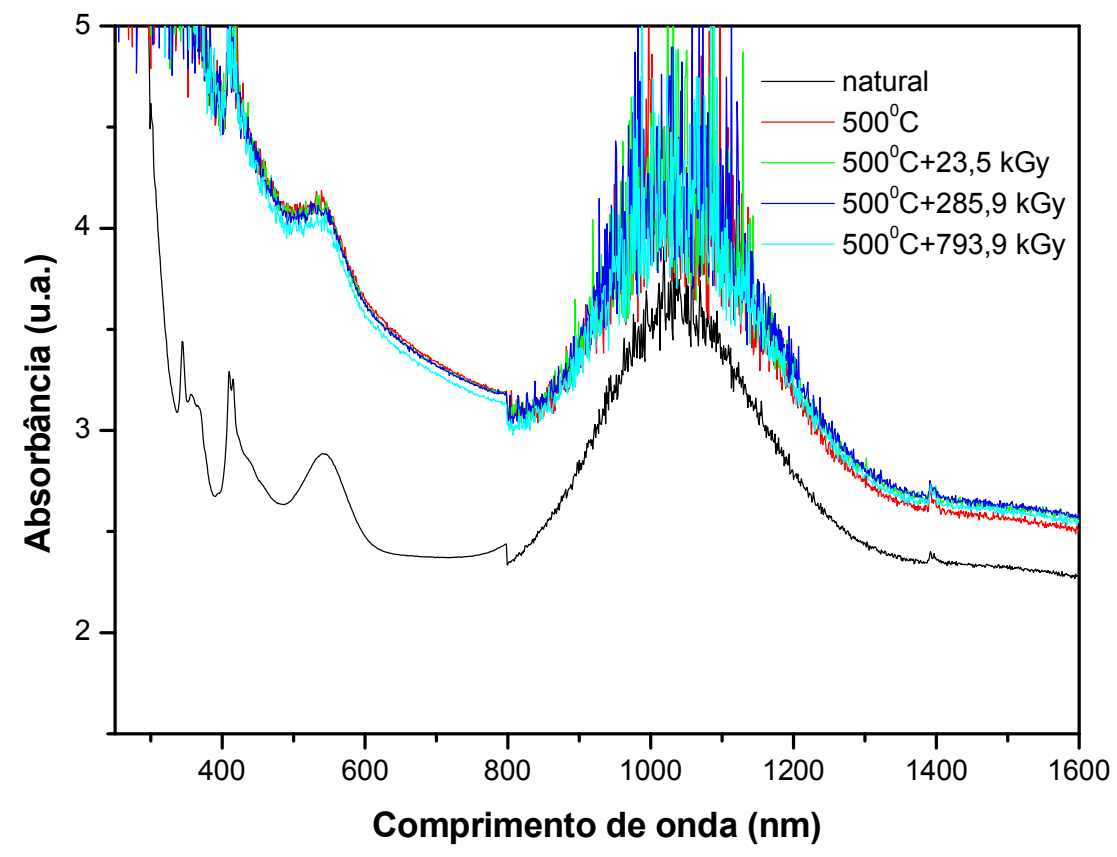

Figura 4.46: Espectro de absorção óptica da rodonita após tratamento térmico em $500^{\circ} \mathrm{Ce}$ doses gama adicionais. 
RESULTADOS

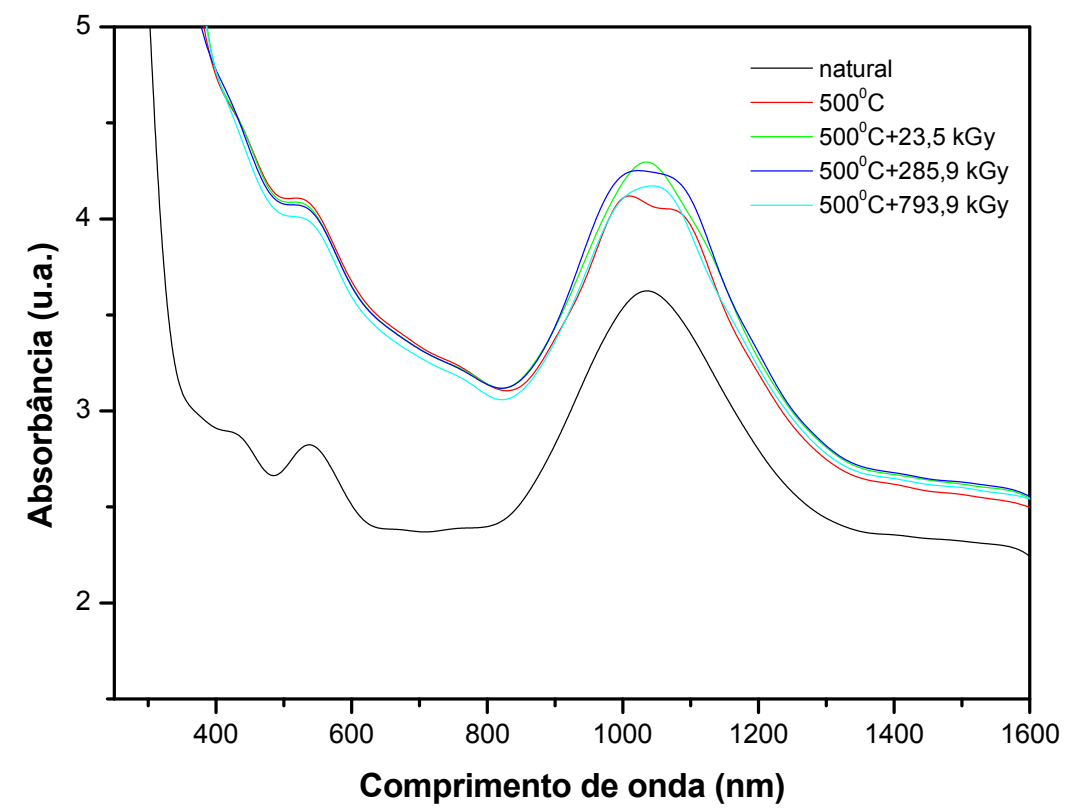

Figura 4.47: Espectro de absorção óptica da rodonita após tratamento térmico em $500{ }^{\circ} \mathrm{C} \mathrm{e}$ doses gama adicionais (média). 


\subsection{1- Cálculo das bandas de AO através da teoria do campo cristalino}

Calculamos as bandas de absorção óptica para um cristal de rodonita considerando $\circ \mathrm{Mn}^{3+}$ em dois ambientes diferentes. Primeiro consideramos o ambiente octaédrico, logo depois consideramos o $\mathrm{Mn}^{3+}$ em um ambiente $\mathrm{C}_{4 \mathrm{v}}$. Nas figuras 4.48 e 4.49 mostramos o esquema de níveis de energia com as transições permitidas para essas duas situações e a comparação entre os valores observados experimentalmente e calculados teoricamente neste trabalho.

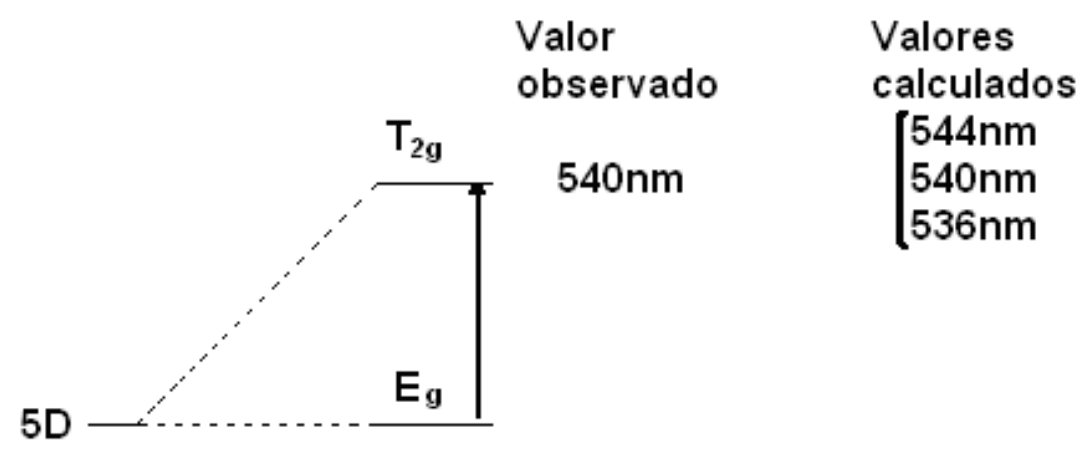

Figura 4.48: Esquema dos níveis de energia (transições permitidas) para o $\mathrm{Mn}^{3+} \mathrm{em}$ ambiente octaédrico.

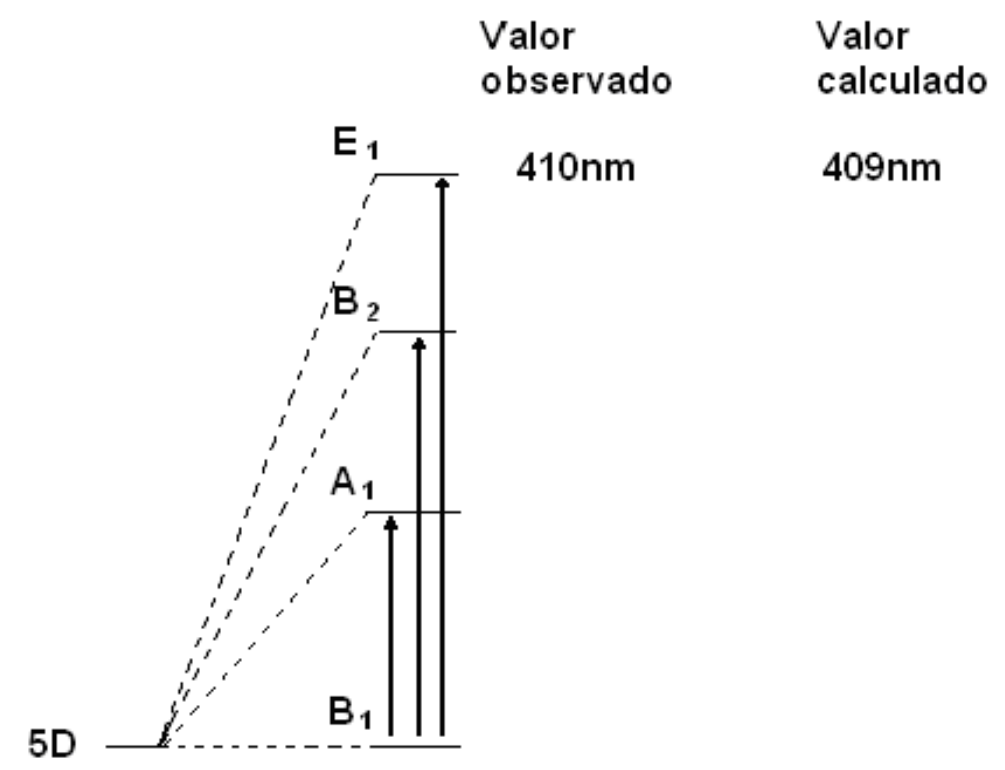

Figura 4.49: Esquema dos níveis de energia (transições permitidas) para o $\mathrm{Mn}^{3+} \mathrm{em}$ ambiente $C_{4 v}$. 


\section{4 - Espectroscopia de fotoelétrons excitados por raios - X (XPS)}

Segundo alguns trabalhos, a cor rosada apresentada pela rodonita natural está associada à presença do $\mathrm{Mn}^{2+}$ (Manning,1968). Com tratamentos térmicos em temperatura ambiente ocorre escurecimento que, acredita-se ser devido à mudança de $\mathrm{Mn}^{2+} \mathrm{e} / \mathrm{ou} \mathrm{Mn}^{3+}$ para $\mathrm{Mn}^{4+}$, pelo menos de forma parcial. Dessa forma, foram realizadas medidas de XPS no laboratório da KRATOS ANALYTICAL nos Estados Unidos, cujo objetivo era determinar a valência do manganês, com e sem tratamento térmico. Os resultados das medidas são mostrados a seguir. Na figura 4.50 podemos ver que o pico de energia de $642,647 \mathrm{eV}$ corresponde ao $\mathrm{MnO}_{2}$, onde o manganês se apresenta no estado de $\mathrm{Mn}^{4+}$ e o pico de energia $641,199 \mathrm{eV}$ corresponde ao duplo óxido $\mathrm{Mn}_{3} \mathrm{O}_{4}$, onde o manganês se apresenta nos estados de $\mathrm{Mn}^{2+}$ e $\mathrm{Mn}^{3+}$, tabela 1.3.

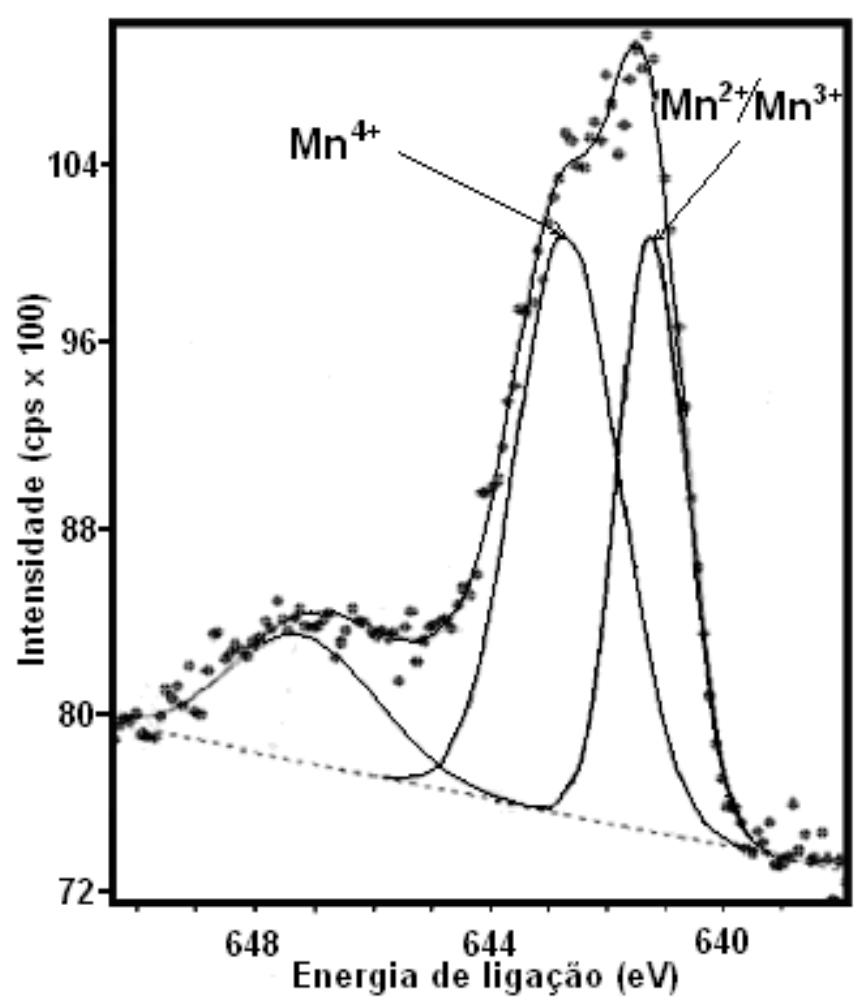

Figura 4.50: Medidas de XPS em rodonita natural antes do tratamento térmico. 
Após tratamento térmico em $600{ }^{\circ} \mathrm{C}$ por 1 hora houve um sensível escurecimento da amostra e ao mesmo tempo uma diminuição da intensidade do pico atribuído ao $\mathrm{Mn}^{2+}$ e um aumentou da intensidade do pico de $\mathrm{Mn}^{4+}$. Nessa medida o $\mathrm{Mn}^{3+}$ não apareceu, figura 4.51 .

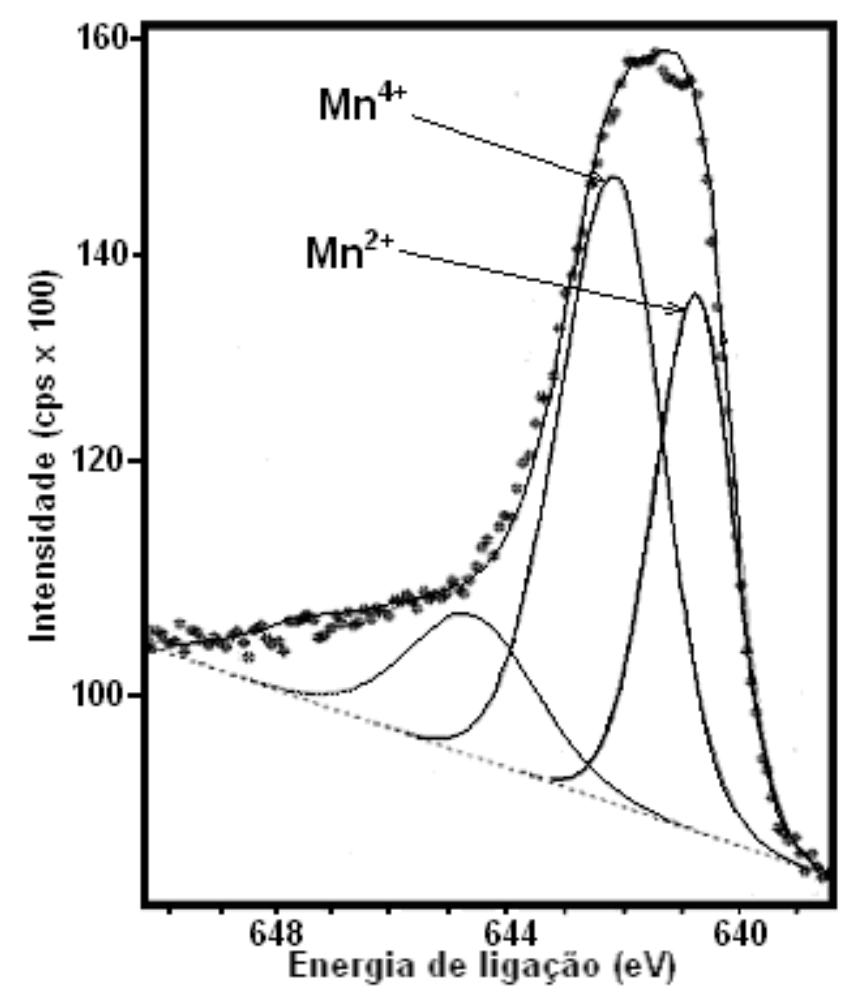

Figura 4.51: Medidas de XPS em rodonita natural após tratamento térmico em $600^{\circ} \mathrm{C} / 1 \mathrm{~h}$. 


\section{5 - Ressonância Paramagnética Eletrônica (RPE)}

Foram realizadas medidas de RPE em amostras de rodonita $(100 \mathrm{mg})$ em pó para diferentes doses de radiação, tanto para a rodonita natural quanto para a natural tratada em $600{ }^{\circ} \mathrm{C} / 1 \mathrm{~h}$, figuras 4.52 e 4.53 . Exceto pela intensidade não foi observado qualquer alteração no sinal.

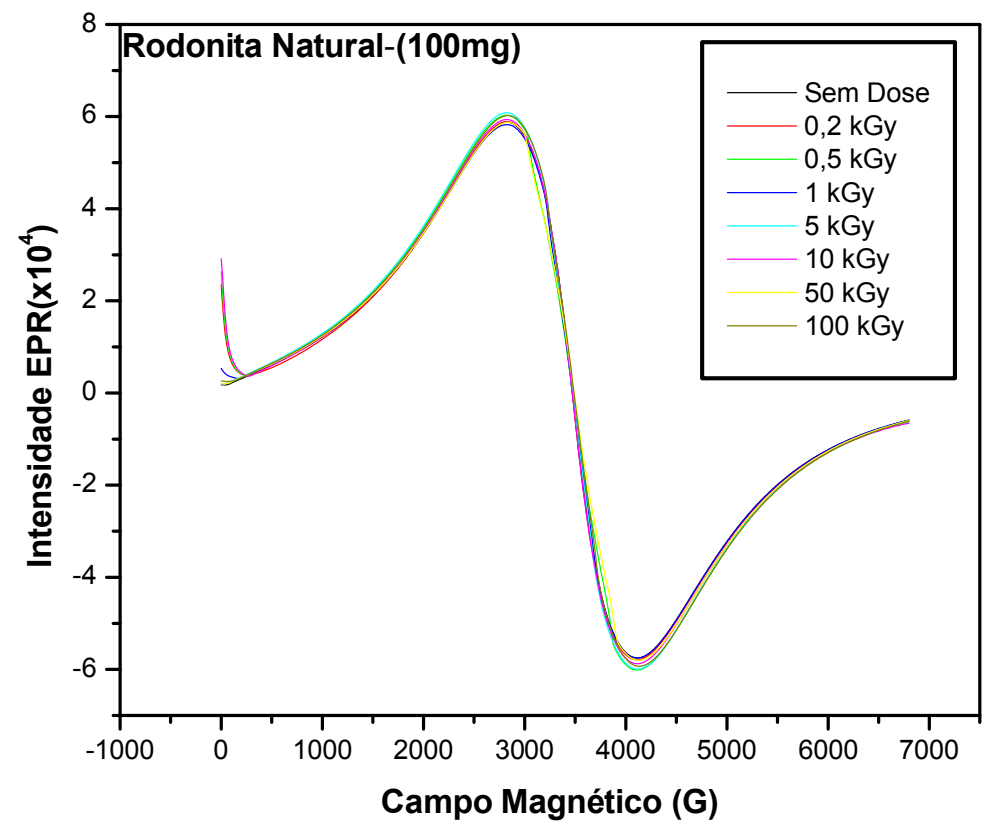

Figura 4.52: Espectro de RPE da rodonita natural com doses gama adicionais. 


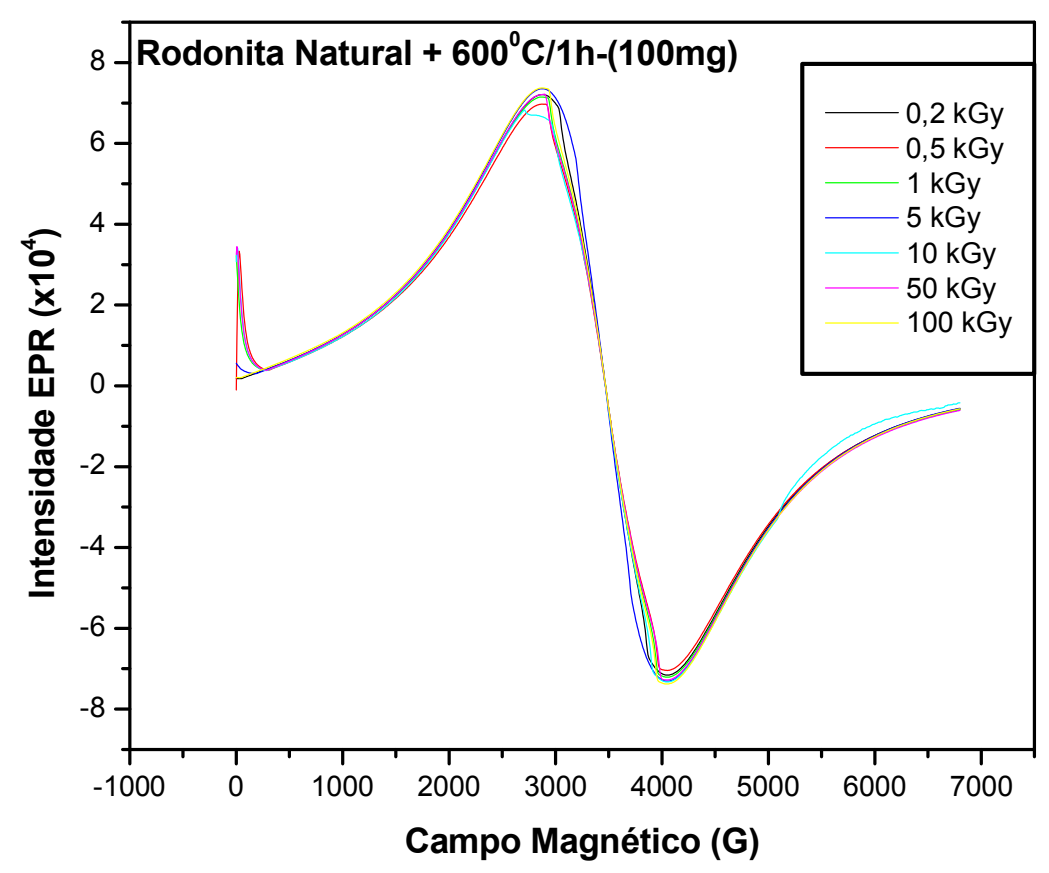

Figura 4.53: Espectro de RPE da rodonita natural tratada em $600^{\circ} \mathrm{C} / 1 \mathrm{~h}$, com doses gama adicionais.

Apesar do sinal RPE não sofrer variações com a dose aplicada, verificamos que o sinal apresenta grande intensidade e largura de pico a pico de mais de $1000 \mathrm{G}$. Esse alargamento é devido à interação spin-spin entre os íons de manganês, que no caso da rodonita faz parte da estrutura do cristal $(\mathrm{Mn}, \mathrm{Ca}, \mathrm{Fe}, \mathrm{Mg}) \mathrm{SiO}_{3}$. Esse forte efeito é evidenciado pelo colapso da estrutura hiperfina, típica do $\mathrm{Mn}^{2+}$, que não é observada neste caso.

Por outro lado, o aquecimento da amostra natural, sem qualquer dose adicional, para temperaturas entre $600^{\circ} \mathrm{C}$ e $1000^{\circ} \mathrm{C}$, por $1 \mathrm{~h}$ indicaram um elevado alargamento e aumento da intensidade do sinal RPE, figura 4.54. 


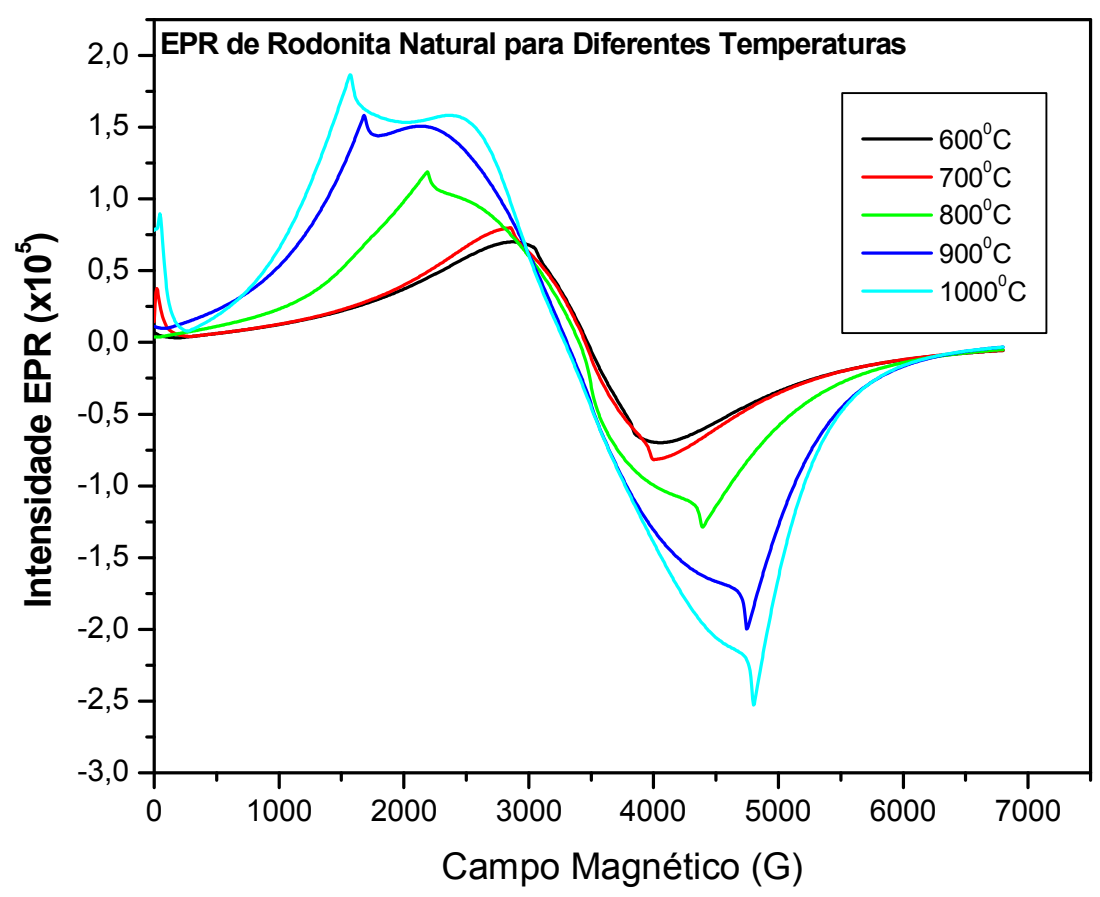

Figura 4.54: Comportamento do sinal EPR para amostras de rodonita tratada termicamente em diferentes temperaturas.

Foram feitas também medidas com amostras artificiais, pura e dopada com ferro e, então comparadas com o espectro da natural e natural tratada em diferentes temperaturas. Existem diferenças nos sinais, sendo que o sinal da amostra dopada com ferro é 3 vezes mais intenso que o da amostra sem ferro, figura 4.55. RPE de amostras dopadas com $\mathrm{Al}$, Ca e $\mathrm{Mg}$ também foram obtidos, porém o espectro manteve o aspecto inicial, além disso, para essas amostras não foram verificadas alterações na forma do sinal RPE para doses entre 0,5 e $100 \mathrm{KGy}$. 


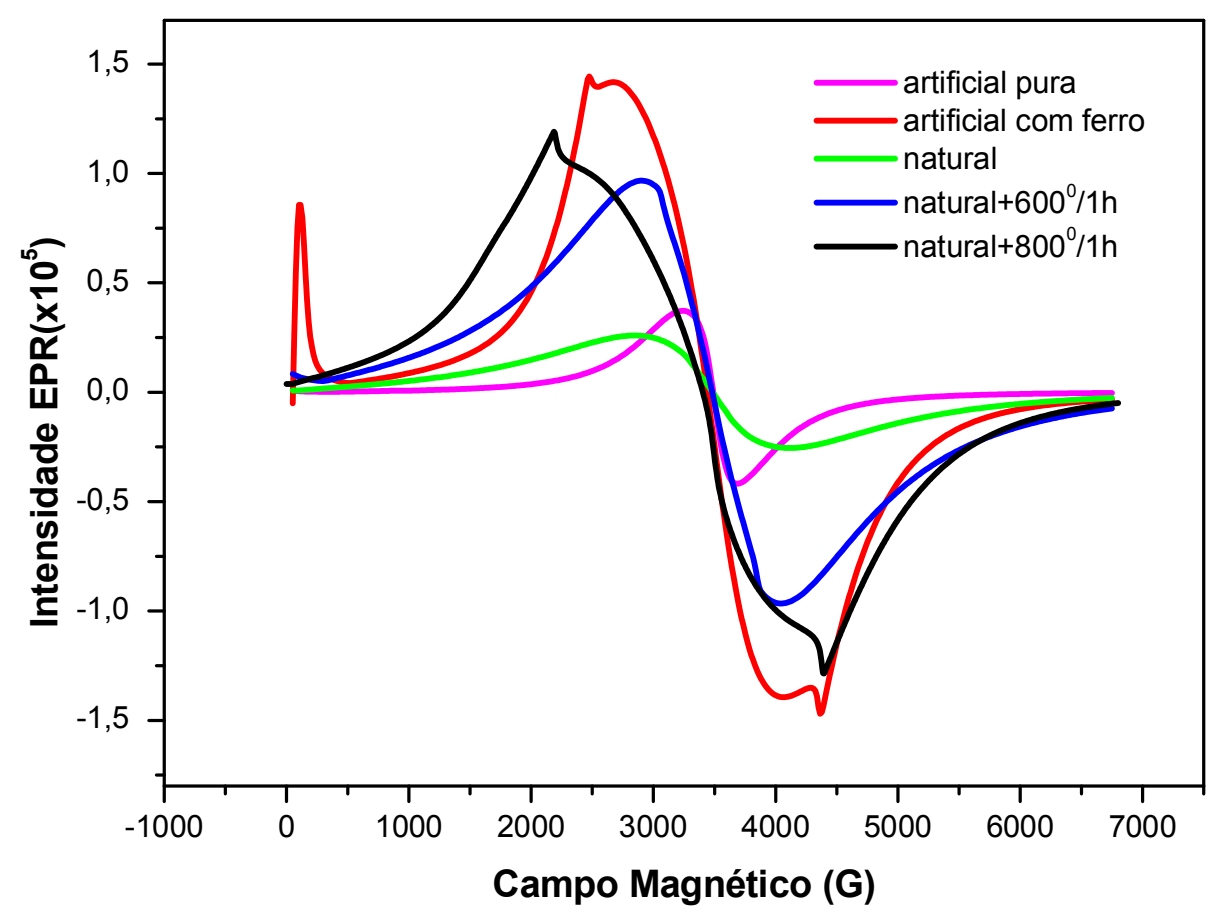

Figura 4.55: Comparação entre espectros RPE de diferentes amostras.

\subsection{1 - Cálculo do segundo momento (teoria de van Vleck)}

O alargamento das linhas de RPE devido à interação spin-spin foi calculado através da teoria de Van Vleck (1948). A relação 1-45 nos diz que:

$$
\left\langle\Delta \mathrm{H}^{2}\right\rangle_{m}=\frac{3}{5} g^{2} \beta^{2} S(S+1) \sum_{j>k} r_{j k}^{-6}
$$

onde, $r_{j k}$ é a distância em centímetros entre os átomos j e k e o campo é dado em gauss.

O óxido de manganês corresponde a aproximadamente $37 \%$ da estrutura do cristal de rodonita, figura 4.1. Medidas de XPS indicaram a presença de $\mathrm{Mn}^{2+}(\mathrm{S}=5 / 2), \mathrm{Mn}^{3+} \mathrm{e}$ $\mathrm{Mn}^{4+}(\mathrm{S}=3 / 2)$, na estrutura da amostra natural e, medidas de AO confirmaram a presença de $\mathrm{Mn}^{2+}$ (Manning,1968) e $\mathrm{Mn}^{3+}$ (Gibbons et. al.,1974). Após tratamento térmico ocorre um 
escurecimento do cristal de rodonita, fato atribuído ao $\mathrm{Mn}^{4+}$. Dessa forma, usando a relação 1-45 e conhecendo as distâncias interatômicas entre os átomos de manganês, figura 4.56, calculamos a contribuição dos íons de manganês em duas situações. Os cálculos foram feitos levando em consideração a contribuição do $\mathrm{Mn}^{2+}$ (rodonita natural), figura 4.57 e do $\mathrm{Mn}^{4+}$ (rodonita tratada termicamente).

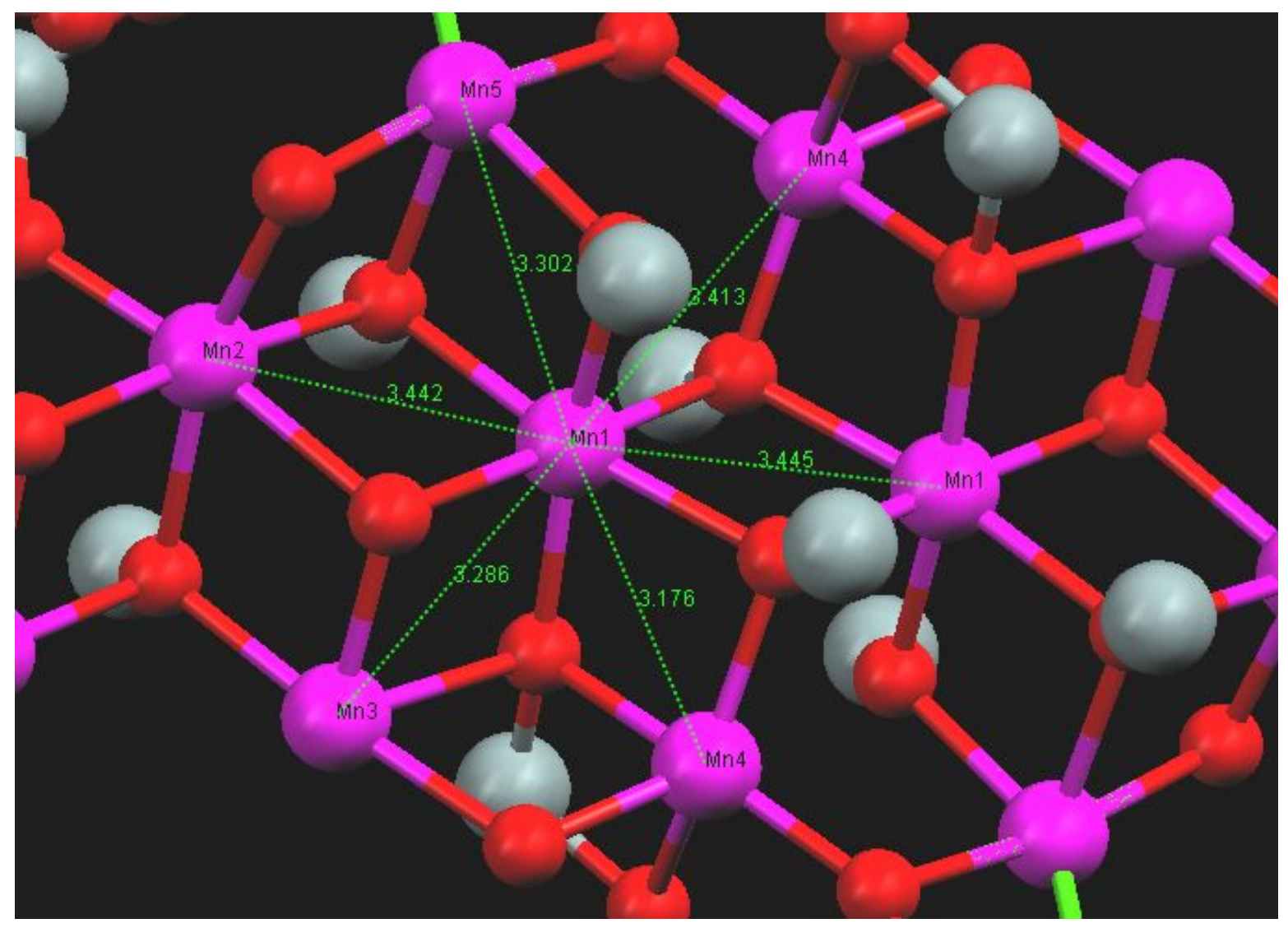

Figura 4.56: Distâncias interatômicas entre os átomos de manganês na estrututa da rodonita [obtido através do programa Mercury e das medidas de Peacor et al.-1978]. 


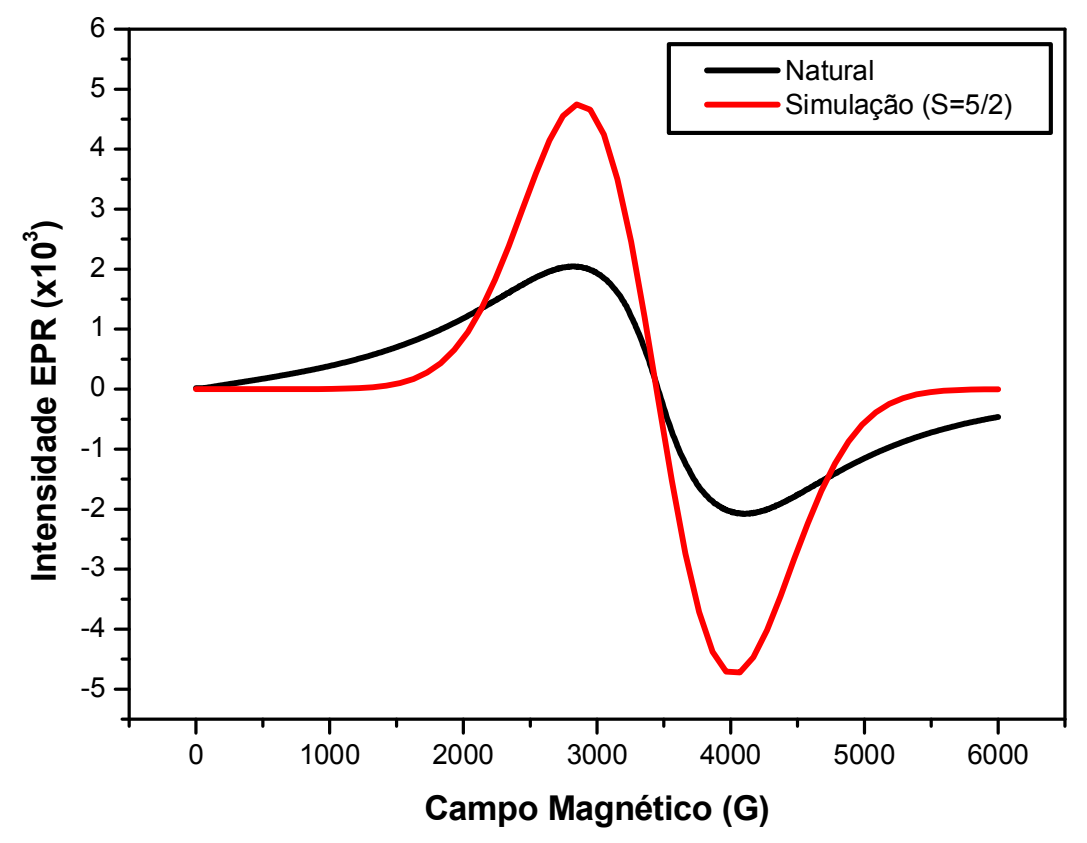

Figura 4.57: Comparação entre os espectros RPE da rodonita natural e simulado $(S=5 / 2)$, utilizando a teoria de Van Vleck. Na simulação usamos um modelo gaussiano.

Apesar das diferenças de intensidades entre os dois sinais percebemos que a distância de pico a pico para os dois casos mostram uma boa concordância. A distância de pico a pico foi de aproximadamente $1150 \mathrm{G}$, enquanto na amostra natural é de $1350 \mathrm{G}$. Em um segundo momento repetimos o cálculo, porém para o caso do $\mathrm{Mn}^{4+}$, que forneceu uma distância de pico a pico de aproximadamente $750 \mathrm{G}$. Um valor bem abaixo do esperado, basta comparar com a figura 4.54 . 
Capítulo 5

\section{Discussão dos}

resultados 


\section{0 - Discussão dos resultados}

\section{1 - Comentários iniciais}

A rodonita natural aqui estudada contém, é claro, segundo a análise de fluorescência de raios - $\mathrm{X}$ realizada no Instituto de Geociências da USP, $\mathrm{SiO}_{2}$ e $\mathrm{MnO}$ como componentes principais. Embora em proporção bem menor, $\mathrm{CaO}, \mathrm{Fe}_{2} \mathrm{O}_{3}, \mathrm{MgO}$ e $\mathrm{Al}_{2} \mathrm{O}_{3}$ estão sempre presentes na rodonita e bustamita, motivo pelo qual em muitos casos, ao invés de $\mathrm{MnSiO}_{3}$, considera-se a fórmula $(\mathrm{Mn}, \mathrm{Ca}, \mathrm{Fe}, \mathrm{Mg}) \mathrm{SiO}_{3}$ como sendo a da rodonita. Há várias outras impurezas com concentrações variando de poucos a 600 ppm. Em mais de 15 minerais naturais de silicatos estudados em nosso laboratório, foi observado que, exceto poucos elementos considerados impurezas, a maioria não tem influência nas propriedades investigadas no presente trabalho. Aliás, para verificar até que ponto o Ti presente com 340 ppm estaria participando, foi preparada uma amostra sintética contendo essa quantidade de Ti. O resultado apresentado na figura 4.26 mostra que seu efeito é cerca de 15 vezes menor que o de $\mathrm{Al}_{2} \mathrm{O}_{3}$ (pico de $140^{\circ} \mathrm{C}$ e dose de $50 \mathrm{kGy}$ ). Mais adiante, discutiremos a influência das impurezas. O difratograma da amostra natural comparado com o padrão mostra que, excetuando-se poucas linhas, há coincidência, da difração nas linhas mais típicas.

\subsection{Termoluminescência}

O resultado dos difratograma de raios - $\mathrm{X}$ de amostras tratadas em temperaturas acima de $400{ }^{\circ} \mathrm{C}$ e inferior a $800{ }^{\circ} \mathrm{C}$ mostra variação apenas nas intensidades das linhas, mas a estrutura até essa temperatura mantém-se.

As curvas de emissão TL de amostras naturais irradiadas com doses até cerca de $50 \mathrm{kGy}$ exibem picos TL em torno de $140{ }^{\circ} \mathrm{C}, 250{ }^{\circ} \mathrm{C}, 280{ }^{\circ} \mathrm{C}, 335{ }^{\circ} \mathrm{C}$, e $460{ }^{\circ} \mathrm{C}$. Esses picos intensos (exceto o de $280{ }^{\circ} \mathrm{C}$ ), crescem sublinearmente. As amostras tratadas termicamente em $600{ }^{\circ} \mathrm{C}$ por uma hora para eliminar qualquer efeito de radiação anteriormente recebido, por exemplo, da radiação natural, quando irradiadas, também, até 
cerca de $50 \mathrm{kGy}$, apresentam um pico adicional fraco em $175{ }^{\circ} \mathrm{C}$. O crescimento desses picos continua sublinear. A banda de emissão TL está, em geral, diretamente associada ao centro de recombinação. A amostra de rodonita apresentou uma banda larga que se estende de $500 \mathrm{~nm}$ a $625 \mathrm{~nm}$ para o pico de $260{ }^{\circ} \mathrm{C}$; a banda do pico de $140{ }^{\circ} \mathrm{C}$ se estende de $500 \mathrm{~nm}$ a $650 \mathrm{~nm}$. Pode-se inferir que só há um tipo de centro de recombinação, cuja natureza será discutida depois.

Usando o processo de fusão e lento resfriamento, foram produzidas amostras sintéticas puras (de $\mathrm{MnSiO}_{3}$ ), bem como dopadas controladamente com as principais impurezas encontradas na rodonita natural. Primeiramente, a amostra sintética obtida através da amostra natural apresentou praticamente todos os picos $T L$ da amostra natural $\left(600^{\circ} \mathrm{C} / 1 \mathrm{~h}\right)$, diferindo apenas na proporção entre as intensidades dos picos. Porém, a difração de raios - $\mathrm{X}$ indicou que a estrutura obtida não era a da rodonita, mas do cristal de bustamita, cuja composição química é muito parecida com a do cristal aqui estudado. Medidas TL na amostra sintética obtida pela mistura de todos os componentes apresentaram boa concordância com as medidas na amostra natural $\left(600^{\circ} \mathrm{C} / 1 \mathrm{~h}\right)$ quanto à posição dos picos, como pode ser observado nas figura 4.16 e 4.17 .

A sensibilidade TL para a mesma dose de $10 \mathrm{kGy}$ foi menor por um fator de 50 quando comparamos o mesmo pico TL de $340^{\circ} \mathrm{C}$ (entre as amostras sintética e natural $\left(600^{\circ} \mathrm{C} / 1 \mathrm{~h}\right)$. A difração de raios-X das amostras sintéticas puras, obtidas em atmosfera ambiente e controlada apresentaram difratogramas praticamente iguais às do padrão, exceto para poucas linhas. As figuras 4.18 a 4.19 confirmam que o método pode ser usado perfeitamente para produção de amostras sintéticas do cristal de rodonita. As figuras de 4.13 a 4.39 ilustram o comportamento de amostras sintéticas, ambas puras (uma em atmosfera ambiente e a outra em atmosfera de argônio) e outras dopadas com $\mathrm{Fe}_{2} \mathrm{O}_{3}, \mathrm{CaO}, \mathrm{TiO}_{2}, \mathrm{MgO}$ e $\mathrm{Al}_{2} \mathrm{O}_{3}$ que são as principais impurezas (exceto $\mathrm{TiO}_{2}$ ) em relação a $\mathrm{MnSiO}_{3}$. Três características saltam à vista: a primeira é o fato de as suas curvas de emissão apresentarem claramente os picos TL encontrados na amostra natural, entre outros que estão deslocados, indicando que a sua presença deve-se a defeitos intrínsecos, ou seja, independem das impurezas. Vale ressaltar que em nenhuma das amostras sintéticas foi observado o pico de $460^{\circ} \mathrm{C}$; segundo, o pico TL em $330^{\circ} \mathrm{C}$ sofre um crescimento destacado com a dose de radiação, enquanto na amostra natural, embora este pico cresça bastante, é 
o pico em $250{ }^{\circ} \mathrm{C}-260{ }^{\circ} \mathrm{C}$ que cresce mais; terceiro, a amostra pura em atmosfera ambiente responde fracamente à radiação, enquanto a obtida em atmosfera de argônio responde fortemente, figura 4.22 e dopadas respondem menos à radiação. Entretanto, é a presença de $\mathrm{Al}_{2} \mathrm{O}_{3}$ que destacadamente altera o comportamento $\mathrm{TL}$ da rodonita. Agora, porém, é o pico TL em $140{ }^{\circ} \mathrm{C}-150{ }^{\circ} \mathrm{C}$ que responde muito intensamente à radiação. Para uma dose de $50 \mathrm{kGy}$, a amostra dopada com o alumínio apresenta uma intensidade TL maior por um fator de 90 comparado à amostra pura obtida em atmosfera ambiente. Mesmo os outros picos, inclusive o de $330{ }^{\circ} \mathrm{C}$, crescem muito mais do que nas amostras dopadas com os elementos acima mencionados.

É, portanto, natural admitir o papel importante do $\mathrm{Al}_{2} \mathrm{O}_{3}$ na emissão TL. Note-se, porém, que o íon $\mathrm{Al}^{3+}$ costuma substituir o $\mathrm{Si}^{4+}$ no tetraedro $\mathrm{SiO}_{4}$; o desequilíbrio de carga costuma ser compensado através dos sempre presentes íons alcalinos monovalentes. Inicialmente forma-se um centro segundo a reação:

$$
\mathrm{Al}^{3+}+\mathrm{M}+\left[\mathrm{SiO}_{4}^{4-}\right]^{0} \rightarrow\left[\mathrm{AlO}_{4} / \mathrm{M}^{+}\right]^{0}+\mathrm{Si}+e^{-}
$$

A irradiação remove $\mathrm{M}^{+}$deixando $\left[\mathrm{AlO}_{4} / \mathrm{h}\right]^{0}$ que é conhecido como centro de buraco alumínio.

$$
\left[\mathrm{AlO}_{4} / \mathrm{M}^{+}\right]^{0} \stackrel{\mathrm{irr}}{\rightarrow}\left[\mathrm{AlO}_{4} / \mathrm{h}\right]^{0}+\mathrm{M}
$$

Durante o aquecimento para a leitura, $\mathrm{M}^{+}$que se tornara $\mathrm{M}^{0}$ por captura de um elétron da ionização (irradiação), agora libera um elétron que se recombina com o buraco do centro de alumínio, produzindo a luz TL e regenerando o centro $\left[\mathrm{AlO}_{4} / \mathrm{M}^{+}\right]$. Outra possibilidade seria a captura do elétron da ionização por uma vacância de oxigênio que se encontra com grande probabilidade nas unidades $\left[\mathrm{SiO}_{4}^{4-}\right]$ ou $\left[\mathrm{AlO}_{4}^{4-}\right]$ cuja carga estava naturalmente compensada antes da irradiação. Com a ocupação do elétron da ionização essa carga negativa passaria a ser compensada pelo $\mathrm{M}^{+}$. O centro de recombinação a que se referiu a figura 4.7 é o centro de alumínio aqui discutido. As figuras 4.32 e 4.34 mostram um fato curioso. $O$ acréscimo de $\mathrm{MgO}$ e $\mathrm{Fe}_{2} \mathrm{O}_{3}$ na amostra dopada com $\mathrm{Al}_{2} \mathrm{O}_{3}$, faz com que o efeito TL diminua, sendo o efeito de $\mathrm{Fe}_{2} \mathrm{O}_{3}$ mais acentuado. Souza et al (2003) encontrou semelhante efeito inibidor do ferro no espodumênio. Por outro lado, o acréscimo de CaO produz uma sensibilização dos picos TL, figura 4.36. 


\subsection{Absorção óptica}

\subsubsection{Aspectos gerais}

Abaixo reproduzimos a figura 4.41 (aqui chamada de 5.1) que mostra o espectro de $A O$ da amostra de rodonita natural, no intervalo de $300 \mathrm{~nm}$ a $600 \mathrm{~nm}$.

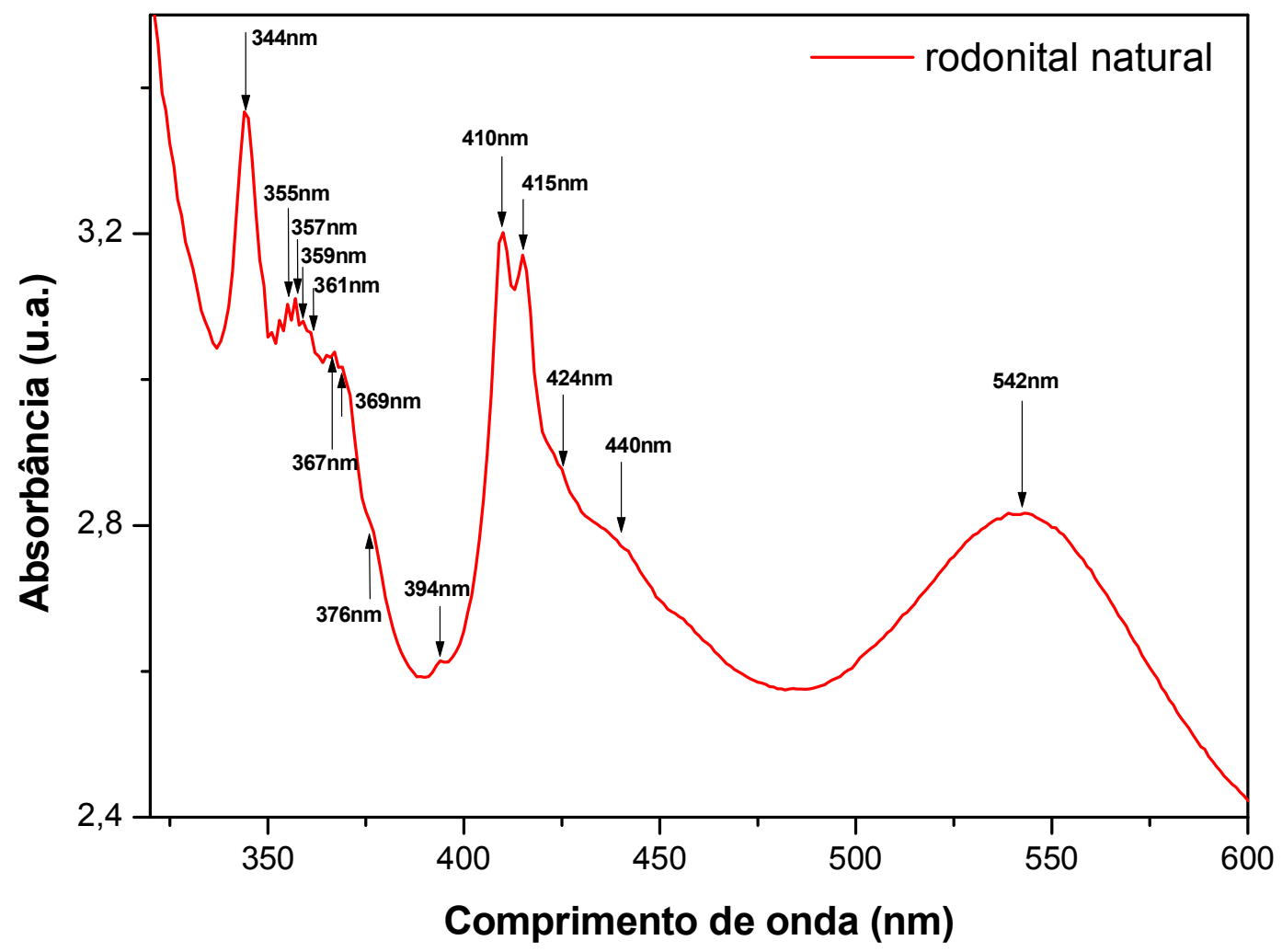

Figura 5.1: Espectro de $A O$ da rodonita natural entre $300 \mathrm{~nm}$ e $600 \mathrm{~nm}$.

Este espectro apresenta bandas em 344nm, 355 nm, 357nm, 359nm, 361nm, 367nm, $369 \mathrm{~nm}, 376 \mathrm{~nm}, 394 \mathrm{~nm}, 410 \mathrm{~nm}, 415 \mathrm{~nm}$ e $542 \mathrm{~nm}$. Acima de $600 \mathrm{~nm}$ destacamos uma banda larga e muito intensa centrada em torno de $1040 \mathrm{~nm}$ e uma fraca na região de $1500 \mathrm{~nm}$, visualizadas na figura 4.40. Manning (1968) cita as bandas em 344nm, 370nm, 410nm, $434 \mathrm{~nm}, 530 \mathrm{~nm}, 1050 \mathrm{~nm}$ e $1450 \mathrm{~nm}$, associando as cinco primeiras ao $\mathrm{Mn}$ (II) octaédrico. Isto significa que as bandas em torno de $367 \mathrm{~nm}$ e $410 \mathrm{~nm}$, encontradas no presente trabalho 
aparecem desdobradas, o que parece razoável, pois, as bandas em $370 \mathrm{~nm}$ e $410 \mathrm{~nm}$ de Manning (1968) comportam esse desdobramento.

Por outro lado, Gibbons et al. (1974), usando cristal de $\mathrm{MnSiO}_{3}$; mostraram que sob pressão de até cerca de $500 \mathrm{kbar}$, a banda em 540nm desaparece. Eles interpretaram o resultado atribuindo a banda inicialmente ao $\mathrm{Mn}^{3+}$ que, sob pressão, transforma-se em $\mathrm{Mn}^{2+}$. Faye ( 1975) argumenta que a intensificação ou alargamento da absorção devido à transferência de carga $\mathrm{O}^{2-} \rightarrow\left(\mathrm{Mn}^{2+}, \mathrm{Fe}^{2+}\right)$ no ultravioleta, provocada pela alta pressão explica melhor os resultados de Manning(1968).

Os espectros de absorção óptica da figura 4.42 e 4.44 mostraram que a banda em $540 \mathrm{~nm}$ diminui com o aquecimento, ao ar, até $1000{ }^{\circ} \mathrm{C}$. Este resultado e o de Gibbons et al. (1974) são mais coerentes com a atribuição da banda de $540 \mathrm{~nm}$ ao $\mathrm{Mn}^{3+}$ pois, tanto o efeito da pressão como do aquecimento no ar não afetam as bandas entre $350 \mathrm{~nm}$ e $450 \mathrm{~nm}$, consideradas devido ao $\mathrm{Mn}^{2+}$.

Gibbons et al. (1974) submeteram, também uma amostra de rodonita natural a um aquecimento até $1250{ }^{\circ} \mathrm{C}$, numa amostra de hidrogênio e argônio. Observaram que não houve, essencialmente, nenhuma mudança, concluindo que a presença de hidrogênio não reduziu a banda em $540 \mathrm{~nm}$, isto é a concentração de $\mathrm{Mn}^{3+}$.

No presente trabalho, foi feito o recozimento de uma amostra natural de rodonita a vácuo, em $800^{\circ} \mathrm{C}$. Essa amostra, praticamente não mudou de cor, enquanto que o aquecimento acima de $500^{\circ} \mathrm{C}$ em atmosfera ambiente tornou a rodonita preta. Esse resultado foi interpretado como sendo devido a oxidação do $\mathrm{Mn}^{2+}$ ou $\mathrm{Mn}^{3+}$ que dá origem a $\mathrm{Mn}^{4+}$.

Sabe-se em química (Ohlweiler-1972) que na formação de compostos, o manganês pode atuar com carga $(2+)$ até $(7+)$, porém, só se formam óxidos de $\mathrm{Mn}^{2+}$, de $\mathrm{Mn}^{3+}$, $\mathrm{Mn}(2+, 4+)$ e $\mathrm{Mn}(4+)$. O óxido de $\mathrm{Mn}(2+, 4+)=\mathrm{Mn}_{3} \mathrm{O}_{4}$ é chamado de hausmanita. Abaixo seguem algumas características dos óxidos.

Dióxido de manganês $\mathrm{MnO}_{2}$ ocorre como pirolusita e, é cinzento a preto, praticamente insolúvel na água. É o óxido mais comumente encontrado.

Óxido de $\mathrm{Mn}^{3+} \mathrm{Mn}_{2} \mathrm{O}_{3}$, ocorre na natureza como braunita; perde o oxigênio quando aquecido acima de $940{ }^{\circ} \mathrm{C}$ no ar e acima de $1090{ }^{\circ} \mathrm{C}$ na atmosfera de oxigênio passa a $\mathrm{Mn}_{3} \mathrm{O}_{4}$. 
Óxido de $\mathrm{Mn}(2+, 3+) \mathrm{Mn}_{3} \mathrm{O}_{4}$ é obtido por meio de aquecimento de um dos óxidos, mais elevados em $1000^{\circ} \mathrm{C}$, durante 6 a 8 horas, é o mais estável dos óxidos de manganês, frente ao aquecimento no ar.

Óxido de $\mathrm{Mn}(2+) \mathrm{MnO}$ se obtém mediante redução dos óxidos superiores num ambiente de hidrogênio ou monóxido de carbono. É convertido no ar, mesmo a frio em $\mathrm{Mn}_{3} \mathrm{O}_{4}$ e $\mathrm{Mn}_{2} \mathrm{O}_{3}$.

A figura 5.2 mostra o $\mathrm{MnO}$ como adquirido no mercado, com cor verde escura (a cor não está visível). Nesta mesma figura mostramos a rodonita sintética obtida por fusão e lento resfriamento numa atmosfera ambiente.

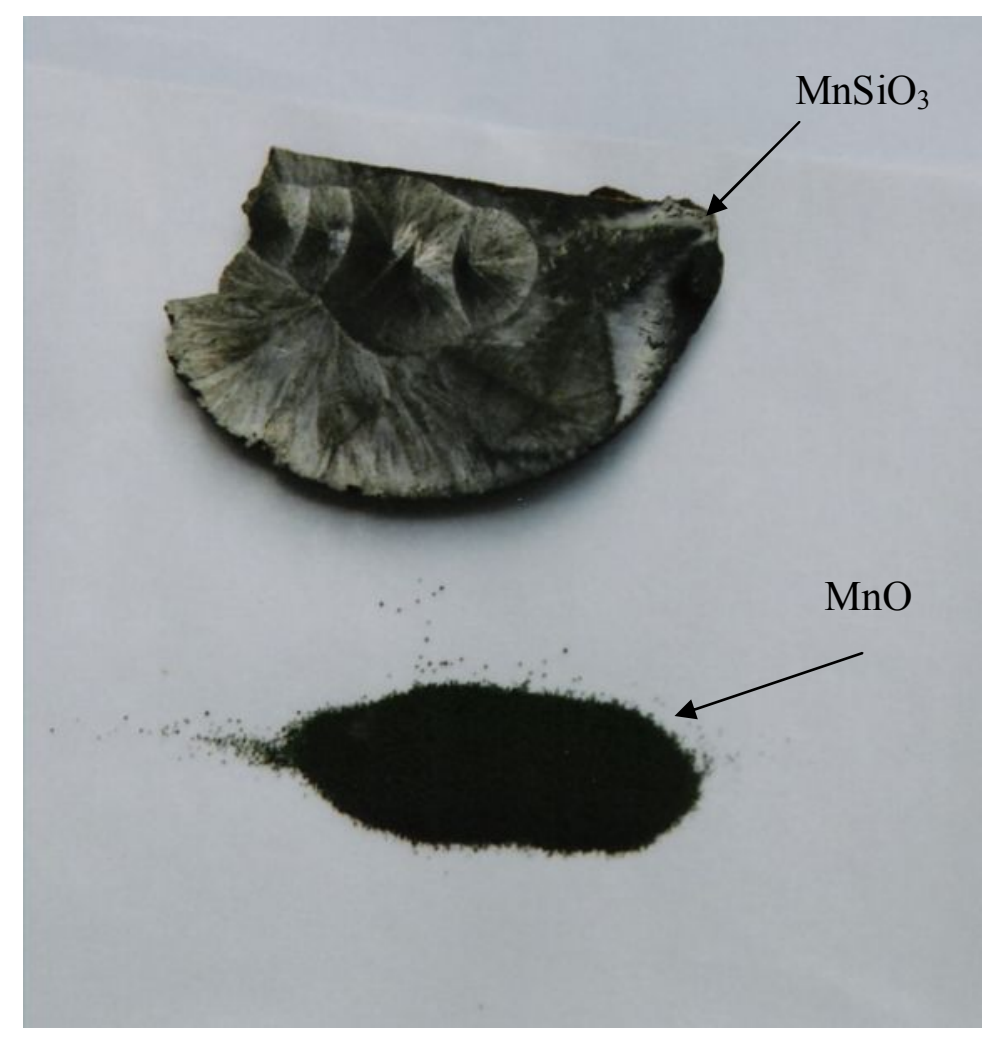

Figura 5.2: Rodonita sintética pura obtida em atmosfera ambiente e o óxido de manganês usado na sua obtenção.

A rodonita obtida em atmosfera controlada de argônio, tem cor rosa quase igual à da rodonita natural e, é mostrada na figura 4.3, ao lado de uma amostra natural, tratada em $600^{\circ} \mathrm{C} / 1 \mathrm{~h}$ e de uma amostra rodonita sintética obtida em atmosfera ambiente. 


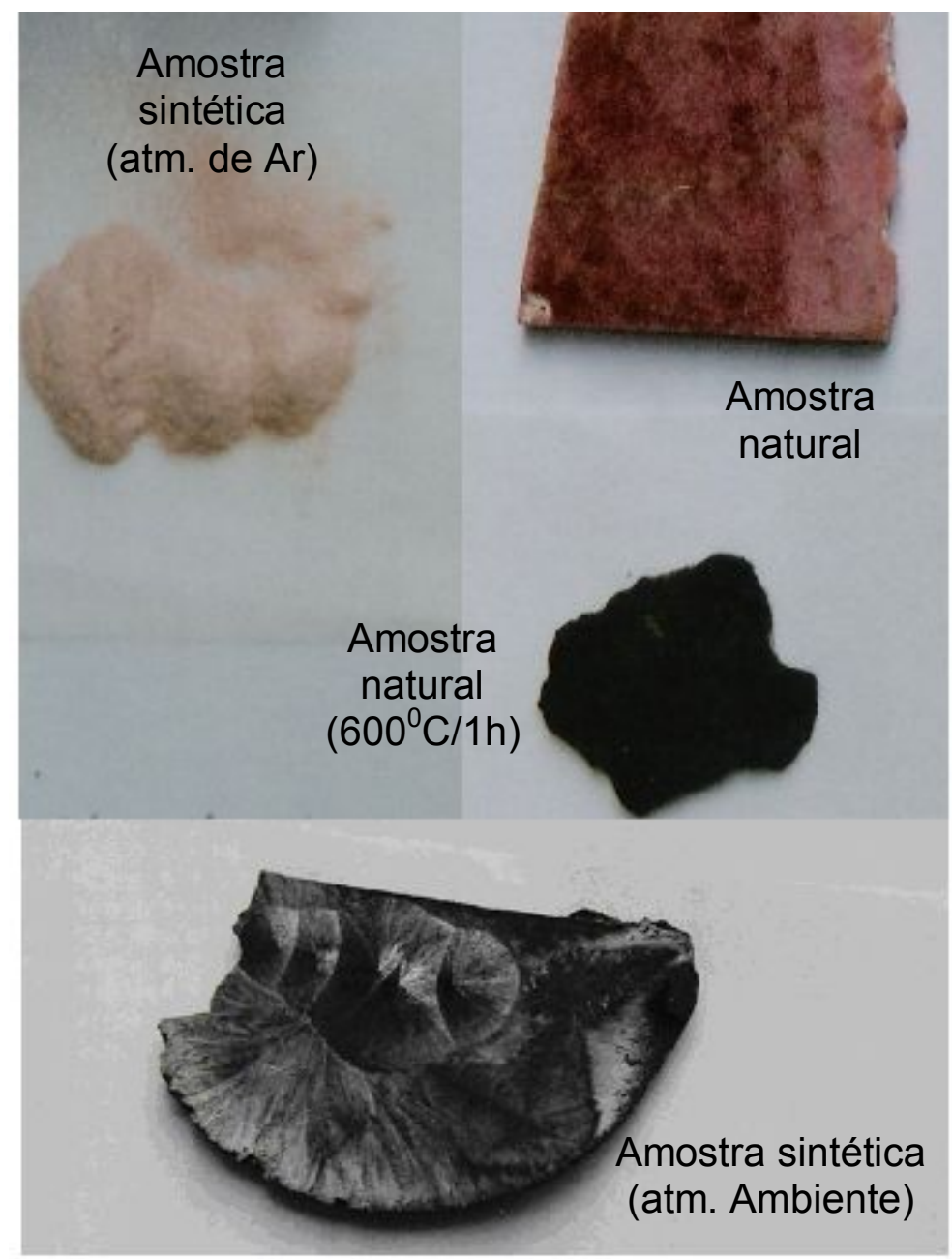

Figura5.3: Comparação entre amostras de rodonita natural, natural $\left(600^{\circ} \mathrm{C} / 1 \mathrm{~h}\right)$, sintética em atmosfera ambiente e sintética em atmosfera de Ar.

Não resta dúvida de que, ao aquecer a rodonita natural ao ar, acima de $500{ }^{\circ} \mathrm{C}$, forte oxidação ocorre convertendo senão totalmente, uma fração significativa de óxido de $\mathrm{Mn}^{2+}$ e talvez de $\mathrm{Mn}^{3+}$ em dióxido de manganês (4+), tornando a amostra, inicialmente, rosada em rodonita preta. 


\subsubsection{Cálculo das bandas de AO por teoria do campo cristalino}

O grande número de bandas de $\mathrm{AO}$ observadas e a presença de uma grande quantidade (aproximadamente $37 \%$ ) de óxido de manganês no cristal de rodonita sugere que suas bandas de $\mathrm{AO}$ estão associadas aos íons de manganês que devem existir na estrutura em diferentes estados, $\mathrm{Mn}^{2+}, \mathrm{Mn}^{3+}, \mathrm{Mn}^{4+}$ e talvez outros estados.

Como já mencionado, Maning (1968) associou as bandas em $531 \mathrm{~nm}, 434 \mathrm{~nm}$, $408 \mathrm{~nm}, 361 \mathrm{~nm}$ e em $344 \mathrm{~nm}$ (em nosso caso $542 \mathrm{~nm}$, $440 \mathrm{~nm}$, $410 \mathrm{~nm} 361 \mathrm{~nm}$, e $344 \mathrm{~nm}$ respectivamente) ao $\mathrm{Mn}^{2+}$ em um ambiente octaédrico regular. Seus resultados foram obtidos, principalmente por comparação com as bandas de $\mathrm{AO}$ devido ao $\mathrm{Mn}^{2+}$ em um ambiente octaédrico regular de $\mathrm{Mn}(\mathrm{OH} 2)_{6}{ }^{2+}$ obtidas por Heidt et al. (1959) e em KCl obtidas por Mehra et al. (1966). Dessa forma Maning (1968) sugere que a cor rosa da rodonita é devido ao $\mathrm{Mn}^{2+}$ em um ambiente octaédrico regular.

Lakshman e Reddy (1973) calcularam as bandas de $\mathrm{AO}$ para $\circ \mathrm{Mn}^{2+}$ na rodonita, usando um modelo de acoplamento spin-órbita, porém, os resultados não são muito concordantes com os dados observados, particularmente algumas bandas, por exemplo, 424nm, 376nm, 374nm, 369nm, 368nm, 355nm e $344 \mathrm{~nm}$ que não podem ser explicados por esse modelo. Esses autores inferiram que essa discrepância seria devido a algum tipo de distorção no campo cristalino ao redor do $\mathrm{Mn}^{2+}$. Sang-Bo et al. (1986) admitiram que em rodonita com baixa quantidade de ferro (como a amostra do presente trabalho) $\circ \mathrm{Mn}^{2+}$ poderia estar principalmente, em dois ambientes, um $\mathrm{O}_{\mathrm{h}}$ e o outro $\mathrm{C}_{4 \mathrm{v}}$ que é formado por uma distorção tetragonal do $\mathrm{O}_{\mathrm{h}}$. Esses autores calcularam as bandas de $\mathrm{AO}$ devido ao $\mathrm{Mn}^{2+}$ para a rodonita considerando os ambientes acima. Porém seus resultados, bem como os de Lakshman e Reddy (1973) não explicam as bandas entre 442nm e 378nm. No presente trabalho, considerando o $\mathrm{Mn}^{3+}$ em ambiente $\mathrm{O}_{\mathrm{h}}$ e $\mathrm{C}_{4 \mathrm{v}}$, calculamos as bandas de AO para a rodonita. A tabela 5.1 mostra os resultados de Sang-Bo (1986) e Lakshman e Reddy (1973) e os resultados do presente trabalho, comparados com nossas medidas experimentais de $\mathrm{AO}$. 
Tabela 5.1: Comparação entre as bandas de absorção calculada para a rodonita considerando $\mathrm{Mn}^{2+}$ e $\mathrm{Mn}^{3+}$ em diferentes ambientes e a comparação com os dados experimentais.

\begin{tabular}{|c|c|c|c|c|c|}
\hline \multicolumn{2}{|c|}{$\begin{array}{c}\text { Sang-Bo et. Al. (1986) } \\
\text { Admitindo } \\
\bar{v}_{1}=333, \bar{v}_{2}=411, \bar{v}_{3}=450\end{array}$} & \multirow{2}{*}{$\begin{array}{c}\text { Lakshman e } \\
\text { Reddy (1973) } \\
\mathrm{Mn}^{2+} \text { em ambiente } \\
\mathrm{O} \\
\left(\mathrm{cm}^{-1}\right)\end{array}$} & \multicolumn{2}{|c|}{ Presente trabalho } & \multirow[t]{2}{*}{$\begin{array}{c}\text { Resultados } \\
\text { experimentais } \\
\text { (Presente trabalho) }\end{array}$} \\
\hline $\begin{array}{c}\mathrm{Mn}^{2+} \text { em ambiente } \\
\mathrm{O}_{\mathrm{h}} \\
\left(\mathrm{cm}^{-1}\right)\end{array}$ & $\begin{array}{c}\mathrm{Mn}^{2+} \text { em } \\
\text { ambiente } \mathrm{C}_{4 \mathrm{~V}} \\
\left(\mathrm{~cm}^{-1}\right)\end{array}$ & & $\begin{array}{c}\mathrm{Mn}^{3+} \text { em ambiente } \\
\mathrm{O}_{\mathrm{h}} \\
\left(\mathrm{cm}^{-1}\right)\end{array}$ & $\begin{array}{c}\mathrm{Mn}^{3+} \text { em ambiente } \\
\mathrm{C}_{4 \mathrm{v}} \\
\left(\mathrm{cm}^{-1}\right)\end{array}$ & \\
\hline $18299(546,5 \mathrm{~nm})$ & & & & & $18450(542 \mathrm{~nm})$ \\
\hline $18309(546,0 \mathrm{~nm})$ & & 18799 & & & \\
\hline \multirow[t]{2}{*}{$18320(545,8 \mathrm{~nm})$} & $18677(535,4 \mathrm{~nm})$ & $?$ & $18382(544 \mathrm{~nm})$ & & \\
\hline & & $?$ & & & \\
\hline $18473(541 \mathrm{~nm})$ & & $?$ & & & \\
\hline \multirow[t]{2}{*}{$18572(538 \mathrm{~nm})$} & & $?$ & $18518(540 \mathrm{~nm})$ & & \\
\hline & & $?$ & $18656(536 \mathrm{~nm})$ & & \\
\hline 21305 & $20113+3 \bar{v}_{3}$ & $?$ & & & \\
\hline 21320 & $20386+2 \bar{v}_{3}$ & $?$ & & & \\
\hline 21334 & $21068+\bar{v}_{3}$ & $?$ & & & \\
\hline 21710 & $21255+\overline{V_{1}}$ & $?$ & & & \\
\hline 21715 & 21757 & $?$ & & & \\
\hline \multirow[t]{8}{*}{21946} & 21809 & 22206 & & & \\
\hline & 22866 & & & & \\
\hline & 23092 & & & & \\
\hline & 23331 & & & & \\
\hline & 23515 & & & & \\
\hline & 23554 & & & & \\
\hline & 23641 & & & & \\
\hline & 23756 & & & & \\
\hline \multirow[t]{2}{*}{23900} & 23900 & 24054 & & & \\
\hline & & 24054 & & & \\
\hline$?$ & $23900+\bar{v}_{1}$ & $?$ & & & \\
\hline \multicolumn{6}{|l|}{$?$} \\
\hline$?$ & $23900+\bar{v}_{2}$ & $?$ & & & \\
\hline \multicolumn{6}{|l|}{$?$} \\
\hline$?$ & $23900+\bar{v}_{3}$ & $?$ & & $24450(409 \mathrm{~nm})$ & $24390(410 \mathrm{~nm})$ \\
\hline \multicolumn{6}{|l|}{$?$} \\
\hline$?$ & $23900+2 \bar{v}_{1}$ & $?$ & & & \\
\hline
\end{tabular}




\begin{tabular}{|c|c|c|c|c|c|}
\hline$?$ & $23900+2 \bar{v}_{2}$ & $?$ & & & \\
\hline \multicolumn{6}{|l|}{$?$} \\
\hline$?$ & $23900+2 \bar{v}_{3}$ & $?$ & & & \\
\hline$?$ & $23900+3 \bar{v}_{2}$ & $?$ & & & $25380(394 \mathrm{~nm})$ \\
\hline \multicolumn{6}{|l|}{26428} \\
\hline \multicolumn{6}{|l|}{26584} \\
\hline 26585 & & $?$ & & & 26595(376nm) \\
\hline 26857 & & ? & & & \\
\hline \multicolumn{6}{|l|}{26858} \\
\hline \multirow[t]{8}{*}{26861} & 26913 & $?$ & & & \\
\hline & 27131 & & & & $27100(369)$ \\
\hline & 27188 & & & & $27247(367)$ \\
\hline & 27477 & & & & \\
\hline & 27623 & 27663 & & & \\
\hline & 27694 & & & & $27700(361)$ \\
\hline & 27962 & & & & 27855(359) \\
\hline & & & & & $28011(357)$ \\
\hline 28380 & 28380 & & & & 28169(355) \\
\hline $28380+\bar{v}_{3}$ & $28380+\bar{v}_{3}$ & & & & \\
\hline \multirow[t]{2}{*}{$28380+2 \overline{v_{1}}$} & $28380+2 \bar{v}_{1}$ & & & & $29069(344)$ \\
\hline & & 29374 & & & \\
\hline $\begin{array}{l}\text { Parâmetros } \\
\text { ambiente } O_{h}\end{array}$ & arâmetros ambiente $\mathrm{C}_{4}$ & $\begin{array}{l}\text { Parâmetros } \\
\text { ambiente } \mathrm{O}\end{array}$ & $\begin{array}{l}\text { Parâmetros } \\
\text { ambiente } O_{h}\end{array}$ & $\begin{array}{l}\text { Parâmetros } \\
\text { ambiente } C_{4 v}\end{array}$ & \\
\hline$B=640 \mathrm{~cm}^{-1}$ & $B=640 \mathrm{~cm}^{-1}$ & $B=760 \mathrm{~cm}^{-1}$ & $B=860 \mathrm{~cm}^{-1}$ & $B=860 \mathrm{~cm}^{-1}$ & \\
\hline$C=3500 \mathrm{~cm}^{-1}$ & $C=3500 \mathrm{~cm}^{-1}$ & $C=3290 \mathrm{~cm}^{-1}$ & $C=4472 \mathrm{~cm}^{-1}$ & $C=4472 \mathrm{~cm}^{-1}$ & \\
\hline$D q=800 \mathrm{~cm}^{-1}$ & $D q=750 \mathrm{~cm}^{-1}$ & $D q=750 \mathrm{~cm}^{-1}$ & $D q=1850 \mathrm{~cm}^{-1}$ & $D q=1535 \mathrm{~cm}^{-1}$ & \\
\hline \multirow[t]{3}{*}{$\xi=320 \mathrm{~cm}^{-1}$} & $\xi=320 \mathrm{~cm}^{-1}$ & $\xi=390 \mathrm{~cm}^{-1}$ & $\xi=255 \mathrm{~cm}^{-1}$ & $\xi=255 \mathrm{~cm}^{-1}$ & \\
\hline & $D_{S}=100 \mathrm{~cm}^{-1}$ & & & $D_{S}=242 \mathrm{~cm}^{-1}$ & \\
\hline & $D_{t}=500 \mathrm{~cm}^{-1}$ & & & $D_{t}=-337 \mathrm{~cm}^{-1}$ & \\
\hline
\end{tabular}


Os cálculos realizados mostraram que a banda em $540 \mathrm{~nm}$ pode ser explicada pela presença do $\mathrm{Mn}^{3+}$ em um ambiente octaédrico, Sang-Bo et al. (1986) encontraram resultado semelhante, porém considerando o $\mathrm{Mn}^{2+}$ neste mesmo ambiente. Por outro lado, considerando $\circ \mathrm{Mn}^{3+}$ em um ambiente $\mathrm{C}_{4 \mathrm{v}}$ foi encontrada a banda de $409 \mathrm{~nm}$ que está em excelente concordância com os dados experimentais, fato este, não descrito por Sang-Bo et al. (1986) ou por Lakshman e Reddy (1973).

Algumas razões nos levam a acreditar que $\circ \mathrm{Mn}^{3+}$ em um ambiente octaédrico possa ser o, ou um dos responsáveis pela banda de $540 \mathrm{~nm}$ e, quando em um ambiente $\mathrm{C}_{4 \mathrm{v}}$, responsável pela banda de 410nm. Em primeiro lugar, a rodonita é composta por aproximadamente $37 \%$ de óxido de manganês. Dessa forma, ele deve existir em diferentes estados, como $\mathrm{Mn}^{2+}, \mathrm{Mn}^{3+}, \mathrm{Mn}^{4+}$ talvez outros.

Gibbons et al. (1974) mostraram que sob pressão de aproximadamente 500Kbar a banda de 540nm desaparece por completo, como já mencionado. Esses autores acreditam que está banda é devido ao $\mathrm{Mn}^{3+}$ pois segundo Burns (1993), em um resumo sobre a teoria do campo cristalino, descreve o efeito Jahn-Teller sobre certos íons de metais de transição. Burns (1993) argumenta que, se a distribuição de elétrons em orbitais d de um íon de metal de transição é tal que o estado fundamental é degenerado, o poliedro de coordenação irá distorcer espontaneamente para remover a degenerescência e tornar o nível de energia mais estável, Jahn e Teller (1937). O $\mathrm{Mn}^{3+}$ com configuração eletrônica $\mathrm{d}^{4}$, é adequado para tal distorção, o qual é estabilizado em um octaedro distorcido. Por outro lado, o $\mathrm{Mn}^{3+}$ não é tão estável em um octaedro regular e, neste ambiente, tem uma tendência para oxidar ou reduzir para configurações mais estáveis de $\mathrm{Mn}^{4+}$ ou $\mathrm{Mn}^{2+}$, respectivamente. Da estrutura da rodonita, figura 5.4 e dos trabalhos de Peacor e Niizeki (1963), sabemos que a maioria dos sítios onde se encontra algum manganês são distorcidos de simetria octaédrica. 


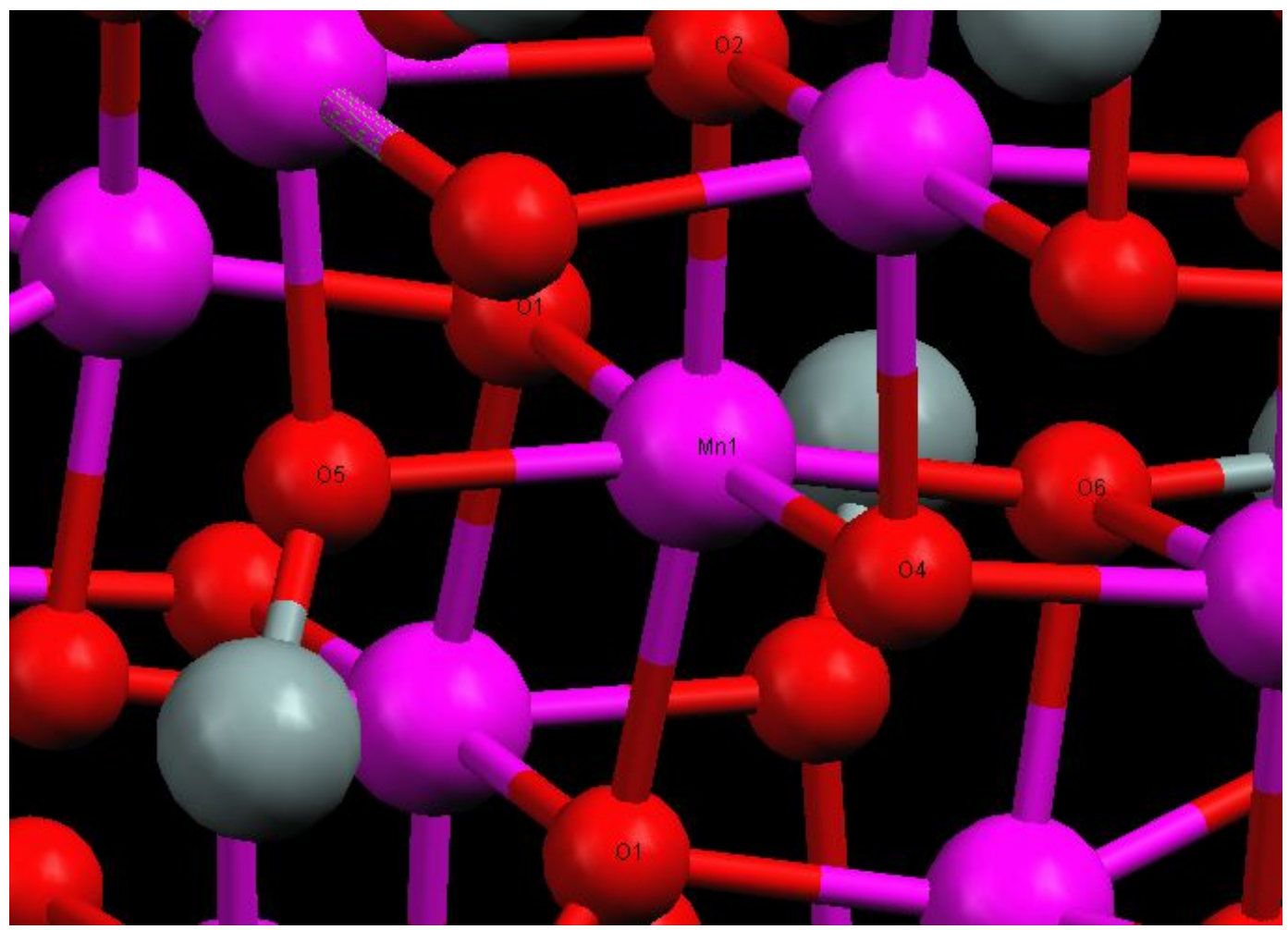

Figura 5.4 Estrutura da rodonita mostrando o manganês em um ambiente octaédrico distorcido [estrutura obtida através do programa Mercury usando dados de difração de raios $-X$ obtidos por Peacor et al. (1978)].

Quanto à banda de absorção em torno de $1040 \mathrm{~nm}$, associada ao $\mathrm{Fe}^{2+}$, o tratamento térmico diminui a sua intensidade, como se vê nas figuras 4.42 e 4.44 , o que se deve à oxidação do $\mathrm{Fe}^{2+}$ para $\mathrm{Fe}^{3+}$.

A espectroscopia XPS da amostra antes do tratamento térmico, figura $4.50 \mathrm{e}$ depois do recozimento em $600{ }^{\circ} \mathrm{C}$ por uma hora, figura 4.51 , mostrou a presença de $\mathrm{Mn}^{2+}$, $\mathrm{Mn}^{3+}$ e $\mathrm{Mn}^{4+}$ em concentrações quase iguais antes do tratamento térmico e um aumento da concentração de $\mathrm{Mn}^{4+}$ com a diminuição de $\mathrm{Mn}^{2+}$ e o possível desaparecimento do $\mathrm{Mn}^{3+}$ após recozimento. 


\subsection{Ressonância Paramagnética Eletrônica}

O espectro de RPE da amostra natural indicou uma banda de absorção muito larga, o que indica que se trata de interação dipolo magnético - dipolo magnético. Essa característica não se altera com um tratamento térmico em $600{ }^{\circ} \mathrm{C}$ por uma hora. Entretanto, como se vê na figura 4.54 , tratamentos térmicos em temperaturas superiores a $600{ }^{\circ} \mathrm{C}$, alargam ainda mais o sinal RPE.

Van Vleck (1948) desenvolveu a teoria da interação spin-spin, deduzindo uma expressão que permite o cálculo da largura da banda de absorção de microonda. Admitindo distâncias interatômicas entre os átomos vizinhos de manganês, determinados por Peacor e Niizeki (1963) e Peacor et al. (1978) ) , o cálculo usando a expressão de Van Vleck mostrou o resultado apresentado na figura 4.57. O valor obtido para a distância de pico a pico foi um pouco abaixo do valor obtido para a amostra natural, porém, sabe-se que a largura das linhas é a soma de duas contribuições, $\Delta H=\Delta H_{I}+\Delta H_{D}$ onde $\Delta H_{I}$ é a largura que aparece devido a processos intramoleculares e $\Delta H_{D}$ é a largura devido à interação spin-spin entre primeiros vizinhos do $\mathrm{Mn}^{2+}$, Hinckley e Morgan (1966). Dessa forma, essa diferença pode ser associada a estes processos intramoleculares. Um refinamento melhor pode ser necessário, mas esse resultado acima já mostrou um alargamento razoável devido à interação spin-spin do manganês.

Em conseqüência, estruturas finas do espectro RPE, por exemplo, aquelas devido a defeitos intrínsecos e de outras impurezas, se existirem, tornam-se invisíveis, exceto a linha do $\mathrm{Fe}^{3+}$, como veremos em seguida.

A figura 4.52 mostra o efeito do tratamento térmico em altas temperaturas sobre o espectro RPE da rodonita natural. A partir de uma temperatura entre $700{ }^{\circ} \mathrm{C}$ e $800{ }^{\circ} \mathrm{C}$, o aquecimento alarga ainda mais a linha RPE, possivelmente, devido à formação de agrupamentos. Além de íons de manganês (II) na amostra natural, agora, com o aquecimento têm-se íons de manganês (IV) e, os íons de $\mathrm{Fe}^{3+}$ reforçam o agrupamento. Supomos isto baseado no fato de que a banda de AO da amostra natural em 1040 nm diminui sensivelmente com o tratamento térmico a partir de $500^{\circ} \mathrm{C}$, donde concluímos que o $\mathrm{Fe}^{2+}$ esteja passando para $\mathrm{Fe}^{3+}$, e possivelmente formando agrupamentos explicando $\mathrm{o}$ 
alargamento intenso das linhas de RPE a partir de $800^{\circ} \mathrm{C}$. Contudo, na figura 4.54 pode-se ver o sinal de $\mathrm{Fe}^{3+}$ superposto ao sinal largo, a partir de $800{ }^{\circ} \mathrm{C}$.

As figuras 4.52 e 4.53 indicam que a irradiação tão intensa quanto 50 a 100 kGy não altera o espectro RPE da rodonita natural, indicando que a distribuição dos íons de $\mathrm{Mn}$, responsáveis pelo espectro, não é alterada por irradiação, mesmo intensa. 


\section{Capítulo 6 Conclusões}




\section{1 - Conclusões gerais}

1- A análise por fluorescência de raios- $X$ mostrou que a amostra de rodonita estudada neste trabalho, contém, além de $\mathrm{SiO}_{2}$ e $\mathrm{MnO}$, outros óxidos, tais como: $\mathrm{CaO}, \mathrm{MgO}, \mathrm{Fe}_{2} \mathrm{O}_{3}$, e $\mathrm{Al}_{2} \mathrm{O}_{3}$ em quantidades que vão de $1,7 \%$ a 9,0\% em massa, indicando que participam da estrutura cristalina. Outros elementos como $\mathrm{P}, \mathrm{Ti}$ e $\mathrm{Zn}$ estão presentes, em pequenas quantidades. Deste trabalho e, de outros do grupo (Souza - 2001), envolvendo cristais naturais de silicatos, ficou claro que somente duas ou três impurezas influenciam as propriedades de AO, RPE e TL.

2- As curvas de emissão da amostra natural irradiada com doses variando entre $0,1 \mathrm{kGy}$ e $50 \mathrm{kGy}$ apresentaram picos TL em $140{ }^{\circ} \mathrm{C}, 250{ }^{\circ} \mathrm{C}, 280{ }^{\circ} \mathrm{C}, 335{ }^{\circ} \mathrm{C}$ e $460{ }^{\circ} \mathrm{C}$, os quais crescem sublinearmente. Por outro lado, as curvas de emissão da amostra das porções recozidas em $600^{\circ} \mathrm{C} / 1 \mathrm{~h}$ e, depois irradiadas com doses de radiação variando de 0,1 a 50 kGy apresentam picos TL em $140{ }^{\circ} \mathrm{C}, 180{ }^{\circ} \mathrm{C}, 260{ }^{\circ} \mathrm{C}, 300{ }^{\circ} \mathrm{C}, 340{ }^{\circ} \mathrm{C}$ e $460{ }^{\circ} \mathrm{C}$. Sendo a presença do pico de $180^{\circ} \mathrm{C}$ a grande diferença com relação à amostra natural sem tratamento térmico. Observamos também que, na amostra tratada ocorre um pequeno deslocamento da posição dos picos quando comparamos com a amostra natural. No caso da amostra tratada, os picos crescem paralela e sublinearmente com a dose até cerca de 5 kGy, saturando-se, em seguida.

3 -Usando método de fusão e lento resfriamento, foram produzidas amostras sintéticas de $\mathrm{MnSiO}_{3}$ pura (em atmosfera ambiente e atmosfera de argônio) e de $\mathrm{MnSiO}_{3}$ contendo $\mathrm{CaO}$, $\mathrm{MgO}, \mathrm{Fe}_{2} \mathrm{O}_{3}$ e $\mathrm{Al}_{2} \mathrm{O}_{3}$, bem como, algumas cobinações, como $\mathrm{Al}_{2} \mathrm{O}_{3}+\mathrm{CaO}$ e $\mathrm{Al}_{2} \mathrm{O}_{3}+\mathrm{Fe}_{2} \mathrm{O}_{3}$. As amostras sintéticas apresentaram curvas de emissão similares à natural, com relação à posição dos picos. No caso da amostra contendo $\mathrm{Al}_{2} \mathrm{O}_{3}$ o pico em $340{ }^{\circ} \mathrm{C}$ é proeminente e os outros não. Vale lembrar que na amostra pura obtida em atmosfera de argônio houve uma resposta TL muito intensa, aproximando-se do valor obtido para a amostra natural (para uma mesma dose gama). Nas amostras contendo $\mathrm{CaO}$ e $\mathrm{MgO}$, o pico em $340{ }^{\circ} \mathrm{C}$ cresceu aproximadamente 8 vezes mais do que nas amostras pura e com $\mathrm{Fe}_{2} \mathrm{O}_{3}$. A presença de $\mathrm{Al}_{2} \mathrm{O}_{3}$ produziu uma curva de emissão bem diferente, todos os picos são intensos, sendo o 
de $140{ }^{\circ} \mathrm{C}$ o mais proeminente seguido do pico de $340{ }^{\circ} \mathrm{C}$. Esses dois picos, com largura muito grande escondem os outros picos.

4- $\mathrm{O}$ resultado acima mostra que, $\mathrm{o} \mathrm{Al}_{2} \mathrm{O}_{3}$ tem um papel importante na definição das propriedades TL da rodonita. Entretanto, nas curvas de emissão de amostras tratadas em $600{ }^{\circ} \mathrm{C} / 1 \mathrm{~h}$ e, depois irradiadas, são os picos em $260^{\circ} \mathrm{C}$ e $290^{\circ} \mathrm{C}$ os mais proeminentes. Os picos em $140{ }^{\circ} \mathrm{C}$ e $340^{\circ} \mathrm{C}$ são menos intensos com larguras pequenas.

5- Sendo a presença de $\mathrm{Al}_{2} \mathrm{O}_{3}$ tão importante em respeito às propriedades $\mathrm{TL}$, propomos o seguinte mecanismo de emissão TL para a rodonita. Inicialmente forma-se um centro seguindo a reação:

$$
\mathrm{Al}^{3+}+\mathrm{M}+\left[\mathrm{SiO}_{4}^{4-}\right]^{0} \rightarrow\left[\mathrm{AlO}_{4} / \mathrm{M}^{+}\right]^{0}+\mathrm{Si}+e^{-}
$$

A irradiação remove $\mathrm{M}^{+}$deixando $\left[\mathrm{AIO}_{4} / \mathrm{h}\right]^{0}$ que é conhecido como centro de alumínio de buraco.

$$
\left[\mathrm{AlO}_{4} / \mathrm{M}^{+}\right]^{0} \stackrel{\text { irr }}{\rightarrow}\left[\mathrm{AlO}_{4} / \mathrm{h}\right]^{0}+\mathrm{M}
$$

Durante o aquecimento para a leitura, $\mathrm{M}^{+}$que se tornara $\mathrm{M}^{0}$ por captura de um elétron da ionização (irradiação), agora libera um elétron que se recombina com o buraco do centro de alumínio, produzindo a luz $\mathrm{TL}$ e regenerando o centro $\left[\mathrm{AlO}_{4} / \mathrm{M}^{+}\right]$. Uma outra possibilidade não envolve reação com $\mathrm{M}^{+}$, mas o elétron poderia ser capturado por uma vacância de oxigênio. $O$ centro de recombinação a que se referiu a figura 4.7 é o centro de alumínio aqui discutido.

6- Para as amostras sintéticas puras, obtidas ou não em atmosfera controlada, bem como, para as amostras obtidas com impurezas ou ainda aquelas com combinações de impurezas, foram realizadas medidas de difração de raios - $X$, que mostraram que a estrutura de tais amostras são muito próximas às do padrão, indicando que o método pode ser usado para produção de amostras sintéticas do cristal de rodonita. Entre as vantagens deste método em relação a outros, tais como sol-gel ou hidrotérmico estão o baixo custo de produção e a possibilidade de obtenção de grandes quantidades de amostra. 
7- $\quad$ Através do espectro de absorção óptica identificamos várias bandas em 344nm, 355 $\mathrm{nm}, 357 \mathrm{~nm}, 359 \mathrm{~nm}, 361 \mathrm{~nm}, 367 \mathrm{~nm}, 369 \mathrm{~nm}, 376 \mathrm{~nm}, 394 \mathrm{~nm}, 410 \mathrm{~nm}, 415 \mathrm{~nm}$ e $542 \mathrm{~nm}$. Acima de 600nm destacamos uma banda larga e muito intensa estendendo-se de $820 \mathrm{~nm}$ a $1300 \mathrm{~nm}$ no infravermelho e centrada em 1040 nm, que segundo Manning (1969) é atribuida ao $\mathrm{Fe}^{2+}$, e uma fraca na região de $1500 \mathrm{~nm}$.

8- Através de cálculos envolvendo teoria do campo cristalino, mostramos teoricamente que as bandas intensas em $410 \mathrm{~nm}$ e $\mathbf{5 4 2} \mathrm{nm}$ podem ser explicadas pela presença do $\mathrm{Mn}^{3+}$ em ambientes $\mathrm{O}_{\mathrm{h}}$ e $\mathrm{C}_{4 \mathrm{v}}$. Sang-Bo et. al (1986) admitiram que em rodonita com baixa quantidade de ferro (como a amostra do presente trabalho) $\circ \mathrm{Mn}^{2+}$ poderia estar principalmente, em dois ambientes, um $\mathrm{O}_{\mathrm{h}}$ e o outro $\mathrm{C}_{4 \mathrm{v}}$ que é formado por uma distorção tetragonal do $\mathrm{O}_{\mathrm{h}}$. Seus resultados, bem como os de Lakshman e Reddy (1973) não explicam de forma satisfatória as bandas entre $542 \mathrm{~nm}$ e $378 \mathrm{~nm}$. No presente trabalho, considerando o $\mathrm{Mn}^{3+}$ em ambiente $\mathrm{O}_{\mathrm{h}}$ e $\mathrm{C}_{4 \mathrm{v}}$, calculamos as bandas de $\mathrm{AO}$ para a rodonita. $\mathrm{A}$ banda em $410 \mathrm{~nm}$ foi obtida considerando-se $0 \mathrm{Mn}^{3+}$ em um ambiente $\mathrm{C}_{4 \mathrm{~V}}$ (levando em conta apenas transições permitidas). A banda em $542 \mathrm{~nm}$ foi obtida considerando-se $\mathrm{O} \mathrm{Mn}^{3+}$ em um ambiente $O_{h}$ (levando em conta apenas transições permitidas). A tabela 5.1 mostra que Sang-Bo (1986) e Lakshman e Reddy (1973) obtiveram resultados próximos para essa mesma banda, mas é preciso ressaltar que levam em consideração transições não permitidas, o que sozinho não poderia produzir uma banda tão intensa. Dessa forma, acreditamos que a banda de 540nm seja devido tanto as transições não permitidas devido à presença do $\mathrm{Mn}^{2+}$ em ambiente $\mathrm{O}_{\mathrm{h}}$, como de $\mathrm{Mn}^{3+}$ em ambiente $\mathrm{O}_{\mathrm{h}}$, com a diferença de possuir transição permitida nesta região, o $\mathrm{Mn}^{3+}$ seria o responsável pela maior intensidade desta banda. Através da tabela 5.1 podemos verificar a boa concordância com os dados experimentais deste trabalho.

9- Amostras irradiadas com doses entre 0,5 kGy e 300 kGy, não apresentaram alterações no espectro de AO. Para lâminas submetidas a tratamento térmico entre a temperatura ambiente e $1000{ }^{\circ} \mathrm{C}$, verificou-se que o fundo de absorção começa a crescer muito a partir de cerca de $400{ }^{\circ} \mathrm{C}$ e as bandas de absorção acima mencionadas começam a ser encobertas. Somente vestígios dessas bandas ainda são observáveis em $500{ }^{\circ} \mathrm{C}$, com o 
cristal tornando-se escuro. As bandas de absorção associadas ao $\mathrm{Mn}^{2+}$ e ao $\mathrm{Mn}^{3+}$ diminuem após aquecimento acima de $400{ }^{\circ} \mathrm{C}$, todavia, a banda associada ao $\mathrm{Fe}^{2+}$ diminui mesmo com aquecimentos abaixo de $200^{\circ} \mathrm{C}$. Até $300{ }^{\circ} \mathrm{C}$ as bandas de $540 \mathrm{~nm}$ têm mesma intensidade e a partir de $400{ }^{\circ} \mathrm{C}$ o fundo aumenta e a banda de $542 \mathrm{~nm}$ diminui. O efeito do escurecimento pode estar associada às mudanças de estado do $\mathrm{Mn}^{2+}$ e $\mathrm{Mn}^{3+}$ para $\mathrm{Mn}^{4+}$.

10- Excetuando-se as bandas em $410 \mathrm{~nm}$ e $542 \mathrm{~nm}$, as mais intensas, podemos dizer que as outras bandas entre $542 \mathrm{~nm}$ e $378 \mathrm{~nm}$ estão associadas com a presença do $\mathrm{Mn}^{2+} \mathrm{em}$ ambiente $\mathrm{O}_{\mathrm{h}}$ e $\mathrm{C}_{4 \mathrm{~V}}$. Sendo, então, as bandas em 410nm e $542 \mathrm{~nm}$ as mais intensas, acreditamos que a cor rosa da rodonita natural seja devido à presença do $\mathrm{Mn}^{3+}$ na estrutura e não devido ao $\mathrm{Mn}^{2+}$ como sugerida por outros autores. Dessa forma, este trabalho concorda com as evidências experimentais de Gibbons et al. (1974).

11- O óxido de manganês toma parte da estrutura da rodonita, sendo aproximadamente $37 \%$ do total, dessa forma deve existir em vários estados, tais como $\mathrm{Mn}^{2+}, \mathrm{Mn}^{3+}, \mathrm{Mn}^{4+}$, talvez outros. A espectroscopia XPS da amostra antes do tratamento térmico, indicou que o pico associado à energia de ligação de 642,199 eV está relacionada com a espécie cristalina $\mathrm{Mn}_{3} \mathrm{O}_{4}$, que é um óxido duplo que comporta $\mathrm{Mn}^{2+}$ e o $\mathrm{Mn}^{3+}$. Para essa mesma energia de ligação podemos relacionar a espécie cristalina $\mathrm{Mn}_{2} \mathrm{O}_{3}$, na qual tem se $\mathrm{Mn}^{3+}$. Nesta mesma medida, aparece também o pico associado à energia de ligação de 642,647 eV que está relacionado com a espécie cristalina $\mathrm{MnO}_{2}$, na qual tem-se $\mathrm{Mn}^{4+}$. Após tratamento térmico em $600{ }^{\circ} \mathrm{C} / 1 \mathrm{~h}$, identificamos dois picos, o primeiro associado à energia de 640,893 eV que está relacionado com a espécie cristalina $\mathrm{MnO}$ na qual tem-se $\mathrm{O} \mathrm{Mn}^{2+}$. O segundo pico com energia de ligação 642,351 eV está associado com a espécie cristalina $\mathrm{MnO}_{2}$, para a qual se tem $\mathrm{Mn}^{4+}$. Segundo as medidas de XPS, o $\mathrm{Mn}^{3+}$, não aparece após o escurecimento da amostra de rodonita natural contribuindo assim para que a cor rosa da rodonita esteja associada com o $\mathrm{Mn}^{3+}$ e não com o $\mathrm{Mn}^{2+}$, que, mesmo após escurecimento, permanece na estrutura.

12- A Rodonita, com fórmula química $(\mathrm{Mn}, \mathrm{Ca}, \mathrm{Fe}, \mathrm{Mg}) \mathrm{SiO}_{3}$ contém em seu estado natural, principalmente $\mathrm{Mn}^{2+}$ e $\mathrm{Mn}^{3+}$. O espectro de RPE mostrou uma larga e intensa linha em 
$\mathrm{g}=1,988$. A largura de linha de pico a pico de aproximadamente 1,35 KG que é característico de alargamento dipolar, devido a uma forte interação spin-spin entre os $\mathrm{Mn}^{2+}$. Após tratamento térmico em $600^{\circ} \mathrm{C} / 1 \mathrm{~h}$ a linha fica um pouco mais estreita, e a distância de pico a pico cai para aproximadamente 1,170 KG. Isso pode ser explicado observando as figuras 4.50 e 4.51 , donde percebemos que a quantidade de $\mathrm{Mn}^{2+}$ diminuiu, passando para, provavelmente o estado $\mathrm{Mn}^{4+}$.

13- A partir de $700^{\circ} \mathrm{C}$ e principalmente após $800^{\circ} \mathrm{C}$, verificamos um intenso alargamento das linhas RPE. Nesta altura a quantidade de $\mathrm{Mn}^{2+}$ diminui sensivelmente, o que pode ser verificado pelas bandas de $\mathrm{AO}$ das figuras 4.42 e 4.44 . Ao mesmo tempo ocorre um aumento da quantidade de $\mathrm{Mn}^{4+}$, que não pode explicar esse alargamento (teoria de Van Vleck). Na rodonita aqui estudada, encontramos aproximadamente 2,2\% de $\mathrm{Fe}_{2} \mathrm{O}_{3}$. Dos espectros de $A O$ verificamos que a banda em $1040 \mathrm{~nm}$ devido ao $\mathrm{Fe}^{2+}$ diminui com o aquecimento, onde $\circ \mathrm{Fe}^{2+}$, transforma-se em $\mathrm{Fe}^{3+} . \mathrm{O} \mathrm{Fe}^{3+}$ é paramagnético e, como sabemos que em muitas situações o ferro substitui o manganês na estrutura, podemos dizer que após o aquecimento ocorrem agrupamentos de $\mathrm{Fe}^{3+}$, o que pode explicar o intenso alargamento da linha. Elerbrock (trabalho não publicado) encontrou semelhante resultado em um cristal de albita, que após ser aquecido foi submetido à separação magnética, de onde os grãos separados, após análise química indicaram a presença de $\mathrm{Fe}^{3+}$. Elerbrock (2005) encontrou que após essa separação, as linhas RPE sofreram um razoável estreitamento.

14- Usando a teoria de Van VlecK (1948) calculamos a distância de pico a pico devido a presença de $\mathrm{Mn}^{2+}$, na estrutura da rodonita natural, onde encontramos 1,15 kG, um valor próximo ao obtido experimentalmente que é de 1,35 kG. Essa diferença está ligada ao fato de não termos considerado a parcela devido às interações intramoleculares. Considerando a presença de $\mathrm{Mn}^{4+}$ na estrutura, esse valor caiu para aproximadamente $0,75 \mathrm{kG}$, mostrando que apenas $0 \mathrm{Mn}^{4+}$ não pode explicar o alargamento obtido.

15- Para amostra sintética produzida a partir de $\mathrm{MnSiO}_{3}$ e $\mathrm{Fe}_{2} \mathrm{O}_{3}$, encontramos uma linha RPE bem alargada e com formato próximo ao da rodonita natural, tratada em $800^{\circ} \mathrm{C} / 1 \mathrm{~h}$, 
figura 4.55, que é mais uma evidência de que o ferro é o responsável pelo alargamento após intenso tratamento térmico.

16- A difração de raios- $x$ da rodonita natural, tratada em temperaturas entre $400^{\circ} \mathrm{C} \mathrm{e}$ $800^{\circ} \mathrm{C}$, mostrou variação apenas nas intensidades das linhas, mas a estrutura se manteve.

17- Verificamos também que os espectros de RPE e de AO não sofrem alterações devido à irradiação, mesmo para doses altas. 


\section{2 - Trabalhos futuros}

1- A amostra sintética obtida em atmosfera de argônio apresentou resposta TL bem maior que a amostra sintética obtida em atmosfera ambiente. Dessa forma, poder-se-ia sintetizar outras amostras neste tipo de atmosfera e verificar sua influência nos picos TL.

2- Medidas de TL da amostra natural tratada termicamente em $600{ }^{\circ} \mathrm{C}$ mostraram a presença do pico de $180{ }^{\circ} \mathrm{C}$, fato não observado em medidas usando amostra natural sem tratamento térmico. Dessa forma poder-se-ia elaborar um modelo que pudesse explicar seu aparecimento.

3- A amostra sintética obtida em atmosfera de argônio apresentou uma cor rosa, próxima à da rodonita natural, porém, quando tratada em temperaturas de até $900{ }^{\circ} \mathrm{C}$, pouco escureceu, fato facilmente observado na amostra natural. Assim, poder-se-ia preparar amostras com diferentes impurezas ( $\mathrm{Fe}, \mathrm{Al}, \mathrm{Ca}, \mathrm{Mg}, \mathrm{Ti}$ ) como as obtidas neste trabalho, porém em atmosfera de argônio e, verificar se influenciam de alguma forma a cor da amostra após tratamento térmico.

4- Ainda com relação às amostras sintéticas, poderíamos adicionar diferentes quantidades de $\mathrm{Fe}_{2} \mathrm{O}_{3}$ ou $\mathrm{Al}_{2} \mathrm{O}_{3}$ ou $\mathrm{MgO}$ e através dessas amostras entender completamente o efeito de cada um nas propriedades TL e RPE.

5- Uma medida importante, mas que não foi feita com as amostras sintéticas é a obtenção de espectros de absorção óptica de tais amostras, que neste caso deveriam ser por meio de reflectância. 
Capítulo 7

\section{Referências}




\section{0 - Referências}

1. Abragam, A. and Bleaney, B. (1970) - Electron paramagnetic resonance of transition ions - Clarendon Press: Oxford.

2. Andrew, E. R. and Eades, R. G. (1952) - A nuclear magnetic resonance investigation of solid cyclohexene - Proc. Roy. Soc. A, 216, 398.

3. Becker, R. and Döring, W. (1935), Ann. Der Phys., 24, 719.

4. Burns, R. G. (1993) - Mineralogical applications of crystal field theory, $2^{\text {nd }}$ Edition, Cambridge University Press, p. 33-34.

5. Deer, W. A., Howie, R.A. and Zussman, J. (1992) - An Introduction to the Rock Forming Minerals, $2^{\text {nd }}$ Edition, Longman, p. 211-212.

6. Elerbrock, L. H. (2005), Doutorado em andamento, IFUSP-SP.

7. Faye, G. H. (1975) - Spectra of Shock-Affected Rhodonite: A discussion - American mineralogist, volume 60, $939-941$.

8. Gibbons, R.V., Ahrens, T. J. and Rossman, G. R. (1974) - A spectrographic interpretation of the shock-produced color change in rhodonite $\left(\mathrm{MnSiO}_{3}\right)$ : the shock-induced reduction of $\mathrm{Mn}(\mathrm{III})$ to $\mathrm{Mn}(\mathrm{II})$ - Am. Mineral. 59,177 -182.

9. Ghose, S., Kersten, M., Langer. K., Rossi, G. and Ungaretti, L. (1986) - Crystal field spectra and Jahn Teller effect of $\mathrm{Mn}^{3+}$ in clinopyroxene and clinoamphiboles from India Phys. Chem. Minerals, 12, $291-305$. 
10. Haren, J. L. M., Woensdregt, C. F. (2001) - Melt growth of sperssatite $\left(\mathrm{Mn}_{3} \mathrm{Al}_{2} \mathrm{Si}_{3} \mathrm{O}_{12}\right)$ Journal of Crystal Growth, volume 226, 107 - 110.

11. Heidt, L. J., Koster, G. F. and Johnson, A. M. (1958) - Experimental and crystal field study of the absorption spectrum of manganous perchlorate in aqueous perchloric acid $-\mathrm{J}$. Am. Chem. Soc. 80, 6471.

12. Hinckley, C.C., Morgan, L.O. (1965) - Eletron spin resonance linewidths of manganese (II) ions in concentrated aqueous solutions - Journal of Chemical Physics, 44(3), 898 - 905.

13. Ikeya, M. (1993) - New Applications of Eletron Spin Resonance - Dating, Dosimetry and Microscopy - World Scientific: Singapore, $1^{\text {a }}$ ed.

14. Ito, J. (1972) - Rhodonite - Pyroximangite Peritectic Along the Join $\mathrm{MnSiO}_{3}-\mathrm{MgSiO}_{3}$ in air - American mineralogist, volume 57, $865-876$.

15. Jahn, H. A., Teller, E., (1937) - Stability of Polyatomic Molecules in Degenerate Eletronic States. I.Orbital degeneracy - Proc. Roy, Soc. (London), A161, 220 - 235.

16. Kirsh, Y. (1992) - Kinetic Analysis of Thermoluminescence; theoretical and practical aspects - Physica Statu Solidi (a) 129, 15, 16 - 48. 
17. Lakshaman, S. V. J. and Reddy, B. J. (1972) - Optical Absorption spectrum of $\mathrm{Mn}^{2+}$ in rhodonite - Physica 66, $601-610$.

18. Liebau, F., Hilmer, W., Thilo, E. and Dornberger-Schiff, K. (1956) - Ein neuer Kettentyp in der Kristallstruktur des Rhodonits [(Mn, $\left.\mathrm{Ca}) \mathrm{SiO}_{3}\right]$ - Naturwissensch. 43, 177-178.

19. Liebau, F., Hilmer, W. and Lindermann, G. (1959) - Uber die Kristllastruktur des Rhodonits [(Mn, $\left.\mathrm{Ca}) \mathrm{SiO}_{3}\right]$ - volume 12, $182-187$.

20. Liebau, F. (1985) - "Structural Chemistry of Silicates" - Spring-Verlag: Berlin.

21. Marfunin, A. S. (1979) - Physics of minerals and inorganic materials - Spring-Verlag: Berlin.

22. Mamedov, Kh. S. (1958) - The crystal structure of rhodonite - Doklady Akad. Nauk Azerb. S.S.R. 16, 445-450.

23. Manning, P. G. (1969). - Absorption spectra of manganese-bearing chain silicates pyroximangite, rhodonite, bustamite and serandite - Can. Mineral. 9, 348-357.

24. Manning, P. G. (1976) - Ferrous-Ferric interaction on adjacent face sharing antiprismatic sites in vesuvianites: Evidence for ferric ion eight coordination - Can. Mineral. $14,216-220$. 
25. Mehra, A., Venkateswarlu, P. (1966) - Absorption spectrum of $\mathrm{Mn}^{2+}$ in $\mathrm{KCl}-\mathrm{J}$. Chem. Phys., 45, 3381.

26. McKeever, S.W. S. (1985) - Thermoluminescence of solids - Cambridge University: Canbridge.

27. McBride, M.,Pinnavaia, T. J. and Mortland, M. M. ( 1975) - Eletron spin relaxation and the mobility of manganese (II) exchange ions in Smectites - American mineralogist, volume $60,66-72$.

28. Mercury 1.3 - The Cambridge Crystallographic Data Centre - 2005, disponível em: www.ccdc.cam.ac.uk/products/csd system/mercury/downloads/.

29. Murakami, T., Takéuchi, Y. (1979) - Structure of synthetic rhodonite, $\mathrm{Mn}_{0.685} \mathrm{Mg}_{0.315} \mathrm{SiO}_{3}$, and compositional transformations in pyroxenoids - volume 9, $\mathrm{N}^{0} 5,286$ -304 .

30. Nassau, K. (1978) - The origins of color of minerals - American mineralogist, volume 63, $219-229$.

31. Peacor, D. R. and N. Niizeki, N. (1963) - The Redetermination and refinement of the crystal structure of Rhodonite, ( $\mathrm{Mn}, \mathrm{Ca}$ ) $\mathrm{SiO}_{3}-$ Z. Kristal. 119,98 - 116.

32. Peacor, D. R.,Essene, E. J., Brown, P. E., Winter, G. (1978) - The crystal chemistry and petrogenesis of a magnesian rhodonite - American mineralogist, volume 63, 1137 - 1142. 
33. Sang-Bo, Z.,Hui-Su,W. and Kang-Wei, Z.(1985) - A simplified strong-field scheme and the absorption spectrum of $\mathrm{Mn}^{2+}$ in Rhodonite - J. Phys. C: Sol. State Phys. 19, $2729-2740$.

34. Slichter, C. P. (1990) - Principles of Magnetic Resonance - Spring-Verlag: Berlin, $3^{\mathrm{a}}$ ed.

35. Souza, S. O., Ferraz, G. M. and Watanabe, S. (2004) - Effects of Mn and impurities on $\mathrm{TL}$ and EPR properties of artificial spodumene polycrystals under irradiation - Nuclear Instruments and Methods in Physics Research B. 218, 259 - 263.

36. Stucki, J. W. and Banwart, W. L. (1979) - Advanced Chemical methods for soil and clay minerals research - D, Reidel Publishing Company, Boston.

37. Sunta, C. M. (1984) - Radiation Protection Dosimetry, 8, 25 - 44.

38. Turnbull, D. and Cohen, M. D. (1958) - Concerning Reconstructive Transformation and Formation of Glass, - J. Chem. Phys., 29, 1049 - 1054.

39. Turnbull, D. and Fisher, J. C., J. Chem. Phys., 17, 71, 1949.

40. Van Vleck, J. H. (1948) - The dipolar broadening of magnetic resonance lines in crystals - Physical Review, 74, 1168 - 1183.

41. Varshneya, A. K. (1994) - Fundamentals of Inorganic Glasses - Academic Press, Inc. Boston.

42. Volmer, M. and Weber, A. (1925), Z. Phys. Chem., 119, 277.

43. Zarzycki, J. (1982) - Glasses and Vitreous State - Cambridge University: Cambridge.

44. Warren, B. E. and Biscoe, J. (1931) - The crystal structure of the monoclinic pyroxenes - Z. Kristallogr., 80, $394-401$. 
45. Wagner, C. D., Naumkin, A. V., Kraut-Vass, A., Allison, J. W., Powell, C. J., and Rumble Jr, J. R. -NIST X-ray Photoelectron Spectroscopy Database- http://srdata.nist.gov/xps/, 2005. 